\title{
DESARROLLO DE UN MODELO CONCEPTUAL DE PRODUCCIÓN, TRANSPORTE Y DEPÓSITO DE SEDIMENTOS
}

\author{
Tesis
}

Juan José Montoya Monsalve

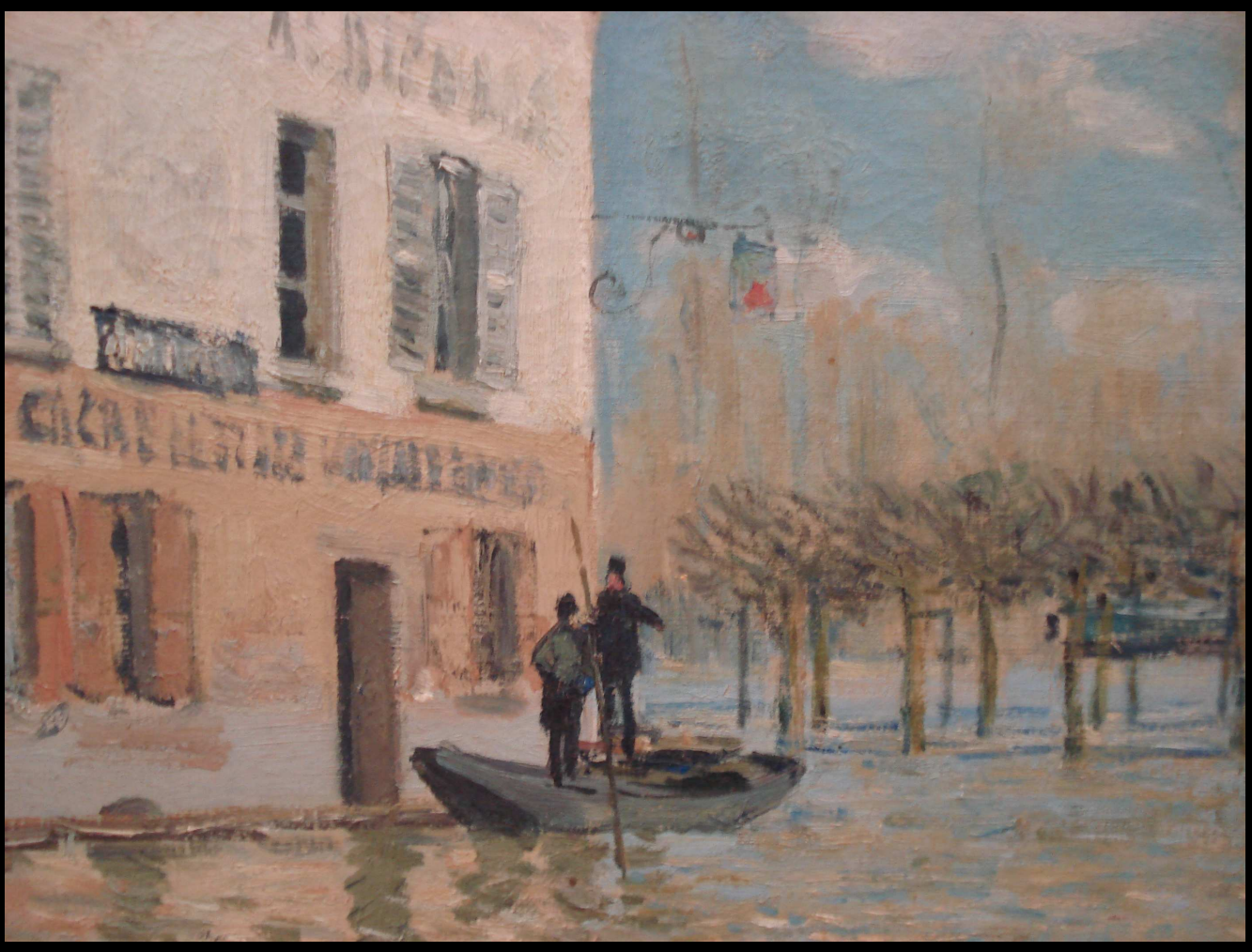

Departamento de Ingeniería Hidráulica y Medio Ambiente UNIVERSIDAD POLITÉCNICA DE VALENCIA

Valencia, Enero de 2008 
Imagen de la portada: Detalle del cuadro Le barque pendant l'inondation, PortMarly (1876) de Alfred Sisley. Museo de Orsay, Paris. 


\title{
DESARROLLO DE UN MODELO CONCEPTUAL DE PRODUCCIÓN, TRANSPORTE Y DEPÓSITO DE SEDIMENTOS
}

\author{
Tesis doctoral \\ Juan José Montoya Monsalve
}

Director: Doctor Félix Francés García

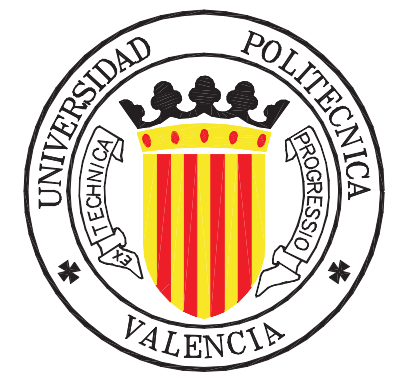

Departamento de Ingeniería Hidráulica y Medio Ambiente UNIVERSIDAD POLITÉCNICA DE VALENCIA

Valencia, Enero de 2008 


\section{EL LUGAR}

El Padre de las Aguas, el Mississippi, el río más extenso del mundo, fue el digno teatro de ese incomparable canalla. (Álvarez de Pineda lo descubrió y su primer explorador fue el capitán Hernando de Soto, antiguo conquistador del Perú, que distrajo los meses de prisión del Inca Atahualpa enseñándole el juego de ajedrez. Murió y le dieron por sepultura sus aguas.)

El Mississippi es río de pecho ancho; es un infinito y oscuro hermano del Paraná, del Uruguay, del Amazonas y del Orinoco. Es un río de aguas mulatas; más de cuatrocientos millones de toneladas de fango insultan anualmente el Golfo de México, descargadas por él. Tanta basura venerable y antigua ha construido un delta, donde los gigantescos cipreses de los pantanos crecen de los despojos de un continente en perpetua disolución y donde los laberintos de barro, de pescados muertos y de juncos, dilatan las fronteras y la paz de su fétido imperio. Más arriba, a la altura del Arkansas y del Ohio, se alargan tierras bajas también. Las habita una estirpe amarillenta de hombres escuálidos, propensos a la fiebre, que miran con avidez las piedras y el hierro, porque entre ellos no hay otra cosa que arena y leña y agua turbia.

Tomado de El atroz redentor Lazarus Morell (Historia universal de la infamia) de Jorge Luis Borges. 


\section{Prólogo}

Estas reflexiones surgen del ejercicio académico de desarrollar un modelo conceptual de producción, transporte y depósito de sedimentos y de la lectura del texto que se generó. El tema del prólogo será el título de la tesis.

$\mathrm{Al}$ tratar de clasificar los modelos naturales, en este caso modelos hidrológicos y geomorfológicos, y sobre todo al intentar separarlos en categorías (probabilísticos, estocásticos y determinísticos, agregados y distribuidos, físicos y empíricos, modelos de eventos y modelos de simulación continua, etc.), tendemos a dejar de lado la variedad de elementos conceptuales que tiene cada modelo y la variedad de ejercicios mentales que hay que realizar para su puesta en práctica.

Una separación categórica de los modelos, por ejemplo en determinísticos y probabilísticos, podría llevarnos a pensar que en los primeros no podemos aplicar herramientas estadísticas y que en los modelos probabilísticos no podemos considerar aspectos físicos, más aún si estos son comprobados por datos observables y/o medibles. Otro ejemplo se puede dar con el binomio modelos agregados y modelos distribuidos. Los modelos actuales discretizan el sistema en elementos espaciales y utilizan intervalos discretos de tiempo para simular su comportamiento. De esta forma agregan el sistema y no lo consideran como un continuo. Pero todos los modelos son conceptuales, pues parten de conceptos, que según Keith Beven, son un paso posterior a la percepción.

Puesto que ante todo son modelos, se basan en ideas perceptivas de la realidad y por tanto, aunque en menor medida que en las ciencias humanas, subjetivas. Con menor medida quiero decir que no es tan grave en el sentido de que al observar y analizar la naturaleza podemos tomar una distancia, que siempre es prudente.

El hecho de la subjetividad de los modelos convierte al modelo en una herramienta didáctica y pedagógica. Por ejemplo, cuando son desarrollados por una persona o por un grupo de investigación, es comprensible y su desempeño es bueno, y son aplicados en diversas situaciones reales por otras persona y grupos, el modelo debe ayudar a que los usuarios aprendan al menos los conceptos y herramientas que comprenden el modelo, además las experiencias en diferentes situaciones y con diferentes personas generan mejoras constantes en todos los aspectos del modelo, de esta forma es una herramienta didáctica. Cabe anotar que modelar un sistema es un ejercicio pedagógico, aprendemos de este ejercicio. Además, el modelo al ser comprensible por otras personas, esto es, los conceptos y herramientas se pueden 
expresar, entender y aprender y por esto aplicar, hace que el modelo sea objetivo, cualidad necesaria en todo método científico.

No es casual que uno de los textos más relevantes para el entendimiento de la Hidrología como ciencia, tal como está definida justo al comenzar el Handbook of Hydrology de David Maidment, sea el Rainfall-Runoff Modelling, The Primer de Keith Beven. Esta valoración está acotada por mi limitada experiencia y por mis pocas lecturas en el tema en cuestión.

La justificación de que en el título de la tesis no se detalle ninguna de las clasificaciones utilizadas con frecuencia y simplemente se utilize la palabra conceptual, se basa en que una de las conclusiones que surgieron de la lectura del mencionado texto de Keith Beven es que todos los modelos utilizan, o al menos pueden utilizar adecuadamente, herramientas estadísticas y a la vez considerar aspectos físicos observables y comprobables. En la estimación de parámetros, por ejemplo, uno de los avances recientes de la Hidrología se basa en reconocer que no existe un único conjunto óptimo de parámetros y que puede utilizarse la equifinalidad para generar juegos de parámetros que alimenten un modelo con base física.

Siguiendo a Keith Beven, cuando reflexiona sobre la complejidad de los sistema hidrológicos y señala como cada hidrólogo tiene su propia percepción del sistema que en muchos casos está en desacuerdo con otras, siempre condicionada por la propia experiencia y en particular por los ambientes hidrológicos en donde el hidrólogo haya adquirido esta experiencia y extendiéndola al problema de desarrollar un modelo, este modelo estará limitado además por las ideas y conceptos que más hayan convencido a cada desarrollador, que le sean más comprensibles.

En la actualidad se encuentran numerosos modelos hidrológicos y sedimentológicos, de una lectura cuidadosa de la forma en que simulan el sistema podemos observar que utilizan básicamente los mismos conceptos y las diferencias entre unos y otros se deben más a como aplican dichos conceptos, a como se llevan a la práctica.

En esta tesis se desarrolló un modelo de producción, transporte y depósito de sedimentos. Se definieron los aspectos físicos claves en la dinámica sedimentológica de una cuenca hidrográfica y se reseñaron y aplicaron diferentes herramientas utilizadas en la modelación.

Ahora cuando la tesis está terminada puedo decir que la intención inicial, la que se detalla en el título, supera los supuestos logros alcanzados y sólo con el tiempo podré saber si cumplí con dicha intención, o no. Puesto que el éxito de un modelo solamente puede ser comprobado con su aplicación en varios ambientes y sobre todo por diferentes personas. Así, una de las graves limitaciones de la tesis es que sólo se utilizó una cuenca hidrográfica para la aplicación del modelo.

Esta tesis no hubiera sido posible sin la ayuda más o menos cotidiana, quiero decir constante y en esa medida efectiva de varias personas e instituciones. Sólo mencionaré aquellas que estuvieron durante los cinco años largos que dediqué en esta tesis. La aclaración cabe, pues estoy convencido que en esta tesis he reflejado muchos de los aprendizajes que he recibido durante mi vida académica, que 
comenzó en la primera escuela.

Gracias al Departamento de Ingeniería Hidráulica y Medio Ambiente de la Universidad Politécnica de Valencia, en especial a Félix Francés García y a Juan Marco Segura, mi tutor en esta universidad, por su apoyo incondicional. Mención especial requiere Felix Francés, director de la tesis, por su acompañamiento constante y sus acertadas sugerencias en todas las fases de la tesis.

A Jaime Ignacio Veléz y a Jorge Julián Vélez por ayudarme a comprender - y tal vez por eso a mejorar - el modelo TETIS. A Nacho se le agradecen además sus estimulantes comentarios y aportes a la tesis.

A los compañeros de trabajo y de encuentros varios: Andrés Ochoa, Andrés Polanco, Blanca Botero, Camilo Munera, Carles Sanchis, Carlos Guillermo Agudelo, Carolina Guardiola, Catalina Montoya, Cesar Espinoza, Chiara Medici, Delva Guichard, Diana Quevedo, Eduardo Cassiraga, Fernando Perez, Guillermo Collazos, Ilona Vaskova, Jorge Eduardo Patiño, Jesús Anaya, Julián Campo, Laura Salazar, Luz Victoria Arango, Marco Morales, Marga Viñes, Maria Isabel Montoya, Marino Puricelli, Miriam Bucuré, Ricardo Gonzales, Rose Mary Castro, Sergio Salazar, Silvia Falco y Verónica Botero. A ustedes gracias por su compañía, su paciencia y sus diversos aportes académicos y personales. En la traducción del resumen se agradece la ayuda de Laura y Carles y en la traducción de la versión resumida en Inglés a Vero.

A Fausto Guzzeti del Istituto di Ricerca per la Protezione Idrogeologica del Consiglio Nazionale di la Ricerca en Perugia, Italia; a Pierre Julien del Engineering Research Center de la Colorado State University en Fort Collins, USA; y a Theo van Asch del Departement Fysische Geografie de la Universiteit Utrecht en Utrecht, Holanda; por permitirme compartir experiencias provechosas para la tesis en las estancias efectuadas en los respectivos institutos.

Al Ministerio de Educación y Ciencia del Estado Español por la ayuda económica por medio de una beca Predoctoral de Formación de Investigadores (FPI) asociada al proyecto de investigación REN2002-00840.

La tesis está dedicada a mi familia, padres y hermanas, que están en la distancia pero que son el verdadero apoyo. 


\section{Resumen}

Esta tesis aborda el desarrollo de un modelo de producción, transporte y depósito de sedimentos a escala de cuenca.

Partiendo de una breve revisión del conocimiento de modelos de evolución del paisaje y específicamente de modelos de erosión se plantean las preguntas fundamentales que deben tenerse en cuenta en el modelo. Posteriormente se estudia la forma en que actualmente se resuelven dichas preguntas, basados tanto en el estado del arte del conocimiento como en la experiencia adquirida en la aplicación de modelos hidrológicos y sedimentológicos.

Con estas bases teóricas y prácticas se formula el modelo y se desarrolla un código de programación con los postulados de la formulación, que será la hipótesis de trabajo. El modelo diseñado es una suma de conceptos y herramientas técnicas coherentemente integradas de forma tal que permitan al usuario aplicar todo el conocimiento disponible para resolver un problema particular. En su parte hidrológica el modelo se basa en el modelo TETIS desarrollado en el Departamento de Ingeniería Hidráulica y Medio Ambiente de la Universidad Politécnica de Valencia y en su parte sedimentológica se fundamenta en el modelo CASC2D-SED desarrollado en el Engineering Research Center de la Colorado State University.

Por último se aplica el modelo en una cuenca natural y se valida la hipótesis de trabajo. La cuenca de análisis es la cuenca de Goodwin Creek en el estado de Mississippi, en Estados Unidos de América, que cuenta con medidas sistemáticas de lluvia, caudal líquido y sólido, información de topografía, suelos y usos del suelo. En la aplicación se reconocen las limitaciones y potencialidades del modelo.

El modelo aprovecha convenientemente el conocimiento de condiciones físicas, por ejemplo la estructura topológica de la red de drenaje y deja de lado aspectos poco entendidos y difíciles de parametrizar, por ejemplo la estructura aleatoria de la red de surcos en ladera. De esta forma es robusto y parsimonioso, especialmente en su parte sedimentológica la cual sólo necesita un elemento de calibración.

El modelo diseñado mejora la forma de conceptualizar una cuenca y a partir de este aporte se logran mejores desempeños en cuanto a la respuesta de una cuenca hidrográfica ante un evento de lluvia. El modelo define de manera precisa en que zonas de la cuenca se presentan las diferentes componentes de la escorrentía. Además, el modelo relaciona dichas zonas con elementos concretos (ladera para la escorrentía directa, cárcava para el interflujo y cauce para el flujo base) a partir 
de parámetros fácilmente identificables en una cuenca natural.

De los resultados del modelo se aprende acerca de la dinámica hidrológica y sedimentológica de la cuenca. Con la herramienta computacional obtenida es posible efectuar análisis de cambios ambientales y antrópicos ante dichas dinámicas. De esta forma el modelo tiene una aplicabilidad no sólo científica, al generar conocimiento y ayudar a la comprensión de procesos naturales, sino también práctica, al ser una herramienta para el diseño ingenieril, el planeamiento del territorio y el análisis de riesgos naturales. 


\section{Abstract}

This thesis deals with the development of erosion, transport and sedimentation model in a catchment scale.

The main questions arise from the review of knowledge in landscape evolution models, more specifically erosion models. Subsequently, it is studied the way these questions have been approached, based either on the state of art as well as on the experience gained in the application of hydrological and sedimentological models.

The model is formulated based on these theoretical and practical backgrounds, from which a source code is developed considering the assumptions of the hypothesis. Thus, the model can be seen as a sum of concepts and techniques coherently integrated, such that it allows the user to include all the knowledge available to solve a particular problem. The model is based on a hydrological model, the TETIS model, developed in the Departamento de Ingeniería Hidráulica y Medio Ambiente of Universidad Politécnica de Valencia and the sedimentological approach is based on the CASC2D-SED model developed in the Engineering Research Center of Colorado State University.

The model is tested in a natural catchment in order to validate the hypothesis. The analyzed catchment is Goodwin Creek, in Mississippi, USA, from which there is information available about rainfall, liquid and solid discharge, topography, soils and soil uses. Through this test, the limitations and potential applications of the model can be realized.

The model takes advantage of the knowledge about physical conditions, for instance the topological structure of the river network, and avoids aspects less known and more difficult to parameterize, for instance the random structure of slope rill network. From this perspective, the model is robust and parsimonious, particularly in the sedimetological behavior, which requires just one calibration element.

The model improves the way a catchment is conceptualized, and hence the response to a rainfall event can be better predicted. Moreover, it defines in which regions of the catchment occur the different components of runoff and relate these regions with concrete elements (slope for the runoff, gully for the interflow and river for base flow) from parameters easily identified in a natural catchment.

From the model itself, it is possible to study the hydrological and sedimentological dynamics of the catchment. On the other hand, from the programming tool 
it is possible to perform analysis to elucidate environmental and anthropogenic changes in the dynamics. Thus, there is not just a scientific applicability, such as knowledge and understanding of natural processes, but also a practical one, such as the improvement of engineering design, the territory planning and the analysis of natural hazards. 


\section{Resum}

Aquesta tesi aborda el desenvolupament d'un model de producció, transport i depòsit de sediments a escala de conca.

Partint d'una revisió del coneixement de models d'evolució del paisatge i específicament de models d'erosió es plantegen les preguntes fonamentals que han de considerar-se en el model. Posteriorment s'estudia la forma en què actualment es resolen dites preguntes, a partir d'una revisió de l'estat de l'art del coneixement i de l'experiència adquirida en l'aplicació de models hidrològics i sedimentològics.

Amb aquestes bases teòriques i pràctiques es formula el model i es desenvolupa un codi de programació amb els postulats de la formulació, que serà la hipòtesi de treball. El model dissenyat és una suma de conceptes i ferramentes tècniques coherentment integrades de forma tal que permeten l'usuari aplicar tot el coneixement disponible per a resoldre un problema particular. En la seua part hidrològica el model es basa en el model TETIS desenvolupat en el Departament d'Enginyeria Hidràulica i Medi Ambient de la Universitat Politècnica de València i en la seua part sedimentològica es fonamenta en el model CASC2D-SED desenrotllat en l'Engineering Research Center de la Colorado State University.

Finalment s'aplica el model en una conca natural i es valida la hipòtesi de treball. La conca d'anàlisi és la conca de Goodwin Creek en l'estat de Mississippi, als Estats Units d'Amèrica, que compta amb mesures sistemàtiques de pluja, cabal líquid i sòlid, informació de topografia, sòls i usos del sòl. En l'aplicació es reconeixen les limitacions i potencialitats del model.

El model aprofita convenientment el coneixement de condicions físiques, per exemple l'estructura topològica de la xarxa de drenatge i deixa de costat aspectes poc entesos i difícils de parametritzar, per exemple l'estructura aleatòria de la xarxa de solcs en vessant. D'aquesta forma és robust i parsimoniós, especialment en la part sedimentològica, la qual només requereix un element de calibratge.

El model dissenyat millora la forma de conceptualitzar una conca i a partir d'aquesta aportació s'aconsegueixen millors resultats quant a la resposta d'una conca hidrogràfica davant d'un esdeveniment de pluja. El model defineix de manera precisa en quines zones de la conca es presenten les diferents components de la correntia. A més, el model relaciona dites zones amb elements concrets (vessant per a la correntia directa, xaragall per a l'interflux i llit per al flux base) a partir de paràmetres fàcilment identificables en una conca natural. 
Dels resultats del model es deriven conclusions sobre la dinàmica hidrològica $\mathrm{i}$ sedimentològica de la conca. Amb la ferramenta computacional obtinguda és possible efectuar l'anàlisi de canvis ambientals i antròpics davant de dites dinàmiques. D'aquesta forma el model té una aplicabilitat no sols científica, en generar coneixement i ajudar a la comprensió de processos naturals, sinó també pràctica, en ser una ferramenta per al disseny enginyeril, el planejament del territori i l'anàlisi de riscos naturals. 


\section{Índice}

Prólogo

$\begin{array}{ll}\text { Resumen } & \text { IX }\end{array}$

$\begin{array}{ll}\text { Abstract } & \text { XI }\end{array}$

Resum XIII

Lista de símbolos $\quad$ XXVII

1. Introducción 1

1.1. La modelación, su necesidad e importancia . . . . . . . . . . . 2

1.2. Planteamiento y objetivos de la tesis . . . . . . . . . . . . . 4

1.3. Estructura del documento . . . . . . . . . . . . . . . 5

I Marco Teórico $\quad 7$

2. Marco histórico $\quad 9$

2.1. Los modelos de evolución del paisaje . . . . . . . . . . . . . 9

2.1.1. Los principios de evolución del paisaje . . . . . . . . . . 11

2.1.2. Modelos de evolución del paisaje actuales . . . . . . . . . 14

2.1.3. Limitaciones de los modelos de evolución del paisaje . . . . 16

2.1.4. Los principios de evolución del paisaje y los modelos de erosión 16

2.2. Los modelos de erosión . . . . . . . . . . . . . . . . . . 18

2.2.1. Tipos de modelos de erosión . . . . . . . . . . . . . 22

2.2.1.1. Modelos de erosión empíricos . . . . . . . . . . 22

2.2.1.2. Modelos de erosión basados en procesos . . . . . . 24

2.2.2. Posibilidades de los modelos de erosión . . . . . . . . . 26

2.2.3. Limitaciones de los modelos de erosión . . . . . . . . . . . 28

2.3. Aspectos destacados del capítulo . . . . . . . . . . . . . . . . 29 
3. Marco Conceptual 31

3.1. La conceptualización del sistema . . . . . . . . . . . . . . . 32

3.1.1. Formas de representar y analizar el terreno . . . . . . . . 32

3.1.1.1. Los atributos primarios de los DEM . . . . . . . 36

3.1.1.2. Los atributos secundarios de los DEM . . . . . . 37

3.1.1.2.1. Índice topográfico de humedad. . . . . . . 37

3.1.1.2.2. Índices de erosión. . . . . . . . . . . . . 38

3.1.2. Las escalas de representación y análisis . . . . . . . . . . 40

3.1.3. Los elementos del sistema . . . . . . . . . . . . . . . . . 43

3.1.3.1. Áreas entre surcos . . . . . . . . . . . . . . . 44

3.1.3.2. Surcos . . . . . . . . . . . . . . . 44

3.1.3.3. Cárcavas . . . . . . . . . . . . . . . 44

3.1.3.3.1. Cárcavas efímeras. . . . . . . . . . . 45

3.1.3.3.2. Cárcavas permanentes. . . . . . . . . 46

3.1.3.4. Zonas de acumulación de sedimentos en ladera . . 47

3.1.3.5. Cauces . . . . . . . . . . . . . . . 48

3.1.3.6. Definición de los elementos del sistema a partir de información topográfica, hidrológica y sedimentológica . . . . . . . . . . . . . . 49

3.1.3.6.1. Forma de diferenciar surcos, cárcavas efímeras y cauces. . . . . . . . . . . 49

3.1.3.6.2. El comienzo de la erosión concentrada. . $\quad 52$

3.1.3.6.3. La finalización de la erosión concentrada. $\quad 55$

3.1.3.6.4. Estimación de la localización y las características geométricas de las cárcavas permanentes. . . . . . . . . . 55

3.2. Los procesos relevantes . . . . . . . . . . . . . . . 56

3.2.1. Los procesos hidrológicos . . . . . . . . . . . 57

3.2.1.1. Los flujos subsuperficiales . . . . . . . . . . 61

3.2.1.2. Los flujos superficiales . . . . . . . . . . . . 63

3.2.1.3. Formas de simular flujos en modelos hidrológicos y sedimentológicos distribuidos . . . . . . . . . 64

3.2.2. Los procesos sedimentológicos . . . . . . . . . . . 65

3.2.2.1. Procesos sedimentológicos en ladera . . . . . . . 67

3.2.2.2. Procesos sedimentológicos en surcos . . . . . . . 69

3.2.2.3. Formas de simular la erosión en laderas . . . . . . 72

3.2.2.3.1. Ecuaciones para tasas de erosión en las áreas entre surcos. . . . . . . . . . . 73

3.2.2.3.2. Ecuaciones para tasas de erosión en surcos. 74

3.2.2.3.3. Ecuaciones para la capacidad de transporte del flujo en ladera deducidas a partir de análisis dimensional. . . . . . . . . . 76

3.2.2.4. Procesos sedimentológicos en cárcavas . . . . . . . 80 
3.2.2.5. Procesos sedimentológicos en cauces . . . . . . . 84

3.2.2.5.1. Capacidad de transporte de sedimentos en cauces. ............ . 86

3.2.2.5.2. Depósito de sedimentos en cauces. . . . . 87

3.3. La estimación de parámetros . . . . . . . . . . . . . . . . 90

3.3.1. Formas de estimar parámetros en modelos ambientales distribuidos . . . . . . . . . . . . . . . 91

3.3.2. Proceso de estimación de parámetros para un modelo ambiental distribuido . . . . . . . . . . . . . . . 93

3.3.3. La calibración y validación . . . . . . . . . . . . 96

3.3.3.1. La calibración manual . . . . . . . . . . . . . 96

3.3.3.2. La calibración automática . . . . . . . . . . . 97

3.4. Aspectos destacados del capítulo . . . . . . . . . . . . . . . 97

\section{Formulación del Modelo $\quad 99$}

4. La formulación del modelo 101

4.1. Definición del sistema . . . . . . . . . . . . . . . . . . . . 101

4.2. Los elementos del sistema . . . . . . . . . . . . . . . . . . 102

4.2.1. Laderas. . . . . . . . . . . . . . . . . . . . . . . . . 102

4.2.2. Cárcavas. . . . . . . . . . . . . . . . . 103

4.2.3. Cauces. . . . . . . . . . . . . . . . 103

4.3. La discretización espacial de la cuenca . . . . . . . . . . . . . . 103

4.3.1. La unidad elemental de discretización, la celda . . . . . . . 105

4.3.1.1. La conexión lateral entre celdas. . . . . . . . . . . 107

4.3.1.2. Los tanques en el modelo TETIS y su conexión vertical. . . . . . . . . . . . . . . . 108

4.3.2. Las unidades geomorfológicas homogéneas . . . . . . . . . 111

4.4. La discretización temporal de los procesos . . . . . . . . . . . . . . 111

4.5. Los procesos y el funcionamiento del modelo . . . . . . . . . . . . . 112

4.5.1. Los procesos hidrológicos . . . . . . . . . . . . . 112

4.5.1.1. El almacenamiento estático . . . . . . . . . . . . . 112

4.5.1.2. El almacenamiento superficial . . . . . . . . . 114

4.5.1.3. El almacenamiento gravitatorio . . . . . . . . . 115

4.5.1.4. El almacenamiento subterráneo, el acuífero . . . . 115

4.5.1.5. La traslación del flujo, la Onda Cinemática Geomorfológica . . . . . . . . . . . 116

4.5.2. Los procesos sedimentológicos . . . . . . . . . . . . 119

4.5.2.1. Los procesos sedimentológicos en ladera . . . . . . 120

4.5.2.2. Los procesos sedimentológicos en canales . . . . . 124

4.5.2.3. El depósito de sedimentos . . . . . . . . . . . . 126

4.6. Los parámetros del modelo . . . . . . . . . . . . . . . . . 126

4.6.1. La variabilidad espacial de los parámetros . . . . . . . . . 128 
4.6.2. Los parámetros hidrológicos . . . . . . . . . . . . . . 132

4.6.3. Los parámetros geomorfológicos . . . . . . . . . . . . 134

4.6.4. Los parámetros sedimentológicos . . . . . . . . . . . . 135

4.6.5. Las condiciones iniciales del modelo . . . . . . . . . . . 136

4.6.6. La calibración y validación . . . . . . . . . . . . 137

4.6.6.1. Los factores correctores de calibración . . . . . . . 137

4.6.6.2. El algoritmo de optimización . . . . . . . . . . . 138

4.6.6.3. La función objetivo . . . . . . . . . . . . . . . 139

4.6.6.4. La validación . . . . . . . . . . . . . . . . . 139

4.7. Los resultados del modelo . . . . . . . . . . . . . . . . . . . . . . . 140

\section{Aplicación del Modelo 141}

5. La Cuenca de Goodwin Creek 143

5.1. Aspectos generales . . . . . . . . . . . . . . . . . . . . 143

5.2. El sistema de instrumentación . . . . . . . . . . . . . . . . . . 146

5.3. Características físicas de la cuenca . . . . . . . . . . . . . . . . 148

5.3.1. Condiciones climáticas . . . . . . . . . . . . . . . . 148

5.3.2. Geología . . . . . . . . . . . . . . . . . . 149

5.3.3. Geomorfología y Geología del Cuaternario . . . . . . . . 150

5.3.3.1. Formaciones superficiales . . . . . . . . . 150

5.3.3.2. Morfología de la red de drenaje . . . . . . . . . . 151

5.3.3.3. Estabilidad de lechos y márgenes de la red de cauces 152

5.3.4. Suelos . . . . . . . . . . . . . . . . 153

5.3.5. Usos del suelo . . . . . . . . . . . . . . . . . 154

5.3.6. Características topográficas . . . . . . . . . 155

6. Estimación de parámetros $\quad 157$

6.1. Los parámetros hidrológicos . . . . . . . . . . . . . . . . 157

6.1.1. Conductividad hidráulica saturada del sustrato del suelo . . 157

6.1.2. Conductividad hidráulica saturada del suelo . . . . . . . . . 158

6.1.3. Capacidad de almacenamiento hídrico del suelo . . . . . . 158

6.1.4. Variabilidad espacial de los parámetros hidrológicos . . . . 159

6.2. Los parámetros geomorfológicos . . . . . . . . . . . . . . 163

6.3. Los parámetros sedimentológicos . . . . . . . . . . . . . 166

7. Calibración y Validación 169

7.1. Calibración del modelo . . . . . . . . . . . . . . . . . . . 170

7.2. Validación temporal . . . . . . . . . . . . . . . . . 173

7.2.1. Evento de validación $2 \ldots \ldots$. . . . . . . . . 174

7.2.2. Evento de validación $3 \ldots \ldots$. . . . . . . . . . 175

7.3. Validación espacial . . . . . . . . . . . . . . . . . . 177

7.3.1. Estación de aforo $04 \ldots \ldots \ldots \ldots$ 
7.3.2. Estación de aforo $07 \ldots \ldots \ldots$. . . . . . . . 179

7.3.3. Estación de aforo $06 \ldots \ldots \ldots$. . . . . . . . 187

7.3.4. Estación de aforo $08 \ldots \ldots \ldots \ldots$. . . . . . . 187

7.3.5. Estación de aforo $14 \ldots \ldots$. . . . . . . . . 188

8. Resultados y análisis $\quad 197$

8.1. Comportamiento general del modelo . . . . . . . . . . . . . . 197

8.2. Las áreas fuentes y los sumideros de sedimentos . . . . . . . . . . . 199

8.3. Las condiciones iniciales de sedimentos . . . . . . . . . . . . . . 204

8.4. La importancia de la conceptualización del sistema . . . . . . . . 205

8.5. Análisis de cambios ambientales . . . . . . . . . . . . 206

9. Conclusiones 211

9.1. Conclusiones generales . . . . . . . . . . . . . . . . . 211

9.1.1. Conclusiones del marco teórico . . . . . . . . . . . . . 211

9.1.2. Conclusiones de la formulación del modelo . . . . . . . . . . 212

9.1.3. Conclusiones de la aplicación del modelo . . . . . . . . . . 213

9.2. Aportes de la tesis . . . . . . . . . . . . . . . . . . . . 214

9.2.1. Aportes del desarrollo del modelo . . . . . . . . . . . . . 214

9.2.2. Aportes de la estimación de parámetros . . . . . . . . . . 215

9.2.3. Aportes de la aplicación del modelo . . . . . . . . . . 216

9.3. Futuras líneas de investigación . . . . . . . . . . . . . . 216 


\section{Lista de figuras}

2.1. Componentes y procesos del sistema físico (paisaje) . . . . . . . 17

2.2. Esquema de un paisaje a escala de cuenca . . . . . . . . . . . 18

2.3. Procesos de erosión hídrica entre las áreas fuente . . . . . . . . . 25

3.1. Formas de representación del terreno . . . . . . . . . . . . . . 33

3.2. Intervalos espacio - temporales característicos de los procesos hidrológicos . . . . . . . . . . . . . . . 40

3.3. Definiciones de la escala de observación . . . . . . . . . . . . 41

3.4. Cárcava efímera en un campo de cultivo antes de las operaciones de labranza . . . . . . . . . . . . . . . . . 45

3.5. Detalle de una cárcava efímera en un campo de cultivo antes de las operaciones de labranza . . . . . . . . . . . . . . 46

3.6. Cárcava permanente . . . . . . . . . . . . . . . . . . . 47

3.7. Detalle de una cárcava permanente . . . . . . . . . . . . . . 48

3.8. Relación idealizada entre vaguadas, áreas fuente y el cauce de primer

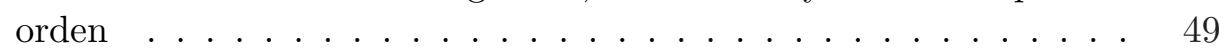

3.9. Relación potencial entre el caudal y el ancho para varios tipos de canales . . . . . . . . . . . . . . . 50

3.10. Ancho simulado de una cárcava efímera según el caudal . . . . . . 52

3.11. Representación de los procesos hidrológicos en ladera en períodos de recesión . . . . . . . . . . . . . . 57

3.12. Representación de los procesos hidrológicos en ladera en períodos de lluvia . . . . . . . . . . . . . . . . . . 58

3.13. Mecanismos de generación de escorrentía por exceso de infiltración 60

3.14. Mecanismo de generación de escorrentía por exceso de saturación . 60

3.15. Mecanismos de generación de escorrentía subsuperficial de tormenta 61

3.16. Esquemas del flujo superficial . . . . . . . . . . . . . . . . 64

3.17. Capacidad de transporte vs suministro de sedimentos . . . . . . 67

3.18. Variables involucradas en la erosión por flujo superficial en ladera . $\quad 77$

3.19. Variación de la capacidad de transporte y el caudal sólido a lo largo de una cárcava efímera con perfil cóncavo . . . . . . . . . . 81

3.20. Variación de la capacidad de transporte y el caudal sólido a lo largo de una cárcava efímera con perfil convexo . . . . . . . . . . 82 
4.1. Elementos del sistema, áreas umbrales y componentes de la escorrentía102

4.2. Esquema simplificado de una celda . . . . . . . . . . . . . . . 106

4.3. Esquema de las celdas y su conexión lateral . . . . . . . . . . . 108

4.4. Esquema de conexión hidrológica entre tanques . . . . . . . . . . . 109

4.5. Esquema de procesos sedimentológicos en ladera para cada celda . 110

4.6. Esquema de procesos sedimentológicos en canal para cada celda . . 111

4.7. Esquema de la variabilidad espacial de parámetros . . . . . . . . 130

4.8. Intersección entre variables ambientales . . . . . . . . . . . . . 131

5.1. Localización de la cuenca de Goodwin Creek . . . . . . . . . . . . 144

5.2. Modelo de Elevación Digital y red de drenaje . . . . . . . . . . . . 145

5.3. Precipitación media mensual de la cuenca Goodwin Creek . . . . . 148

5.4. Columna estratigráfica generalizada de la cuenca Goodwin Creek . 149

5.5. Corte litológico idealizado de las formaciones superficiales . . . . . 150

5.6. Series de suelos en la cuenca Goodwin Creek . . . . . . . . . . . 153

5.7. Usos del suelo en la cuenca Goodwin Creek . . . . . . . . . . . . 155

5.8. Mapa del índice topográfico de humedad . . . . . . . . . . . . . . 155

5.9. Mapas de pendientes y aspecto . . . . . . . . . . . . . 156

5.10. Mapas de la curvatura horizontal y el perfil de curvatura . . . . . . 156

5.11. Mapas de la dirección y acumulación del flujo . . . . . . . . . . 156

6.1. Mapa de la conductividad hidráulica del sustrato del suelo . . . . . 158

6.2. Unidades cartográficas derivadas de la unión entre los suelos y los usos del suelo . . . . . . . . . . . . . . . . . . . . 162

6.3. Mapa de la capacidad de almacenamiento hídrico estimada . . . . 163

6.4. Histograma de la capacidad de almacenamiento hídrico estimada . 164

6.5. Mapa de la conductividad hidráulica del suelo . . . . . . . . . . . . 164

6.6. Histograma de la conductividad hidráulica del suelo . . . . . . . . 165

6.7. Mapa de las áreas para las diferentes componentes de la escorrentía 165

6.8. Mapas de porcentajes de arenas y limos . . . . . . . . . . . . 167

6.9. Mapa de porcentajes de arcillas . . . . . . . . . . . . . . . 167

6.10. Mapas de los factores K y C de la USLE . . . . . . . . . . . . 167

7.1. Estaciones de aforo seleccionadas y su área de captación . . . . . . 170

7.2. Series temporales simuladas en la calibración para la estación Q-01 172

7.3. Relación entre el caudal líquido y el sólido para el evento de calibración 174

7.4. Series temporales simuladas en el evento 2 para la estación Q-01 . 175

7.5. Relación entre el caudal líquido y el sólido para el evento de valida-

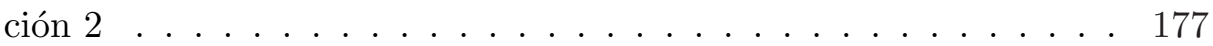

7.6. Series temporales simuladas en el evento 3 para la estación Q-01 . 178

7.7. Relación entre el caudal líquido y el sólido para el evento de valida-

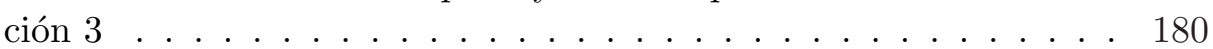

7.8. Series temporales simuladas en el evento 1 para la estación Q-04 . 181

7.9. Series temporales simuladas en el evento 2 para la estación Q-04 . 182 
7.10. Series temporales simuladas en el evento 3 para la estación Q-04 . 183

7.11. Series temporales simuladas en el evento 1 para la estación Q-07 . 184

7.12. Series temporales simuladas en el evento 2 para la estación Q-07 . 185

7.13. Series temporales simuladas en el evento 3 para la estación Q-07 . 186

7.14. Series temporales simuladas en el evento 1 para la estación Q-06 . 188

7.15. Series temporales simuladas en el evento 2 para la estación Q-06 . 189

7.16. Series temporales simuladas en el evento 3 para la estación Q-06 . 190

7.17. Series temporales simuladas en el evento 1 para la estación Q-08 . 191

7.18. Series temporales simuladas en el evento 2 para la estación Q-08 . 192

7.19. Series temporales simuladas en el evento 3 para la estación Q-08 . 193

7.20. Series temporales simuladas en el evento 1 para la estación Q-014 . 194

7.21. Series temporales simuladas en el evento 2 para la estación Q-014 . 195

7.22. Series temporales simuladas en el evento 3 para la estación Q-014 . 196

8.1. Comportamiento hidrológico del modelo . . . . . . . . . . . . 198

8.2. Comportamiento sedimentológico del modelo . . . . . . . . . . . . 199

8.3. Comparación del comportamiento sedimentológico . . . . . . . . . 200

8.4. Distribución espacial de sedimentos erosionados y depositados para el evento de calibración . . . . . . . . . . . . . . . . . 201

8.5. Distribución espacial de sedimentos erosionados y depositados para el evento de validación $2 \ldots$. . . . . . . . . . . . . . 202

8.6. Distribución espacial de sedimentos erosionados y depositados para el evento de validación $3 \ldots$. . . . . . . . . . . . . 203

8.7. Sedimentogramas totales variando las condiciones iniciales de sedimentos . . . . . . . . . . . . . . . . 204

8.8. Hidrogramas con áreas umbrales para el interflujo (tamaño de ladera) diferentes . . . . . . . . . . . . . . . 206

8.9. Sedimentogramas con áreas umbrales para el interflujo (tamaño de ladera) diferentes . . . . . . . . . . . . . . . 207

8.10. Hidrogramas para los tres escenarios . . . . . . . . . . . . 209

8.11. Sedimentogramas para los tres escenarios . . . . . . . . . . 210 


\section{Lista de tablas}

3.1. Intervalos de escalas espaciales de surcos en ladera . . . . . . . 71

3.2. Velocidad de sedimentación en agua limpia para diversos tamaños de partículas . . . . . . . . . . . . . . . 90

4.1. Estructura de parámetros según la conceptualización del modelo 128

4.2. Intervalos de variación de los parámetros de propagación . . . . . . 135

4.3. Intervalos de variación propuestos para los factores correctores . . 138

6.1. Identificar y conductividad hidráulica saturada para las unidades cartográficas . . . . . . . . . . . . . . . . . . 159

6.2. Capacidad de almacenamiento hídrico para las unidades cartográficas 160

6.3. Capacidad de almacenamiento hídrico para las unidades cartográficas 161

6.4. Parámetros de propagación para la cuenca de Goodwin Creek . . . 166

7.1. Coordenadas y áreas de captación de las estaciones de aforo . . . . 170

7.2. Límites, valor inicial y factores resultantes de la calibración automática . . . . . . . . . . . . . . . . . . 171

7.3. Resumen de resultados en la calibración para la estación Q-01 . . . 173

7.4. Desempeño del modelo en la calibración para la estación Q-01 . . 173

7.5. Límites, valor inicial y factores resultantes de la calibración automática de los estados de humedad inicial para el evento 2 . . . 174

7.6. Resumen de resultados en el evento 2 para la estación Q-01 . . . 176

7.7. Desempeño del modelo en el evento 2 para la estación Q-01 . . . 176

7.8. Límites, valor inicial y factores resultantes de la calibración automática de los estados de humedad inicial para el evento 3 . . . 177

7.9. Desempeño del modelo en el evento 3 para la estación Q-01 . . . 179

7.10. Resumen de resultados en el evento 3 para la estación Q-01 . . . 179

7.11. Desempeño del modelo en el evento 1 para la estación Q-04 . . . . 180

7.12. Desempeño del modelo en el evento 2 para la estación Q-04 . . . . 181

7.13. Desempeño del modelo en el evento 3 para la estación Q-04 . . . 182

7.14. Desempeño del modelo en el evento 1 para la estación Q-07 . . . 183

7.15. Desempeño del modelo en el evento 2 para la estación Q-07 . . . . 184

7.16. Desempeño del modelo en el evento 3 para la estación Q-07 . . . 185 
7.17. Desempeño del modelo en el evento 1 para la estación Q-06 . . . 187

7.18. Desempeño del modelo en el evento 2 para la estación Q-06 . . . . 189

7.19. Desempeño del modelo en el evento 3 para la estación Q-06 . . . . 190

7.20. Desempeño del modelo en el evento 1 para la estación Q-08 . . . . 191

7.21. Desempeño del modelo en el evento 2 para la estación Q-08 . . . . 192

7.22. Desempeño del modelo en el evento 3 para la estación Q-08 . . . . 193

7.23. Desempeño del modelo en el evento 1 para la estación Q-014 . . . 194

7.24. Desempeño del modelo en el evento 2 para la estación Q-014 . . . 195

7.25. Desempeño del modelo en el evento 3 para la estación Q-014 . . . 196

8.1. Resumen de resultados con área umbral para el interflujo diferente 208

8.2. Valores de la capacidad de almacenamiento hídrico y la conductividad hidráulica saturada del suelo para los dos escenarios . . . . . 208

8.3. Resumen de resultados para los escenarios analizados . . . . . . . . 210 


\title{
Lista de símbolos
}

\author{
Símbolo Significado \\ A \\ $A_{s}$ \\ Área de captación o de drenaje $\left[L^{2}\right]$ \\ $A_{e}$ \\ $A_{i}$ \\ $A_{t}$ \\ $A S$ \\ $A S L$ \\ Área de captación o de drenaje específica $\left[L^{2} / L\right]$ \\ Área de captación o de drenaje específica efectiva $\left[L^{2} / L\right]$ \\ Área de captación o de drenaje efectiva para una celda $\left[L^{2}\right]$ \\ Área de la sección transversal del cauce $\left[L^{2}\right]$ \\ Índice para la localización de cárcavas basado en la \\ pendiente media ponderada por el área [adimensional] \\ Índice para la localización de cárcavas basado en la \\ pendiente media ponderada por la longitud [adimensional] \\ $b \quad$ Ancho de flujo $[L]$ \\ $C \quad$ Factor de cultivo según la USLE [adimensional] \\ $C_{v} \quad$ Concentración de sedimentos por volumen $\left[L^{3} / L^{3}\right]$ \\ $C_{w} \quad$ Concentración de sedimentos por peso $\left[M / L^{3}\right]$ \\ $C_{i} \quad$ Concentración de sedimentos por volumen para cada \\ fracción de tamaño $\left[L^{3} / L^{3}\right]$ \\ CIT Índice topográfico para la iniciación de cauces \\ [adimensional] \\ $d, d_{s} \quad$ Diámetro de partículas de suelos o sedimentos $[L]$ \\ $d_{\star} \quad$ Diámetro de partículas adimensional [adimensional] \\ $D_{c} \quad$ Capacidad de erosión del flujo en surcos $\left[M / T L^{2}\right]$ \\ $D_{i} \quad$ Tasa de erosión en zonas entre surcos $\left[M / L^{2} T\right]$ \\ $D_{r} \quad$ Tasa de erosión en surcos $\left[M / L^{2} T\right]$ \\ ETP Evapotranspiración potencial $[L]$ \\ ExcCapML Exceso de capacidad de transporte de sedimentos $\left[L^{3}\right]$ \\ $f_{s} \quad$ Factor de fricción para el suelo [adimensional] \\ $f_{t} \quad$ Factor de fricción para el surco [adimensional] \\ $F \quad$ Fuerza total sobre una partícula $\left[M L / T^{2}\right]$ \\ $F_{B} \quad$ Fuerza de empuje sobre una partícula $\left[M L / T^{2}\right]$
}




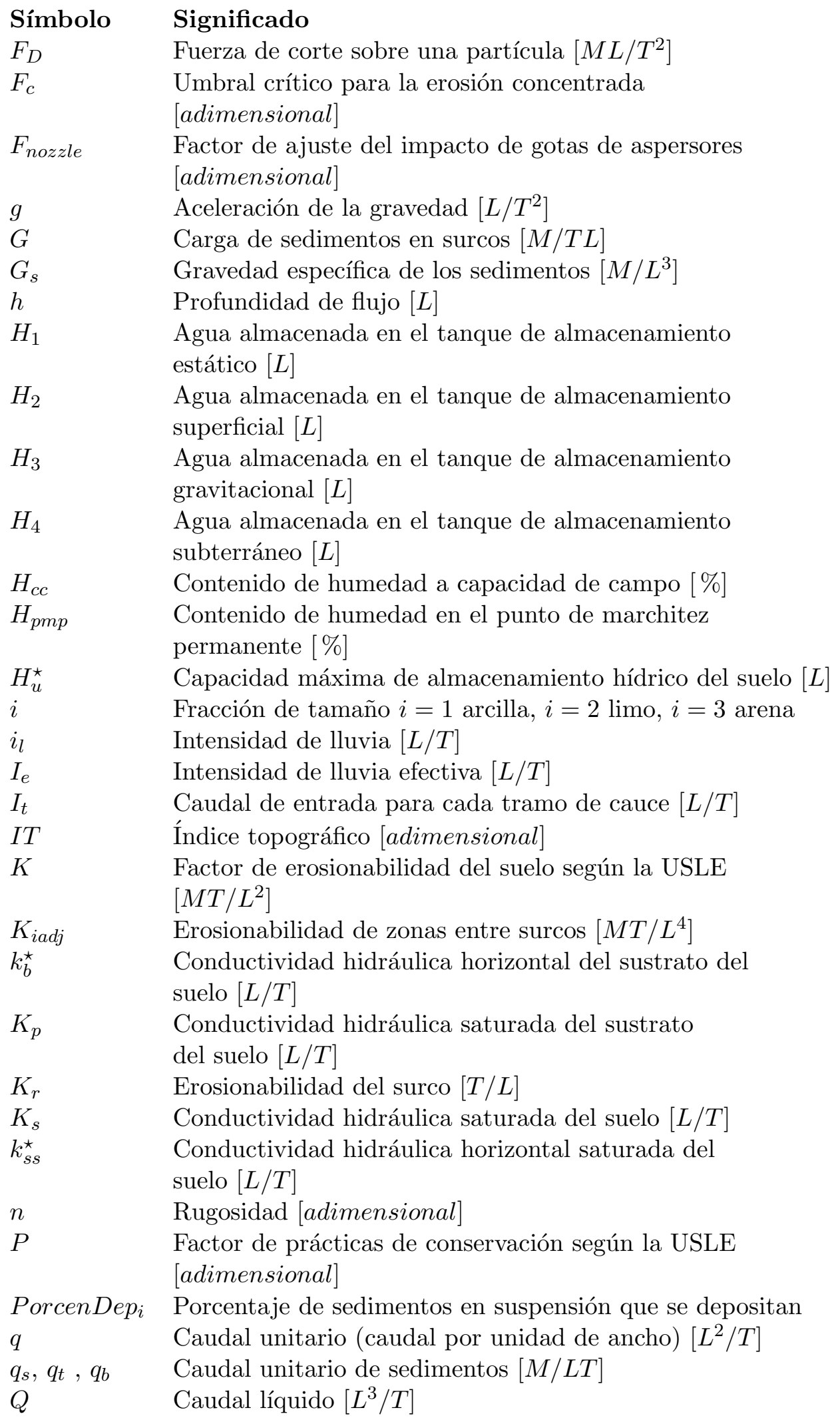




\section{Símbolo Significado}

$Q_{b} \quad$ Caudal a sección llena $\left[L^{3} / T\right]$

$Q_{s} \quad$ Caudal sólido $\left[M^{3} / L T\right]$

$Q_{s_{K R}} \quad$ Volumen de sedimentos transportados en ladera $\left[L^{3}\right]$

$Q_{s_{E H_{i}}} \quad$ Volumen de sedimentos transportados en cauce $\left[L^{3}\right]$

$Q_{s_{A D V_{i}}} \quad$ Tasa de sedimentos transportados por procesos advectivos $\left[L^{3} / T\right]$

$Q_{s_{E R O S}} \quad$ Volumen de sedimentos erosionados $\left[L^{3}\right]$

$Q_{s_{S U S_{i}}} \quad$ Volumen de sedimentos transportados en suspensión $\left[L^{3}\right]$

$R \quad$ Radio de una partícula $[L]$

$R_{c} \quad$ Capacidad de transporte de sedimentos del flujo en ladera $[M / T L]$

$R_{i} \quad$ Factor corrector de calibración hidrológica [adimensional]

$R_{h} \quad$ Radio hidráulico $[L]$

$R_{s} \quad$ Espaciamiento entre surcos $[L]$

$S \quad$ Pendiente [grados]

$S_{c r} \quad$ Pendiente crítica para la sedimentación [adimensional]

$S_{f} \quad$ Ángulo de fricción [grados]

$S_{0} \quad$ Pendiente de la celda [ grados $]$

$S D R_{R R} \quad$ Factor de entrega de sedimentos [adimensional] $t \quad$ Tiempo $[T]$

$T \quad$ Transmisividad del suelo $\left[L^{2} / T\right]$

$T_{c} \quad$ Capacidad de transporte de sedimentos en surcos $[M / T L]$

$T_{c j} \quad$ Índice de potencia de la corriente en la celda $j$ [adimensional]

$v \quad$ Velocidad media del flujo $[L / T]$

$v^{\star} \quad$ Velocidad de flujo en ladera $[L / T]$

$v_{t}^{\star} \quad$ Velocidad de flujo en cauce en el tiempo $t[L / T]$

$V_{f} \quad$ Velocidad de sedimentación de los sedimentos $[L / T]$

$w \quad$ Ancho de flujo $[L]$

$W \quad$ Ancho de un canal (surco, cárcava, cauce) $[L]$

$x \quad$ Longitud de ladera $[L]$

$X_{1} \quad$ Lluvia que cae en cada celda $[L]$

$X_{1, j} \quad$ Lluvia que cae en la estación $j[L]$

$X_{2} \quad$ Excedente de precipitación en cada celda $[L]$

$X_{3} \quad$ Agua que se infiltra en cada celda $[L]$

$X_{4} \quad$ Agua que se percola en cada celda $[L]$

$X_{5} \quad$ Pérdidas subterráneas de agua en cada celda $[L]$

$Y \quad$ Esfuerzo de corte adimensional [adimensional $]$

$Y_{c} \quad$ Esfuerzo de corte crítico adimensional [adimensional]

$Y_{1} \quad$ Agua que sale por evapotranspiración en cada celda $[L]$

$Y_{2} \quad$ Agua que sale por escorrentía directa en cada celda $[L]$

$Y_{3} \quad$ Agua que sale por flujo subsuperficial en cada celda $[L]$

$Y_{4} \quad$ Agua que sale por flujo base en cada celda $[L]$

$z \quad$ Elevación o cota de la celda $[L]$

$z_{j} \quad$ Elevación o cota de la estación $j[L]$ 


\section{Símbolos griegos Significado}

$\alpha$

$\Lambda$

$\gamma$

$\gamma_{s}$

$\lambda^{\star}(m)$

$\nu$

$\nu_{m}$

$\rho$

$\rho_{s}$

$\sigma_{i r}$

$\tau$

$\tau_{c}$

$\tau_{r}$

$\omega$

$\omega_{q d}$

$\omega_{T}$

$\Delta t$

$\Delta x$

$\Delta T_{c j}$

$\Omega$

$\varpi_{j}$
Factor corrector de la ecuación de Kilinc y Richardson [adimensional]

Área de captación o de drenaje $\left[L^{2}\right]$

Peso específico del agua $\left[M / L^{2} T^{2}\right]$

Peso específico de los sedimentos $\left[M / L^{2} T^{2}\right]$

Índice de cobertura vegetal para cada mes $(\mathrm{m})$

[adimensional]

Viscosidad cinemática del fluido $\left[L^{2} / T\right]$

Viscosidad cinemática de la mezcla sedimentos - agua $\left[L^{2} / T\right]$

Densidad del fluido $\left[M / L^{3}\right]$

Densidad de los sedimentos $\left[M / L^{3}\right]$

Tasa de escorrentía $[L / T]$

Esfuerzo de corte del flujo $\left[M / L T^{2}\right]$

Esfuerzo de corte crítico $\left[M / L T^{2}\right]$

Esfuerzo de corte sobre las partículas de suelo $\left[M / L T^{2}\right]$

Índice topográfico de humedad [adimensional]

Índice topográfico de humedad quasi-dinámico [adimensional]

Índice topográfico de humedad con transmisividad variable [adimensional]

Discretización temporal $[T]$

Discretización espacial o tamaño de celda $[L]$

Cambio en el índice de potencia de la corriente en la celda $j$ [adimensional]

Potencia de la corriente $\left[M L / T^{3}\right]$

Factor de ponderación del método de interpolación

espacial para la estación $j$ [adimensional] 


\section{Capítulo 1}

\section{Introducción}

Cada vez hay mayor interés por el aprovechamiento sostenible de los recursos naturales y crece la atención por los cambios ambientales ya sean antrópicos o naturales. El Grupo Intergubernamental de Expertos sobre Cambio Climático, $I P C C^{1}$ de Naciones Unidas, publicó recientemente el Cuarto Informe de Evaluación (AR4, en sus siglas en Inglés) ${ }^{2}$, del cual fue aprobado el Informe de Síntesis, en el mes de noviembre de 2007 en Valencia, España.

La Parte II aprobada en abril de 2007 en Bruselas, trata los impactos, la adaptación y la vulnerabilidad al cambio climático global. En la sección $3.4 .5^{3}$ se aborda el problema de la erosión y el transporte de sedimentos. Justo al inicio se menciona que los cambios en el balance del agua afecta varios procesos geomorfológicos, tales como la erosión, la estabilidad de laderas, los cambios en canales y el transporte de sedimentos. Además se apunta que estos cambios geomorfológicos afectan a su vez la calidad de las aguas.

Se busca un mayor entendimiento de los procesos claves en la dinámica ambiental y se necesitan herramientas adecuadas para la simulación y predicción de estos cambios. La modelación hidrológica debe incluir de una forma integral no sólo los procesos que transforman la lluvia en caudal sino tener en consideración los procesos determinantes en la producción, transporte y depósito de los sedimentos. Esto permitirá analizar aspectos tales como:

a) La localización de zonas donde se presenta deterioro y pérdida de suelos.

b) La identificación de fuentes de sedimentos tanto en laderas como en cauces.

c) La cuantificación de la producción de sedimentos en las cuencas.

d) La estimación de tasas de sedimentación en embalses y cuerpos de agua.

\footnotetext{
${ }^{1}$ En Inglés, Intergovernmental Panel on Climate Change

${ }^{2}$ http://www.ipcc.ch/ipccreports/assessments-reports.htm

${ }^{3}$ En Inglés, Chapter 3: Fresh Water Resources and their Management
} 
e) Los efectos de las variaciones ambientales (cambios antrópicos de los usos de suelo, cambios climáticos) en la dinámica de los sedimentos en la cuenca.

Los procesos geomorfológicos que modelan un paisaje se pueden resumir en tres procesos fundamentales: el arranque de partículas, el transporte y la posterior sedimentación de las mismas. Cada uno de estos procesos está controlado por el agente erosivo, que en la mayor parte de los paisajes naturales es el agua.

Los daños causados por los procesos erosivos reducen el potencial productivo de suelos cultivados por la acción de los siguientes mecanismos: disminución de la capacidad de retención de humedad, pérdida de nutrientes, degradación de la estructura del suelo, reducción de la uniformidad del suelo y modificación de la topografía (Follett y Stewart, 1985). Los procesos erosivos causan daños en las tierras cultivadas, además los sedimentos actúan como contaminantes en las aguas que los transportan y generan procesos de colmatación en presas, canales de irrigación y navegación y cuerpos de agua artificiales y naturales (Hagen y Foster, 1990). En eventos extremos de avenidas, tanto los sedimentos que se mueven por suspensión como los que constituyen la carga de lecho, aumentan la capacidad de arrastre del flujo y ocasionan daños tanto en obras ingenieriles (puentes, taludes, etc.) como en márgenes y lechos de ríos. Además en dichos eventos extremos, el transporte y el posterior depósito de sedimentos en zonas agrícolas y urbanas constituye un grave problema económico y social.

La complejidad de los fenómenos naturales hace que la modelación se convierta en una herramienta para predecir el comportamiento de un sistema geomorfológico ante la ocurrencia de eventos catastróficos, tales como tormentas extremas. La presente tesis doctoral aborda el problema del diseño de un modelo geomorfológico en el cual el agente erosivo modelador del paisaje es el agua.

\subsection{La modelación, su necesidad e importan- cia}

Las ciencias actuales están regidas, en mayor o menor medida, por necesidades prácticas. En las ciencias naturales, los requerimientos se centran en la simulación y predicción del comportamiento del sistema natural por medio de la modelación.

Los sistemas naturales son complejos y para acercarse a dicha complejidad se parte de ideas e impresiones, las cuales constituyen un conocimiento científico sólo cuando se establecen relaciones entre ellas (Wagensberg, 1985).

Según Wagensberg (1985) los pasos para comprender un sistema complejo se pueden resumir en:

Ver: en su sentido más amplio, quiere decir captar información de lo que visita nuestra área de percepción, según sea la contingencia del lugar y momento; 
Mirar: significa seleccionar la información que resulta de dirigir la visión cazada por cierta curiosidad;

Observar: consiste en acumular la información que resulta de mantener la mirada según sea nuestra perplejidad; y

Experimentar: equivale a enriquecer la información como consecuencia de provocar observaciones próximas según sea nuestro ingenio para intervenir en el resto del mundo.

El progreso de cualquier rama de la ciencia se debe a la capacidad de observar y experimentar. Pero esta capacidad es limitada en sistemas complejos naturales, por ejemplo, en una cuenca hidrográfica, puesto que son muchos los procesos que dan cuenta de su comportamiento.

Según Wagensberg (1985) estas limitaciones se pueden eludir acudiendo a una nueva forma de generar conocimiento: la simulación, esto es, la obtención de información que se genera en experimentos inventados. Dicho autor apunta que la simulación representa el máximo grado de iniciativa del científico para percibir, de tal forma que los nuevos científicos simuladores no son ni cientificos teóricos (o creadores) ni científicos experimentales (o aplicadores).

Wagensberg (1985) propone que la simulación no es teoría, ni experiencia, ni un mero útil de cálculo, sino una genuina tercera forma de aproximación a la realidad que acaso esté revolucionando el método científico. La simulación se nutre indistintamente de la teoría y la experiencia, puesto que cuando se modela un sistema se utilizan conceptos y a la vez se hace uso de datos y observaciones, aunque sean parciales, del sistema.

Esta revolución se debe a la capacidad de procesar y modelar grandes cantidades de información con la ayuda de los ordenadores, de tal forma que se pueden manejar con facilidad multitud de relaciones entre los componentes de un sistema.

El uso de modelos para predecir el comportamiento de una cuenca hidrográfica ante una lluvia se remonta al inicio de la Hidrología como ciencia. De la misma forma, el surgimiento de la Geomorfología como ciencia se ubica cuando se comienza a tratar el paisaje como un sistema dinámico. El desarrollo de modelos que permiten considerar la variabilidad espacial y temporal de los procesos y parámetros relevantes en el comportamiento de una cuenca hidrográfica se debe a la utilización de la simulación asistida por herramientas computacionales.

Cuando se trata de determinar la respuesta sedimentológica de una cuenca hidrográfica, se deben considerar con antelación los procesos hidrológicos relevantes, puesto que son los flujos de agua los encargados de erosionar y transportar las partículas de sedimentos. Además, las geoformas generadas por dichos procesos condicionan la respuesta hidrológica, de tal forma hay una relación dinámica entre la Hidrología y la Geomorfología. Dicha relación presenta una variabilidad espacial y temporal, tanto de los procesos como de los parámetros que dan cuenta de dichos procesos. 
De esta forma, la modelación de una cuenca hidrográfica es un ejercicio complejo que requiere tener en consideración muchos aspectos, tanto teóricos como experimentales. Pero este esfuerzo es necesario si se quiere predecir la dinámica sedimentológica ante cambios naturales y antrópicos.

\subsection{Planteamiento y objetivos de la tesis}

De acuerdo con lo dicho hasta el momento, es clara la necesidad de contar con herramientas de modelación, tanto a nivel científico (generación de conocimiento, comprensión de procesos naturales) como a nivel práctico (diseño ingenieril, planeamiento del territorio, análisis de riesgos naturales, usos adecuados del suelo).

El objetivo general de la tesis es desarrollar un modelo conceptual, distribuido en el espacio y en el tiempo y basado en el estado del arte actual, que permita simular la dinámica sedimentológica de una cuenca hidrográfica ante un evento de lluvia.

De este objetivo general se desprenden estos objetivos particulares:

- Desarrollar un herramienta computacional operativa, comprensible y de aplicación en diferentes situaciones, para simular la producción, el transporte y el depósito de sedimentos ante un evento de lluvia. Este programa computacional está basado en un modelo hidrológico distribuido desarrollado en el Departamento de Ingeniería Hidráulica y Medio Ambiente de la Universidad Politécnica de Valencia, (Modelo TETIS) y la aproximación sedimentológica se basa en el modelo CASC2D-SED desarrollado en el Engineering Research Center de la Colorado State University.

- Aplicar el nuevo modelo en una cuenca natural. Puesto que es la primera vez que se aplica el modelo, la cuenca de análisis debe contar con medidas sistemáticas de lluvia, caudal líquido y sólido, información de topografía, suelos y usos del suelo y a ser posible tener resultados de aplicación de otros modelos con el objeto de contrastar el desempeño del nuevo modelo. Una cuenca que reúne estos requisitos es la cuenca de Goodwin Creek, en el estado de Mississippi de los Estados Unidos de América.

El planteamiento propuesto para alcanzar estos objetivos se resume en los siguientes pasos:

- Comenzar con una revisión histórica del conocimiento sobre modelos de evolución del paisaje y específicamente sobre modelos de erosión hídrica.

- De esta revisión se generan una serie de cuestiones que se profundizan en la revisión del estado del arte actual de los modelos de erosión existentes y de aspectos necesarios para el diseño del modelo (conceptualización del sistema, procesos relevantes y estimación de parámetros). 
- Posteriormente se formula un modelo de producción, transporte y depósito de sedimentos a escala de cuenca y se desarrolla un código de programación que contenga los postulados detallados en la formulación. Esta formulación es la hipótesis de trabajo.

- Se aplica el modelo propuesto en una cuenca natural, con medidas sistemáticas de precipitación y series temporales de caudales líquidos y sólidos e información cartográfica (topografía, suelos, usos del suelo). La aplicación del modelo comprende la estimación de parámetros y los estados de humedad inicial, la calibración y su posterior validación. El modelo se evalúa a partir de los resultados arrojados y las diferencias que tengan con los datos medidos, tanto en la etapa de calibración como en la validación. El análisis de los resultados es la forma de validar o rechazar la hipótesis.

\subsection{Estructura del documento}

Para facilitar la lectura se ha estructurado el documento en tres partes generales que componen en total nueve capítulos, incluyendo la introducción y las conclusiones.

En la primera parte se desarrolla el Marco Teórico. En el capítulo 2, denominado Marco Histórico, se formulan las preguntas de la tesis a partir de una revisión de la evolución del conocimiento de modelos de evolución del paisaje, centrada específicamente en modelos de erosión. Del recuento epistemológico ${ }^{4}$ se derivan los aspectos fundamentales que deben ser tenidos en cuenta en la formulación de un modelo de erosión a escala de cuenca. Además se expone brevemente el estado del arte actual de cuyo análisis crítico resultan las bases para la formulación de un modelo de producción, transporte y depósito de sedimentos.

En el capítulo 3, denominado Marco Conceptual, se detalla la forma como se resuelven actualmente las preguntas formuladas en el capítulo 2, repasando el estado del arte actual. En este capítulo se tratan en profundidad los aspectos relevantes de un modelo de producción, transporte y depósito de sedimentos a escala de cuenca.

La segunda parte corresponde a la formulación del modelo, esto es, se expone la hipótesis de trabajo. El modelo diseñado será una suma de conceptos y técnicas coherentemente integradas de forma tal que permitan al usuario aplicar todo el conocimiento disponible para resolver un problema particular. En esta parte se define el sistema, detallando la discretización espacial y temporal y la forma de conectar los elementos del sistema. Además se exponen los procesos tenidos en cuenta en el modelo, los algoritmos utilizados para implementar dichos procesos y el funcionamiento general del modelo. Por último se detallan los procesos de esti-

\footnotetext{
${ }^{4}$ La epistemología se ocupa de las circunstancias históricas, filosóficas y sociológicas que llevan a la obtención del conocimiento científico
} 
mación de parámetros y las estrategias utilizadas para la calibración y validación del modelo.

La tercera parte corresponde a la aplicación del modelo en una cuenca natural. La cuenca de análisis es la cuenca de Goodwin Creek, en el estado de Mississippi, en Estados Unidos de América que cuenta con medidas sistemáticas de lluvia, caudal líquido y sólido, información de topografía, suelos y usos del suelo. Estos datos son de dominio público a través de la página web del Agricultural Research Center del National Sedimentation Laboratory del Departamento de Agricultura de Estados Unidos ${ }^{5}$.

En el capítulo 5 se exponen las características principales de la cuenca de análisis, específicamente aquellas determinantes del comportamiento hidrológico y geomorfológico. Del análisis de estas características se deriva la estimación de parámetros y las condiciones iniciales, esto es, las entradas del modelo que se reseña en el capítulo 6. En el capítulo 7 se detalla la aplicación del modelo en dicha cuenca, abordando los procesos de calibración y validación, por último, en el capítulo 8 se discuten los resultados y se sacan conclusiones del análisis de los mismos.

En el capítulo 9 se exponen las conclusiones obtenidas de la tesis, se reseñan los aportes y se plantean futuros desarrollos y líneas de investigación abiertas.

\footnotetext{
${ }^{5}$ http://www.ars.usda.gov
} 
Parte I

Marco Teórico 



\title{
Capítulo 2
}

\section{Marco histórico}

\author{
"How many years can a mountain exist \\ before it's washed to the sea?... \\ ... The answer, my friend, is blowing in the wind, \\ the answer is blowing in the wind."
}

En este capítulo se desarrolla una revisión de la evolución del conocimiento de modelos de evolución del paisaje, centrada específicamente en modelos de erosión.

Los modelos de evolución del paisaje que se encuentran en la literatura además de contener un modelo de erosión, que puede decirse que es el corazón de los modelos de evolución del paisaje, tienen en consideración los cambios topográficos y geomorfológicos del paisaje, tales como el aumento o disminución de la altura y pendiente local de las geoformas, la formación de suelos, los cambios en la forma de los cauce, etc.; además de considerar la tectónica, esto es, levantamientos tectónicos, vulcanismo, fallas y pliegues.

Según De Pedraza (1996) estos modelos evolutivos responden a una globalización teórica difícilmente contrastable y, por tanto, con escasas posibilidades de validación. Willgoose (2005) señala que la Geomorfología históricamente ha tenido gran cantidad de modelos de evolución y desarrollo del paisaje de tipo descriptivo y cualitativo, la mayoría con capacidades predictivas limitadas y en su totalidad imposibles de probar de una forma científica.

\subsection{Los modelos de evolución del paisaje}

El análisis del paisaje como sistema dinámico comenzó con la teoría del ciclo de evolución propuesta por el geógrafo norteamericano William Morris Davis (1850-1934) a finales del siglo XIX. Davis desarrolló su teoría apoyándose en los paradigmas de las ciencias naturales de la época, esto es, la teoría de la evolución

${ }^{1}$ Tomado de Blowing in the wind de Bob Dylan 
de Charles Darwin (1809-1882) y el principio de uniformitarianismo del físico escocés James Hutton (1726-1797), que plantea que los procesos que ocurren hoy en día son los mismos que los que ocurrieron en el pasado ${ }^{2}$. Davis recopiló y sintetizó en su teoría los trabajos precedentes de John Wesley Powell (1834-1902), que presentaba una línea fisiográfica; y de Grove Karl Gilbert (1843-1918), que se centraba en la génesis del paisaje. Ambos trabajos fueron efectuados en el suroeste árido de Estados Unidos.

Con estos enfoques Davis creó las bases de la Geomorfología moderna. Su formulación es clara y concisa, justo al comenzar la disertación del ciclo geográfico señala lo siguiente: "Toda la variedad de formas del terreno dependen de - o, como dirían los matemáticos, son función de - tres variables, que pueden ser denominadas estructura, proceso, y tiempo" 3 (Davis, 1899).

A finales del siglo XIX, aparecen los primeros textos que pueden considerarse tratados geomorfológicos, tales como Las formas del terreno ${ }^{4}$, de los franceses De la Noë y Margerie; y la Morfología de la superficie de la tierra ${ }^{5}$, del austroalemán Albrecht Penk, los cuales son importantes no tanto por sus contenidos sino porque fueron estudios precursores (De Pedraza, 1996).

La teoría del ciclo de Davis fue la base para los tratados geomorfológicos durante la primera mitad del siglo XX. Las observaciones de paisajes diversos en climas y latitudes diferentes a las que se basó Davis para formular su teoría, contrastaban con la simplicidad descrita por Davis, por lo que dichos conceptos fueron sometidos a crítica dando lugar a nuevas tendencias que culminarían con un análisis geomorfológico estructurado en procesos genéticos definidos según un agente erosivo (ríos, glaciales, viento) o un contexto climático (De Pedraza, 1996).

Se pueden diferenciar dos escuelas de pensamiento. Una basada en las relaciones ambientales y la distribución de procesos según contextos climáticos que algunos autores denominan la escuela francesa debido al protagonismo que tuvieron autores franceses (Engeln, 1948; Birot, 1958; Thornbury, 1960; Tricart y Cailleux, 1965; Derruau, 1978), comúnmente se conoce como la Geomorfología Climática y sus aportes dieron un impulso a la cartografía geomorfológica y a un método de carácter descriptivo.

La otra escuela surgió de forma dispersa en varios países y autores (Horton, 1932, 1945; Strahler, 1957; Young, 1963; Leopold et al., 1964; Scheidegger, 1970; Dury, 1970; Chorley, 1972; Schumm, 1979; Chorley et al., 1984; Selby, 1985; Summerfield, 1991), con un elemento común: el análisis, parametrización y cuantificación de procesos geomorfológicos según la configuración geométrica de las formas producidas y las relaciones dinámicas de los procesos. Dicha escuela se denomina

\footnotetext{
${ }^{2}$ El presente es la clave del pasado

${ }^{3}$ En Inglés, All the varied forms of the lands are dependent upon — or, as the mathematician would say, are function of - three variable quantities, which may be called structure, process, and time

${ }^{4}$ En Francés, Les Formes du Terrain

${ }^{5}$ En Alemán, Morphologie der Erdoberfläche
} 


\section{la Geomorfología Dinámica.}

La Geomorfología Dinámica consideró nuevas teorías y métodos, tales como el análisis sistémico, los fundamentos termodinámicos, los umbrales de cambio y los sistemas de auto-organización. Dichos planteamientos parten de la misma base conceptual de la teoría del ciclo de evolución de Davis, esto es, los ajusten que realizan las corrientes fluviales para mantener el equilibrio caudal - carga de sedimentos - pendiente.

Los modelos actuales se basan en los fundamentos de la Geomorfología Dinámica al centrarse en procesos que se simulan según relaciones matemáticas con sentido físico, pero además tienen en consideración las ideas tomadas de la Geomorfología Climática, especialmente las relaciones ambientales que se dan en una región en particular, por ejemplo en la estimación de parámetros.

\subsubsection{Los principios de evolución del paisaje}

Un paisaje es la expresión de procesos continuos de acreción o levantamiento tectónico (procesos endógenos), y de incisión o erosión por agentes meteóricos (procesos exógenos), actuando simultáneamente en el tiempo.

Scheidegger (1979) ha propuesto el principio del antagonismo señalando que si bien la evolución del paisaje no es cíclica en todo su sentido, el paisaje representa simplemente el estado instantáneo de la interacción entre los procesos exógenos y endógenos, los cuales son antagónicos.

Scheidegger (1987) propone un parámetro cuantitativo para describir el estado de evolución de un paisaje en particular, en términos semejantes a los propuestos por Davis (juvenil, maduro, senil). Este parámetro se basa en la curva hipsométrica de una región.

Así, el estado de evolución de un paisaje puede identificarse según las observaciones de Strahler (1957). Strahler determinó que un paisaje juvenil presenta una curva hipsométrica convexa, en un paisaje maduro esta curva presenta una forma más o menos recta, mientras que en un paisaje senil la curva hipsométrica es cóncava.

Scheidegger (1987) sugiere que la curva hipsométrica es una expresión de la intensidad del antagonismo e introduce el índice de estado.

En cuanto al antagonismo de los procesos se reconoce que los procesos exógenos tienen características aleatorias, mientras que los procesos endógenos tienen características determinísticas. La definición de los procesos geomorfológicos como estocásticos (factores aleatorios y determinísticos) ha sido usada satisfactoriamente (Scheidegger, 1987). El hecho de la estocasticidad de los procesos geomorfológicos fue tratado inicialmente por Leopold y Langbein (1962).

Según Scheidegger (1987), la razón por la cual se da el antagonismo estadístico está determinada por la naturaleza mecánica de los procesos. Así, los procesos exógenos están principalmente conducidos por fenómenos turbulentos del aire y el agua, que se describen mejor por la teoría estocástica, mientras que los procesos 
endógenos están controlados principalmente por esfuerzos tectónicos, los cuales actúan de forma homogénea y sistemática en grandes regiones, comparables con las placas tectónicas.

Para caracterizar la fuerza del antagonismo Scheidegger (1987) introduce el índice de estacionalidad, definido por la relación entre la velocidad de levantamiento y la velocidad de denudación.

Scheidegger (1983) propone el principio de inestabilidad según el cual el equilibrio dinámico de un paisaje es inestable. Este principio ya ha sido tratado por Schumm (1979) en su teoría del umbral geomorfológico y se asemeja a los postulados de la teoría de la catástrofe en Geomorfología (Graf, 1979; Thornes, 1983). Rodriguez-Iturbe y Rinaldo (1997) analizan estos planteamientos, desarrollándolos como la teoría de sistemas de auto - organización crítica.

El principio de inestabilidad se explica por la operación de un mecanismo de retroalimentación, la no uniformidad se acentúa porque la tasa de crecimiento de una desviación de la uniformidad se incrementa con la cantidad de desviación que ya ha sido alcanzada. Esta idea puede ser expresada matemáticamente: la iniciación de una inestabilidad puede ser descrita como un proceso de crecimiento potencial, esto es, una retroalimentación lineal positiva (Scheidegger, 1987).

En un período suficiente prolongado de tiempo, se puede justificar que el sistema geomorfológico se trate como estadísticamente estacionario. Para cada parámetro analizado, es posible establecer un tiempo característico, en el cual la inestabilidad "microscópica" puede ser reemplazada por la uniformidad "macroscópica".

Este tiempo ha sido estudiado por varios autores, denominándolo tiempo de relajación (Allen, 1974; Brunsden y Jones, 1984; Hardisty, 1987), y fue definido por Brunsden y Thornes (1979) como el tiempo que toma un sistema para alcanzar un nuevo equilibrio a partir de un cambio en las entradas o en la operación interna de un sistema. Hardisty (1987) formaliza esta definición.

Otro principio relacionado con el principio de inestabilidad es el principio de la catena ${ }^{6}$ que según Blöschl y Sivapalan (1995) fue definido inicialmente por Milne en el año de 1935 y se originó a partir de la observación de la física de los suelos al notar que ciertas secuencias de tipos de suelos se repiten a lo largo de una ladera en particular, estrechamente conectadas con la posición topográfica relativa en la ladera.

Esta secuencia no sólo se limita a tipos de suelos, sino a los demás elementos geomorfológicos que componen una ladera, así, este concepto se puede ampliar a toda una cuenca hidrográfica, la cual está compuesta por numerosas laderas, cada una de las cuales presenta una secuencia de suelos y elementos morfológicos que dependen de su posición particular en la ladera (Scheidegger, 1987).

El principio de la catena plantea uno de los aspectos fundamentales en los procesos geomorfológicos, su variabilidad espacial. La mayor evidencia geomorfológica del principio de la catena se manifiesta en la disposición de una ladera, con una zona eluvial en la parte alta de la ladera, en donde predominan procesos de forma-

\footnotetext{
${ }^{6}$ Del latín, catenae. Secuencia o cadena en Castellano
} 
ción de suelos; una zona coluvial en la zona media de la ladera, con el predominio de procesos de arranque y transporte de partículas de suelo; y una zona aluvial en donde los procesos dominantes son de sedimentación. El concepto de catena se asienta físicamente en los procesos mecánicos que subyacen al principio de inestabilidad: las tasas de erosión se incrementan con el aumento en la pendiente, así, mientras más abrupta es una pendiente más rápido se degrada.

Uno de los primeros autores que implica en sus teorías el concepto de variabilidad espacial es Horton (1945), al definir una franja en la ladera en la que no se presenta erosión y se caracteriza por la ausencia de procesos de incisión ${ }^{7}$. El trabajo de Horton fue la base para una buena cantidad de investigaciones efectuadas durante la segunda mitad del siglo XX en cuanto a los procesos de formación de paisajes, varias de los cuales se centran en el fenómeno de iniciación de la erosión concentrada.

Otro principio fundamental en la evolución del paisaje se relaciona con la predominancia de geoformas en una región en particular, aun teniendo en cuenta la naturaleza estocástica de los procesos formadores. Según Scheidegger (1987), el principio de selección fue introducido inicialmente por Gerber en el año de 1969, estableciendo que los procesos de erosión ocurren de tal manera que las geoformas estáticamente estables, con referencia a lo esfuerzos actuantes, son seleccionadas preferentemente. A partir de cálculos estructurales de geoformas, Scheidegger y Kohlbeck en el año de 1985 confirman la existencia del principio de selección en geoformas de varias zonas de montaña.

Además de los principios descritos anteriormente, Scheidegger (1987) establece el principio de control estructural, por el cual las características de un paisaje están prediseñadas de acuerdo con la configuración tectónica. Este principio se evidencia en la configuración de la red de drenaje, y en la ocurrencia de procesos erosivos y de movimientos en masa.

Es necesario considerar la variabilidad espacial, tanto de los parámetros como de los procesos, en la aplicación práctica de modelos geomorfológicos e hidrológicos. Esta variabilidad puede ser tratada de forma determinística tanto en la estimación de parámetros como en la definición de zonas en donde los procesos son dominantes.

$\mathrm{Al}$ respecto, Blöschl y Sivapalan (1995) luego de efectuar un análisis de los problemas de escala, la heterogeneidad y la variabilidad espacial y temporal en la modelación hidrológica y geomorfológica, se decantan por la organización, más que por la aleatoriedad, al tratar el paisaje como un sistema. Dichos autores señalan que los métodos determinísticos tienen un potencial mayor que los métodos estocásticos para capturar la organización natural en cuencas hidrográficas.

Ponen, entre otros ejemplos, el análisis de redes de drenajes a partir de los conceptos de Horton (1945) y Strahler (1957); el estudio de la geometría hidráulica basada en las relaciones de Leopold y Maddock (1953); y la estimación de la variabilidad de parámetros hidrológicos del suelo a partir de conceptos tales como la catena de suelos en una ladera y el Índice Topográfico de Beven y Kirkby (1979).

\footnotetext{
${ }^{7}$ Belt of no erosion, según Horton
} 


\subsubsection{Modelos de evolución del paisaje actuales}

Los modelos analíticos de evolución del paisaje tienen una historia relativamente larga, cuyos inicios se pueden ubicar a partir de la teoría de Davis. Según Willgoose (2005) los modelos computacionales que tratan la dinámica de la evolución del paisaje a escala de cuenca, comienzan con el trabajo de Ahnert en el año de 1976.

Los avances recientes en técnicas computacionales han permitido el desarrollo de herramientas para representar la superficie del terreno. La capacidad de trabajar con Modelos de Elevación Digital ${ }^{8}$ y con Redes de Triángulos Irregulares ${ }^{9}$ a principios de la década de los ochenta del siglo pasado, generó un gran interés en la comunidad científica y técnica, en el desarrollo de modelos distribuidos en el espacio, tanto hidrológicos como geomorfológicos. Pero no fue hasta principios de la década de los noventa del pasado siglo que se pudieron aplicar los DEM y los TIN en la modelación de cuencas, debido a la masificación del uso y al incremento de la potencia y velocidad de los ordenadores.

Esto permitió una adecuada representación de los procesos fluviales y de ladera, algunos ejemplos son los trabajos de Kirkby (1987), Willgoose et al. (1991a), Willgoose et al. (1994), Howard (1994), y Tucker y Slingerland (1994).

Se desarrollaron modelos distribuidos en Hidrología de cuencas, por ejemplo los trabajos de Abbott et al. (1986a), Abbott et al. (1986b), Garrote y Bras (1995), y Julien et al. (1995), entre otros

En evolución del paisaje, donde se pueden destacar los trabajos de Willgoose et al. (1991b), Howard (1994), Johnson y Beaumont (1995), Tucker y Slingerland (1997), y Tucker y Bras (1998)

En erosión de suelos, por ejemplo los trabajos de Laflen et al. (1997), y Mitas y Mitasova (1998); y en estabilidad de laderas, como el trabajo de Montgomery y Dietrich (1994).

Estos acercamientos han ayudado a entender las interrelaciones entre la hidrología, la erosión fluvial, los procesos en la ladera, la tectónica, el clima, la litología y su influencia en la génesis y evolución de las geoformas y la red de drenaje (Coulthard, 2001).

Los modelos referenciados tienen tres puntos en común, derivados de la necesidad de modelar flujos sobre la superficie del terreno (Tucker et al., 2001):

a) La división de la superficie del terreno en una serie de elementos discretos y conectados.

b) La aplicación de leyes de conservación de masa para cada elemento del terreno.

c) La definición de la dirección de flujo y la red de drenaje entre cada discretización de la superficie del terreno.

\footnotetext{
${ }^{8}$ En Inglés, Digital Elevation Model (DEM)

${ }^{9}$ En Inglés, Triangulated Irregular Networks (TIN)
} 
Algunos de los modelos de evolución del paisaje que se encuentran referenciados en la literatura utilizan técnicas diferentes para abordar lo comentado. Los modelos CASCADE (Braun y Sambridge, 1997) y CHILD (Tucker et al., 2001) representan el paisaje como una red irregular adaptativa, de tal forma que las áreas que presentan mayor actividad, por ejemplo, alrededor de la red de drenaje, poseen una densidad de nodos mayor y por lo tanto un detalle mayor, que la zona de ladera, que presenta poca actividad.

Los modelos GOLEM (Tucker y Slingerland, 1994) y SIBERIA (Willgoose et al., 1991a, 1994) representan el paisaje como una malla de celdas regulares y en la red de drenaje usan una subdivisión más fina.

El modelo CAESAR (Coulthard et al., 1999, 2000) representa del paisaje usando una gran malla de celdas en la cual a su vez se encuentra una malla de celdas más fina y concentra el $95 \%$ del tiempo de modelación en las celdas activas cerca de la red de drenaje y periódicamente revisa las celdas de ladera.

En cuanto a los procesos, el modelo SIBERIA determina, para cada intervalo temporal de simulación (entre uno y diez años), el caudal para cada celda de acuerdo con un coeficiente de escorrentía y el área de captación. Si el caudal excede un umbral, determinado por la resistencia del material, ocurre erosión fluvial y los materiales se movilizan a la celda aguas abajo. Este acercamiento se encuentra acoplado con un modelo que simula los procesos difusos en ladera (formación de suelos, meteorización, movimientos en masa) que determinan la cantidad de material disponible para la erosión fluvial.

El modelo GOLEM aborda los mismos procesos que el modelo SIBERIA, incluyendo un modelo tectónico de levantamiento orográfico. El modelo CASCADE incluye los mismos procesos que el SIBERIA y el GOLEM y básicamente se diferencia en la representación del paisaje.

El modelo CHILD utiliza los mismos algoritmos que el CASCADE, pero se diferencia en que no utiliza un intervalo temporal de simulación constante, sino que cada iteración representa un evento de lluvia. Además, el modelo CHILD incorpora una representación más elaborada de los procesos fluviales, al calcular la geometría del canal (ancho y profundidad); además considera diferentes tamaños de sedimentos y permite al usuario introducir la edad de los depósitos, permitiendo al modelo construir una estratigrafía aluvial simple.

El modelo CAESAR permite una discretización fina del espacio en la red de drenaje lo que se traduce en un gran detalle en la modelación de procesos fluviales. Además, el intervalo temporal de simulación es variable y depende de la intensidad de lluvia. De esta forma durante evento extremos, es posible simular con intervalos de segundos, mientras que en regímenes de caudales bajos, el intervalo temporal puede ser horario o diario. 


\subsubsection{Limitaciones de los modelos de evolución del paisaje}

Según De Ploey y Poesen (1987), una de las dificultades actuales de la Geomorfología es la disociación que existe entre los planteamientos puramente teóricos, asociados al ciclo geomorfológico, y el desarrollo de modelos que acepten tratamientos matemáticos, basados en procesos físicos, químicos, biológicos.

Dichos autores sugieren que esta disociación que no permite la aplicación práctica de los modelos geomorfológicos, se debe a la inercia conceptual del ciclo geomorfológico de Davis, aunque reconocen los avances recientes en la modelación geomorfológica debido principalmente al trabajo interdiciplinario (geomorfólogos teóricos y prácticos, hidrólogos, agrónomos) con un enfoque más pragmático y basado en el entendimiento de las interacciones físicas, químicas y biológicas que gobiernan los procesos.

Por último apuntan hacia el desarrollo de modelos determinísticos con base física pero señalan que durante mucho tiempo los sistemas geomorfológicos complejos seguirán explicándose en términos verbales, sin el uso de expresiones matemáticas y por lo tanto sin posibilidades para la simulación.

Otra dificultad inherente a los modelos de evolución del paisaje es que no pueden validarse, debido a la imposibilidad de contrastarlos con datos reales sistemáticos.

\subsubsection{Los principios de evolución del paisaje y los mo- delos de erosión}

Para el diseño de un modelo de erosión es necesario tener en cuenta los fundamentos y principios de un modelo de evolución del paisaje repasados hasta ahora. Las preguntas básicas que debe abordar el modelo son:

a) ¿Dónde y cuándo se presenta la erosión (producción de sedimentos)?

b) ¿Hasta dónde se transportan estos sedimentos?

c) ¿Dónde y cuándo se depositan los sedimentos?

d) ¿Cuál es el tiempo de residencia de los sedimentos en una localización específica de la cuenca?

Para acercarse a estas cuestiones se define el sistema físico (el paisaje), los procesos que actúan en el sistema y la escala espacial y temporal de dichos procesos. En la figura 2.1 se esquematiza la representación del sistema físico con sus diversas escalas espacio - temporales.

Una vez definido el sistema geomorfológico de análisis se determinan los componentes físicos del mismo: litología, geomorfología, suelos, vegetación, clima, la 


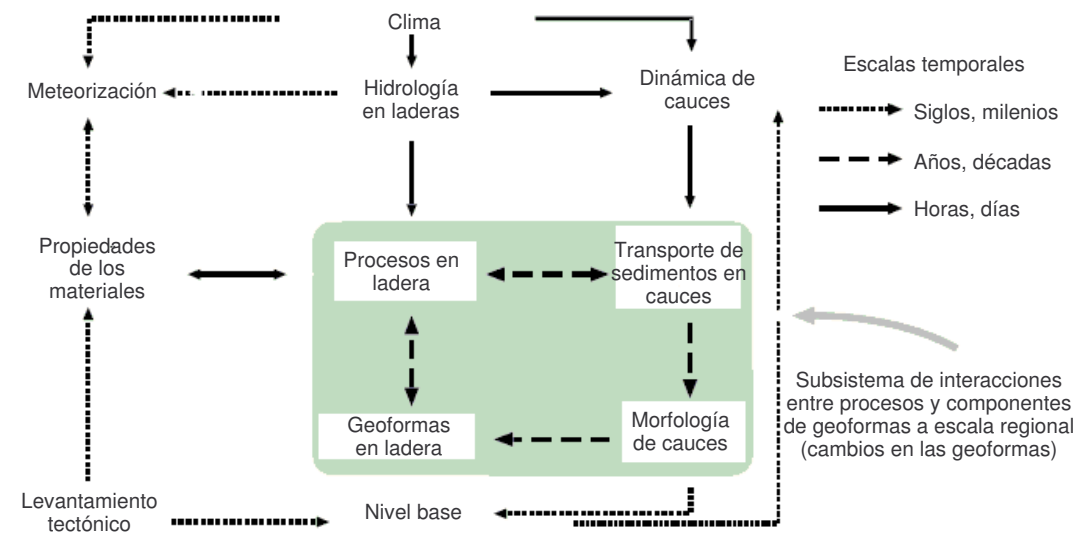

Figura 2.1. Componentes y procesos del sistema físico (paisaje), adaptado de Preston y Schmidt (2003)

arquitectura y el ensamblaje o estructura de las geoformas (posición relativa de las diferentes geoformas).

Dependiendo de la escala de análisis (espacial y temporal) varios de estos componentes pueden considerarse como elementos dinámicos del sistema, sujetos a presentar variaciones, y otros pueden considerarse como condiciones de frontera externas (Schumm y Lichty, 1965).

Además, el sistema físico está sujeto a entradas de energía y a la aplicación de fuerzas de acuerdo con los procesos geomorfológicos que estén actuando. Al igual que los componentes físicos del sistema, algunas entradas de energía y procesos pueden hacer parte de las condiciones de frontera, mientras que otras actúan dinámicamente en el sistema.

Según Chorley y Kennedy (1971) el flujo de sedimentos en el paisaje puede ser concebido como un sistema proceso - respuesta, considerando la morfología como un factor que controla los procesos y al mismo tiempo un producto de la evolución del sistema. Así están implícitos en la definición del sistema los flujos de materia y energía. Los flujos de sedimentos, en un contexto sistémico, están concebidos como una serie de geoformas en el paisaje en las cuales los sedimentos se almacenan en diversidad de longitudes de tiempo (figura 2.2).

El comportamiento a largo plazo del flujo de sedimentos se manifiesta en cambios en las geoformas, Preston y Schmidt (2003) detallan un ejemplo de cambios en los perfiles de suelos debidos a cambios en los usos.

Según Crozier (1999) uno de los desafíos actuales de los investigadores en el campo de la Geomorfología es predecir las geoformas producidas por regímenes de procesos interceptados e interrelacionados pero actuando bajo sus propias frecuencias y magnitudes.

Debido a la diversidad de relaciones magnitud y frecuencia de los procesos que actúan en un sistema geomorfológico, las escalas temporales y espaciales se 


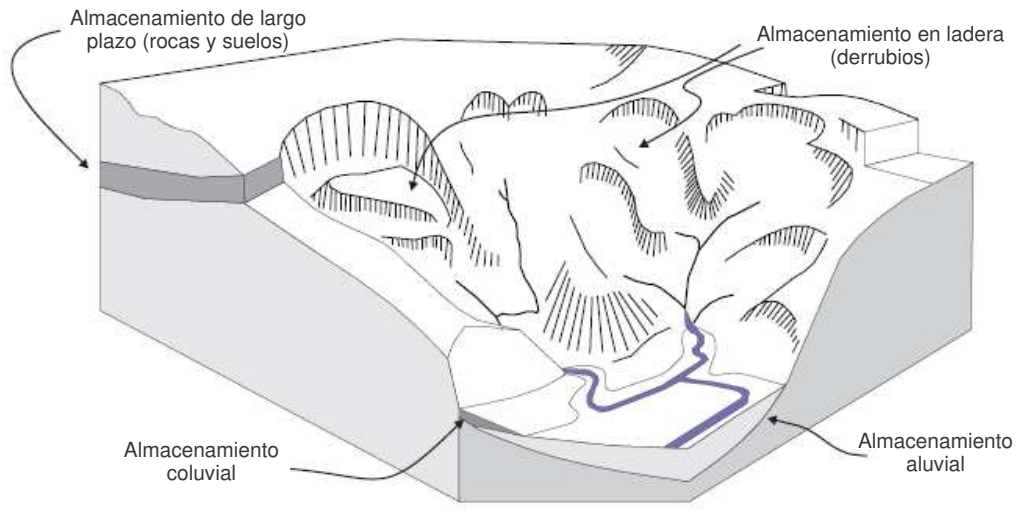

Figura 2.2. Esquema de un paisaje a escala de cuenca, se observan diferentes almacenamientos de sedimentos, adaptado de Preston y Schmidt (2003)

encuentran inevitablemente truncadas, en especial debido a la respuesta compleja y las diferentes reacciones de las geoformas de diferente magnitud a perturbaciones idénticas (Schumm, 1973, 1979).

Preston y Schmidt (2003) señalan que el comportamiento a largo plazo de un sistema geomorfológico está influenciado por dos factores: la interacción de procesos con diferentes espectros de magnitud y frecuencia y los factores relativos a la configuración espacial de los elementos del paisaje.

\subsection{Los modelos de erosión}

Los procesos de erosión hídrica resultan de la operación de leyes físicas y químicas que se suponen de aplicación universal, puesto que los modelos de erosión tratan de describir estos procesos es de esperarse que existan puntos en común en los modelos presentes en la literatura, lo cual no es cierto teniendo en cuenta la multitud de modelos con diferentes enfoques. Estas diferencias se dan básicamente por la conceptualización que cada modelo hace del sistema representado (el paisaje) y las relaciones matemáticas adoptadas, ya sea que tengan un sentido físico o que se basen en relaciones empíricas.

Jetten y Favis-Mortlock (2006) proponen que el desarrollo histórico de los modelos de erosión en Europa difiere del que se ha dado en Estados Unidos.

Los primero intentos para desarrollar métodos de estimación de la erosión se realizaron en Estados Unidos, en la década de los años veinte del siglo pasado, como una respuesta a las elevadas tasas de erosión y pérdida de suelo debido a la modernización de la agricultura, con el aumento en la escala e intensidad de actividades agrícolas.

Las técnicas de predicción de la erosión se utilizan de forma sistemática desde aproximadamente 1940 como una herramienta para la planificación de sistemas de 
cultivos y para la adecuación de medidas de conservación del suelo. Esta aproximación se basa en la evaluación de varios sistemas de conservación alternativos para optar por aquel en el cual el valor calculado para la erosión total sea igual o menor que un valor de pérdida de suelo tolerable para cada suelo y situación de cultivo particular (Follett y Stewart, 1985).

Según Renard et al. (1997) las ideas y conceptos precursores se deben a Cook en el año de 1936, al identificar las principales variables que afectan la erosión del suelo debido al agua. Cook determinó que los tres factores determinantes son: la susceptibilidad del suelo a la erosión, propiedad inherente a los suelos; el potencial erosivo de la lluvia y la escorrentía superficial, propiedad inherente a las condiciones climáticas; y la protección de la cobertura de vegetación ante la erosión, que depende de las labores de protección que se implementan en el campo.

Según Hagen y Foster (1990) la primera ecuación propuesta para el uso en planes de conservación fue asignada por Zingg en el año de 1940, quien relaciona la pérdida de suelo con la erosión laminar y concentrada las cuales a su vez dependen de la longitud y grado de la pendiente. Smith y Whitt en el año de 1947 refinaron estos acercamientos incluyendo otros factores tales como la cobertura de vegetación, las técnicas de manejo y las prácticas de conservación.

Finalmente, luego de un análisis empírico a partir de una gran cantidad de datos tomados en parcelas de erosión en más de 40 localidades de los Estados Unidos de América, se desarrolló la Ecuación Universal de Pérdida de Suelo ${ }^{10}$ por un grupo de trabajo de investigadores dirigidos por W.H. Wischmeier (Wischmeier y Smith, 1978).

Con esta perspectiva, se masificó el uso de la USLE y de la Ecuación de Erosión Eólica ${ }^{11}$ en todo el territorio norteamericano, durante las décadas de los sesentas y setentas del pasado siglo. Alternativamente, se implementó la USLE en otras partes del mundo y se realizaron numerosas investigaciones para adecuar los factores de la ecuación en zonas con características diferentes de las que se dedujeron inicialmente.

Además se desarrollaron modelos de erosión específicos con una conceptualización similar a la USLE, por ejemplo, el modelo $S L E M S A^{12}$ en África (Stocking y Elwell, 1973) y el modelo $U S L E-M^{13}$ en Australia (Kinell, 1997) ${ }^{14}$.

Posteriormente se efectuaron investigaciones tendientes a revisar y actualizar los factores de la USLE obteniéndose la Ecuación Universal de Pérdida de Suelos Revisada ${ }^{15}$ (Renard et al., 1989). Esta modificación se limitó a la transformación de los factores de la anterior USLE pero no cambió su estructura.

La agregación temporal de la ecuación se basa en condiciones medias anuales,

\footnotetext{
${ }^{10}$ En Inglés, Universal Soil Loss Equation (USLE)

${ }^{11}$ En Inglés, Wind Erosion Equation (WEQ)

${ }^{12}$ En Inglés, Soil Loss Estimator for Southern Africa

${ }^{13}$ En Inglés, Universal Soil Loss Equation - Modified Version

${ }^{14}$ Citado por Jetten y Favis-Mortlock (2006)

${ }^{15}$ En Inglés, Revised Universal Soil Loss Equation (RUSLE)
} 
así el resultado de la aplicación de la USLE y la RUSLE en una zona es la masa total de sedimentos producidos por superficie de terreno por año. Como un intento por utilizar la estructura de la USLE en eventos de lluvias generadores de erosión se desarrolló la Ecuación Universal de Pérdida de Suelos Modificada ${ }^{16}$ (William, 1975), que analiza eventos en vez de condiciones medias anuales.

Una de las críticas más frecuentes que se hacen a modelos del tipo de la USLE es que a pesar de ser modelos empíricos, sugieren un uso universal. Además han generado una inercia conceptual que se encuentra incluso en varios de los modelos de erosión utilizados en la actualidad y de reciente desarrollo.

La masificación y modernización de la agricultura se presenta unas décadas más tarde en Europa y consecuentemente la necesidad de desarrollar modelos de erosión se da posteriormente que en Estados Unidos (Jetten y Favis-Mortlock, 2006). Dichos autores señalan el comienzo de la aplicación de modelos de erosión en Europa en los primeros años de la década de los ochenta del siglo pasado, varios años después de que la comunidad técnica y científica tomara conciencia de la problemática relacionada con la erosión del suelo.

La primera generación de modelos desarrollada en Europa se basa en la USLE con pequeñas modificaciones, incluso aun se utiliza la USLE en Europa con ayuda de Sistemas de Información Geográfica, por ejemplo el WATEM/SEDEM ${ }^{17}$ (Van Oost et al., 2000; Van Rompaey et al., 2001) y el RHINEFLOW (Asselman et al., 2003).

Es justo cuando comienza la aplicación de modelos de erosión en Europa que los investigadores se preguntan por la aplicación de modelos basados en la USLE en condiciones diferentes a aquellas zonas en donde se implementó. A partir de la evaluación de los modelos existentes (basados en la USLE) con datos reales de pérdida de suelos, se observa el pobre desempeño particularmente en zonas de Europa, surgiendo la necesidad de desarrollar una nueva generación de modelos.

Jetten y Favis-Mortlock (2006) señalan dos tendencias claras: la adaptación de modelos existentes que utilizan la USLE y el desarrollo de nuevos modelos basados en procesos. Dichos autores sugieren que las condiciones de utilización del suelo, con grandes monocultivos en Estados Unidos en comparación con la diversidad de usos en las cuencas europeas, explica que en Europa los modelos diseñados tienden a distribuir el territorio mientras que los norteamericanos tienden a agregarlo.

Otra diferencia que Jetten y Favis-Mortlock (2006) observan en la evolución histórica de la materia en cuestión, es la formación académica que existe entre los desarrolladores de modelos de erosión en Europa y Norte América. Mientras que en Norte América fueron los ingenieros agrícolas e hidrólogos los que impulsaron la modelación de la erosión, en Europa fueron los geomorfólogos y geógrafos físicos.

Es así como el punto de vista de los modelos norteamericanos es más pragmático y sus objetivos son la evaluación de la productividad del suelo y la calidad de aguas mientras que los modelos europeos tienden a la mejora del conocimiento de

\footnotetext{
${ }^{16}$ En Inglés, Modified Universal Soil Loss Equatio (MUSLE)

${ }^{17}$ En Inglés, Water and Tillage Erosion Model / Sediment Delivery Model
} 
los procesos que modelan el paisaje.

Las diferencias en puntos de vista y objetivos tiene varias consecuencias directas en el diseño de modelos de erosión. Mientras que los modelos basados en la USLE se apoyan fundamentalmente en factores empíricos, los modelos basados en procesos pretender encontrar los fundamentos físicos que controlan la evolución del paisaje.

De esta forma, la USLE tiene una aplicación fácil, rápida y directa. Si a esto se le añade la gran cantidad de aplicaciones y revisiones que se le ha hecho a la USLE, lo que se ha conseguido es construir en papel lo que actualmente se conoce como una base de datos multifactorial (Jetten y Favis-Mortlock, 2006).

Una vez se aceptaron las limitaciones inherentes a los modelos basados en la USLE se hizo evidente la necesidad de desarrollar una nueva generación de modelos, tanto en Estados Unidos como en Europa. Estos modelos presentan variaciones en cuanto a las escalas de análisis, la conceptualización del sistema, los procesos tenidos en cuenta, la estimación de parámetros, la forma de discretizar el espacio y el tiempo, y las relaciones matemáticas utilizadas; en general, tienen en común su base física, en mayor o menor medida, y la integración espacial de áreas en las cuales los procesos que actúan se pueden diferenciar.

De una revisión de los antecedentes y el posterior desarrollo de estos modelos, se observa que han surgido de la colaboración conjunta de investigadores (centros de investigación y universidades) y agencias gubernamentales facultadas de la planificación del territorio.

Las agencias oficiales son las encargas de la utilización final de los modelos, pero además cumplen un papel fundamental en el desarrollo de los modelos, pues tienen la capacidad de adelantar campañas sistemáticas de toma de datos y de aplicar y probar los resultados y conclusiones arrojadas por los modelos. Un ejemplo del desarrollo de un modelo surgido a partir de la colaboración entre diferentes centros de investigación y agencias gubernamentales es el SHETRAN ${ }^{18}$ (Ewen et al., 2000).

El relativo éxito de los modelos de erosión existentes se debe en gran parte a la retroalimentación entre los planificadores (usuarios) y los investigadores (desarrolladores) y a la continuidad en el uso y la mejora del modelo. Si esta comunicación no es fluida y constante, lo que comúnmente ocurre es que el modelo termine siendo utilizado sólo por sus desarrolladores y en el mejor de los casos como herramienta didáctica en las universidades.

Además de estos modelos con amplia referencia bibliográfica, existen modelos que se han desarrollado con fines académicos y en su mayoría no trascienden sus objetivos iniciales al no contar con un grupo de usuarios. Es así como se pueden encontrar modelos con una excelente conceptualización, basados en el conocimiento actual, pero que al no tener una suficiente divulgación, un uso constante y una mejora continua no alcanzan a imponerse en la comunidad técnica y científica.

\footnotetext{
${ }^{18}$ En Francés, Système Hydrologique Européen Transport
} 


\subsubsection{Tipos de modelos de erosión}

Son varias las formas de clasificar los modelos de erosión. Se pueden clasificar de acuerdo con la escala de análisis, que en el caso de la escala espacial varía desde la escala de parcela experimental hasta modelos de escala continental; en el caso de la escala temporal, se encuentran modelos de eventos con intervalos de simulación del orden de minutos o segundos hasta modelos de evolución de paisajes en donde es necesario considerar varios miles de años.

Otra forma de clasificación es de acuerdo con la forma en que el modelo representa el sistema físico (por ejemplo, la representación de la topografía). Además es posible clasificar los modelos de acuerdo con la forma de encontrar las relaciones que explican los procesos de erosión: los métodos de evaluación empíricos y los que tienen base física.

La mayoría de los modelos de erosión son de tipo híbrido incluyendo tanto componentes empíricos como teóricos (Haan et al., 1994).

Los modelos empíricos, siendo el más aceptado y usado el método de la USLE (y sus derivados), se usan principalmente con fines de planificación territorial e interventoría de recursos naturales. Los modelos basados en procesos se basan en un mejor entendimiento de los principios físicos que actúan en la naturaleza, pero exigen gran cantidad de datos y más recursos computacionales, dificultando su implementación en situaciones reales. Los esfuerzos actuales en la modelación geomorfológica se centran en los modelos basados en procesos, discretizados tanto en el espacio como en el tiempo (Hagen y Foster, 1990).

\subsubsection{Modelos de erosión empíricos}

La totalidad de modelos de erosión empíricos que se encuentran en la literatura o que se utilizan actualmente en programas computacionales disponibles, se derivan de la USLE. Por tal motivo, al reseñar dichos modelos se expondrán las características de esta ecuación.

La USLE se diseño para parcelas dedicadas a la agricultura, es válida para áreas de 1 hectárea. La USLE toma en cuenta la longitud de la pendiente (factor $\mathrm{L}$ ), la inclinación (factor S), el clima (factor R), los suelos (factor K), el cultivo (factor C) y el manejo del suelo (factor P).

El uso de la USLE y sus derivados están limitados a la estimación de la erosión bruta careciendo del cálculo de la sedimentación a lo largo de la ladera, en depresiones, valles o canales. Según Rojas (2002) el hecho de que la erosión puede ocurrir sólo a lo largo de una línea de flujo sin la influencia del flujo de agua sobre ladera por si mismo restringe la aplicación directa de la USLE a terrenos complejos derivados de un Sistema de Información Geográfica ${ }^{19}$.

La USLE evalúa la pérdida de suelo producida por la erosión hídrica por flujo laminar y en surcos en zonas en donde no hay formación de cárcavas, no estima

\footnotetext{
${ }^{19}$ En Inglés, Geographic Information System (GIS)
} 
el transporte de sedimentos de la red fluvial ni la erosión que se deriva en las márgenes y lechos de los ríos.

Según Piest et al. (1975a), evidencias empíricas demuestran que alrededor del $80 \%$ de los sedimentos producidos en una cuenca de drenaje se depositan dentro de ella, ya sea en laderas cóncavas, en microbarreras producidas por la vegetación y en remansos ubicados en el sistema fluvial, hecho que no está presente en la formulación de la USLE.

La USLE y sus derivados son modelos totalmente empíricos y su bondad depende del rigor con que los multiplicandos que componen la ecuación reproduzcan las condiciones del medio, por lo que se limita su capacidad de extrapolación a condiciones ambientales diferentes.

Foster y Wischmeier (1974) apuntan que aunque se puede modificar la USLE para considerar la variación en la erosión a lo largo de un perfil del paisaje, los modelos de erosión que se basan en procesos y que tienen en cuenta la variabilidad espacial arrojan resultados más satisfactorios.

A continuación se reseñan las características principales de los modelos que se basan en la USLE y sus derivados.

El modelo $S W A T^{20}$ (Arnold et al., 1995) es un descendiente del modelo $S W R R B{ }^{21}$ (Williams et al., 1985). Es un modelo de simulación continua que predice los efectos de cambios en las condiciones ambientales de una cuenca (clima, vegetación, gestión de embalses, utilización de aguas subterráneas, transvases) sobre la producción de sedimentos y contaminantes químicos en cuencas grandes (hasta $1500 \mathrm{~km}^{2}$ ), subdividiéndolas en subcuencas que se suponen con características homogéneas. Puede efectuar simulación continua desde un año hasta cien años, con intervalo temporal diario.

El modelo ANSWER ${ }^{22}$ (Beasley et al., 1980) es uno de los primeros modelos distribuidos que se desarrollaron. Se aplica en cuencas de entre 10 y $100 \mathrm{~km}^{2}$. Hay poca información disponible del modelo.

El desarrollo del modelo de cuencas para eventos denominado AGNPS ${ }^{23}$ (Young et al., 1989) comenzó en 1980. Su versión continua se denomina AnnAGN$P S{ }^{24}$. El AnnAGNPS ha sido diseñado para analizar el impacto de contaminantes de fuentes no puntuales en cuencas predominantemente agrícolas. Modela la hidrología y el transporte de sedimentos, nutrientes y pesticidas.

El modelo WATEM/SEDEM se puede aplicar en cuencas de tamaños diversos (entre $0.01 \mathrm{~km}^{2}$ y $5000 \mathrm{~km}^{2}$ ), el intervalo temporal de simulación es de un año y el la discretización espacial se basa en celdas cuadradas entre 1 y $50 \mathrm{~m}$ de ancho.

El modelo RHINEFLOW está diseñado para cuencas grandes, entre $100 \mathrm{y}$ $50000 \mathrm{~km}^{2}$, con intervalo temporal de simulación de un mes. El espacio se divide

${ }^{20}$ En Inglés, Soil and Water Assessment Tool

${ }^{21}$ En Inglés, Simulator for Water Resources in Rural Basin

${ }^{22}$ En Inglés, Areal Non-point Source Watershed Environment Response Simulation

${ }^{23}$ En Inglés, Agricultural Non-point Source Pollution Model

${ }^{24}$ En Inglés, Annualized Agricultural Nonpoint 
en celdas cuadradas de $3 \mathrm{~km}$ de ancho.

El modelo EPIC ${ }^{25}$ (Williams et al., 1984) tiene como objetivo la cuantificación de la productividad del suelo. Predice los efectos de las políticas de manejo en las dinámicas del agua, los sedimentos, los nutrientes y los pesticidas en una cuenca específica. Trabaja con un intervalo temporal de simulación diario y puede abarcar períodos entre 1 y 4000 años.

\subsubsection{Modelos de erosión basados en procesos}

Las técnicas y métodos de estimación de la erosión hídrica basadas en procesos se caracterizan por utilizar relaciones matemáticas para describir los procesos fundamentales que actúan, esto es, el arranque, el transporte y la sedimentación, tanto de partículas individuales del suelo como de agregados.

Otra característica de los modelos de erosión basados en procesos es la integración espacial de áreas en las cuales los procesos que actúan se pueden diferenciar. Hagen y Foster (1990) indican el concepto de área fuente y señalan que la mayoría de modelos de erosión basados en procesos dividen el paisaje en las siguientes áreas fuentes: áreas entre surcos, surcos y cárcavas efímeras, mientras que las zonas de acumulación se encuentran en las depresiones del terreno. Estas áreas representan elementos hidrológicos que pueden interrelacionarse de acuerdo con los patrones de flujo del paisaje.

El paisaje es representado y analizado como un conjunto de áreas entre surcos, en donde los procesos de erosión se dan por el impacto de las gotas de lluvia y por flujo superficial en ladera (laminar); y una red de surcos en donde se presentan procesos de arranque, transporte y sedimentación debido al flujo concentrado y turbulento del agua. La figura 2.3 es una representación de los procesos de erosión que actúan en las diferentes áreas fuente.

Los modelos de erosión basados en procesos tratan cada uno de los procesos de forma independiente, basados en relaciones matemáticas empíricas y/o con base física que relacionan propiedades del suelo con factores de erosionabilidad y con esfuerzos tangenciales producidos por los flujos de agua debido a las acumulaciones de flujo, ya sea en zonas entre surcos, en surcos o en cárcavas.

A continuación se reseñan las características principales de algunos de los modelos de erosión basados en procesos que se encuentran referenciados en la literatura, haciendo una diferenciación de acuerdo con la escala de aplicación recomendada por sus desarrolladores. Cabe mencionar que esta clasificación es un tanto arbitraria y en algunos casos la aplicabilidad de un modelo específico es más restringida que los intervalos escogidos y en otros es extensible a varias escalas espaciales.

Escala de parcela. El modelo Rillgrow (Favis-Mortlock et al., 2000) se aplica en áreas de unos cuantos metros cuadrados y genera surcos partiendo de un DEM y una superficie digital de rugosidad. El modelo se basa en el concepto de autoorganización. El intervalo temporal de simulación es de 1 x $10^{-6}$ s y la discretización

\footnotetext{
${ }^{25}$ En Inglés, Erosion-Productivity Impact Calculator
} 


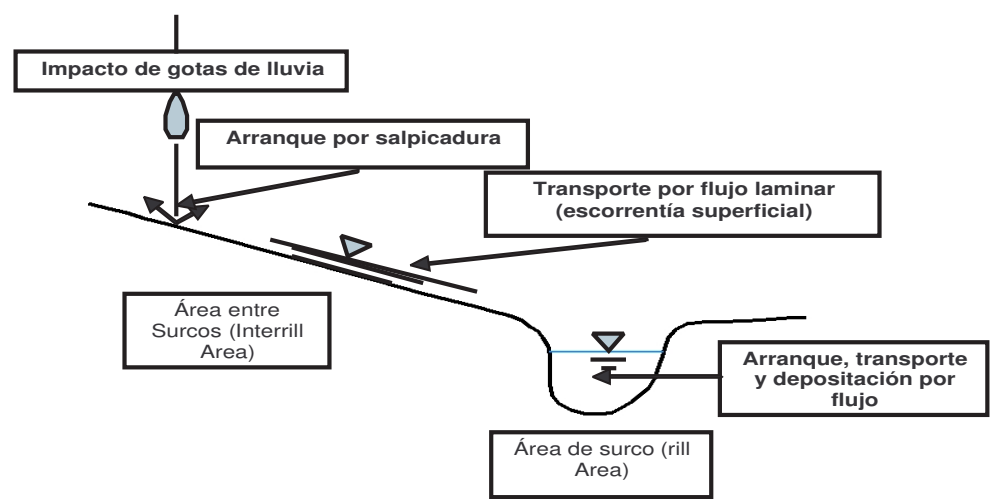

Figura 2.3. Procesos de erosión hídrica entre las áreas fuente, adaptado de Hagen y Foster (1990)

espacial es de celdas cuadradas de menos de 0.01 metros de lado.

El modelo $M M F^{26}$ (Morgan, 2001) es agregado en el espacio (trata la parcela como un todo) y en el tiempo (condiciones anuales). Simula la erosión debida a la caída de las gotas de lluvia a partir de la energía cinética. La capacidad de transporte y la erosión debida al flujo superficial son funciones del caudal y la pendiente.

El modelo CREAMS ${ }^{27}$ (Knisel, 1980) predice la escorrentía, la erosión y el transporte de contaminantes en parcelas. Además de simular tormentas puede utilizarse para predecir estos procesos en períodos largos (entre 2 y 50 años).

El modelo GLEAMS ${ }^{28}$ (Leonard et al., 1987) se basa en el modelo CREAMS, añadiendo nuevos componentes para simular diferentes alternativas de manejo (labranza en curvas de nivel, terraceo, límites de parcelas). Además incluye la simulación de nutrientes y pesticidas.

Escala de ladera. El modelo PSEM-3D ${ }^{29}$ (actualmente en desarrollo en el Laboratorio de Estudios de Transferencia en Hidrología y Ambiente, en Grenoble, Francia) y los modelos Erosion2D y su versión tridimensional el Erosion3D (Schmidt y Mauersberger, 2004) trabajan específicamente en escala de ladera.

El modelo WEPP ${ }^{30}$ (Lane y Nearing, 1989; Flanagan y Nearing, 1995) es un modelo distribuido con base física orientado a la simulación continua para la predicción de procesos de erosión en laderas.

Escala de microcuenca. Se agrupan en esta categoría los modelos que trabajan con cuencas pequeñas, menores de $100 \mathrm{~km}^{2}$.

\footnotetext{
${ }^{26}$ En Inglés, Morgan-Morgan-Finney Model

${ }^{27}$ En Inglés, Chemical, Runoff, Erosion and Agricultural Management Systems

${ }^{28}$ En Inglés, Groundwater Loading Effects of Agricultural Management Systems

${ }^{29}$ En Inglés, Physical Soil Erosion Model

${ }^{30}$ En Inglés, Water Erosion Prediction Project
} 
El modelo LISEM ${ }^{31}$ (Jetten y De Roo, 2001) es una derivación del modelo EUROSEM ${ }^{32}$ (Morgan et al., 1998). Estos modelos han sido diseñados para simular la escorrentía y la erosión como consecuencia de una tormenta en cuencas agrícolas pequeñas, siendo distribuidos tanto en el espacio como en el tiempo.

El modelo STREAM ${ }^{33}$ (Cerdan et al., 2002) es distribuido en el espacio pero agregado en el tiempo.

El CASC2D-SED ${ }^{34}$ (Julien y Rojas, 2002) es un modelo hidrológico y de erosión de suelos con base física y distribuido, que simula la respuesta hidrológica de una cuenca sujeta a un campo de lluvia dado.

Escala de cuenca. Los modelos a escala de cuenca permiten simular procesos hidrológicos y sedimentológicos en cuencas entre 100 y $10000 \mathrm{~km}^{2}$.

El modelo SHETRAN se diseñó para modelar el transporte de químicos, incluidos los transportados por sedimentos, en una cuenca hidrográfica con área entre 10 y $1000 \mathrm{~km}^{2}$, discretizada en celdas cuadradas entre 10 y 1000 metros de largo; mientras que el intervalo temporal de simulación está entre quince minutos y dos horas.

El modelo SEMMED ${ }^{35}$ (De Jong et al., 1999) presenta los mismos procesos que el modelo MMF, diferenciándose en la escala espacial.

El modelo KINEROS ${ }^{36}$ (Woolhiser et al., 1990) analiza eventos, tiene base física utilizando el modelo de infiltración de Smith/Parlange y una aproximación de la onda cinemática para definir la ruta del flujo y los sedimentos.

Escala continental. Se trata de modelos para el cálculo de la erosión a escala global (áreas mayores de $10000 \mathrm{~km}^{2}$ ). Un ejemplo de un modelo a esta escala con significado físico es el PESERA ${ }^{37}$ (Kirkby et al., 2004). Este modelo estima el caudal promedio mensual para celdas cuadradas derivadas de un DEM de $1 \mathrm{~km}$ de largo.

\subsubsection{Posibilidades de los modelos de erosión}

Para redondear los conceptos analizados hasta el momento se plantea esta pregunta: ¿Es posible un modelo universal de erosión? Es posible en la medida de que se base en la física de los procesos y que las simplificaciones que haga, que provienen en gran medida de la discretización del espacio-tiempo, permitan que las ecuaciones conceptuales de los procesos que ocurren sean representativas de la escala temporal (intervalo temporal de simulación) y la escala espacial (discretización del espacio).

\footnotetext{
${ }^{31}$ En Inglés, Limburg Soil Erosion Model

${ }^{32}$ En Inglés, European Soil Erosion Model

${ }^{33}$ En Inglés, Sealing Transfer Runoff Erosion Agricultural Modification

${ }^{34}$ En Inglés, Cascade 2 Dimensional Sediment

${ }^{35}$ En Inglés, Soil Erosion Model for the Mediterranean

${ }^{36}$ En Inglés, Kinematic Runoff and Erosion Model

${ }^{37}$ En Inglés, Pan European Soil Erosion Risk Assessment
} 
Los cambios en las escalas temporales y espaciales generalmente se presentan interrelacionados. Por ejemplo, para modelar la erosión a escala de parcela o de una ladera particular, el tiempo, el volumen y la distribución espacial y temporal del flujo superficial son los factores críticos. Si la escala de análisis es regional o de cuenca, los parámetros determinantes son la topografía, los suelos y la vegetación, mientras que el intervalo temporal debe comprender no solamente eventos de tormenta sino varías décadas o centenas de años, en las cuales dichos parámetros pueden variar. En análisis globales, de escala nacional o continental, las variables críticas son el clima y la litología, con intervalos temporales que van desde decenas de años a cientos o miles de años, en los cuales ocurren cambios climáticos naturales (Kirkby, 1999).

Además es imperativo un conocimiento exhaustivo de las condiciones físicas de la zona de estudio (que normalmente es una cuenca hidrográfica), esto es, las características de los suelos, el régimen climático, la vegetación, los usos del suelo, etc.; e integrar este conocimiento en el modelo, que en términos reales se traduce en una adecuada parametrización y en la determinación a priori de los procesos relevantes según sea la escala y el objetivo del análisis.

Por tal motivo, el modelo debe tener estrategias de modelación que permitan al usuario definir cuales de los procesos actuantes tienen relevancia y debe contar con un marco general de estimación de parámetros. Por ejemplo, en una cuenca hidrográfica ubicada en una zona húmeda, con una cubierta de vegetación densa y con suelos bien drenados es posible que no se presente escorrentía de tipo hortonia$n a$ y que el flujo base y el flujo subsuperficial sean los mecanismos más importantes en el comportamiento hidrológico; mientras que en una cuenca ubicada en una zona árida, con una cubierta de vegetación pobre y con suelos poco desarrollados y mal drenados, el comportamiento hidrológico se deba exclusivamente a la escorrentía hortoniana. Estas consideraciones adquieren una importancia mayor al modelar la erosión.

Para modelar a escalas regionales o de cuenca, necesariamente hay que llegar a una solución de compromiso entre los tiempos de cálculo, los parámetros que alimentan el modelo y el entendimiento de los procesos particulares de la zona de estudio que actúan en los fenómenos de erosión.

Otra de las posibilidades de los modelos de erosión es que al tratar aspectos relacionados con la evolución del paisaje, necesariamente mejoran el conocimiento de la Hidrología. Al respecto, Dunne (1998) señala la importancia de considerar el paisaje y su dinámica en la Hidrología. Para enfatizar esta relación menciona como la topografía condiciona las líneas de flujo (de agua y sedimentos), tanto en la superficie como en los primeros niveles del suelo; como los efectos gravitatorios (relacionados directamente con la topografía) tienen relevancia en parámetros del suelo tales como la profundidad y la concentración de macroporos; recalca la importancia de entender el umbral de la transición entre laderas y canales; y como la densidad de canales por unidad de área tiene implicaciones tanto en las características del paisaje como en el comportamiento hidrológico. 


\subsubsection{Limitaciones de los modelos de erosión}

Los procesos básicos de la erosión hídrica están regidos por variables hidrológicas. Consecuentemente, los modelos de erosión están subordinados a modelos hidrológicos, cuyos resultados son variables de entrada para el modelo de erosión. Así el modelo de erosión hereda las mismas capacidades y limitaciones que el modelo hidrológico en el que se basa.

La erosión presenta una gran variabilidad espacial y temporal, tanto en los parámetros como en los procesos, de esta forma es necesario que el modelo hidrológico subyacente al modelo de erosión de cuenta de dicha variabilidad.

Un modelo de erosión debe tener en cuenta las variaciones estacionales de las condiciones ambientales naturales, por ejemplo, los ciclo anuales de congelación deshielo en las zonas climáticas templadas. Además es necesario que tenga en cuenta las perturbaciones de las condiciones de la superficie del suelo por las labores de labranza, que normalmente se efectúan de acuerdo con los cambios estacionales. Estas labores agrícolas afectan la estructura del suelo, la porosidad, la densidad y la distribución de tamaños; propiedades que perturban las características hidráulicas del suelo. Por ejemplo, Regüés y Gallart (2004) encuentran una correlación significativa entre propiedades físicas del suelo y variaciones estacionales en un estudio efectuado en los Pirineos Españoles.

Algunos parámetros como la resistencia hidráulica en laderas y canales o la conductividad hidráulica saturada del suelo no son constantes en el tiempo e incluso varían en el curso de un evento de lluvia (Takken y Govers, 2000; Wainwright, 1996). Los modelos normalmente ignoran estos cambios temporales.

Ante la imposibilidad real de considerar estas variaciones puesto que por definición los parámetros de los modelos deben ser constantes en el tiempo, de otra forma serían variables de estado, una adecuada modelación debe contar con estrategias que permitan al usuario determinar a priori la variación de los parámetros en el tiempo, por ejemplo los cambios en las propiedades hidrológicas en los suelos debido a labores de labranza.

Otra limitación de los modelos de erosión es la dificultad para calibrar y validar los resultados arrojados por el modelo, debido a la imposibilidad de obtener medidas directas de campo de una forma lógica, sistemática e instrumental. Los paisajes cambian sólo imperceptiblemente y sólo unas medidas adecuadas y sistemáticas en largos períodos de tiempo pueden producir resultados satisfactorios para ser usadas en la validación del modelo (Campbell, 1981).

Generalmente los modelos de erosión se validan usando datos de caudal líquido y carga de sedimentos tomados en la salida de la cuenca. Esto implica que no se puede examinar uno de los aspectos más importantes del modelo, en especial los de tipo distribuido: la predicción de la variación espacial de los procesos de erosión y sedimentación en la cuenca. Una validación de este tipo puede enmascarar variaciones espaciales importantes dentro de la cuenca.

Una parte considerable del suelo erosionado se deposita dentro de la cuenca sin llegar a la salida de la misma, así, si se considera la pérdida de suelos en las 
partes altas de la cuenca y se ignora la sedimentación dentro de la cuenca y se extrapolan los resultados para toda la cuenca, se obtiene una sobreestimación de la erosión total (Gafur et al., 2003).

Por lo tanto el modelo debe dar cuenta de las variaciones espaciales de los procesos y debe distinguir entre zonas de producción de sedimentos, zonas de transporte y zonas de sedimentación.

La falta de conocimiento de la distribución espacial de procesos hidrológicos y sedimentológicos, y de los parámetros asociados, da como resultado una calibración del modelo en la cual se supone una homogeneidad mayor que la que en realidad se presenta. El resultado puede ser una calibración correcta, esto es hidrogramas y sedimentogramas simulados cercanos a los observados, partiendo de razones incorrectas (Favis-Mortlock et al., 2001). Estas carencias solamente pueden ser detectadas con una validación espacial, que en pocos casos se lleva a cabo.

Estas cuestiones son un campo abierto a la investigación, que se resumen como el principio de la equifinalidad. Dicho principio, originario de la teoría de sistemas, dice que en sistemas abiertos un estado final se puede alcanzar a partir de muchas formas posibles. Aplicado específicamente a modelos se puede explicar como que a partir de muchos juegos de parámetros posibles se alcanza una respuesta similar.

La equifinalidad en la modelación hidrológica fue tratada inicialmente por Beven y Binley (1992), Duan et al. (1992) y Beven (1993). Según Beven (2001a) la equifinalidad adquiere mayor relevancia en modelos distribuidos debido al potencial de usar parámetros diferentes para cada elemento de la discretización espacial. Esto significa que se pueden especificar cientos de miles de juegos de parámetros para una cuenca en particular, los cuales se hacen imposibles de optimizar.

Otro aspecto poco tenido en cuenta por la mayoría de modelos de erosión y que tiene gran relevancia en la producción de sedimentos es la modelación de procesos de movimientos en masa, en especial aquellos desencadenados por lluvias intensas. Al respecto Van-Asch et al. (1999) informan una alta correlación entre la presencia de deslizamientos en laderas y generación de flujos hiperconcentrados con eventos de lluvias extremos. En un análisis efectuado para determinar mecanismos desencadenadores de movimientos en masa, estos autores determinan que estos se pueden modelar adecuadamente con la utilización de modelos hidrológicos de tanques de tipo distribuido.

\subsection{Aspectos destacados del capítulo}

En el diseño de un modelo geomorfológico, es necesario considerar la variabilidad espacial y temporal de los parámetros. De esta forma hay que definir una discretización en el tiempo y en el espacio que represente de manera lo más cercana a la realidad la interrelación entre procesos, parámetros y variables de estado.

Un aspecto fundamental que se deriva de la revisión de los modelos de evolu- 
ción del paisaje encontrados en la literatura, es la visión holística ${ }^{38}$ que tienen de los procesos que ocurren en una cuenca hidrográfica. Al respecto, Willgoose et al. (1994) apuntan que así como la hidrología puede determinar la forma de una cuenca, dicha forma condiciona a su vez a la hidrología. Esta retroalimentación hace que los modelos de evolución del paisaje sean especialmente difíciles de implementar debido a la gran cantidad de procesos actuantes con diferentes escalas espaciales y temporales.

En este capítulo se hizo un breve repaso de la evolución del conocimiento en cuanto a modelos geomorfológicos, y específicamente en modelos de erosión hídrica existentes en la literatura. Del análisis crítico surgen las bases para la formulación de un modelo de producción, transporte y depósito de sedimentos a escala de cuenca. En el próximo capítulo se profundizará en los aspectos relevantes a tener en cuenta:

a) Conceptualización del sistema (cuenca hidrográfica).

b) Escalas de análisis (temporal y espacial).

c) Procesos relevantes, tanto hidrológicos como sedimentológicos.

d) Estimación de parámetros.

\footnotetext{
${ }^{38}$ Todas las propiedades de un sistema no pueden ser determinadas como la suma de sus componentes. La holística enfatiza en la interdependencia de las partes de un sistema
} 


\title{
Capítulo 3
}

\section{Marco Conceptual}

"DEL RIGOR EN LA CIENCIA

\begin{abstract}
En aquel Imperio, el Arte de la Cartografía logró tal perfección que el Mapa de una sola Provincia ocupaba toda una Ciudad, y el Mapa del Imperio, toda una Provincia. Con el tiempo, estos Mapas Desmesurados no satisficieron y los Colegios de Cartógrafos levantaron un Mapa del Imperio, que tenía el tamaño del Imperio y coincidía puntualmente con él. Menos Adictas al Estudio de la Cartografía, las Generaciones Siguientes entendieron que ese dilatado Mapa era inútil y no sin impiedad lo entregaron a las inclemencias del sol y de los inviernos. En los Desiertos del Oeste perduran despedazadas Ruinas del Mapa, habitadas por Animales y por Mendigos; en todo el País no hay otra reliquia de las Disciplinas Geográficas"
\end{abstract}

En el capítulo anterior se exponen las bases teóricas y la evolución histórica del conocimiento de los modelos geomorfológicos, centrados en modelos de erosión hídrica. Este breve recuento epistemológico deriva en la definición de las preguntas fundamentales que deben considerarse cuando se pretende entender la dinámica hidrológica y sedimentológica del paisaje. En este capítulo se define el marco conceptual del modelo propuesto, profundizando en los aspectos importantes que deben ser tenidos en cuenta en el diseño de un modelo de producción, transporte y depósito de sedimentos. El objetivo es acercase a las siguientes cuestiones:

a) ¿Cómo representar la cuenca hidrográfica utilizando las técnicas actuales?

b) ¿Cómo se discretiza el espacio y el tiempo?

c) ¿Cómo se conectan los elementos en los cuales se ha discretizado el sistema?

\footnotetext{
${ }^{1}$ Suárez Miranda: Viajes de varones prudentes, Libro Cuarto, cap. XIV, Lérida, 1658. Tomado de Cuentos breves y extraordinarios de Jorge Luis Borges y Adolfo Bioy Casares
} 
d) ¿Cómo diferenciar las zonas de producción, transporte y depósito de sedimentos?

e) ¿Cómo definir los procesos relevantes que actúan en cada una de las zonas?

f) ¿Cuáles son las relaciones matemáticas que describen los procesos?

g) ¿Qué estrategia de modelación es la más adecuada para considerar los procesos relevantes en un paisaje particular?

h) ¿Cómo integrar el conocimiento previo de las condiciones físicas de la cuenca en el modelo?

El paisaje es complejo y su evolución comprende diferentes escalas temporales y espaciales. Los procesos conductores de su dinámica están influenciados por interrelaciones complejas, por lo cual se necesita un intenso análisis para acercarse al entendimiento de los procesos y los factores condicionantes en las diversas escalas. Además, es necesario tener en consideración las condiciones físicas particulares de cada paisaje, las cuales dependen del régimen climático, la geología (dominio tectónico, litología), los suelos, la vegetación, etc.

Estos análisis no son universales y dependen de las condiciones particulares de cada situación de estudio, por lo cual, es necesario conocer a priori dichas particularidades para acercarse a una adecuada modelación. Aun así, es posible diseñar herramientas de modelación que puedan aplicarse en situaciones diversas.

\subsection{La conceptualización del sistema}

En esta primera sección se afronta el tema de la representación del sistema, que en el caso del modelo de erosión propuesto se trata de una cuenca hidrográfica. El objetivo es utilizar adecuadamente las herramientas actuales, específicamente aquellas que permiten representar y analizar el terreno; y las diversas formas de discretizar el espacio y el tiempo.

\subsubsection{Formas de representar y analizar el terreno}

Existen diversas formas de representar el terreno, cada una de las cuales tiene sus propias particularidades, posibilidades y limitaciones. Un aspecto clave desde el punto de vista científico de estas representaciones, es que se supone una correspondencia entre el espacio (y el tiempo ${ }^{2}$ ) geográfico y los procesos físicos actuantes de intercambio de masa y energía (Raper, 1999). De esta forma, la topografía se puede interpretar como un producto de la dinámica de los procesos actuantes.

Siguiendo esta idea, es posible representar las secuencias topográficas de los elementos morfológicos que se encuentran en las laderas (la catena de suelos) de una

\footnotetext{
${ }^{2} \mathrm{El}$ paisaje cambia en el tiempo, es dinámico
} 
cuenca a partir de Modelos de Elevación Digital. Además, se puede conceptualizar una cuenca hidrográfica como un sistema jerárquico conectado por la dirección de flujo. De esta forma la red de drenaje se puede considerar como el esqueleto topográfico de un paisaje generado por procesos de erosión fluvial (Band, 1999). Análogamente, mientras las redes de drenaje se consideran líneas en donde converge el flujo, las divisorias de agua son las líneas en donde diverge el flujo.

Las técnicas desarrolladas a partir de estos conceptos básicos incluyen estos tres elementos (Band, 1999):

a) Algoritmos de clasificación y correspondencia, los cuales se encargan de buscar evidencias topográficas locales para la presencia de corrientes o divisorias de agua y de construir la red de drenaje.

b) Un proceso global secuencial que se encarga de llenar sumideros sobre la superficie topográfica y asegurar así sistemas de flujo convergente a la red de drenaje.

c) Una técnica que incorpora reglas basadas en el conocimiento previo (por ejemplo, en una red de drenaje tomada de mapas topográficos o fotografías aéreas o en la geometría de una geoforma específica) para completar vacíos de información o inconsistencias en el modelo de terreno construido.

En la literatura se encuentran diversas metodologías que contienen estos elementos, los cuales se pueden diferenciar según la fuente original de información: un Modelo de Elevación Digital, una Red de Triángulos Irregulares, o un mapa de Curvas de Nivel.

En la figura 3.1 se observan los diferentes métodos de representación del terreno. En la parte $a$ ) de la figura se presenta un malla de cuadrados regulares (DEM), la parte $b$ ) es una red de triángulos irregulares (TIN), mientras que la parte $c$ ) se trata de una red de polígonos irregulares derivados de curvas de nivel y una red de drenaje.

a)

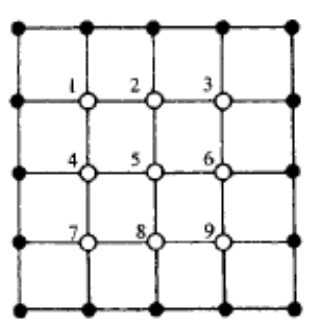

b)

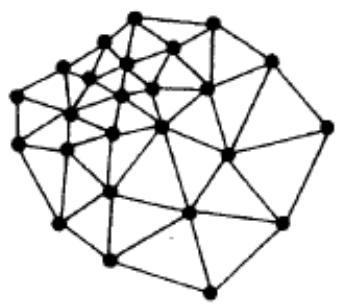

c)

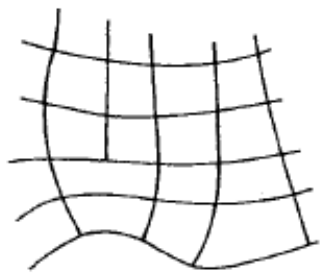

Figura 3.1. Formas de representación del terreno, figura tomada de Wilson y Gallant (2000a)

Las redes de triángulos irregulares (TIN) se basan en discretizar el terreno en elementos triangulares, también conocidos como facetas, con vértices en los 
puntos de muestreo (Moore et al., 1991). Estas facetas triangulares consisten en planos unidos por tres puntos adyacentes en la red de triángulos y normalmente se construyen usando la triangulación de Delauney (Weibel y Heller, 1991).

Los TIN tienen mayores capacidades que los DEM para representar cambios abruptos del terreno tales como escarpes, picos, depresiones, etc., siempre y cuando los puntos de muestreo se ubiquen en donde la pendiente del terreno cambia. Además, los TIN pueden incorporar fácilmente discontinuidades y la estructura de datos es más eficiente puesto que la densidad de triángulos puede variar de acuerdo con los cambios naturales del terreno (Moore et al., 1991).

Otra forma de representación se basa en discretizar el paisaje en elementos poligonales pequeños y de forma irregular. Esta estructura es utilizada en aplicaciones hidrológicas debido a que puede reducir la complejidad de las ecuaciones de conservación de masa y momentum tridimensionales en terrenos complejos (Moore y Grayson, 1991).

Ambas representaciones son más adecuadas para captar los cambios naturales de la superficie del terreno, sin embargo son poco utilizadas en la modelación hidrológica y sedimentológica y en la actualidad casi la totalidad de modelos se basan en Modelos de Elevación Digital en formato matricial de mallas de elementos cuadrados.

Las razones son diversas; las matrices de elementos cuadrados permiten la resolución de ecuación en diferencias finitas de forma sistemática en cada una de las discretizaciones del terreno, puesto que los elementos tienen igual área y forma; la estructura matricial permite implementar con facilidad herramientas de interpolación espacial de datos tomados en unos pocos puntos, por ejemplo, datos de precipitación de estaciones pluviométricas; la mayor parte de las técnicas y métodos utilizados en los SIG de uso común se han desarrollado para estructuras matriciales de elementos cuadrados; además, los DEM se adaptan mejor a los datos derivados de técnicas propias de la teledetección (imágenes de satélite, fotografías aéreas, datos de radar, y láser).

Un Modelo de Elevación Digital es una representación de la topografía de la superficie terrestre almacenado en forma matricial. Cada elemento de un DEM puede considerarse un nodo en el cual su valor corresponde a la cota promedio de la porción del terreno que representa. Sus elementos son cuadrados y para definir un DEM es necesario conocer las esquinas del área total que representa, el tamaño de celda y la orientación (que normalmente corresponde con los ejes geográficos Norte - Sur, Este - Oeste). En la actualidad, la mayor parte de los modelos hidrológicos y sedimentológicos distribuidos se basan en DEM.

Los primeros intentos para derivar atributos hidrológicos y geomorfológicos, específicamente la configuración topológica de una región particular a partir de un DEM, surgieron a partir del trabajo de Greysukh (1967), que se basaron en técnicas de búsqueda y comparación local (comparación de la celda con sus vecinas). Posteriormente se desarrollaron métodos para clasificar celdas en cóncavas y convexas con el objetivo de producir líneas divisorias de cuencas y redes de drenaje. 
Los trabajos posteriores se basan en procesos globales secuenciales, que combinan técnicas de búsqueda y comparación locales con reglas y restricciones globales. Algunos trabajos siguiendo esta tendencia se deben a Marks et al. (1984), O'Callaghan y Mark (1984), Band (1986a,b, 1989), Douglas (1986), Jenson y Domingue (1988), Martz y Jong (1988), Tarboton et al. (1988), Smith et al. (1990), Tribe (1991, 1992), y Martz y Garbrecht (1992).

O'Callaghan y Mark (1984) desarrollaron un proceso iterativo que localizaba las celdas con un valor máximo local de cota, a partir de dichas celdas se buscan las celdas con pendiente máxima local y se etiquetan de acuerdo con su área de drenaje acumulada, o lo que es lo mismo, el número de celdas que drenan a cada celda. El resultado es una superficie constante en la cual cada celda es un nodo, es decir, todas las celdas son puntos de confluencia del flujo.

El último paso para derivar una red de drenaje es definir un área umbral a partir de la cual se encuentra en la celda un cauce permanente y diferenciar dichas celdas del resto. Esto se logra utilizando el concepto de la constante de mantenimiento del cauce, que depende de condiciones ambientales particulares, por lo tanto no es necesariamente constante para toda una cuenca (Schumm, 1956).

Montgomery y Dietrich (1988) proponen umbrales basados en relaciones pendiente - área de drenaje, combinando argumentos empíricos y teóricos. Un aspecto para resaltar en esta aproximación es que es consistente con la teoría geomorfológica de sistemas fluviales, en términos de la disipación de la energía potencial, al relacionar el área de drenaje, que es proporcional a la cantidad de flujo entre celdas específicas, con la pendiente local, que puede considerarse la función de energía de la conectividad entre celdas.

Es posible diferenciar geoformas aplicando principios de la Geomorfología (por ejemplo el principio de la catena) en un Modelo de Elevación Digital. Al respecto, Band (1999) señala que en un sistema geomorfológico a cada geoforma que lo compone se le puede asignar características en cuanto a su posición topográfica, el tipo de suelo y la vegetación. La posición topográfica de una geoforma, el tipo de suelo y vegetación se encuentra estrechamente ligada a la secuencia topológica definida por la catena. De esta forma, la presencia de una geoforma implica la presencia de otra geoforma relacionada por el principio de la catena. Según el autor, este tipo de planteamiento es esencial para entender el paisaje como un sistema.

Una limitación para la aplicación de estos planteamientos surge debido a la carencia de información cartográfica de suelos en una escala adecuada y similar a la información de la topografía y la vegetación. Las unidades cartográficas de suelos generalmente se presentan como agrupaciones de suelos en las cuales es raro distinguir la secuencia de la catena en una ladera específica.

Como un intento de suplir esta limitación, se han desarrollado trabajos con el objeto de encontrar relaciones entre características físicas del suelo y la posición topográfica relativa en una ladera. Al respecto, Moore et al. (1993a) investigan la correlación entre un conjunto de propiedades del suelo y un juego de variables del 
terreno en una zona experimental de estudio en Colorado, USA. La hipótesis de trabajo era que la variación espacial de las propiedades del suelo en una toposecuencia (catena de suelos en una ladera) responde al movimiento del agua tanto en la superficie como al interior del paisaje. Los resultados indican una fuerte correlación entre las variables del suelo y las del terreno, particularmente el Índice Topográfico (Beven y Kirkby, 1979) $\left(T I=\ln \left(A_{s} / \tan S\right)\right)$, donde $A_{s}$ es el área de captación y $S$ es la pendiente local.

En un trabajo efectuado en Australia, Gessler et al. (1995) encuentran una correlación significativa entre la profundidad del suelo y de sus horizontes (especialmente el horizonte A) con la curvatura del terreno y el Índice Topográfico. Ambos estudios se efectuaron en áreas muy bien conocidas, con una base de datos de propiedades del suelo extensa.

Para recalcar la importancia de los aspectos topográficos de una cuenca en su comportamiento hidrológico, Kirkby (1993) señala que una de las mayores ventajas de los modelos hidrológicos (y sedimentológicos) basados en variables topográficas es que estas pueden derivarse de mapas y modelos de elevación digital de forma automática. Además, según dicho autor, puesto que los datos topográficos tienen una mayor disponibilidad que los datos hidráulicos y de suelos, hacer el mejor uso posible de los datos topográficos es una buena estrategia, así se minimiza la necesidad de datos que sólo se pueden determinar por mediciones directas.

\subsubsection{Los atributos primarios de los DEM}

A partir de un DEM es posible derivar varios atributos del terreno útiles para la modelación hidrológica y sedimentológica. Gallant y Wilson (2000) detallan la forma en que se calculan estos atributos a partir de un DEM.

A continuación se reseñan brevemente estos atributos, recalcando su importancia en los procesos hidrológicos y sedimentológicos.

a) La pendiente, es la tasa de cambio de la cota con respecto a la distancia horizontal, esto es, la primera derivada de la altura con respecto a la distancia horizontal. Tiene relevancia en la velocidad del flujo superficial y subsuperficial y en la capacidad de retención de agua en los niveles superiores del suelo.

b) El aspecto, es la dirección con respecto a un eje horizontal de referencia (por ejemplo el norte geográfico) de la pendiente. Es importante para el cálculo de la radiación solar, la evapotranspiración, y la distribución de vegetación.

c) La curvatura, está basada en la segunda derivada de la cota, esto es, la tasa de cambio de la primera derivada (la pendiente) con respecto a la distancia en una dirección en particular. Las curvaturas más utilizadas son la curvatura horizontal, o curvatura de contorno, que se calcula con respecto a la dirección de la curva de nivel (dirección horizontal perpendicular al 
aspecto); y el perfil de curvatura, que se calcula con respecto a la vertical en la dirección de la línea de flujo, o lo que es lo mismo, al aspecto.

El perfil de curvatura tiene relevancia en la aceleración del flujo y en las tasas de erosión y depósito de sedimentos; la curvatura horizontal es determinante en la propensión del agua a converger o divergir, en el contenido de agua en el suelo y en algunas características del suelo.

d) La dirección de flujo, es la dirección por la cual fluye el agua, esto es, la dirección de la máxima pendiente. Para una celda en un DEM existen ocho posibles direcciones de flujo (las ocho celdas vecinas): norte, noreste, este, sureste, sur, suroeste, oeste, noroeste.

e) El área de captación o área de drenaje, es el área aguas arriba de cierta longitud de contorno (en la dirección de la curva de nivel) que contribuye al flujo del agua. En un DEM, la longitud de contorno corresponde al tamaño de celda y el área de captación se determina por el número de celdas que contribuyen al flujo en cada celda. El área de captación específica se define como el área de captación sobre la longitud de contorno $\left(\mathrm{m}^{2} / \mathrm{m}\right)$.

Se han desarrollado métodos automáticos de generación de direcciones de flujo y de áreas de drenaje, disponibles en SIG de uso común. El programa TAPES$G$ y los comandos Flowdirection y Flowaccumulation del ArcInfo GIS utilizan el método descrito por Jenson y Domingue (1988).

\subsubsection{Los atributos secundarios de los DEM}

Los atributos secundarios que se derivan de los DEM se basan en combinar uno o varios atributos primarios y se utilizan para caracterizar la variabilidad espacial de procesos y parámetros hidrológicos, geomorfológicos y ecológicos. Estos atributos se basan en representaciones simplificadas con sentido físico de los procesos y parámetros en cuestión e incluyen factores claves que simulan el comportamiento del sistema (el paisaje) (Wilson y Gallant, 2000b).

Siguiendo esta aproximación se sacrifican algunas sofisticaciones físicas para permitir mejorar las estimaciones de parámetros y procesos que ocurren en el paisaje (Moore et al., 1993b). A partir de datos derivados del DEM es posible estimar índices de temperatura y radiación solar, variaciones espaciales de las características del suelo y el potencial erosivo de la escorrentía superficial.

Los índices más relevantes en la modelación hidrológica y sedimentológica de una cuenca que se derivan de un DEM son los índices topográficos de humedad, y algunos índices de erosión y potencial erosivo de la escorrentía superficial. A continuación se detallan la forma como se calculan estos índices y su significado.

3.1.1.2.1. Índice topográfico de humedad. El Índice Topográfico de Humedad $(\omega)$ se basa en suponer que la distribución espacial del contenido de agua en el suelo está controlada por la posición topográfica relativa del suelo en la ladera. 
Existen varias relaciones que aplican este concepto (Beven y Kirkby, 1979):

$$
\begin{gathered}
\omega_{T}=\ln \left(\frac{A_{s}}{T \tan S}\right) \\
\omega=\ln \left(\frac{A_{s}}{\tan S}\right)
\end{gathered}
$$

donde $A_{s}$ es el área de captación específica $\left(\mathrm{m}^{2} / \mathrm{m}\right), T$ es la transmisividad del suelo $\left(m^{2} / s\right)$, y $S$ es la pendiente en grados.

En la ecuación 3.1 se supone un flujo subsuperficial estacionario en condiciones saturadas, para describir la distribución espacial y la extensión de las zonas de saturación para la generación de escorrentía y se tiene en cuenta la variación espacial de la transmisividad; mientras que en la ecuación 3.2 se supone que la transmisividad del suelo es uniforme en toda el área de captación.

Estas dos ecuaciones predicen zonas de saturación cuando $A_{s}$ es grande y $S$ es pequeña, condiciones que se presentan en las rutas naturales de agua y en zonas de concentración de agua en el paisaje.

El programa DYNWET (Moore, 1992) supone condiciones de flujo subsuperficial quasi-dinámico, para el cálculo del índice topográfico de humedad, utilizando el área de captación específica efectiva, $A_{e}$.

El área de captación efectiva $A_{i}$ para una celda se determina siguiendo la ruta del flujo en la dirección de la pendiente aguas arriba y acumulando el tiempo de viaje hasta que se alcanza un tiempo de drenaje especificado con anterioridad. De esta forma el área de drenaje específica se calcula de la siguiente forma (Wilson y Gallant, 2000b):

$$
A_{e}=\frac{A_{i}}{w}
$$

donde $w$ es el ancho del flujo.

El índice topográfico de humedad quasi-dinámico se calcula de la siguiente forma:

$$
\omega_{q d}=\ln \left(\frac{A_{e}}{\tan S}\right)
$$

3.1.1.2.2. Índices de erosión. En la literatura se encuentran varios índices basados en atributos topográficos del terreno y propiedades del flujo del agua que tienen relación con procesos erosivos.

El concepto de la potencia de la corriente, $\Omega$, fue tratado inicialmente por Bagnold (1977) y se define como el flujo de energía del agua, se utiliza en estudios de erosión y transporte de sedimentos como una medida del poder de erosión de la escorrentía superficial (Moore et al., 1991). Normalmente se calcula como (Wilson y Gallant, 2000a):

$$
\Omega=\rho g q \tan S
$$


donde $\rho$ es la densidad del fluido, $g$ es la aceleración de la gravedad, $q$ es el caudal específico (caudal por unidad de ancho), y $S$ es la pendiente.

El Índice Topográfico (IT) (Wilson y Gallant, 2000a):

$$
I T=A_{s} \tan S
$$

Es una medida da la potencia de la corriente, puesto que el peso específico del agua $(\gamma=\rho g)$ es prácticamente constante y $q$ se supone proporcional al área de captación específica, $A_{s}$.

El programa EROS (Moore, 1992) calcula la distribución espacial de la pérdida de suelos potencial a partir de un índice de potencia de la corriente adimensional, o lo que es lo mismo, la capacidad de transporte de sedimentos, $T_{c j}$ (Wilson y Gallant, 2000b):

$$
T_{c j}=\left(\frac{\sum_{i \epsilon C_{j}}\left(\mu_{i} a_{i}\right) / b_{j}}{22,13}\right)^{m}\left(\frac{\sin S_{j}}{0,0896}\right)^{n}
$$

donde $\mu_{i}$ es un coeficiente de peso $\left(0 \leqslant \mu_{i} \leqslant 1\right)$ y dependen del mecanismo de generación de la escorrentía y las propiedades del suelo (cuando $\mu=0$ no se genera escorrentía, mientras que cuando $\mu=1$ toda la precipitación se convierte en escorrentía), $a_{i}$ es el área de la $i$-enésima celda, $b_{j}$ es el ancho de la celda, $S_{j}$ es la pendiente en grados, $m$ y $n$ son constantes ( 0,6 y 1,3 , respectivamente), y $C_{j}$ es el grupo de elementos que tiene conexión hidrológica con la celda $j$ (el área de captación de la celda, incluyendo la propia celda).

Otro índice que calcula el programa EROS representa el cambio en la capacidad de transporte a lo largo de cada celda, $\Delta T_{c}$ y se puede entender como una medida del potencial de erosión o sedimentación en cada celda (Moore y Burch, 1986). Esta relación puede ser escrita como:

$$
\Delta T_{c j}=\phi\left[\left(\sum_{i \in C_{j-}} \frac{\mu_{i} a_{i}}{b_{j-}}\right)^{m}\left(\sin S_{j-}\right)^{n}-\left(\sum_{i \in C_{j}} \frac{\mu_{i} a_{i}}{b_{j}}\right)^{m}\left(\sin S_{j}\right)^{n}\right]
$$

donde $\phi$ es una constante, el subíndice $j$ significa la salida de la celda $j$ y el subíndice $j$ - significa la entrada de la celda $j$, y $C_{j-}$ es el grupo de elementos que tienen conexión hidrológica con la celda $j$, excluyendo dicha celda.

Cuando $\Delta T_{c j}$ toma valores positivos hay sedimnetación neta, mientras que cuando es negativo indica erosión neta.

El programa TAPES-G calcula una versión simplificada de los dos índices anteriores:

$$
\begin{gathered}
T_{c j}=\left(\frac{A_{s}}{22,13}\right)^{m}\left(\frac{\sin S}{0,0896}\right)^{n} \\
\Delta T_{c j}=\phi\left[A_{s j-}^{m}\left(\sin S_{j-}\right)^{n}-A_{s j}^{m}\left(\sin S_{j}\right)^{n}\right]
\end{gathered}
$$

donde $A_{s}$ es el área de captación específica $\left(\mathrm{m}^{2} / \mathrm{m}\right)$.

Estas relaciones simples tienen gran utilidad en modelos hidrológicos y sedimentológicos a escala de cuenca, por lo cual deben ser incorporadas en la conceptualización de la cuenca y en la estimación de parámetros. 


\subsubsection{Las escalas de representación y análisis}

El término escala se refiere a un tiempo o longitud que caracteriza un proceso, una observación o un modelo y el término escalamiento se refiere a la transformación de la escala original en otra (Blöschl y Sivapalan, 1995). Los procesos hidrológicos y geomorfológicos ocurren en un amplio intervalo de escalas tanto espaciales como temporales, las cuales se encuentran interrelacionadas. En la figura 3.2 se observan las escalas en las cuales tienen lugar los procesos hidrológicos. Las partes sombreadas de la figura muestran las relaciones características (tiempo - espacio) de dichos procesos y puede ser vista como el espectro potencial entre ciertos umbrales.

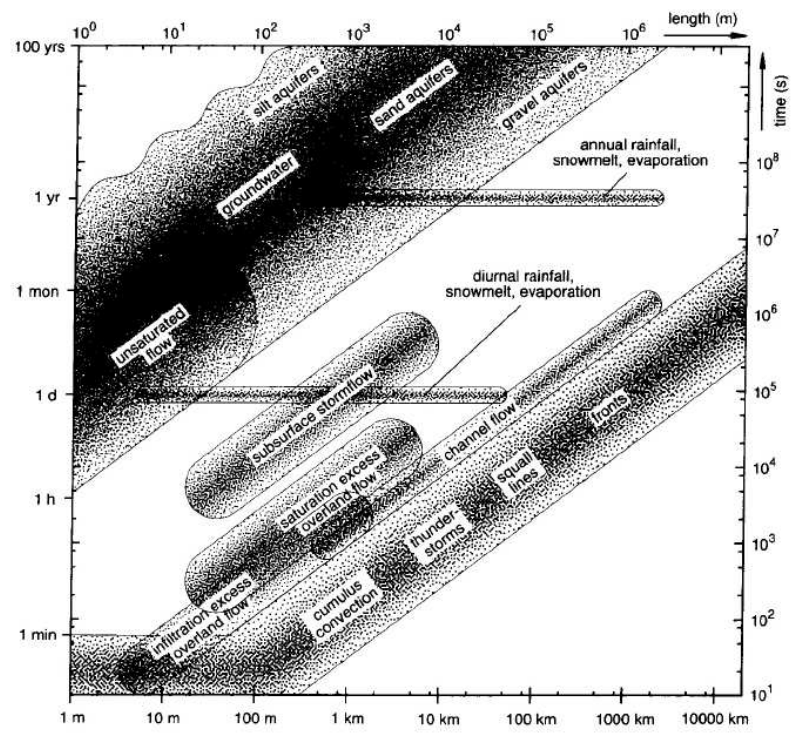

Figura 3.2. Intervalos espacio - temporales característicos de los procesos hidrológicos, figura tomada de Blöschl y Sivapalan (1995)

La respuesta hidrológica, y por ende sedimentológica, de una cuenca da cuenta de varios procesos que ocurren a diferentes escalas. El tiempo de respuesta depende de los mecanismos de producción de escorrentía dominantes, el cual se incrementa a medida que el agua pasa a niveles más inferiores del suelo (Pearce et al., 1986). Así mismo, dicha respuesta también depende del espacio en el cual ocurren los procesos.

Por ejemplo, la producción de escorrentía por exceso de infiltración (escorrentía hortoniana), al ser un fenómeno puntual, que ocurre en una escala espacial pequeña (de centímetros a pocos metros) es un proceso de respuesta inmediata (de segundos a minutos). La escorrentía por exceso de saturación (escorrentía de Dunne), la escorrentía de retorno del flujo subsuperficial o interflujo, y la escorrentía subsuperficial de tormenta, son procesos que exigen un área de drenaje mínima en 
donde no solamente se dan flujos verticales, sino y sobre todo laterales, al interior del suelo, por lo que son más lentas.

El factor entre las escalas espaciales y temporales de cada proceso se denomina velocidad característica (Blösch et al., 1995) o escala natural (Blöschl y Sivapalan, 1995). Al respecto, Blöschl y Sivapalan (1995) señalan que la velocidad característica para los procesos atmosféricos es del orden de $10 \mathrm{~m} / \mathrm{s}$, para el flujo en cauce es del orden de $1 \mathrm{~m} / \mathrm{s}$, y para la escorrentía subsuperficial de tormenta es del orden de $0.1 \mathrm{~m} / \mathrm{s}$.

Kirkby y Chorley (1967) informan que el flujo superficial en ladera debido al exceso de infiltración presenta una velocidad del mismo orden que la escorrentía subsuperficial de tormenta $(0.1 \mathrm{~m} / \mathrm{s})$. Este hecho puede ser explicado debido a que la escorrentía subsuperficial de tormenta se presenta en discontinuidades en los niveles superiores del suelo en donde se encuentran macroporos integrados en un sistema natural de tubos subsuperficiales (Vélez, 2001), el cual puede compararse a la red de pequeños surcos interconectados por los cuales se transporta el flujo superficial en la ladera.

En cuanto a las escalas de observación, Blöschl y Sivapalan (1995) diferencian tres definiciones (figura 3.3):

a) La extensión (espacio) o duración (tiempo) de los datos de medida.

b) El espaciamiento entre los datos, o resolución.

c) El volumen de integración de una muestra, que depende del instrumento de medida.

a)

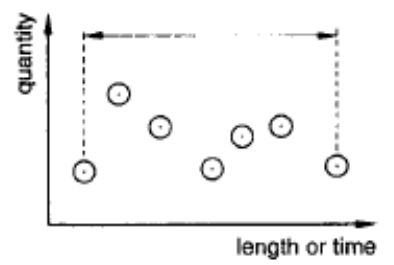

b)

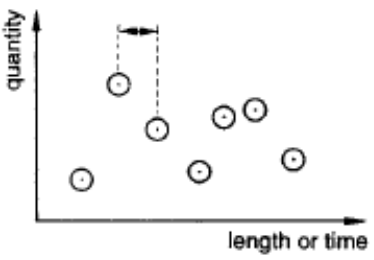

c)

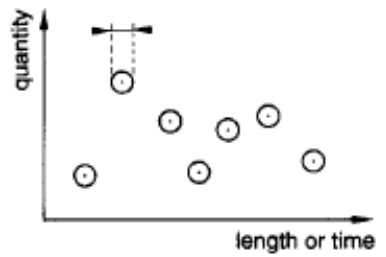

Figura 3.3. Definiciones de la escala de observación, figura tomada de Blöschl y Sivapalan (1995)

En la práctica hidrológica existe una brecha entre la escala de los procesos y la escala de observación (Blöschl y Sivapalan, 1995). Por ejemplo, la mayoría de datos con los cuales se calibran los modelos se toman en la salida de la cuenca y en algunos casos en pocos puntos interiores. Estas medidas son una integración de la totalidad de procesos que ocurren al interior de la cuenca, con un amplio intervalo de escalas representativas. 
En relación con la escala de modelación, esta depende de los objetivos de la misma. Si se modelan eventos, se exigen intervalos de simulación del orden de minutos o incluso segundos, mientras que la escala espacial, definida como el tamaño de celda en modelos distribuidos (resolución), suele ser del orden de 10 metros a 100 metros de ancho (escala de parcela y de ladera). Si el objetivo es una modelación del comportamiento anual, la escala temporal es del orden de un día y la escala espacial puede ser de celdas entre 100 metros y 500 metros (escala de ladera y microcuenca). Para una modelación a largo plazo para la planeación de recursos hídricos, el intervalo temporal de simulación será entre un mes y un año y la escala espacial puede ser de celdas entre 500 metros y 1 kilómetro de ancho.

Desafortunadamente, la escala de modelación es más grande o más pequeña que la escala de observación, por lo cual es necesario efectuar operaciones de escalamiento (Blöschl y Sivapalan, 1995). Gupta et al. (1986) definen el término upscaling como la transformación de una escala dada en una más grande, mientras que downscaling es el proceso contrario, pasar de una escala dada a una más pequeña.

Hutchinson y Gallant (2000) resumen las escalas espaciales de los DEM (tamaño de celda o resolución) utilizadas en aplicaciones prácticas en hidro-ecología:

a) Escala topográfica fina. Con resolución de 5 a 50 metros. La fuente de datos proviene de curvas de nivel derivadas de fotografías aéreas y mapas topográficos con escalas entre 1:5,000 y 1:50,000, datos tomados con Sistema de Posición Global ${ }^{3}$, o datos de elevación de satélites (radar o láser). Se utiliza en modelos hidrológicos distribuidos, análisis espacial de las propiedades del suelo, y aspectos topográficos que afectan la radiación solar, la evaporación y las variaciones locales de la vegetación.

b) Escala topográfica gruesa. Con resolución de 50 a 200 metros. Los datos provienen de curvas de nivel derivadas de fotografías aéreas y mapas topográficos con escala entre 1:50,000 y 1:200,000. Es utilizada en modelos hidrológicos distribuidos con poco detalle y en análisis de biodiversidad.

c) Meso-escala. Con resolución entre 200 metros y 5 kilómetros. La fuente de datos son imágenes de satélite y mapas topográficos con escala entre 1:100,000 y 1:250,000. Se utilizan en representaciones de aspectos dependientes de la cota tales como la temperatura y la precipitación y en la determinación de divisorias de cuencas grandes.

d) Macro-escala. Con resolución entre 5 y 500 kilómetros. Los datos provienen de mapas topográficos con escala entre 1:250,000 y 1:1,000,000. Se utilizan en modelos climáticos globales.

\footnotetext{
${ }^{3}$ En Inglés, Global Position System (GPS)
} 


\subsubsection{Los elementos del sistema}

A partir de relaciones topográficas que pueden derivarse de un DEM, las características del flujo de agua y de los sedimentos que dicho flujo erosione, transporte o deposite, y propiedades del suelo; es posible diferenciar el paisaje en diferentes elementos con la utilización de umbrales con sentido físico, dependientes de las condiciones físicas específicas de una región (clima, suelos, vegetación, etc.), y por tanto no aplicables a toda la cuenca hidrográfica. Estos umbrales representan el inicio de la erosión concentrada, ya sea en surcos, cárcavas o cauces.

Además es posible determinar zonas en donde se imponga la coluviación masiva, de esta forma se pueden diferenciar redes de surcos o cárcavas efímeras que terminen en depósitos coluviales (por ejemplo, pequeños abanicos coluviales ubicados en el pie de la ladera) y que no estén conectadas con la red de drenaje de cauces, de otras redes de surcos o cárcavas que estén debidamente conectadas con la red de drenaje de cauces. La ubicación de vaguadas o thalwegs ${ }^{4}$ y zonas de acumulación de sedimentos en laderas es crucial en un modelo sedimentológico a escala de cuenca.

Para la adecuada definición de los elementos del sistema para los diferentes procesos erosivos que se dan en una cuenca hidrográfica, se encuentran en la literatura numerosos estudios que tienen relación con el inicio de la erosión concentrada. Es importante anotar que el tipo de erosión concentrada que se da en una cuenca en particular (erosión en surcos, erosión en cárcavas, erosión en cauces) depende de los mecanismos de generación de escorrentía superficial.

Por ejemplo, en zonas áridas en donde la producción de escorrentía se da principalmente por exceso de infiltración (escorrentía hortoniana), la erosión concentrada se da en pequeños surcos en la superficie del terreno; mientras que en zonas húmedas, donde los mecanismos productores de la escorrentía son la escorrentía por exceso de saturación (escorrentía de Dunne), la escorrentía de retorno del flujo subsuperficial o interflujo, y la escorrentía subsuperficial de tormenta; la erosión concentrada se da en cauces que generalmente comienzan en pequeños valles no canalizados o vaguadas (Montgomery y Dietrich, 1989).

Para recalcar la importancia de la definición de áreas fuente, la densidad de drenaje y la iniciación de cauces, Montgomery y Dietrich (1989) señalan que debido a que las cabeceras de los cauces representan la mayor frontera entre la ladera y los cauces, los factores que gobiernan la iniciación de cauces son componentes esenciales de teorías cuantitativas para la evolución tanto de laderas como de redes de drenaje.

Según dichos autores, aunque muchas propiedades de las redes de drenaje se pueden predecir por el modelo de topología aleatoria de Shreve (1966), para parámetros tales como la densidad de drenaje es necesario conocer el número de

\footnotetext{
${ }^{4}$ Depresiones naturales del terreno en donde se acumula agua y sedimentos pero no presentan un cauce definido. Thalweg, palabra de origen alemán, que literalmente significa "camino del valle"
} 
fuentes por unidad de área, una propiedad que la topología no puede predecir. Los autores proponen que teorías basadas en la física para predecir las áreas fuentes que contribuyen a las cabeceras de los cauces contribuirán a modelos de redes de drenaje y proporcionan un vínculo entre los procesos de ladera y las propiedades de las redes de drenaje de cauces naturales.

Siguiendo estas consideraciones, se diferencia el paisaje en los siguientes elementos.

\subsubsection{1. Áreas entre surcos}

Corresponde a las zonas de la ladera en donde no se presenta erosión concentrada, esto es, las zonas en donde el agua fluye como una delgada capa uniforme sin canalizarse. La ubicación de las áreas entre surcos no es precisa puesto que depende de la microtopografía (al igual que los surcos), de esto modo, se presenta en toda la ladera. Los procesos erosivos se dan por el impacto de las gotas de lluvia y la escorrentía laminar.

\subsubsection{Surcos}

Los surcos son pequeños y numerosos canales que se presentan en la ladera generalmente de forma aleatoria los cuales están definidos por la microtopografía. Se forman debido al flujo superficial en ladera en eventos de lluvia intensos cuando este flujo se concentra y tiene la potencia necesaria para erosionar además de las partículas finas, las gruesas. Estos pequeños canales se encargan de transportar tanto el agua como los sedimentos que se producen en la ladera durante el evento de lluvia. En zonas de cultivo, los surcos corresponden a las franjas entre las plantas y generalmente se presentan paralelos a las curvas de nivel. Otros ejemplos de surcos artificiales son las huellas de tractores, pequeños caminos forestales y las pistas generadas por el paso de ganado de pastoreo.

Los surcos se desarrollan ladera abajo, y a medida que se van desarrollando las posibilidades de infiltración del agua que fluye sobre él son menores puesto que los sedimentos que transporta el agua pueden ir sellando los sitios por donde se infiltra. En el largo plazo, la colmatación acumulada proporciona condiciones más desfavorables para la infiltración (Vélez, 2001).

\subsubsection{Cárcavas}

Una cárcava se define como un pequeño cauce natural o escarpe, causado por la erosión debido a un flujo superficial intermitente de agua, usualmente durante e inmediatamente después de una lluvia intensa.

Estos cauces naturales son lo suficientemente profundos para la eliminación con operaciones de labranza. Debido a que las operaciones normales de labranza varían tanto en el tiempo como en el espacio, no hay acuerdos en cuanto a las dimensiones para distinguir los surcos y las cárcavas. Por tal motivo es necesario 
usar una definición más rigurosa como la propuesta por Hauge (1977): los surcos se distinguen de las cárcavas por que estas poseen una sección transversal mínima aproximada de $929 \mathrm{~cm}^{2}$ (1 pie cuadrado).

Basados en la localización en el paisaje, en la morfología y en los procesos de formación, se han distinguido dos tipos de cárcavas en zonas dedicadas a la agricultura: las cárcavas efímeras y las cárcavas permanentes.

3.1.3.3.1. Cárcavas efímeras. La topografía de la mayoría de campos de cultivo causa que la escorrentía y los sedimentos se concentren en pocas rutas naturales, tales como cauces de orden cero, vaguadas, hondonadas, o depresiones naturales; o a lo largo de elementos lineales en el paisaje tales como caminos sin pavimentar, rutas de tractores y límites de parcelas, antes de que salgan del campo (Foster, 1982a; Thorne, 1984). La erosión que ocurre en estos cauces se conoce como erosión en cárcavas efímeras. Estos elementos son cauces temporales y discontinuos que normalmente se eliminan en operaciones de labranza. La figura 3.4 muestra una cárcava efímera en un campo de cultivo antes de las operaciones de labranza y la figura 3.5 es un detalle de esta misma cárcava.

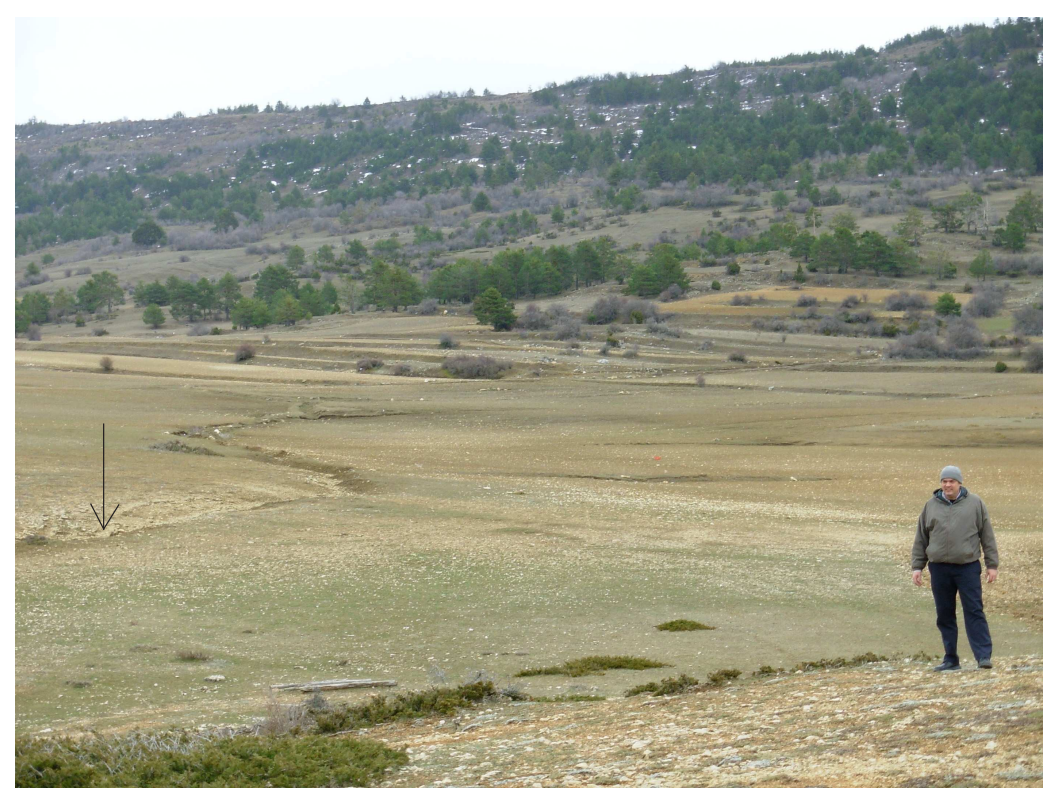

Figura 3.4. Cárcava efímera en un campo de cultivo antes de las operaciones de labranza (Montes Universales, Teruel, España)

Según Foster (1982a) el flujo en surcos se suele clasificar como parte del flujo superficial, el cual se supone que ocurre uniformemente a lo largo de una ladera. El flujo en cárcavas efímeras se presenta claramente canalizado. Las cárcavas efímeras 


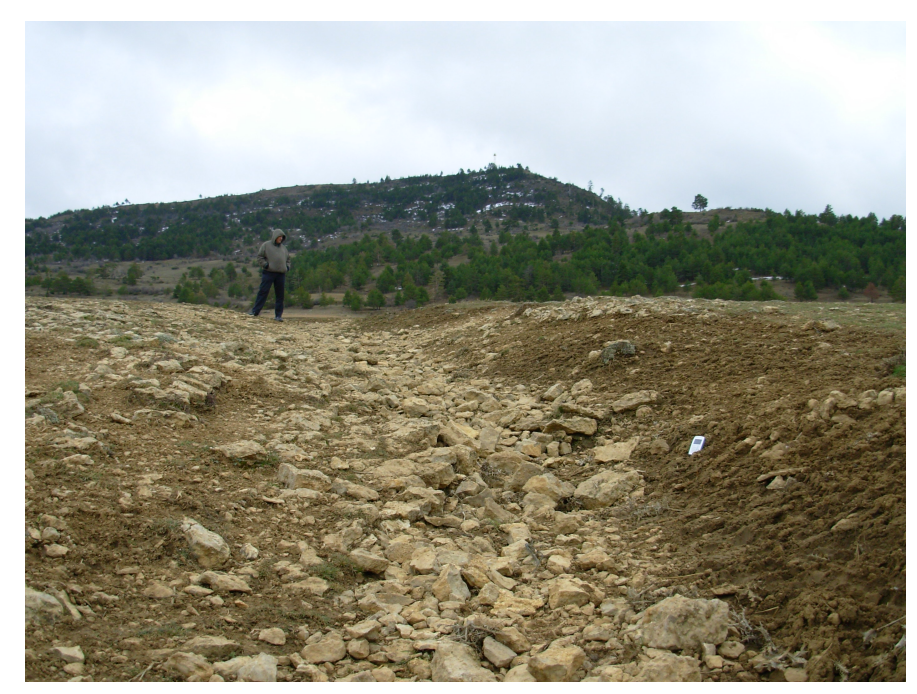

Figura 3.5. Detalle de una cárcava efímera en un campo de cultivo antes de las operaciones de labranza

son recurrentes en la misma área cada año, mientras que los surcos están fuertemente influenciados por las marcas de labranza y no suelen formarse en diferentes áreas año a año.

A partir de observaciones de campo de la morfología de cárcavas efímeras en gran variedad de ambientes agrícolas en Europa se ha determinado que además de las características de la tormenta, son varios los factores locales que juegan un papel importante en la forma y tamaño de la sección transversal de la cárcava: usos del suelo, topografía (área de drenaje y pendiente local) y las propiedades del perfil del suelo (Poesen, 1989).

Algunos modelos predicen la forma y tamaño de cárcavas efímeras: CREAMS, GLEAMS, EGEM, el modelo de ladera WEEP y el modelo de microcuenca LISEM.

A partir de mediciones y observaciones de campo en gran variedad de ambientes (Bradford y Piest, 1980; Govers y Poesen, 1988; Radoane et al., 1995) se puede concluir que una vez que se forman las cárcavas, ya sean efímeras o permanentes, los procesos de movimientos en masa proporcionan gran cantidad de sedimentos a las cárcavas, que se encargan de evacuarlos durante eventos tormentosos.

3.1.3.3.2. Cárcavas permanentes. Se forman donde las líneas de flujo o una cárcava ya establecida cruza una banca de tierra (una terraza, otra cárcava, la pared de un deslizamiento, un cauce, un talud artificial). Estas cárcavas son cauces permanentes y continuos los cuales no se pueden eliminar con operaciones normales de labranza.

Las cárcavas permanentes estan menos controlados por la intensidad del flujo superficial y más por procesos de movimientos en masa y el flujo subsuperficial. 
Así dependen más de características locales (presencia e intensidad de macroporos y tipo de suelo) que del tamaño de la cuenca de drenaje. Esto implica que la predicción de la localización exacta y el volumen de material erosionado en las cárcavas permanentes sea más difícil que en las cárcavas efímeras. En la figura 3.6 se observa una cárcava permanente. La figura 3.7 es un detalle de la misma cárcava permanente.

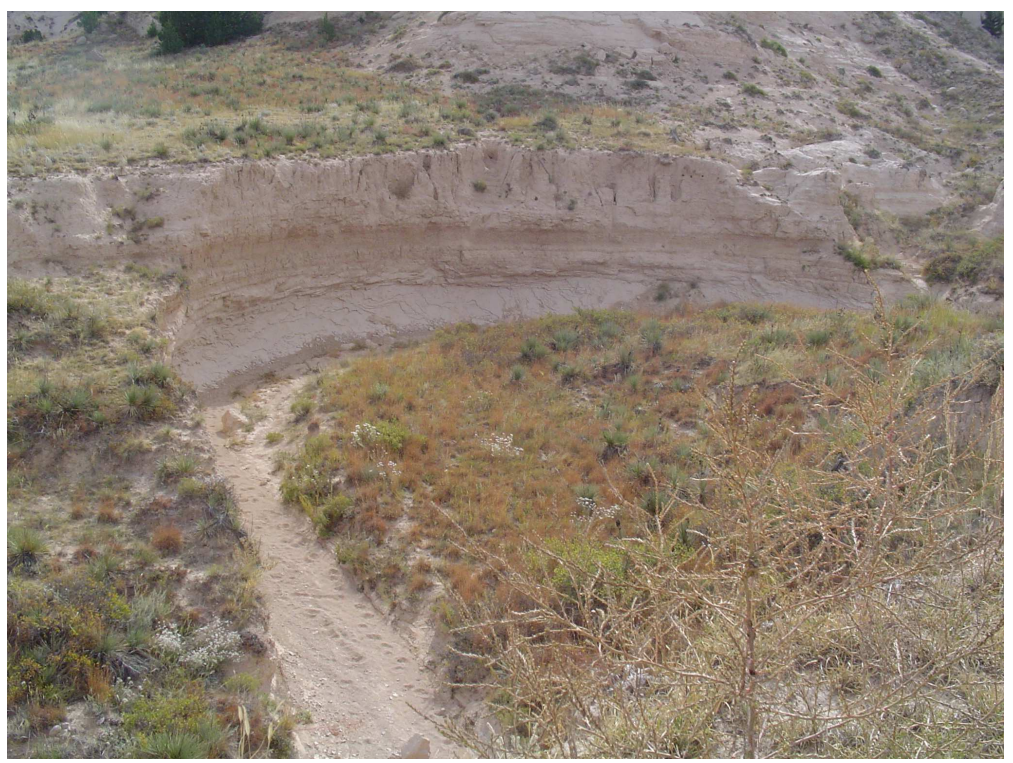

Figura 3.6. Cárcava permanente (Pawnee Buttes Area, Colorado, USA)

\subsubsection{Zonas de acumulación de sedimentos en ladera}

Las depresiones del terreno, también denominadas vaguadas o hondonadas cumplen una función importante en la evolución del paisaje y específicamente en la respuesta sedimentológica de una cuenca. Esto es debido a que en estas zonas se presenta la acumulación de sedimentos producidos aguas arriba y en multitud de paisajes representa la transición entre la ladera y la red de drenaje de cauces naturales.

Son varios los estudios que concluyen que muchas de las redes de surcos y las redes de cárcavas en una ladera terminan en zonas de acumulación, tales como depósitos coluviales y pequeños abanicos aluviales, los cuales sirven de barrera para la conexión hidrológica con la red de drenaje de cauces propiamente dicha. Estos estudios concluyen que se pueden derivar relaciones dependientes de la topografía (área de drenaje - pendiente) para predecir la ubicación de estas zonas de coluviación masiva. 


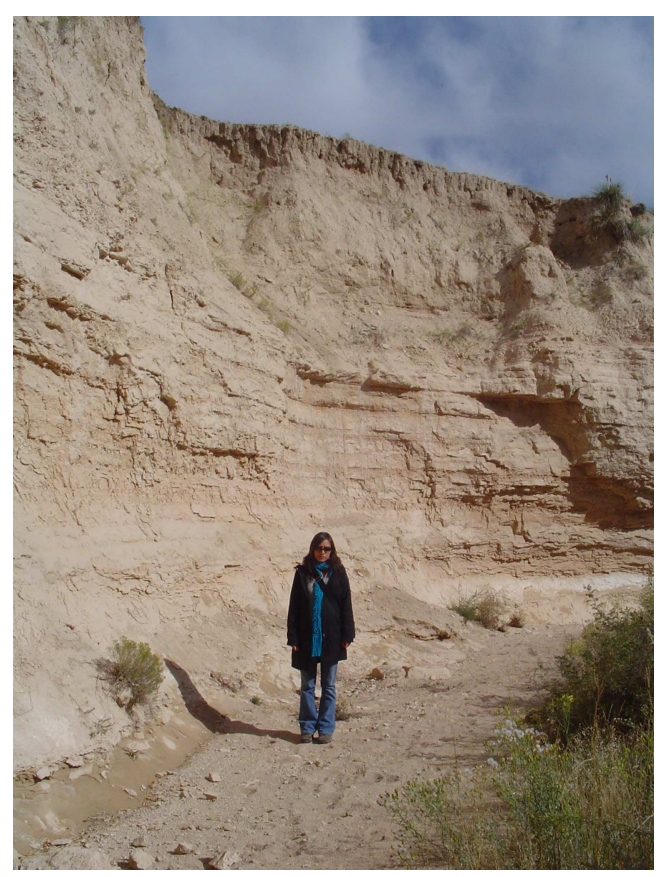

Figura 3.7. Detalle de una cárcava permanente

\subsubsection{Cauces}

Un cauce es una hendidura natural del terreno formada por la acción erosiva del agua, confinada lateralmente por la banca y horizontalmente por el lecho. La red de drenaje de cauces naturales en una cuenca hidrográfica se encuentra interconectada y forma estructuras topológicas definidas. Esta red se encarga de evacuar el agua y los sedimentos producidos en las laderas y por ende los procesos fundamentales que se producen en el cauce son el transporte de masa y los intercambio de energía propios de los mecanismos de transporte.

Montgomery y Dietrich (1989) diferencian los cauces de las vaguadas en que aquellos tienen márgenes bien definidas, y por tanto medibles, y la cabecera del cauce representa la transición entre las vaguadas no canalizadas y la red de drenaje de cauces.

La figura 3.8 es un esquema idealizado de la relación entre una vaguada ${ }^{5}$, su área fuente ${ }^{6} \mathrm{y}$ el cauce de primer orden ${ }^{7}$. El punto de unión entre la vaguada y el cauce de primer orden es la cabecera ${ }^{8}$.

\footnotetext{
${ }^{5}$ En Inglés, hollow

${ }^{6}$ En Inglés, source area

${ }^{7}$ En Inglés, first-order channel

${ }^{8}$ En Inglés, channel head
} 


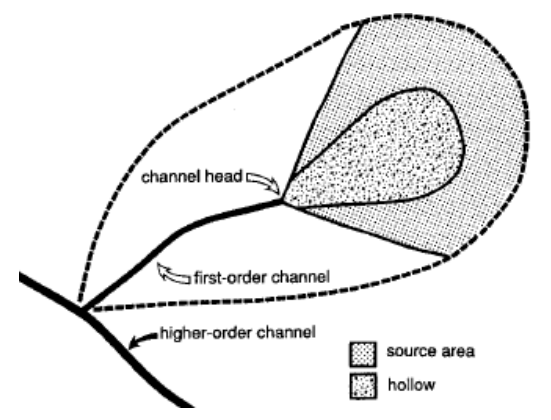

Figura 3.8. Relación idealizada entre vaguadas, áreas fuente y el cauce de primer orden, figura tomada de Montgomery y Dietrich (1989)

\subsubsection{Definición de los elementos del sistema a partir de infor- mación topográfica, hidrológica y sedimentológica}

Son numerosos los estudios con relación al inicio de la erosión concentrada, ya sea en surcos o cárcavas efímeras. En cuanto a la finalización de surcos y cárcavas efímeras se reconoce que terminan con una coluviación masiva en depresiones naturales del terreno, donde la energía del flujo disminuye de tal forma que no es capaz de transportar los sedimentos, formándose un depósito coluvial (en ladera) o aluvial (en cauces). Cabe anotar que la energía del flujo depende de las características del evento de lluvia y la producción de escorrentía (que a la vez depende de los usos del suelo y las características del suelo), por lo cual tanto la iniciación de erosión concentrada como la finalización es dinámica en el tiempo y en el espacio.

3.1.3.6.1. Forma de diferenciar surcos, cárcavas efímeras y cauces. Son varios los criterios encontrados en la literatura en cuanto a las diferencias entre surcos, cárcavas (efímeras y permanentes) y cauces. Al respecto Poesen et al. (2003) efectúan una recopilación de las diferentes formas de diferenciar estos elementos y señalan que aunque estas diferencias son subjetivas, se reconoce en la mayoría de los estudios que la transición entre surcos, cárcavas efímeras, cárcavas permanentes y cauces representa un continuo.

La forma más objetiva de diferenciar estos elementos es por su ancho. Nachtergaele et al. (2002) demuestran que las cárcavas efímeras pueden considerarse como canales caracterizadas por un ancho medio que se encuentra entre el ancho de los surcos y el ancho de pequeños ríos. Dichos autores efectúan un análisis del ancho característico de estos elementos partiendo de una extensa base de datos de diferentes partes del mundo y se apoyan en los conceptos de la geometría hidráulica de Leopold y Maddock (1953) para comprobar que las relaciones encontradas por estos autores en cauces se cumplen también para surcos y cárcavas. En la figura 3.9 se observa que en surcos, cárcavas y cauces se encuentra una relación potencial 
entre el ancho, $W$ en $(m)$, y el caudal, $Q$ en $\left(\mathrm{m}^{3} / \mathrm{s}\right)$, de la forma $W=a Q^{b}$, con el exponente $b$ variando entre 0,3 para surcos, 0,4 para cárcavas, y 0,5 para ríos.

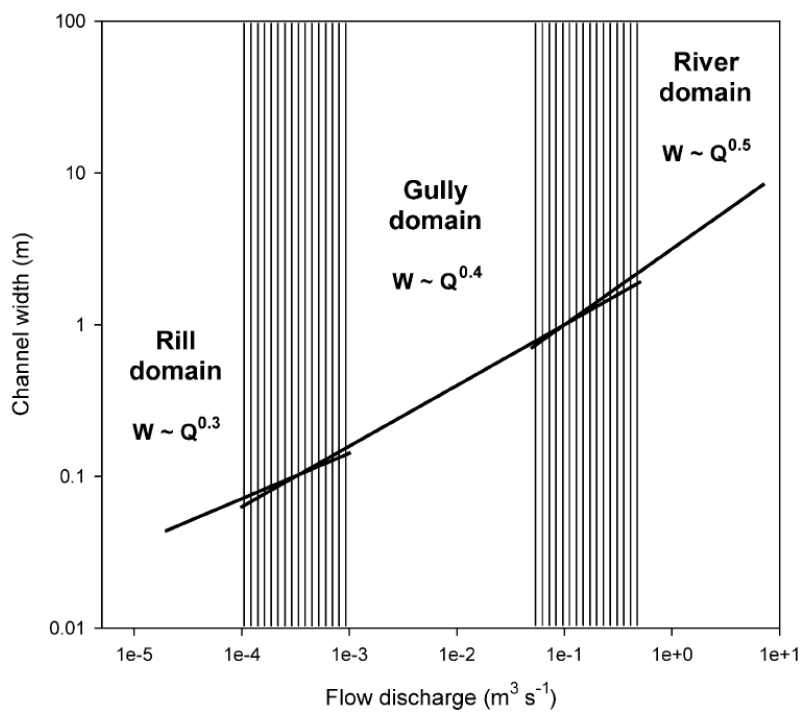

Figura 3.9. Relación potencial entre el caudal y el ancho para varios tipos de canales (surcos, cárcavas y ríos). Las barras verticales indican zonas de transición. Figura tomada de Nachtergaele et al. (2002)

Nachtergaele et al. (2002) atribuyen la diferencia en los exponentes a tres razones:

a) La distribución del esfuerzo de corte sobre el perímetro mojado presenta variaciones para surcos, cárcavas y ríos. En surcos esta variación presenta una distribución logarítmica - polinómica. La condición de esta función es tal que el esfuerzo de corte se distribuye simétricamente alrededor del surco, tomando un valor de cero en la intersección de la pared y el agua superficial y un valor máximo en el lecho del surco. En los ríos la distribución del esfuerzo de corte alrededor del canal es más uniforme y toma un valor aproximadamente igual sobre todo el perímetro mojado. De esta forma, la erosión en surcos se concentra en el lecho, lo que no ocurre en ríos y en cárcavas.

b) Cuando un canal que está inciso encuentra una capa resistente a la erosión, el canal comienza a ensancharse. La probabilidad para que un canal encuentre un canal menos erosionable se incrementa con la profundidad, así la tendencia a incrementar el ancho es menor en surcos que en cárcavas y ríos. Además, los ríos tienden a desarrollar capas resistentes a la erosión en sus lechos, de esta forma la erosión se hace más probable en sus paredes, esta situación es poco común en surcos. 
c) La pendiente longitudinal de ríos normalmente es menor que en cárcavas y surcos. De esta forma, el potencial para causar incisión decrece en la relación surcos - cárcavas - ríos.

Torri et al. (2006) basados en datos geométricos e hidráulicos (caudales) para surcos y cárcavas efímeras tomados en Italia, Bélgica y España (datos de campo) en condiciones climáticas diferentes y con suelos y usos del suelo variados, concluyen que las relaciones de Leopold y Maddock (1953) se cumplen para surcos y cárcavas y proponen exponentes para la relación $W=a Q^{b}$ para surcos entre 0,3 y 0,35 , para cárcavas entre 0,35 y 0,45 y para arroyos y ríos $>0,5$. Además encuentran que la pendiente, el tipo se suelos y los usos del suelo tienen poco efecto en esta relación.

Los modelos de erosión que tratan de manera explícita y de forma física los surcos y las cárcavas efímeras presentan relaciones de tipo potencial (de la forma $W=a Q^{b}$ ) para determinar el ancho de estos elementos. Puesto que el ancho depende del caudal, este se considera dinámico ya que varía de acuerdo a las condiciones de la tormenta y a la producción de escorrentía (que depende del tipo de suelo y de la cobertura de vegetación). Cabe anotar que una vez se alcanza el caudal pico en un evento específico, el ancho de los surcos y las cárcavas no disminuye, permaneciendo constante.

El modelo LISEM es un ejemplo de como se puede tratar el ancho de las cárcavas efímeras de forma dinámica. Al iniciar un evento, se supone que el ancho de las cárcavas es de $0,1 \mathrm{~m}$. El ancho se incrementa con el caudal hasta que se alcanza el caudal pico de acuerdo con la siguiente relación, tomada del trabajo de Nachtergaele et al. (2002):

$$
W=2,51 Q^{0,412}
$$

donde $W$ es el ancho de las cárcavas efímeras $(m)$, y $Q$ es el caudal $\left(m^{3} / s\right)$.

La ecuación 3.11 se ha deducido a partir de una extensa base de datos, tomados tanto en campo como en laboratorio bajo situaciones diversas de usos del suelo y condiciones climáticas, por lo cual se considera una ecuación promedio para el ancho de cárcavas efímeras dependiendo del caudal. Si se analizan situaciones particulares de usos del suelo y condiciones climáticas se encuentran otras relaciones, esto es, se presentan variaciones en el coeficiente y exponente (Nachtergaele et al., 2002). Por tal motivo en el modelo LISEM estos valores son definidos por el usuario, y los presentados por Nachtergaele et al. (2002) son los valores por defecto del modelo.

En la figura 3.10 (tomada de la página web del LISEM ${ }^{9}$ ) se observa como se simula la variación del ancho de una cárcava efímera en un evento específico según el caudal para el modelo LISEM.

En cuanto al ancho de los surcos, Gilley et al. (1990) desarrollan una relación $W-Q$ basados en datos tomados en 11 parcelas experimentales en el este de los

\footnotetext{
${ }^{9}$ http://www.geog.uu.nl/lisem/
} 


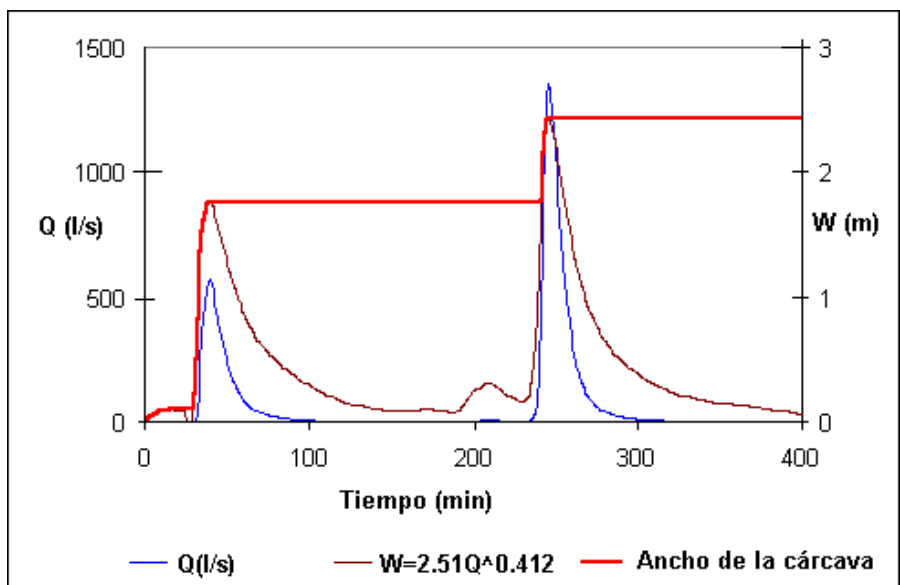

Figura 3.10. Ancho simulado de una cárcava efímera según el caudal para el modelo LISEM. Figura tomada de la página web del LISEM

Estados Unidos utilizando simuladores de lluvia, de la forma:

$$
W=1,13 Q^{0,303}
$$

donde $W$ es el ancho de los $\operatorname{surcos}(m)$, y $Q$ es el caudal $\left(\mathrm{m}^{3} / \mathrm{s}\right)$.

La ecuación 3.12 es utilizada por el modelo WEEP, el cual supone una densidad aproximada de $1,0 \mathrm{surco} / \mathrm{m}$ y un caudal similar para cada surco.

3.1.3.6.2. El comienzo de la erosión concentrada. Con respecto al comienzo de los surcos y las cárcavas efímeras, una aproximación a esta cuestión es la planteada inicialmente por Patton y Schumm (1975) quienes introducen el concepto de umbral de un sistema geomorfológico. Este concepto se basa en suponer que en un paisaje con un clima y un uso del suelo dado existe un área de drenaje crítica asociada a una pendiente específica necesaria para causar incisión ya sea en surcos o en cárcavas. Mientras mayor sea la pendiente, el área de drenaje crítica decrece y viceversa. Así se pueden definir áreas de drenaje críticas para la iniciación de cauces, de acuerdo con las condiciones ambientales con una base física. A partir de la definición del concepto de umbral geomorfológico se han realizado numerosos estudios de campo para encontrar estas relaciones.

Estos umbrales se pueden representar por una ecuación potencial:

$$
S=a \cdot A^{b}
$$

donde $S$ es la pendiente crítica para el desarrollo erosión concentrada (en grados), $A$ es el área de drenaje correspondiente (en hectáreas), $a$ es el coeficiente y $b$ es el exponente. 
Según Vandaele et al. (1996), el exponente $b$ varía entre -0,3 y -0,4 para cárcavas efímeras en zonas cultivadas. El valor del coeficiente $a$ varía considerablemente, por ejemplo en Portugal se han informado valores de 0,02 mientras que en el Reino Unido de 0,12. Uno de los factores que controla el valor de $a$ es la metodología utilizada para establecer el umbral, así en una curva umbral deducida de datos de campo en Bélgica se informa un valor de 0,08 mientras que en el mismo estudio se encuentra un valor de 0,025 a partir de análisis de fotografías aéreas (Poesen, 1989). Otros factores que controlan la posición de la curva umbral son: el clima, los suelos, el uso del suelo; por lo cual, dicho umbral debe ser característico de una unidad ambiental con dichos factores homogéneos.

La curva umbral refleja una intensidad de flujo crítica la cual es necesario exceder para iniciar ya sea un surco o una cárcava efímera. Este flujo crítico depende del régimen de lluvias y el uso del suelo. Una vez se establece la curva umbral para una variedad de climas, suelos y usos del suelo, es posible predecir el efecto de un cambio climático y de usos del suelo en la densidad de la red de surcos y cárcavas efímeras y su localización.

En la implementación práctica de las curvas umbrales, son varias las expresiones empíricas que se han propuesto. El objetivo es determinar celdas de un Modelo de Elevación Digital en donde se presenta erosión concentrada, ya sea en cárcavas efímeras o en surcos, a partir de un umbral crítico que depende de la pendiente y el área de drenaje normalizada por el ancho. Para la ubicación de cárcavas efímeras a partir de datos topográficos, las expresiones más utilizadas son:

Según Vandaele et al. (1996):

$$
F_{c}=S\left(\frac{A}{w}\right)^{0,4}>0,5
$$

Según Moore et al. (1988b):

$$
F_{c}=S\left(\frac{A}{w}\right)>18 \mathrm{y} \ln \left(\frac{A / w}{S}\right)>6,8
$$

Según Vandaele et al. (1996):

$$
F_{c}=S>0,025\left(\frac{A}{10000}\right)^{-0,4}
$$

Según Desmet y Govers (1997):

$$
F_{c}=S\left(\frac{A}{w}\right)^{0,4}>0,72
$$

Según Vandaele et al. (1997):

$$
F_{c}=S\left(\frac{A}{w}\right)>40 \mathrm{y} \ln \left(\frac{A / w}{S}\right)>9,8
$$


Para surcos Desmet y Govers (1997) proponen la siguiente relación:

$$
F_{c}=S\left(\frac{A}{w}\right)^{0,4}>0,22
$$

En las ecuaciones $3.14-3.19, F_{c}$ es el umbral crítico a partir del cual se encuentra una cárcava efímera o un surco, $S$ es la pendiente $(\mathrm{m} / \mathrm{m}), A$ es el área de captación $\left(m^{2}\right)$, y $w$ es el ancho de flujo $(m)$.

En las ecuaciones anteriores, el término $S(A / w)^{b}$ es una medida de la intensidad de escorrentía superficial Hortoniana, mientras que el término $\ln (A / S)$ representa el índice de humedad de Beven y Kirkby y es una medida de la intensidad de escorrentía por exceso de saturación. De esta manera, estos índices no solo pueden predecir el comienzo de la erosión concentrada en cárcavas efímeras sino también el comienzo del interflujo.

Montgomery y Dietrich (1989) y Montgomery y Foufoula-Georgiou (1993) utilizan una variación del Índice Topográfico para predecir la localización del inicio de cauces naturales:

$$
C I T=A_{s}(\tan S)^{2}
$$

donde $A_{s}$ es el área de captación específica $\left(\mathrm{m}^{2} / \mathrm{m}\right)$ y $S$ es la pendiente (grados).

Moore et al. (1988a) simulan la distribución de cárcavas efímeras en una microcuenca de 7.5 hectáreas con suelo desnudo y en barbecho. Estos autores encuentran que la localización de cárcavas efímeras pueden predecirse a partir del Índice Topográfico de Humedad estacionario, $I T=\ln \left(A_{s} / S\right)$, y del Índice de potencia de la corriente, $I P C=A_{s} S$, donde $A_{s}$ es el área de captación por unidad de ancho y $S$ es la pendiente local.

Casalí et al. (1999) a partir de datos de campo en el sur de la provincia de Navarra, España, proponen dos índices para predecir la localización de cárcavas efímeras. El primero está basado en la pendiente media, ponderada por el área de drenaje y toma la siguiente forma:

$$
A S=A \frac{\sum_{i=1}^{n} A_{i} S_{i}}{\sum_{i=1}^{n} A_{i}}=\sum_{i=1}^{n} A_{i} S_{i}
$$

donde la pendiente de cada franja con características uniformes, $S_{i}$, está ponderada por su área de drenaje respectiva, $A_{i}$, y luego, multiplicada por el área total, $A$.

El segundo se basa en la pendiente media, ponderada por la longitud de drenaje y toma la siguiente forma:

$$
A S L=A \frac{\sum_{i=1}^{n} L_{i} S_{i}}{\sum_{i=1}^{n} L_{i}}
$$

donde $L_{i}$ es la longitud de cada segmento de una cárcava.

Una dificultad inherente a la definición de las áreas fuentes y que pocos estudios tienen en cuenta es que estas presentan variaciones de acuerdo a las características de la tormenta y a las condiciones de humedad precedentes de la cuenca, puesto 
que las zonas de acumulación de flujo se dilatan en eventos de lluvia intensos y se contraen en períodos de recesion. La mayoría de las aproximaciones para el inicio de la erosión concentrada se basan en características topográficas, específicamente el área de captación y la pendiente, de esta forma se suponen unas condiciones estacionarias.

Para suplir esta carencia, Barling et al. (1994) desarrollan un índice topográfico de humedad quasi-dinámico que mejora el índice topográfico de humedad estacionario incorporando además del área de captación y la pendiente, el tiempo requerido por el drenaje subsuperficial para redistribuir el agua en el suelo (ver parágrafo 3.1.1.2.1). A partir de observaciones de campo en cuencas experimentales efectuadas por Moore et al. (1988a) se ha verificado que el índice topográfico de humedad quasi-dinámico predice mejor la distribución de humedad en el suelo y la localización de cárcavas efímeras que el estático (Barling et al., 1994).

3.1.3.6.3. La finalización de la erosión concentrada. Con respecto a la finalización de las cárcavas efímeras, se supone que una sedimentación masiva finaliza el desarrollo de la cárcava efímera. Para esto, se han desarrollado modelos para predecir las condiciones donde la sedimentación (coluviación) se impone. De Ploey (1984) propone un modelo de sedimentación masiva (Ecuación 3.23):

$$
S_{c r}=\frac{a \cdot C_{w}^{0,8}}{q^{0,5}}
$$

donde $S_{c r}$ es la pendiente crítica en la cual la sedimentación ocurre (en grados); $C_{w}$ es la concentración de sedimentos en el flujo superficial, en $g r / l ; q$ es el caudal unitario de flujo, en $\mathrm{cm}^{2} / s ;$ y $a$ es un coeficiente empírico que depende del tamaño medio de los sedimentos.

Las medidas de campo en zonas cultivadas revelan que usualmente ocurre un depósito de sedimentos importante en un estrecho intervalo de pendientes locales a lo largo de una catena con el mismo uso del suelo: pendientes entre $2 \%$ y $4 \%$ para suelos cultivados en Bélgica y pendientes entre $4 \%$ y $6 \%$ en suelos cultivados en el sureste de España. El modelo LISEM utiliza un umbral crítico para la sedimentación masiva basado en la pendiente de las celdas, dicho umbral toma el valor de $4 \%$.

De estos análisis se puede concluir que es posible determinar donde comienzan y donde terminan las cárcavas efímeras, dependiendo de las condiciones ambientales locales y la pendiente. Si además de las curvas umbrales se determinan las direcciones de flujo, el área de drenaje y la pendiente local, por medio de Modelos de Elevación Digital, es posible predecir la longitud total de los surcos para un clima, suelo y uso del suelo determinado. El siguiente paso es determinar la forma y tamaño de la sección transversal de los cárcavas efímeras en función de los factores ambientales, aspecto que se detalla en el parágrafo 3.1.3.6.1. 
3.1.3.6.4. Estimación de la localización y las características geométricas de las cárcavas permanentes. Con respecto a la localización de las cárcavas permanentes, se han efectuado pocas investigaciones. Poesen (1989) y Poesen et al. (1993) a partir de un estudio realizado en Bélgica central, concluyen que los volúmenes de sedimentos generados por erosión en cárcavas permanentes no son significativos con relación a las medidas de intensidad de flujo superficial (producto de la pendiente local y el área de drenaje) y que la localización de las cárcavas de permanentes no tiene relación con concentraciones de flujo superficial controladas por la topografía. Según estos autores, su localización está más relacionada con la presencia de macroporos (bioporos y huellas de tensión) y con la ocurrencia de procesos de movimientos en masa. Además la formación de cárcavas permanentes no siempre se relaciona con eventos de lluvia intensos y de corta duración.

Poesen (1989) cita que las cárcavas permanentes se forman durante lluvias de poca intensidad y larga duración, particularmente donde se presentan suelos con horizontes erosionable con poca profundidad. Aunque las cárcavas permanentes producen localmente gran cantidad de sedimentos, las pérdidas de suelos de este tipo de surcos son de un orden de magnitud menor a las producidas por cárcavas efímeras, al considerar zonas extensas, por ejemplo, una cuenca hidrográfica.

Por lo dicho hasta el momento, es claro que las condiciones que presentan alta dependencia en cuanto al área de drenaje y a la topografía local, como son el inicio y el final de los surcos y las cárcavas efímeras son factibles de determinarse a partir de un Modelo de Elevación Digital. En cuanto a la localización y características de las cárcavas permanentes, más dependiente de las características del suelo y a la ocurrencia de movimientos en masa, se debe recurrir a una cartografía de procesos erosivos, producto de un proceso cartográfico normal (interpretación de fotografías aéreas, campañas de mapeo, etc.). Con relación a la forma y tamaño de las secciones transversales de las cárcavas permanentes, necesarias para hacer cuantificaciones adecuadas de volumen de sedimentos erosionados, es necesario recurrir a cartografía temática geomorfológica (mapas geomorfológicos, unidades geográficas, mapas de procesos erosivos, mapas de suelos).

\subsection{Los procesos relevantes}

En esta sección, además de definir los procesos hidrológicos y sedimentológicos relevantes se hace un recuento de la forma en que habitualmente se abordan.

Los procesos relevantes difieren de acuerdo con las condiciones particulares de cada cuenca hidrográfica. Por tal motivo, es necesario diseñar estrategias de modelación que permitan al usuario definir cuales de los procesos actuantes tienen relevancia. Este aspecto, fundamental en el éxito de la aplicación del modelo en una cuenca en particular, será tratado en la formulación del modelo (segunda parte de la tesis). 


\subsubsection{Los procesos hidrológicos}

Un problema que complica el entendimiento de los sistemas hidrológicos es que la mayor parte de los flujos de agua ocurren en el interior del suelo y las rocas. La capacidad para medir los procesos de flujo subsuperficial es muy limitada y las técnicas de medición actuales solamente reflejan las condiciones de las inmediaciones del sitio de medida (Beven, 2001b). Además, más del $95 \%$ del agua que circula por los cauces proviene de las laderas, en donde los flujos de agua son esencialmente subsuperficiales, por lo cual es necesario entender los procesos hidrológicos que se dan al interior del suelo para acercarse a una buena modelación del sistema, lo cual es complejo.

Otra dificultad inherente a los procesos hidrológicos es que los procesos relevantes varían de acuerdo con las condiciones ambientales particulares de cada cuenca de estudio, dependiendo de las características topográficas, suelos, vegetación, litología. A esto se añade la alta variabilidad espacial y temporal en que se presentan los diferentes procesos.

Debido a dicha complejidad, se hace necesaria la utilización de modelos perceptuales que reflejen la variedad de procesos hidrológicos que ocurren en la naturaleza. Según Beven (2001b) estos modelos perceptuales son un paso previo a los modelos conceptuales. A continuación se resume un modelo perceptual propuesto por Beven (2001b).

En la figura 3.11 se representan los diversos procesos hidrológicos que ocurren en una ladera en los períodos de recesión. En estos períodos se hace relevante la transpiración de las plantas y la percolación y los almacenamientos de agua en el suelo y la roca disminuyen, mientras que el nivel freático (si existe) se hace más profundo.

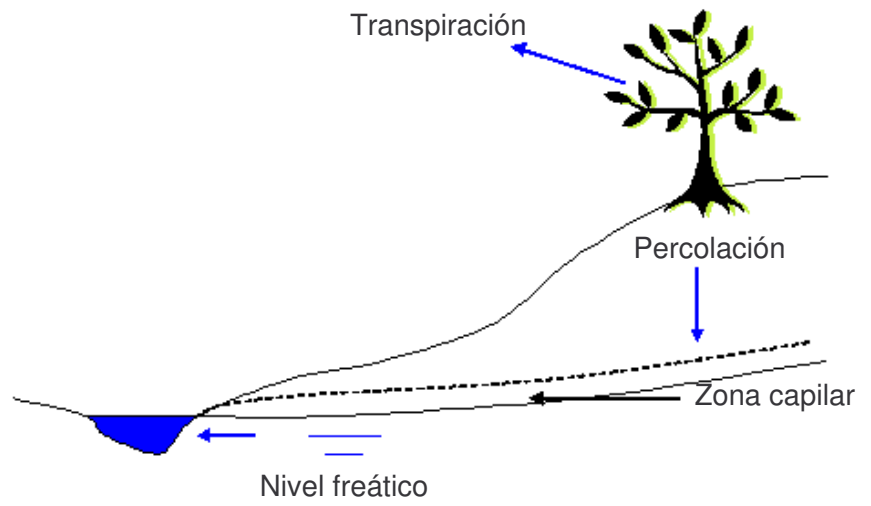

Figura 3.11. Representación de los procesos hidrológicos en ladera en períodos de recesión, adaptado de Beven (2001b)

El almacenamiento de agua se concentra en el fondo del valle, en las inmediaciones de los cauces, esto es, en zonas riparias debido esencialmente a la convergencia 
del flujo en depresiones naturales del terreno. Además, el almacenamiento de agua en zonas riparias puede darse por el flujo de retorno en capas profundas (Huff et al., 1982; Genereux et al., 1993) ${ }^{10}$ y también porque los suelos tienden a ser más profundos en los fondos del valle y las depresiones del terreno (Piñol et al, 1997) ${ }^{11}$, esto debido a la acumulación coluvial de sedimentos que se da en dichas zonas.

La evapotranspiración depende del régimen climático, el tipo de vegetación y la profundidad de raíces. Además la percolación tiene dependencia de la vegetación, puesto que las plantas pueden llegar a tomar agua en niveles profundos del suelo (decenas de metros) y las raíces actúan como una ruta del agua infiltrada. Estos procesos son importantes para determinar las condiciones de humedad precedente en un evento de lluvia.

Estas condiciones de humedad precedente, junto con el volumen e intensidad de la lluvia, son cruciales para definir cuales procesos son relevantes durante el evento de lluvia en la respuesta hidrológica de una cuenca. La figura 3.12 representa los procesos que se dan en un evento de lluvia.

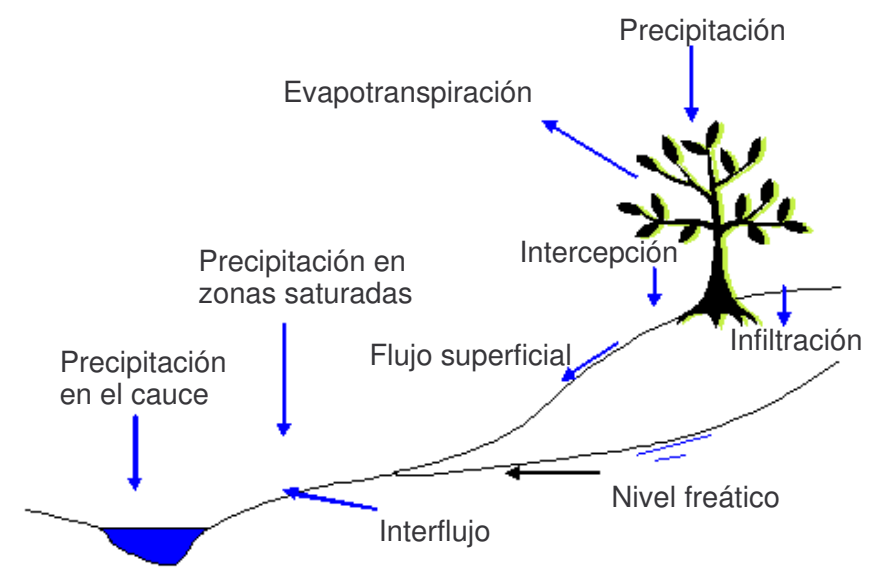

Figura 3.12. Representación de los procesos hidrológicos en ladera en períodos de lluvia, adaptado de Beven (2001b)

En eventos de lluvia, en la zonas riparias rápidamente el suelo se satura y dichas zonas contribuyen directamente a la escorrentía. Aunque estas áreas son relativamente pequeñas, cubriendo entre 1 y $3 \%$ del área total de la cuenca, cumplen una función importante en la respuesta hidrológica de la cuenca. Además la red de drenaje de cauces se expande a medida que la tormenta progresa, efecto que se amplifica en períodos lluviosos.

La precipitación puede ser debida a la lluvia y al deshielo o la fusión de nieve. La precipitación presenta una alta variabilidad espacial y temporal, tanto en

\footnotetext{
${ }^{10}$ Tomados de Beven (2001b)

${ }^{11}$ Tomado de Beven (2001b)
} 
volumen como en intensidad, y aún no existen técnicas lo suficientemente precisas para captar adecuadamente dicha variabilidad. Parte de esta lluvia cae directamente sobre la superficie del terreno y parte es interceptada por la cobertura de vegetación. La lluvia interceptada retorna a la atmósfera por evapotranspiración, la cual generalmente ocurre posteriormente al evento de lluvia. Durante el evento, ocurre evapotranspiración cuando el aire no está saturado, restringiendo la evapotranspiración en eventos de lluvia a situaciones específicas y poco frecuentes (ambientes áridos y sólo al comienzo de la lluvia). La fusión de nieve depende de la cota y el aspecto de la pendiente y también presenta alta variabilidad.

Una vez la lluvia que no es interceptada llega a la superficie se retiene en pequeñas depresiones del terreno, proceso conocido como almacenamiento en depresiones y/o comienza a infiltrarse al nivel superior del suelo, excepto en zonas impermeables (roca desnuda impermeable, suelos congelados, y superficies artificiales impermeables) en donde la escorrentía directa comienza casi inmediatamente. La tasa de infiltración está limitada por las condiciones locales de precipitación, la intercepción y la capacidad de infiltración del suelo. Si la precipitación efectiva excede la capacidad de infiltración se genera escorrentía directa por exceso de infiltración, o escorrentía hortoniana. Esta escorrentía se restringe a zonas áridas y con escasa cobertura de vegetación, al menos que el suelo se encuentre completamente saturado. Además, donde se excede la capacidad de infiltración, la escorrentía comienza en áreas con suelos poco permeables o con altos contenidos de humedad, puesto que la capacidad de infiltración tiende a decrecer al aumentar la humedad, la cual se expande gradualmente a áreas con mayor permeabilidad.

En suelos desnudos es frecuente que la lluvia produzca una costra impermeable debido a que el impacto de las gotas de lluvia reorganiza las partículas del suelo en la superficie. La presencia de esta costra produce, en estas condiciones, escorrentía directa. Cuando se encuentra una cobertura de vegetación la estructura del suelo y particularmente la macroporosidad controlan las tasas de infiltración. La macroporosidad se debe a las raíces de la vegetación, a poros producidos por animales que viven en la capa más superficial del suelo, a fracturas, y a la propia estructura del suelo. Esta macroporosidad se limita a los niveles más superficiales del suelo y tiene crucial importancia en la escorrentía por exceso de saturación, o escorrentía de Dunne, a la escorrentía de retorno del flujo subsuperficial, o interflujo y a la escorrentía subsuperficial de tormenta.

La escorrentía por exceso de saturación ocurre en áreas donde el suelo presenta un deficit de humedad pequeño. Generalmente estas áreas se ubican en los fondos de los valles y en las vaguadas y donde los suelos son delgados o poco permeables. El área saturada se expande a medida que la tormenta progresa y se reduce en el período de recesión. Este fenómeno define el concepto de área contribuyente dinámica (Beven, 2001b). El área saturada no sólo se explica por la lluvia local, también se debe a procesos de flujo superficial y subsuperficial aguas arriba, de tal forma que la expansión y reducción de estas áreas no sólo dependen de la lluvia sino de los mecanismos de flujo en las zonas contribuyentes aguas arriba. 
En las figuras 3.13 - 3.15 se representan los mecanismos que generan diversos procesos de escorrentía. La figura 3.13 corresponde a la escorrentía por exceso de infiltración, la parte a) de la figura representa la escorrentía hortoniana (Horton, 1933), mientras que la parte b) es un esquema de la escorrentía por exceso de infiltración en áreas parciales (Betson, 1964); la figura 3.14 muestra la escorrentía por exceso de saturación (Dunne y Black, 1970); la parte a) de la figura 3.15 representa la escorrentía subsuperficial de tormenta (Hewlett, 1961) ${ }^{12}$, y la parte b) de la figura 3.15 es un esquema de la escorrentía subsuperficial de tormenta debido a la saturación por cuñas de interflujo (Weyman, 1970). En las figuras $P$ representa la precipitación, $I$ la infiltración, $Q p$ la escorrentía superficial en ladera, $Q r$ la escorrentía superficial de retorno o interflujo, y $Q s$ la escorrentía debida al flujo base.

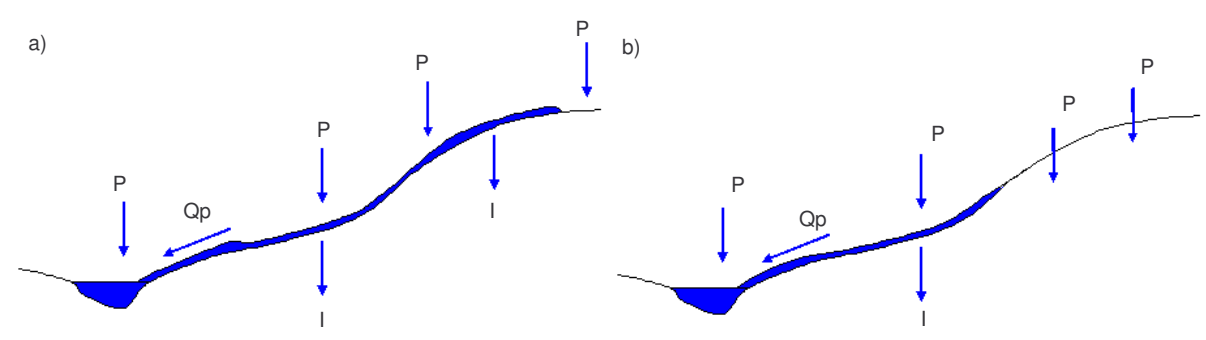

Figura 3.13. Mecanismos de generación de escorrentía por exceso de infiltración, adaptado de Beven (2001b)

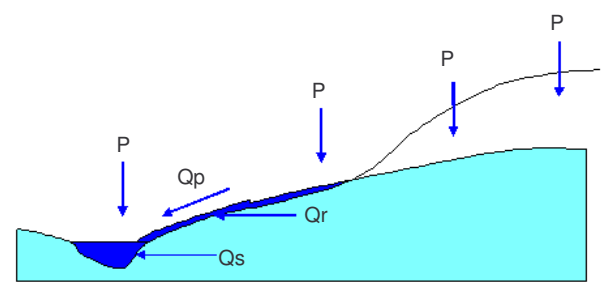

Figura 3.14. Mecanismo de generación de escorrentía por exceso de saturación, adaptado de Beven (2001b)

Un mecanismo de producción de la escorrentía subsuperficial de tormenta se debe a la permeabilidad de los niveles inferiores del suelo o al sustrato rocoso. Aunque es normal que se considere al sustrato rocoso como impermeable, es común que las rocas presenten una permeabilidad secundaria debido al diaclazamiento y fracturación. Por dichas diaclasas y fracturas se da un flujo lento del agua que en muchas situaciones mantienen el nivel base de las corrientes durante períodos

\footnotetext{
${ }^{12}$ Tomado de Beven (2001b)
} 


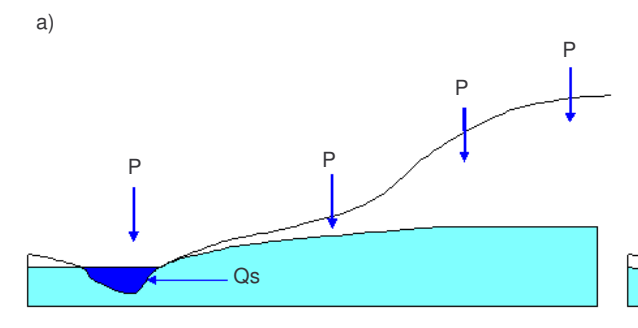

b)

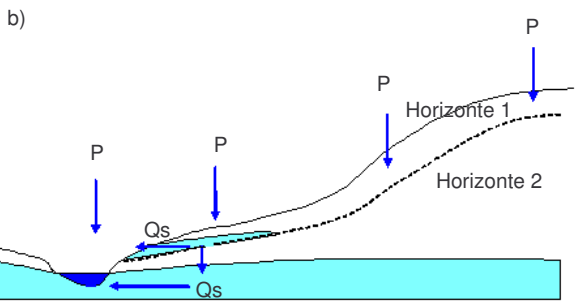

Figura 3.15. Mecanismos de generación de escorrentía subsuperficial de tormenta, adaptado de Beven (2001b)

de tiempo prolongados. Durante una tormenta, puede darse el caso que el agua infiltrada y percolada aumente significativamente la presión de los sistemas de diaclasas y fracturas, aumentando la velocidad de agua en la roca y presentándose una movilización rápida de las aguas retenidas en estas fracturas. Si hay una conexión efectiva entre los sistemas de fracturas y los cauces, se presenta escorrentía superficial de tormenta.

Un ejemplo de un análisis de los mecanismos de generación de escorrentía en los Pirineos de España se encuentra en García-Ruiz et al. (2005).

$\mathrm{Al}$ analizar los diferentes procesos hidrológicos que ocurren en una cuenca hidrográfica y relacionarlos con la dinámica sedimentológica se concluye que los procesos relevantes y que deben ser mejor entendidos son los flujos de agua que se dan en un evento de lluvia una vez el agua llega al suelo. Estos flujos se presentan principalmente en la superficie del terreno y en niveles superiores del suelo y dan cuenta de la respuesta hidrológica de la cuenca ante una lluvia.

Aunque procesos tales como la evapotranspiración, la percolación, son determinantes para una correcta cuantificación de las condiciones de humedad precedente, pierden relevancia en eventos de lluvia intensos. Es importante anotar que es en estos eventos en donde se presenta la movilización de sedimentos (producción, transporte y sedimentación) y acercarse a un buen entendimiento de los flujos de agua asegura una correcta modelación de la dinámica sedimentólógica.

A continuación se detalla la forma de abordar los procesos hidrológicos relevantes en la dinámica sedimentológica de una cuenca hidrográfica, esto es, los flujos subsuperficiales y los flujos superficiales.

\subsubsection{Los flujos subsuperficiales}

La base para la descripción de los flujos de agua que se dan al interior del suelo es la Ley de Darcy, que supone una relación lineal entre la velocidad de flujo y un coeficiente de proporcionalidad denominado coeficiente de permeabilidad. Esta ecuación se aplica en suelos saturados. 
Richards (1931) ${ }^{13}$ generaliza esta relación para flujo en suelos no saturados, al suponer que sigue existiendo una relación lineal pero el coeficiente de permeabilidad es función del contenido de humedad.

La Ley de Darcy es válida para el flujo en una matriz homogénea del suelo, pero el flujo al interior del suelo está altamente influenciado por los macroporos, por lo cual la Ley de Darcy se restringe a un intervalo muy limitado de escalas. Cuando se utiliza en modelos hidrológicos distribuidos, el coeficiente de permeabilidad necesita tomar un valor promedio o un valor efectivo en la escala de modelación, que tenga en cuenta la porosidad en la matriz del suelo y los efectos de los macroporos, de esta forma, no es posible utilizar valores del coeficiente de permeabilidad medidos en campo en modelos hidrológicos distribuidos (Beven, 2001b).

Otra ecuación importante para describir el flujo del agua en el suelo se conoce como la Ecuación de Richards y resulta de combinar la Ley de Darcy con la ecuación de continuidad (o balance de masa).

Puesto que la Ecuación de Richards es una ecuación en diferencias parciales y el coeficiente de permeabilidad cambia no linealmente con respecto al contenido de humedad, esta ecuación es una ecuación diferencial parcial no lineal, que en pocos casos se puede resolver analíticamente. Por tal motivo, es necesario hacer algunas suposiciones (Beven, 2001b):

a) Tanto para el flujo en suelo saturado como en suelo no saturado, la velocidad de flujo es función lineal del potencial hidráulico, de acuerdo con la ley de Darcy.

b) Las relaciones funcionales pueden especificarse por medio de curvas características de humedad del suelo, potencial hidráulico y coeficiente de permeabilidad.

c) No se tiene en cuenta los flujos de agua en forma de vapor de agua.

d) El tensor del coeficiente de permeabilidad es isotrópico.

e) El medio poroso es incompresible.

f) La temperatura y la densidad del agua son constantes.

La mayoría de modelos hidrológicos y sedimentológicos distribuidos utilizan simplificaciones para estimar las tasas de infiltración en los niveles superiores del suelo, las cuales tienen solución analítica explícita en elementos discretos del espacio y en intervalos acotados de tiempo.

Entre las más utilizadas se encuentran la ecuación de infiltración de Horton (Horton, 1933, 1940), la ecuación de infiltración de Green-Ampt (Green y Ampt, 1911), la ecuación de infiltración de Philip (Philip, 1957), la ecuación de infiltración de Smith-Parlange (Smith y Parlange, 1978) y la ecuación de infiltración basada en la capacidad de almacenamiento del suelo propuesta por Kirkby (1975).

\footnotetext{
${ }^{13}$ Tomado de Beven (2001b)
} 
Al utilizar un valor efectivo del coeficiente de permeabilidad en modelos distribuidos, no se tiene en cuenta que las velocidad de flujo y los tiempos de residencia del agua en la matriz del suelo y los macroporos difieren en varios órdenes de magnitud.

Por ejemplo, en el flujo subsuperficial de tormenta se observan valores muy altos del coeficiente de permeabilidad del suelo, debido esencialmente a que este proceso ocurre en los macroporos, donde el flujo de agua no cumple la Ley de Darcy. Cuando se utilizan valores efectivos del coeficiente de permeabilidad, entendidos como un promedio de la microporosidad y la macroporosidad, no se puede describir adecuadamente tanto el flujo de agua en la matriz del suelo (que ocurre esencialmente en períodos de recesión) como el flujo subsuperficial rápido (que ocurre en eventos de lluvia).

Una forma de abordar la doble porosidad del suelo, esto es, la porosidad de la matriz y los macroporos, se basa en considerar que en el suelo ocurren dos procesos de infiltración, condicionados por ambas porosidades.

El modelo HILLFLOW propuesto por Bronstert (1999) se basa en las premisas anteriores y logra considerar adecuadamente la infiltración en el suelo tanto en eventos de lluvia, como en períodos de recesión.

\subsubsection{Los flujos superficiales}

Según Beven (2001b) las bases físicas para modelar los flujos superficiales en laderas y cauces son esencialmente las mismas. En ambos casos se considera una aproximación conveniente modelar el flujo en una dimensión, en la dirección aguas abajo. La variable a solucionar, en el caso unidimensional, será la velocidad promedio a lo largo del perfil transversal (perpendicular al flujo) por donde pasa el flujo. La figura 3.16 representa las variables tanto en flujo en cauce, parte (a) de la figura, como en flujo en ladera, parte (b) de la figura.

Para el flujo en cauce, las variables representadas en la figura 3.16 son, el caudal $Q\left[L^{3} T^{-1}\right]$, el área de la sección transversal $A\left[L^{2}\right]$, el perímetro mojado $P[L]$, la velocidad promedio $v\left[L T^{-1}\right]$, y la profundidad promedio $y[L]$. Para el flujo en ladera, las variables son el caudal específico $q\left[L^{2} T^{-1}\right]$, el ancho de flujo $W[L]$, la velocidad promedio $v\left[L T^{-1}\right]$, y la profundidad promedio $h[L]$. En ambos casos la pendiente $S_{o}$ y la distancia $x$ se miden en la dirección de la pendiente.

La solución de la ecuación de flujo unidimensional fue desarrollada por Barré de St Venant (1797-1886) ${ }^{14}$ aplicando las leyes de conservación de masa y momentum.

Beven (2001b) expone de forma clara y comprensible la derivación de las ecuaciones de St Venant. Para aplicaciones prácticas se exigen algoritmos de solución numérica, puesto que es una ecuación diferencial parcial no lineal. Se han desarrollado soluciones explícitas en diferencias finitas las cuales son muy sensibles a las condiciones de frontera para cada elemento de discretización. Por tal motivo, en su solución se encuentran problemas de difusión numérica que es conveniente

\footnotetext{
${ }^{14}$ Tomado de Beven (2001b)
} 
(a)

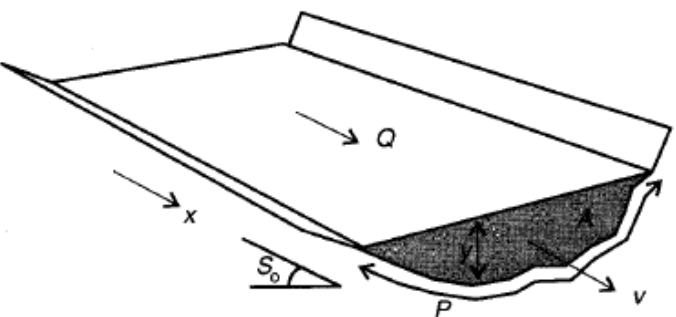

(b)

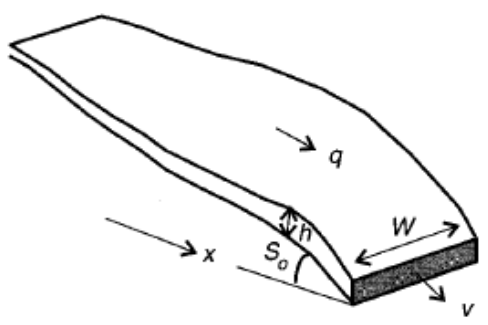

Figura 3.16. Esquemas del flujo superficial, figura tomada de Beven (2001b)

analizar usando diferentes intervalos temporales y diversas discretizaciones para precisar la convergencia y la estabilidad de los algoritmos de solución.

\subsubsection{Formas de simular flujos en modelos hidrológicos y sedi- mentológicos distribuidos}

Debido a las dificultades con respecto a la solución de las ecuaciones de flujo para todos los elementos de discretización, los modelos hidrológicos y sedimentológicos utilizan simplificaciones y suposiciones, tales como desechar algunos términos de la ecuación, reducir hasta donde sea posible los elementos de discretización y no considerar el flujo en tres dimensiones.

De esta forma, los flujos en la zona no saturada del suelo normalmente se tratan verticalmente en una dimensión, en la zona saturada donde los flujos son predominantemente laterales se tratan en dos dimensiones, mientras que los flujos superficiales se simulan unidimensionalmente en la dirección de la pendiente aguas abajo.

Con la mejora constante en la potencia de los ordenadores y los algoritmos de cálculo, es posible aumentar los elementos de discretización y los intervalos temporales de simulación. La limitación es entonces la definición de parámetros para cada elemento de discretización y las condiciones de frontera.

En cuanto a la forma de discretizar los elementos de una cuenca hidrográfica se encuentran dos acercamientos. Los basados en elementos cuadrados regulares (DEM), tales como los utilizados por los modelos SHETRAN, CASC2D-SED, LISEM Y HILLFLOW, entre otros. Por otro lado se encuentran modelos que hacen una subdivisión en planos de ladera, entre estos se encuentran el KINEROS y el 
TAPES, entre otros. Independiente de la forma de discretizar los elementos, la mayoría de modelos utilizan la simplificación de la onda cinemática unidimensional.

La onda cinemática se basa en desechar los términos de presión e inercia al suponer que la superficie de agua es siempre paralela a la superficie del cauce o ladera.

Los problemas de estimación de parámetros y la incertidumbre en el conocimiento de la geometría y los valores de entrada de agua en el dominio de aplicación pueden ser poco importantes en aplicaciones reales, y la aproximación de la solución de flujo de la onda cinemática puede ser un modelo predictivo útil (Beven, 2001b).

La onda cinemática se utiliza por igual para simular flujo superficial en ladera como para flujos en cauces. Se supone un flujo unidimensional en la dirección de la pendiente aguas abajo y se necesita una función para la relación entre el almacenamiento y el caudal en cada elemento de discretización. Comúnmente se usa una relación de flujo uniforme tal como la ecuación de Manning.

\subsubsection{Los procesos sedimentológicos}

Como ya se ha mencionado, los procesos sedimentológicos se diferencian en la erosión o el arranque de partículas y agregados del suelo, el transporte de estas partículas y su sedimentación. En una cuenca hidrográfica estos procesos ocurren en todas las áreas fuentes. De esta forma en una cuenca en particular y en un evento de lluvia, tanto en las áreas entre surcos, en los surcos, en las cárcavas y en los cauces ocurren los tres tipos de procesos. Una vez una partícula o agregado se erosiona y es arrastrada por un flujo de agua, este flujo la transportará hasta cierta zona en donde la energía del flujo no es suficiente para seguirla transportando y se deposita.

La mayor parte de los flujos de agua que se presentan en la superficie del terreno normalmente aparecen concentrados, ya sea en pequeños surcos, en cárcavas o en canales. Sólo en ambientes áridos con poca vegetación, en suelos poco permeables o saturados y en lluvias muy intensas se observa el flujo laminar en ladera.

En ambientes húmedos y semiáridos con cubierta de vegetación la microtopografía, las raíces superficiales y la rugosidad del suelo controlan la formación de pequeños surcos que si se encuentran conectados a los macroporos del nivel más superficial del suelo generan condiciones para que se concentre el agua en flujos en donde se puede iniciar la erosión.

De este modo, es fundamental un conocimiento de las condiciones físicas para que se de el inicio de la erosión y la finalización del mismo. Pero estas condiciones varían de acuerdo con las condiciones hidrológicas imperantes, a los mecanismos de producción de escorrentía y a las áreas fuente. Tal como se ha reseñado con anterioridad, es posible inferir estas condiciones a partir de datos derivados de la topografía y a las características del flujo (sección 3.1.3.6).

Además, tanto el inicio de la erosión concentrada como la coluviación masiva 
(en ladera) o la sedimentación aluvial (en cauces y llanuras de inundación) está estrechamente ligada a las características de la red de drenaje y a su conexión.

Estos aspectos no pueden ser tratados siguiendo métodos empíricos derivados de la USLE. Una solución para considerar el depósito de sedimentos dentro de una zona de agregación de una cuenca hidrográfica cuando se aplica la USLE o sus derivados es añadir factores de entrega de sedimentos para cada zona (SDR) ${ }^{15}$. La aproximación se basa en ajustar datos medidos de transporte de sedimentos con los simulados por la ecuación (la USLE y la RUSLE para condiciones anuales y la MUSLE para eventos).

La mayor dificultad siguiendo esta aproximación, es que el SDR depende del área de agregación y no se puede extrapolar en áreas mayores a las medidas, ni incluso en zonas de igual área pero con condiciones diferentes. De esta forma, este factor termina siendo otro "factor de seguridad", utilizado para condiciones específicas y sin posibilidades de validación. Aunque se encuentran numerosos estudios y modelos que utilizan la USLE y sus derivados, con buen desempeño, una de las limitaciones reconocidas por sus autores es que los factores encontrados solamente se pueden aplicar para las condiciones específicas. Esto es debido al poco sentido físico que tiene este acercamiento.

Otro acercamiento se basa en reconocer que los procesos de erosión, transporte y sedimentación que se presentan en flujos de agua, dependen tanto de la cantidad de material disponible como de la capacidad que tiene el flujo para arrancar y transportar esta cantidad de material. El primero que planteó dicha idea fue Einstein (1964) ${ }^{16}$. De esta forma la cantidad de material que puede transportar una corriente de agua depende de dos grupos de variables Julien (1998):

- Aquellas que gobiernan la capacidad de transporte de sedimentos de una corriente, tales como la geometría del cauce, la pendiente, la rugosidad, la distribución de las velocidades, las fuerzas de fricción, la turbulencia y el caudal, entre otras.

- Aquellas que reflejan la cantidad y las propiedades de los materiales disponibles para el transporte, tales como la magnitud, intensidad y duración de la lluvia, la vegetación, la granulometría del suelo, la cohesión de los agregados, los movimientos en masa, entre otras.

Julien (1998) presenta una gráfica que resume estos conceptos (Figura 3.17).

Es difícil efectuar un análisis cuantitativo para determinar la cantidad de sedimentos disponibles en una corriente de agua debido a la complejidad de procesos físicos actuantes en toda el área de captación y a la variabilidad espacial y temporal de todos los parámetros involucrados en la erosión superficial, los desprendimientos de banca y movimientos en masa que se dan en un evento de lluvia particular. Sin

\footnotetext{
${ }^{15}$ En Inglés, Sediment Delivery Ratio

${ }^{16}$ Citado por Julien (1998)
} 


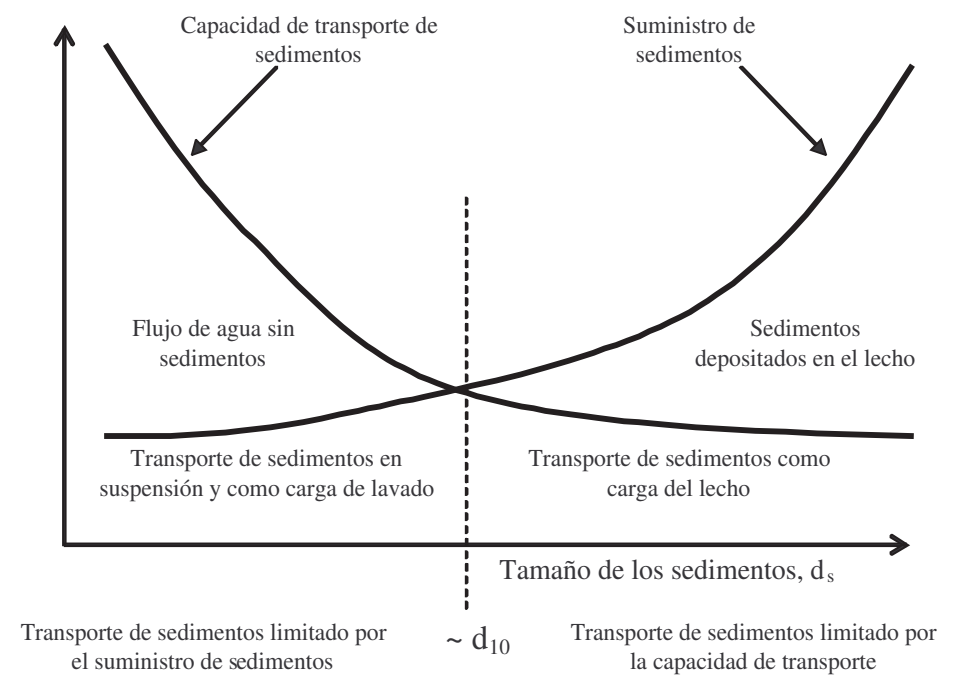

Figura 3.17. Capacidad de transporte vs suministro de sedimentos, adaptado de Julien (1998)

embargo, la capacidad de transporte de sedimentos en un cauce puede tratarse de una forma analítica.

Esta aproximación es posible adaptarla de forma simple en modelos distribuidos. Se necesita encontrar una relación para cada elemento de discretización (celda) que calcule la capacidad de transporte de sedimentos y otra para calcular el suministro de sedimentos. Por último es necesaria una relación para calcular la cantidad de sedimentos que se depositan. Estos cálculos, además de efectuarlos para cada elemento espacial es necesario efectuarlos para cada intervalo temporal de simulación.

Si se define adecuadamente la forma del canal que concentra el agua, ya sean surcos, cárcavas o cauces y se define el inicio y finalización de dichos elementos, es posible aplicar estos conceptos en un modelo distribuido de erosión, transporte y depósito de sedimentos a escala de cuenca. A continuación se detallan los diferentes procesos sedimentológicos que se presentan para cada área fuente, tal como se definieron en la sección anterior.

\subsubsection{Procesos sedimentológicos en ladera}

En las zonas de la ladera donde no se concentra el flujo los procesos de erosión se deben al impacto de las gotas de lluvia y a la escorrentía superficial laminar. El impacto de las gotas de lluvia en el suelo es una combinación de procesos de arranque de partículas de suelo y mecanismos de transporte. Terry (1998) a partir de técnicas fotográficas y de video en laboratorio, identifica cinco mecanismos:

- Desmonoramiento de agregados. 
- Formación de pequeños cráteres.

- Salpicamiento.

- Saltación por salpicamiento.

- Arrastre por salpicamiento.

A pesar de la gran cantidad de estudios referenciados en la literatura con relación al impacto de las gotas de lluvia en el suelo, la mayor parte de ellos efectuados en laboratorio y considerando el efecto de una gota de lluvia en particular, no se tiene en cuenta la poca importancia que tiene este fenómeno en los procesos de erosión a escala mayor, incluso a escala de parcela experimental y canaletas de laboratorio. Julien y Simons (1985) señalan que cuando se da flujo laminar en laderas, las perturbaciones inducidas por el impacto de las gotas de lluvia y la rugosidad de la superficie son altamente atenuadas debido a la gran magnitud de las fuerzas viscosas y a los bajos números de Reynolds que se presentan en el flujo laminar. Este hecho ha sido comprobado empíricamente en análisis efectuados en parcelas de laboratorio expuestas a lluvias simuladas (Abrahams et al., 2001; Raff et al., 2004; Liu et al., 2006). Además, en estas parcelas experimentales la escorrentía laminar se concentra en distancias cortas, del orden de centímetros, en pequeños surcos, por lo que en los modelos propuestos por varios autores se ignora el efecto del impacto de las gotas de lluvia en la erosión en ladera.

La USLE y sus modelos derivados utilizan un índice para caracterizar la lluvia, el cual tiene en consideración el efecto del impacto de las gotas de lluvia en el suelo. Este factor denominado Índice de Erosión de la Precipitación ${ }^{17}$ estima la energía cinética de una tormenta como función de la cantidad de lluvia y su intensidad. Puesto que la USLE no tiene en cuenta el caudal producido por la lluvia, se hace necesario la inclusión de un término que de cuenta de la energía de la tormenta, ignorando el hecho de que son los flujos de agua que se dan en la superficie, especialmente los que se presentan canalizados, los que permiten la movilización de sedimentos.

Por otro lado, la erosión por escorrentía laminar es poco frecuente en la naturaleza. Al respecto, Boardman (2006) señala la gran importancia que se da a la erosión por escorrentía laminar, aunque no existen evidencias empíricas considerables, sobre todo en regiones templadas y húmedas, que demuestren que la erosión por escorrentía laminar es importante. El autor menciona que en la mayor parte de los casos, los procesos dominantes de erosión se dan en surcos y/o cárcavas efímeras.

La erosión por escorrentía laminar remueve el suelo uniformemente en una capa delgada y es practicamente imperceptible, sin embargo se han medido tasas de 20 tons/acre/año (Meyer, 1981). Esta magnitud en la erosión se considera mayor que la que el suelo puede tolerar sin degradarse (Schertz, 1983).

\footnotetext{
${ }^{17}$ En Inglés, Rainfall Erosion Index
} 
Los modelos que consideran la erosión en zonas entre surcos de forma explícita y con base física poseen un módulo anterior de transformación lluvia-caudal, que calcula el caudal unitario (o caudal específico) $q\left[L^{2} T^{-1}\right]$, el ancho del flujo $W[L]$, la velocidad promedio del flujo $v\left[L T^{-1}\right]$, y la profundidad promedio del flujo $h[L]$ . Puesto que la erosión en zonas entre surcos se debe a la escorrentía superficial, estos modelos no tienen en cuenta los flujos laterales al interior del suelo (flujo subsuperficial, flujo base), de esta forma solo contienen un modelo de infiltración y la escorrentía se genera por exceso de infiltración. Además, la escorrentía en zonas entre surcos no se presenta canalizada (escorrentía laminar), por lo que en algunos modelos la tratan en dos dimensiones (Tayfur, 2007). Los modelos que simulan de forma explícita y con base física la erosión en zonas entre surcos, lo hacen de igual forma para los surcos. Estos modelos están diseñados para escala de parcela o de ladera (Rillgrow, MMF, CREAMS, WEEP).

Esta aproximación posee dos supuestos que no corresponden con la forma en que se presenta el flujo en ladera:

- La escorrentía en ladera no presenta un ancho de flujo característico, puesto que se concentra en microcanales o en flujos superficiales dispersos, de acuerdo con la pendiente, la rugosidad y el caudal.

- La profundidad del flujo presenta una alta variabilidad.

En la sección 3.2.2.3 se detallan algunas de las aproximaciones utilizadas para resolver analíticamente la erosión en zonas entre surcos.

De acuerdo con la teoría de erosión entre surcos y en surcos (Foster y Meyer, 1972), el flujo se concentra rápidamente y en distancias cortas en cauces muy pequeños que se distribuyen uniformemente en la ladera y hace parte del flujo superficial. La erosión por la caída de gotas de lluvia en las áreas entre surcos, separa las partículas de suelo debido al impacto y mueven los sedimentos lateralmente a los surcos en donde ocurre el transporte de sedimentos en la ladera.

Siguiendo esta idea se puede considerar que para que exista erosión es necesaria la presencia de surcos encargados del transporte de las partículas y agregados del suelo que se desprenden por el impacto de las gotas de lluvia, de otra forma, dichas partículas y agregados sólo se moverían unos pocos centímetros en la ladera. De esta forma se puede considerar el impacto de las gotas de lluvia como un proceso de preparación del suelo para la erosión, pero es sólo en los surcos donde efectivamente se presenta la erosión y es la capacidad de transporte del flujo de agua que se concentra en dichos surcos la que explica la erosión en ladera.

\subsubsection{Procesos sedimentológicos en surcos}

La erosión en surcos se define como la erosión en pequeños y numerosos cauces que pueden ser borrados por actividades normales de labranza (Hutchinson y Pritchard, 1976). Aunque la erosión laminar es imperceptible, la erosión en surcos 
(sección transversal mínima aproximada de $0,10 \mathrm{~m}^{2}$ ) se percibe con facilidad. Los surcos pueden seguir marcas de labranza o pueden desarrollarse como una red de drenaje. La erosión en surcos grave excede tasas de 200 tons/acre/año (Schertz, 1983).

Un punto común en muchos autores es que el inicio de la erosión concentrada se da en el momento en que se presenta una mezcla entre flujos laminares y turbulentos en la ladera, cuando el esfuerzo tangencial que generan estos flujos no sólo superan las fuerzas cohesivas de las partículas finas del suelo sino que son capaces de arrancar y arrastrar las partículas gruesas que componen el suelo, formando un surco. Horton (1945) relacionó la formación de estos surcos con una longitud de flujo umbral que se da en una zona concreta de la ladera en donde la acumulación del flujo aguas arriba de dicha zona produce las condiciones hidráulicas necesarias para la iniciación de la incisión. Schumm (1956) redondea y expande el concepto de umbral, asociándolo a una cuenca de drenaje umbral.

Un aspecto importante en el desarrollo de surcos es su permanencia temporal. Horton no diferencia entre surcos permanentes y surcos efímeros, aun cuando este hecho es fundamental en el potencial que tienen los procesos de iniciación de la incisión con los modelos de formación de paisajes; Schumm por el contrario, distingue pequeños surcos en la parte alta de la ladera, los cuales se desarrollan durante los períodos de lluvia y se eliminan en invierno por la acción del hielo, de surcos permanentes en la parte baja de la ladera, los cuales permanecen durante el invierno (Bryan, 1987). Schumm y Lusby (1963) describen un ciclo estacional similar de formación - eliminación de surcos en un estudio realizado en arcillas; mientras que Bryan y Price (1980) ${ }^{18}$ describen la eliminación estacional de surcos al sur del Canadá, ahora por la acción de pequeños movimientos en masa superficiales.

Los surcos permanentes, que persisten en el mismo lugar por largos períodos de tiempo, generalmente se desarrollan y amplifican ladera abajo y pueden formar el estado inicial de un sistema de drenaje mayor, mientras que la influencia potencial en la formación de drenajes de los surcos efímeros no es tan clara. Schumm (1956) al respecto, informa la existencia de algunos surcos que se amplían y profundizan ladera abajo hasta converger en surcos permanentes; mientras que otros se hacen delgados y estrechos a medida que se desciende en la ladera, desapareciendo y pasando a ser pequeños surcos trenzados y superficiales.

Favis-Mortlock (1998) demuestra que algunos surcos son más efectivos que otros, en el sentido de que tales surcos crecen en tamaño y caudal durante un evento de lluvia, este autor denomina estos surcos como competentes o preferentes. Así de una población inicial de pequeños surcos sólo una parte se puede desarrollar en surcos más grandes y eventualmente formar parte de una red de drenaje interconectada. Así, es posible diferenciar entre surcos preferentes, aquellos que se hacen mayores a medida que transportan más escorrentía y sedimentos y surcos no preferentes que se hacen menos importantes a medida que transportan sedimentos y que pueden ser "capturados" por surcos preferentes o simplemente comenzar a

\footnotetext{
${ }^{18}$ Citado por Bryan (1987)
} 
ser inactivos.

La probabilidad de encontrar surcos preferentes se incrementa a medida que el área de captación aumenta. Así en la parte alta de la ladera se encuentran surcos pequeños y cortos; en la parte media es común la presencia de surcos discontinuos y bien definidos; mientras que en la parte baja de la ladera los surcos son continuos y bien desarrollados.

Favis-Mortlock (1998) sugiere que la microtopografía posee un papel fundamental en el desarrollo de surcos. Este autor recalca que la microtopografía no es estática en el tiempo puesto que los procesos de erosión modifican la superficie del suelo. Por ejemplo, la escorrentía producida durante la última parte del evento fluirá sobre una superficie de suelo que difiere de la que se encontraba al inicio de la tormenta. En este sentido la erosión crea su propia superficie.

Esta modificación en la microtopografía producida por la erosión constituye una retroalimentación positiva, así los surcos preferentes tendrán un efecto modificador de la microtopografía mayor que los surcos no preferentes, por lo tanto serán más efectivos para capturar y transportar la escorrentía directa y los sedimentos asociados. La existencia de una retroalimentación positiva es un requisito para la existencia de un sistema dinámico auto-organizado.

Se han desarrollado numerosas investigaciones en relación a los conceptos de auto-organización en sistemas naturales, específicamente en la evolución del paisaje. Está ampliamente reconocido el hecho que los procesos de erosión en ladera son una manifestación de un sistema auto-organizado, cubriendo un amplio intervalo de escalas (Tabla 3.1).

\begin{tabular}{|c|c|}
\hline Componente & Escala \\
\hline Impacto de gota de lluvia & Milímetros \\
\hline Microtopografía & Milímetros - centímetros \\
\hline Microsurcos & Milímetros - centímetros \\
\hline Surcos & Centímetros - decenas de metros \\
\hline Sistema de surcos en ladera & Decenas a cientos de metros \\
\hline
\end{tabular}

Tabla 3.1. Intervalos de escalas espaciales de surcos en ladera, tomado de Favis-Mortlock (1998)

Siguiendo la perspectiva de sistemas de auto-organización en la formación de surcos en ladera se puede concluir (Favis-Mortlock, 1998) :

a) La producción de sedimentos se incrementa con un aumento en la pendiente.

b) La importancia relativa de los procesos se erosión en surcos y entre surcos varía con respecto a la posición en la ladera y con el tiempo.

c) En general, los surcos en ladera se presentan uniformemente espaciados en 
suelos desnudos. En campos agrícolas el espaciamiento entre surcos está controlado por la labranza.

d) El espaciamiento entre surcos decrece a medida que la pendiente aumenta, esto es, aumenta la densidad de drenaje.

e) En pendientes fuertes los surcos muestran un incremento en su longitud y se presentan paralelos.

f) Existe un zona en la parte alta de la ladera en la cual no se presenta disección por surcos.

La importancia de estos planteamientos es que están estrechamente relacionados con la posición topográfica relativa, cimiento de los modelos de erosión con base distribuida y con la permanencia en el tiempo de ciertas condiciones, por lo cual el modelo debe tener una agregación temporal adecuada.

Se ha demostrado tanto teóricamente (Favis-Mortlock, 1998) como en estudios experimentales en parcelas de laboratorio (Raff et al., 2004) que los surcos forman estructuras topológicas definidas, similares a la red de cauces en una cuenca hidrográfica. En el diseño de algunos experimentos en parcelas de laboratorio, antes de someter al suelo a un evento de lluvia (con simuladores de lluvia), la superficie se suaviza y se compacta para evitar la presencia de rutas preferentes para el flujo. Aún sin la presencia inicial de estas rutas preferentes, se observa que se forman redes de surcos con características geomorfológicas similares a las redes de drenaje de una cuenca hidrográfica, con dimensiones fractales y escalares similares, por lo que es posible aplicar relaciones basadas en la geometría hidráulica en una red de surcos en ladera (Raff et al., 2004).

\subsubsection{Formas de simular la erosión en laderas}

La mayoría de modelos de erosión, tanto los basados en la USLE como los basados en procesos, consideran la erosión entre surcos y la erosión en surcos de forma conjunta, englobando estos dos procesos como la erosión en ladera. Puesto que los surcos son retirados anualmente por labores de labranza, la erosión en surcos y entre surcos remueve el suelo uniformemente en un sentido local, por lo cual se justifica tratarlos de forma conjunta, sin embargo la erosión presenta una enorme variación espacial sobre el paisaje (Foster, 1986).

La USLE se derivó empíricamente de datos de parcelas con una longitud de ladera de 11, 22 y 44 metros (36, 73 y 145 pies), excepto en dos parcelas con longitud de ladera de 82 y 192 metros (270 y 630 pies). En todos los casos, los cauces erosionados eran surcos. De acuerdo con la definición de la longitud de la ladera según la USLE, el flujo en cauces definidos marca el final de la longitud de la ladera (Wischmeier y Smith, 1978), los cauces definidos incluyen las cárcavas aun si no ocurre flujo y erosión en ellas. 
Una de las dificultades que se encuentran en la implementación de los procesos de erosión en ladera cuando se considera la erosión entre surcos y la erosión en surcos de forma conjunta, es la determinación de la longitud del ancho de los elementos de ladera en donde se aplican las relaciones que determinan la erosión en ladera. Si se considera que efectivamente la erosión se presenta en surcos, esta longitud dependerá de la densidad de surcos y el área entre surcos que define dicho ancho. Estos valores serán parámetros del modelo y necesariamente se tendrán que definir a priori.

Los modelos que tratan de forma explícita y física los surcos y las zonas entre surcos se basan en la ecuación de continuidad de sedimentos, que puede escribirse de la siguiente forma:

$$
\frac{\partial h C_{w}}{\partial t}+\frac{\partial q C_{w}}{\partial x}=D_{r}+D_{i}
$$

donde $h$ es la profundidad del flujo $[L], C_{w}$ es la concentración de sedimentos $\left[M L^{-3}\right], q$ es el caudal unitario $\left[L^{2} T^{-1}\right], t$ es el tiempo $[T], x$ es la longitud de la ladera $[L], D_{r}$ es la tasa de erosión en surcos $\left[M L^{-2} T^{-1}\right]$, y $D_{i}$ es la tasa de erosión en las zonas entre surcos $\left[M L^{-2} T^{-1}\right]$.

La tasa de erosión en las zonas entre surcos representa los procesos de arranque y entrega de sedimentos a los surcos. La tasa de erosión en surcos toma valores negativos cuando hay sedimentación y positivos cuando hay erosión en el surco.

Las diferencias entre los distintos modelos se encuentran en la forma de conceptualizar las zonas entre surcos y los surcos, la forma de resolución de las ecuaciones y las relaciones utilizadas para encontrar las tasas de erosión.

3.2.2.3.1. Ecuaciones para tasas de erosión en las áreas entre surcos. Los modelos LISEM, EUROSEM y GLEAMS se basan en el esquema adoptado por el modelo WEEP el cual se basa en el modelo CREAMS. La erosión en zonas entre surcos está conceptualizada como un proceso de entrega de sedimentos a canales en donde se concentra el flujo (surcos), por lo cual los sedimentos generados en las zonas entre surcos se transportan o depositan en la ladera por los surcos. La entrega de sedimentos en las áreas entre surcos se considera proporcional al producto de la intensidad de precipitación y la tasa de escorrentía, con un parámetro de entrada que define la constante de proporcionalidad. Además se incluye un factor para la rugosidad del suelo. La forma general de la ecuación para encontrar la tasa de sedimentos en zonas entre surcos, $D_{i}\left(k g \cdot s^{-1} \cdot m^{-2}\right)$, es:

$$
D_{i}=K_{i a d j} \cdot I_{e} \cdot \sigma_{i r} \cdot S D R_{R R} \cdot F_{n o z z l e} \cdot\left[\frac{R_{s}}{W}\right]
$$

donde $K_{i a d j}$ es un factor de proporcionalidad denominado erosionabilidad del área entre surcos $\left(\mathrm{kg} \cdot \mathrm{s} \cdot \mathrm{m}^{-4}\right) ; I_{e}$ es la intensidad de la lluvia efectiva $\left(\mathrm{m} \cdot \mathrm{s}^{-1}\right) ; \sigma_{i r}$ es la tasa de escorrentía $\left(m \cdot s^{-1}\right) ; S D R_{R R}$ es un factor adimensional de entrega de sedimentos en función de la rugosidad, la velocidad de sedimentación de las clases de tamaño de los sedimentos simulados y la distribución de tamaños de 
los sedimentos; $F_{n o z z l e}$ es un factor de ajuste adimensional que da cuenta del impacto de las gotas provenientes de sistemas de irrigación por aspersores; $R_{s}$ es el espaciamiento entre surcos $(m)$; y $W$ es al ancho de los surcos $(m)$.

En la documentación del WEEP se encuentran tablas y relaciones empíricas para calcular los factores de ajuste de la ecuación 3.25. Cabe anotar que dicha ecuación además de contener tres factores de ajuste, exige del espaciamiento entre surcos y el ancho, los cuales son básicamente aleatorios. De esta forma es poco parsimoniosa y su implementación presenta un alto grado de incertidumbre.

Liu et al. (2006) basados en análisis de regresión de datos tomados en parcelas experimentales, proponen la siguiente ecuación para la tasa de erosión en zonas entre surcos:

$$
\frac{D_{i} d}{R_{c}}=1,8 \cdot 10^{-9}\left(\frac{h}{d}\right)^{1,5}\left(1,05-0,85 e^{-4 \sin S}\right)
$$

donde $R_{c}$ es la capacidad de transporte de sedimentos del flujo superficial en ladera $\left(\mathrm{kg} \cdot \mathrm{s}^{-1} \cdot \mathrm{m}^{-1}\right) ; d$ es el diámetro de las partículas del suelo $(\mathrm{m}) ; h$ es la profundidad del flujo $(m)$; y $S$ es la pendiente (grados).

Para calcular la capacidad de transporte de sedimentos para el flujo superficial en ladera, Liu et al. (2006) utilizan la siguiente ecuación:

$$
R_{c}=\frac{6,42}{(s-1)^{0,5}}\left(Y-Y_{c}\right) d S_{f}^{0,6} v \rho_{s}
$$

donde $Y=\tau /\left[\left(\rho_{s}-\rho\right) g d\right]$ es la tensión de corte adimensional; $Y_{c}=\tau_{c} /\left[\left(\rho_{s}-\rho\right) g d\right]$ es el esfuerzo de corte crítico adimensional; $\tau$ es el esfuerzo de corte del flujo $(P a)$; $\rho$ es la densidad del fluido $\left(\mathrm{kg} \cdot \mathrm{m}^{-3}\right) ; \rho_{s}$ es la densidad de los sedimentos $\left(\mathrm{kg} \cdot \mathrm{m}^{-3}\right)$; $s=\rho_{s} / \rho ; g$ es la aceleración debido a la gravedad $\left(m \cdot s^{-2}\right) ; S_{f}$ es la pendiente de energía; y $v$ es la velocidad media del flujo $\left(m \cdot s^{-1}\right)$.

3.2.2.3.2. Ecuaciones para tasas de erosión en surcos. Para el cálculo de la tasa de erosión en surcos, el modelo WEEP y los que se basan en él (LISEM, EUROSEM), diferencian dos situaciones: a) cuando el esfuerzo de corte del flujo excede el esfuerzo de corte del suelo y cuando el caudal sólido es menor que la capacidad de transporte, en este caso se presenta erosión en los surcos; b) cuando el caudal sólido es mayor que la capacidad de transporte del surco, en este caso se presenta sedimentación.

Para el primer caso la tasa de erosión es positiva y se calcula según la siguiente ecuación:

$$
D_{r}=D_{c}\left(1-\frac{Q_{s}}{T_{c}}\right)
$$

donde $D_{c}$ es la capacidad de erosión del flujo en el surco $\left(\mathrm{kg} \cdot \mathrm{s}^{-1} \cdot \mathrm{m}^{-2}\right) ; Q_{s}$ es el caudal sólido $\left(\mathrm{kg} \cdot \mathrm{s}^{-1} \cdot \mathrm{m}^{-1}\right)$; y $T_{c}$ es la capacidad de transporte de sedimentos en el surco $\left(k g \cdot s^{-1} \cdot m^{-1}\right)$.

La capacidad de erosión del flujo en el surco se expresa como:

$$
D_{c}=K_{r}\left(\tau_{r}-\tau_{c}\right)
$$


donde $K_{r}$ es un parámetro de erosionabilidad del surco $\left(s \cdot m^{-1}\right) ; \tau_{r}$ es la tensión de corte que actúa sobre las partículas del suelo $(P a)$; y $\tau_{c}$ es el esfuerzo de corte crítico del suelo $(P a)$.

Para el caso en que el caudal sólido es mayor que la capacidad de transporte, se presenta sedimentación en el surco que se calcula según la ecuación:

$$
D_{r}=\frac{\beta V_{f}}{q}\left(T_{c}-Q_{s}\right)
$$

donde $\beta$ es un coeficiente adimensional de turbulencia inducida por el impacto de la gota de lluvia; $V_{f}$ es la velocidad de sedimentación de los sedimentos $\left(m \cdot s^{-1}\right)$; $q$ es el caudal unitario (caudal por unidad de ancho) $\left(m^{2} \cdot s^{-1}\right)$; y $T_{c}$ y $Q_{s}$ como se definieron en la ecuación 3.28.

En el cálculo del esfuerzo de corte del flujo en surcos se supone una geometría rectangular y se promedia para toda la longitud. El ancho de los surcos, $W(m)$, puede ser un parámetro de entrada o se calcula usando la siguiente ecuación:

$$
W=1,13 Q^{0,303}
$$

donde $Q$ es el caudal que pasa por el surco $\left(m^{3} \cdot s^{-1}\right)$.

Posteriormente se calcula la profundidad del flujo utilizando el factor de fricción de Darcy-Weisbach y la pendiente. Por último se calcula el radio hidráulico, $R_{h}$ $(m)$. El esfuerzo de corte que actúa sobre el suelo, $\tau_{r}(P a)$, se calcula según la ecuación:

$$
\tau_{r}=\gamma R_{h} \sin (\alpha)\left(\frac{f_{s}}{f_{t}}\right)
$$

donde $\gamma$ es el peso específico del agua $\left(\mathrm{kg} \cdot \mathrm{m}^{-2} \cdot \mathrm{s}^{-2}\right) ; \alpha$ es la pendiente promedio; $f_{s}$ es el factor de fricción para el suelo; y $f_{t}$ es el factor de fricción total para el surco.

Tanto la capacidad de transporte de sedimentos como el caudal sólido se calcula para un ancho de surco unitario. La capacidad de transporte de sedimentos se calcula de forma simplificada, usando la siguiente ecuación:

$$
T_{c}=k_{t} \tau_{r}^{3 / 2}
$$

donde $k_{t}$ es un coeficiente de transporte $\left(m^{0,5} \cdot s^{2} \cdot k g^{-0,5}\right)$.

Los coeficientes empíricos utilizados en las ecuaciones utilizadas en el WEEP se basan en numerosos experimentos bajo condiciones controladas. En la documentación del programa se encuentran tablas y relaciones para estimar dichos parámetros. Al igual que se indicó en el parágrafo 3.2.2.3.1 esta aproximación se hace poco parsimoniosa, más si se quiere aplicar a un modelo de erosión a escala de cuenca debido a la gran cantidad de parámetros que deben ser estimados para cada elemento de discretización.

Liu et al. (2006) proponen un modelo de erosión en surcos más simple, aunque con base física. Este modelo se basa en un serie de experimentos realizados en canaletas de laboratorio y en los mismos conceptos que se utilizan para el transporte 
de sedimentos en canales abiertos. La tasa de erosión en surcos se supone proporcional a la diferencia entre la capacidad de transporte del flujo, $T_{c}\left(\mathrm{~kg} \cdot \mathrm{s}^{-1} \cdot \mathrm{m}^{-1}\right)$, y el caudal sólido, $q_{s}\left(\mathrm{~kg} \cdot \mathrm{s}^{-1} \cdot \mathrm{m}^{-1}\right)$, de esta forma:

$$
D_{r}=\alpha\left(T_{c}-q_{s}\right)
$$

donde $\alpha$ es un coeficiente y su recíproco, $1 / \alpha[L]$, denota la distancia en la cual la concentración de sedimentos del flujo en el surco pasa de cero a su valor máximo, esto es, cuando la capacidad de transporte se hace menor que el caudal sólido (a partir del cual hay sedimentación).

A partir de análisis dimensional y regresiones múltiples con datos experimentales Liu et al. (2006) han llegado a la siguiente ecuación:

$$
\frac{1 / \alpha}{R_{h}}=1,5 \cdot 10^{4}\left[\frac{\tau-\tau_{c}}{\left(\rho_{s}-\rho\right) g d}\right]^{0,15}\left(\frac{v}{\sqrt{g d}}\right)^{-1} S^{1,5}
$$

donde $R$ es el radio hidráulico del surco $(m) ; \tau$ es el esfuerzo de corte del flujo $(P a)$; $\tau_{c}$ es el esfuerzo de corte crítico $(P a) ; \rho_{s}$ es la densidad del sedimento $\left(k g \cdot m^{-3}\right)$; $\rho$ es la densidad del fluido $\left(\mathrm{kg} \cdot \mathrm{m}^{-3}\right) ; g$ es la aceleración debido a la gravedad $\left(m \cdot s^{-2}\right) ; d$ es el diámetro medio de las partículas del suelo $(m) ; v$ es la velocidad media del flujo $\left(m \cdot s^{-1}\right)$; y $S$ es la pendiente.

Para el cálculo de la capacidad de transporte del flujo en surcos, Liu et al. (2006) proponen la fórmula de Yalin (1963):

$$
\begin{gathered}
T_{c}=Q_{s} Y^{0,5}\left(Y-Y_{c}\right) d[g d(s-1)]^{0,5} \rho_{s} \\
Q_{s}=\frac{0,635}{Y_{c}}\left[1-\frac{\ln (1+a s)}{a s}\right] \\
a s=\frac{2,45}{s^{0,4}} Y_{c}^{0,5}\left(\frac{Y}{Y_{c}}-1\right)
\end{gathered}
$$

con $Y$ y $Y_{c}$ tal como se definieron en la ecuación 3.27.

Estas aproximaciones exigen gran cantidad de parámetros, específicamente de la geometría de los surcos que tal como se ha señalado son básicamente aleatorias. Para implementarlas en un modelo de erosión distribuido es necesaria una discretización espacial que en la actualidad solo es posible en parcelas experimentales y en canaletas de laboratorio. Por tal motivo, es justificable el uso de relaciones simple que den cuenta de manera conjunta de la erosión en zonas entre surcos y de la erosión en surcos para modelos de erosión a escala de cuenca.

3.2.2.3.3. Ecuaciones para la capacidad de transporte del flujo en ladera deducidas a partir de análisis dimensional. El análisis dimensional de un fenómeno físico se basa en cuantificar las variables implicadas ya sean geométricas, cinemáticas o dinámicas en sus dimensiones fundamentales y analizar la dependencia entre las variables implicadas. A partir de este método de análisis se puede 
deducir información acerca de un fenómeno partiendo de la premisa que este se puede describir a partir de una ecuación dimensionalmente correcta entre ciertas variables. Julien (1998) señala que el análisis dimensional tiene como objetivo reducir el número de variables y proporcionar parámetros adimensionales, los cuales son independientes del sistema de unidades. Aunque el razonamiento dimensional no conducirá por si mismo ni a una solución completa de un fenómeno físico ni a un entendimiento claro de su funcionamiento, es una herramienta útil para tratar matemáticamente las dimensiones de las variables involucradas.

Para el caso de la erosión en ladera y específicamente para la capacidad de transporte de sedimentos del flujo en ladera Julien y Simons (1985) desarrollan un análisis dimensional con el objeto de obtener una relación con sentido físico y con parámetros adimensionales que puedan ser obtenidos empíricamente.

El primer paso es la definición de la variable dependiente en función de las variables independientes, algunas de las cuales se muestran en la figura 3.18.

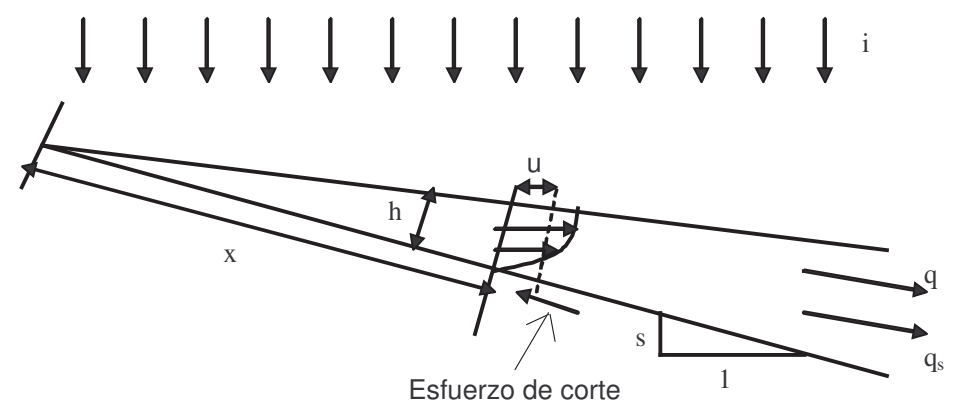

Figura 3.18. Variables involucradas en la erosión por flujo superficial en ladera, adaptado de Julien y Simons (1985)

Para la erosión en ladera se considera que el caudal unitario de sedimentos, $q_{s}$, es el resultado del arranque de partículas del suelo debido al impacto de las gotas de lluvia y al flujo superficial en ladera, y es función de las siguientes variables:

$$
q_{s}=f\left(x, S, i_{l}, \bar{v}, h, q, \tau_{o}, \tau_{c}, d_{s}, \gamma_{s}, \gamma, \nu, g\right)
$$

Las primeras dos variables, la longitud $x$ y la pendiente $S$ de la ladera describen la geometría; las siguientes cinco representan características del flujo, esto es, la intensidad de lluvia $i_{l}$, la velocidad media del flujo $\bar{v}$, la profundidad del flujo $h$, el caudal unitario $q$, y el esfuerzo de corte $\tau_{o}$; las últimas seis variables están asociadas a las propiedades del suelo y el fluido y a la aceleración de la gravedad: el esfuerzo de corte crítico $\tau_{c}$, el tamaño de las partículas del suelo $d_{s}$, el peso específico del suelo $\gamma_{s}$ y del agua $\gamma$, la viscosidad cinemática $\nu$, y la aceleración de la gravedad $g$.

El esfuerzo de corte es difícil de medir en el campo y normalmente se calcula a partir de otras variables. En un río, las variables $S, \bar{v}, h$ y $q$ se utilizan para 
describir el flujo puesto que la velocidad y la profundidad se miden con mucha mayor facilidad que la intensidad de la lluvia, $i_{l}$, y la longitud de la escorrentía, $x$. Esta razón justifica la reducción de algunas ecuaciones de transporte de sedimentos en canales para que queden en función de $\bar{v}$ y $h$. Pero en el caso de la erosión en ladera, las variables $i$ y $x$ tienen un significado físico importante. La pendiente y el caudal líquido unitario pueden medirse con más facilidad que la velocidad y la profundidad del flujo. De esta forma, las variables $S$ y $q$ pueden resultar más convenientes que $\bar{v}$ y $h$ como componentes de relaciones para la capacidad de transporte en ladera en condiciones estacionarias. Es posible la eliminación de las variables $\bar{v}$ y $h$ de las ecuaciones de continuidad y de fricción (Darcy-Weisbach).

El esfuerzo de corte crítico, $\tau_{c}$, corresponde al inicio del movimiento de las partículas de sedimentos. Las relaciones fundamentales que definen el movimiento incipiente de los sedimentos indican que el esfuerzo de corte crítico es función del tamaño de las partículas y el peso específico del agua y los sedimentos. De esta forma, el tamaño de los sedimentos puede reemplazarse por el esfuerzo de corte crítico en las ecuaciones de transporte de sedimentos. El peso específico del agua y los sedimentos se pueden considerar constantes.

Tomando en cuenta estas consideraciones, la ecuación 3.39 se reduce a:

$$
f\left(q_{s}, q, i_{l}, x, \gamma, \nu, \tau_{c} / \tau_{o}, S\right)=0
$$

En la ecuación $3.40 \tau_{c}, \tau_{o}$ y $S$ son variables adimensionales, mientras que las otras seis son función de tres dimensiones fundamentales $[M, L, T]$ y pueden transformarse en tres parámetros adimensionales. Estas variables escritas en términos de sus dimensiones fundamentales son:

- $q_{s}=M / L T$

- $q=L^{2} / T$

- $i_{l}=L / T$

$-x=L$

- $\nu=L^{2} / T$

- $\gamma=M / L^{3}$

Las dimensiones fundamentales pueden escribirse en términos de las variables repetidas $x, \nu, \mathrm{y} \gamma$ :

- $M=\gamma x^{3}$

$-T=x^{2} / \nu$

- $L=x$ 
Los tres parámetros pueden obtenerse sustituyendo las dimensiones fundamentales en las relaciones para $q_{s}, q$ e $i_{l}$, de la siguiente forma:

$$
\begin{gathered}
\frac{q_{s}}{M} L T=\frac{q_{s} x x^{2}}{\gamma x^{3} \nu}=\frac{q_{s}}{\gamma \nu} \\
\frac{q T}{L^{2}}=\frac{q x^{2}}{x^{2} \nu}=\frac{q}{\nu}=R_{e} \\
\frac{i_{l} T}{L}=\frac{i_{l} x^{2}}{x \nu}=\frac{i_{l} x}{\nu}
\end{gathered}
$$

De esta forma la ecuación 3.40 puede escribirse como:

$$
f\left(\frac{q_{s}}{\gamma \nu}, \frac{q}{\nu}, \frac{i_{l} x}{\nu}, \frac{\tau_{c}}{\tau_{o}}, S\right)=0
$$

Y el transporte de sedimentos puede tomar la siguiente forma:

$$
\left(\frac{q_{s}}{\gamma \nu}\right)=\bar{\alpha} S^{\beta}\left(\frac{q}{\nu}\right)^{\gamma}\left(\frac{i_{l} x}{\nu}\right)^{\delta}\left(1-\frac{\tau_{c}}{\tau_{o}}\right)^{\epsilon}
$$

donde $\bar{\alpha}, \beta, \gamma, \delta$, y $\epsilon$ son coeficientes experimentales y las ecuaciones de transporte de sedimentos basadas en las fuerzas de tracción y el concepto de potencia de corriente están representadas en el término $1-\left(\tau_{c} / \tau_{o}\right)$.

La ecuación 3.42 se puede transformar para que adquiera un forma dimensional quedando así:

$$
q_{s}=\alpha S^{\beta} q^{\gamma} i_{l}^{\delta}\left(1-\frac{\tau_{c}}{\tau_{o}}\right)^{\epsilon}
$$

donde

$$
\alpha=\frac{\bar{\alpha} \gamma x^{\delta}}{\nu^{\gamma+\delta-1}}
$$

Los tres primeros factores de la ecuación $3.43\left(S, q, i_{l}\right)$ representan el potencial erosivo de la capacidad de transporte de sedimentos del flujo superficial en ladera. Esta capacidad de transporte se disminuye por el último factor que refleja la resistencia del suelo a la erosión. Cuando $\tau_{c}$ es pequeño en comparación con $\tau_{o}$, la ecuación para la capacidad de transporte de sedimentos por flujo superficial en ladera es:

$$
q_{s}=\alpha S^{\beta} q^{\gamma} i_{l}^{\delta}
$$

Como se ha mencionado anteriormente cuando se da flujo en ladera, tanto laminar como concentrado en pequeños canales, la capacidad de transporte de sedimentos no es función de la intensidad de la lluvia, puesto que estos flujos son básicamente turbulentos. En este caso, $\delta=0$ en la ecuación 3.45.

Los valores de los exponentes $\beta$ y $\gamma$ se obtienen de investigaciones de campo. Julien y Simons (1985) hacen una extensa recopilación de los valores citados en la literatura. Los intervalos típicos son $1,2<\beta<1,9$ y $1,4<\gamma<2,4$. El coeficiente 
$\alpha$ depende de las características del suelo, la vegetación, la intensidad de la lluvia y las escalas (espacial y temporal) de aplicación de la ecuación.

Para calcular la erosión en ladera, se integra la capacidad de transporte en el espacio y en el tiempo de la siguiente forma:

$$
A_{u}=\int_{\text {tiempo }} \int_{\text {ancho }} q_{s} d w d t
$$

donde $A_{u}$ son los sedimentos erosionados en el tiempo $t$ y en una sección de ladera de ancho $w$.

Este último acercamiento es susceptible de utilizarse en un modelo de erosión distribuido en el espacio y en el tiempo a escala de cuenca. Aunque no trata de manera explícita los procesos de erosión en zonas entre surcos y en surcos, resulta más conveniente, puesto que la sofisticación de modelos con base física, tales como los reseñados anteriormente, termina siendo opacada por la alta incertidumbre debido a la gran cantidad de parámetros que necesariamente habrá que estimar.

A partir de estudios experimentales se ha encontrado que los exponentes de la ecuación 3.45 presentan poca variación en situaciones diversas, mientras que el coeficiente $\alpha$ da cuenta de las características ambientales (tipos de suelos, usos del suelo, clima) y de las escalas de aplicación de la ecuación. Por tanto, se justifica que dicho coeficiente sea el parámetro a calibrar en la aplicación del modelo.

Otra ventaja de este acercamiento es que las variables independientes, esto es el caudal unitario de flujo $q$ y la pendiente $S$, se pueden estimar directamente para cada elemento de discretización (celda) y para cada intervalo temporal de simulación, si se parte de un modelo hidrológico distribuido.

\subsubsection{Procesos sedimentológicos en cárcavas}

La erosión en cárcavas se define como la erosión en cauces demasiado profundos como para ser suprimidos con equipos de labranza. Una vez establecidas, las cárcavas permanecen a menos que sean llenadas con suelo excavado con maquinaria pesada. Las cárcavas destruyen porciones enteras de tierras productivas y dividen los campos de labranza lo cual reduce la eficiencia de la utilización de maquinaría agrícola. La erosión en cárcavas reduce significativamente la calidad de las tierras y su valor (Foster, 1986).

Las cárcavas se desarrollan por erosión intensa causada por flujos en la cabecera de los cauces, causando una erosión remontante que se mueve aguas arriba siguiendo la red de drenaje natural, de esta forma, se pueden formar afuera del campo cultivado hasta llegar a él. Las cárcavas también pueden migrar lateralmente debido al colapso de sus paredes. El flujo subsuperficial cuando corta las paredes de las cárcavas reduce significativamente las fuerzas cohesivas del suelo y acelera la erosión en cárcavas (Piest et al., 1975b).

Los sedimentos disponibles para el transporte en cárcavas proceden de dos fuentes: a) de la erosión entre surcos y la erosión en surcos en áreas adyacentes 
donde se presenta el flujo superficial, y b) la erosión en la zona aguas arriba de la misma cárcava.

El perfil longitudinal de muchas cárcavas efímeras es concavo y gradualmente decreciente. Aunque la capacidad de transporte tiende a incrementar cuando el caudal aumenta a lo largo de una cárcava, la disminución en el perfil (se reduce la pendiente) tiende a bajar la capacidad de transporte. El resultado neto en las cárcavas con perfil cóncavo es que la capacidad de transporte se incrementa hasta un máximo en una zona concreta a lo largo de la cárcava a partir del cual comienza a decrecer (ver figura 3.19).

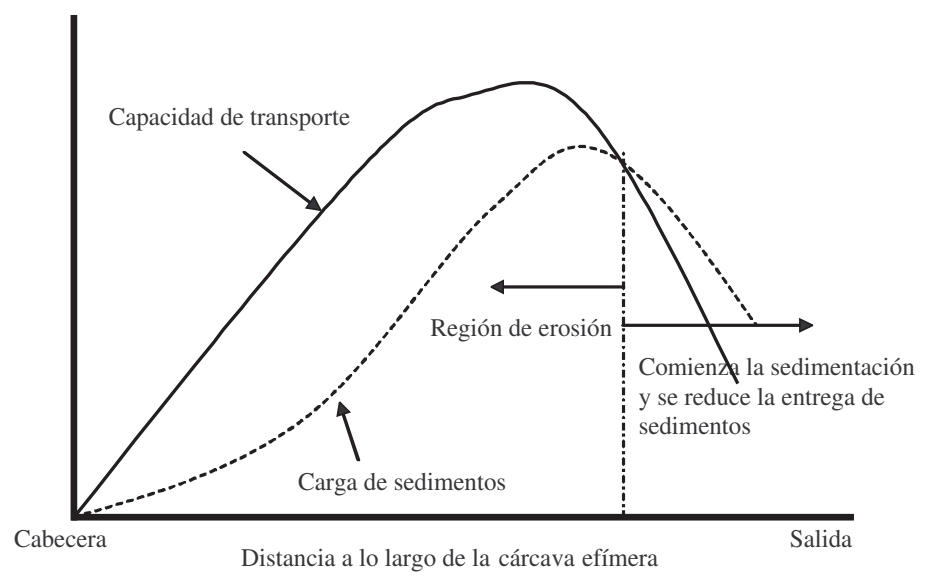

Figura 3.19. Variación de la capacidad de transporte y el caudal sólido a lo largo de una cárcava efímera con perfil cóncavo, adaptado de Foster (1986)

El caudal sólido se incrementa a lo largo de la cárcava por los sedimentos añadidos por el flujo superficial adyacente al área de la cárcava y por los sedimentos producidos aguas arriba. Si la pendiente longitudinal decrece significativamente, la capacidad de transporte se iguala a el caudal sólido en un punto concreto de la cárcava, en este punto comienza la sedimentación que continua hasta la salida, como se ve en la figura 3.19. Cuando la concavidad del perfil de la cárcava es poca, la sedimentación puede no ocurrir.

Los remansos ubicados a la salida de una cárcava pueden también reducir la capacidad de transporte y causar sedimentación. Cuando la sedimentación ocurre, la producción de sedimentos está controlada principalmente por la capacidad de transporte del flujo cerca de la salida de la cárcava más que por la cantidad de erosión aguas arriba de la salida (Foster, 1982b). Cuando la pendiente es uniforme a lo largo de la cárcava, la sedimentación puede o no ocurrir, dependiendo de la cantidad de escorrentía y los sedimentos que llegan de las áreas de flujo superficial adyacentes. Si la sedimentación ocurre, esta ocurre a lo largo de la cárcava, justo como ocurre a lo largo de una terraza con pendiente uniforme (Foster y Ferreira, 1981). 
Cuando el perfil de la cárcava es convexo, la sedimentación ocurre en las partes altas donde la pendiente es relativamente baja. La capacidad de transporte se incrementa a lo largo de la cárcava más rápido que el caudal sólido, causando sedimentación al inicio y erosión en la salida de la cárcava (ver figura 3.20). La combinación de fuertes pendientes y caudales altos cerca de la salida de la cárcava con perfil longitudinal convexo ocasiona tasas altas de erosión.

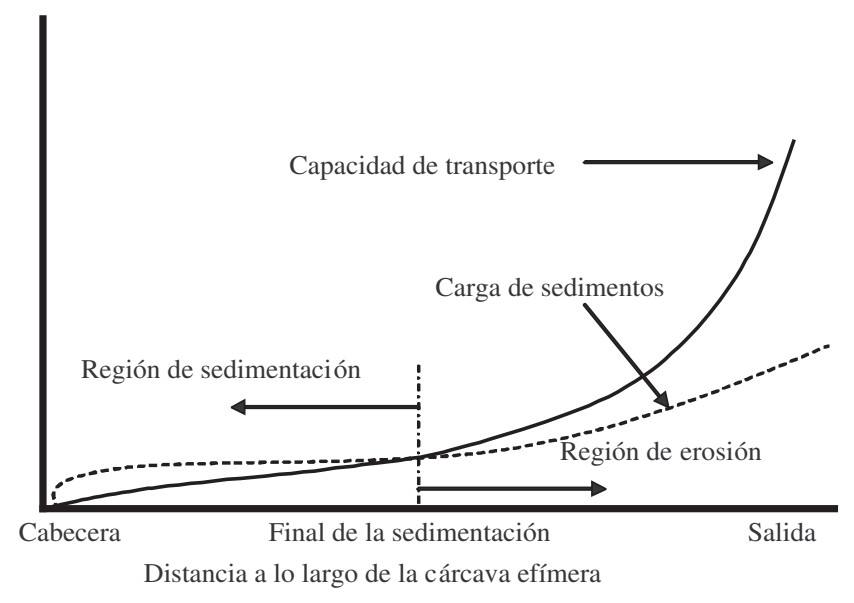

Figura 3.20. Variación de la capacidad de transporte y el caudal sólido a lo largo de una cárcava efímera con perfil convexo, adaptado de Foster (1986)

Las áreas de sedimentación que usualmente se ubican cerca de la salida de las cárcavas pueden expandirse y contraerse durante una tormenta y en períodos entre tormentas. Por ejemplo, cuando la capacidad de transporte decrece más lentamente que el caudal sólido, la localización de la sedimentación se mueve aguas abajo, así el flujo puede erosionar sedimentos depositados previamente, por lo tanto es importante que el modelo de erosión tenga en cuenta el estado inicial de sedimentos depositados, más si se trata de un modelo de eventos.

Si una tormenta ocurre cuando se encuentra una cobertura vegetal desarrollada y por tanto se reduce la tasa de producción de sedimentos en las áreas entre surcos y en los surcos, sin disminuir la capacidad de transporte del flujo en las cárcavas, los sedimentos disponibles para el transporte en estas cárcavas se reducen en relación con la capacidad de transporte. El resultado es que la localización donde la sedimentación comienza se mueve aguas abajo y los sedimentos depositados previamente se erosionan (Foster, 1986).

Los sedimentos depositados anteriormente, permanecen saturados durante una tormenta y son erosionados con facilidad. Además, los cambios en el contenido de humedad del suelo que se dan entre eventos de lluvia pueden incrementar significativamente el esfuerzo tangencial crítico de los sedimentos depositados (Foster et al., 1982). 
El desarrollo de cárcavas tiene un efecto en la evolución del paisaje, específicamente en las zonas aledañas. La erosión en cárcavas efímeras ocurre en el mismo sitio cada año y produce una red de drenaje que gradualmente causa incisión en el paisaje. La incisión reduce el nivel base para el flujo superficial en las laderas adyacentes a la cárcava. El incremento en la convexidad de la ladera y el consecuente aumento de la pendiente incrementa significativamente la erosión en surcos y entre surcos en zonas adyacentes a las cárcavas (Foster, 1986).

Los sedimentos que salen de un campo de cultivo específico usualmente son menores que los estimados debido a que se produce sedimentación en el mismo campo de cultivo que es mayor que la que se supone (Priest et al, $1975^{19}$ ). Además, suponer un factor de entrega de sedimentos constante para todo un campo es un error común, puesto que no es lo mismo que los sedimentos se produzcan en surcos y en zonas entre surcos a que se produzcan en cárcavas. Si bien es cierto que las cárcavas efímeras son una fuente importante de sedimentos, normalmente se encuentra que en las salidas de estas se encuentren zonas de sedimentación. Esto además tiene efecto en la producción de contaminantes químicos asociados a los sedimentos.

La mayoría de los modelos de erosión tratan los procesos de erosión en cárcavas de la misma forma que en los cauces y los surcos. Esto se debe a que en todos los casos el flujo se encuentra concentrado y estos elementos son canales que transportan agua y sedimentos y los procesos son similares.

La diferencia fundamental entre surcos, cárcavas y cauces se da en sus dimensiones geométricas y su densidad. Como se ha anotado anteriormente tanto la geometría como la densidad de surcos son básicamente aleatoria y su escala representativa es inferior a la de una celda en un modelo de erosión a escala de cuenca, por tanto, no es posible definir las propiedades topológicas a partir de un modelo de elevación digital con resoluciones mayores al metro (incluso con resoluciones menores).

Otra diferencia en cuanto a los procesos es que tanto en cárcavas como en canales no se tiene en cuenta la erosión debido al flujo concentrado, esto se justifica porque dichos procesos se deben más a condiciones locales y se considera una buena aproximación suponer que los cauces y las cárcavas se encargan de transportar y depositar los sedimentos producidos en las zonas entre surcos y los surcos. Aún modelos a escala de ladera como el WEEP y a escala de microcuenca como el LISEM adoptan esta suposición.

Puesto que el inicio y la forma de las cárcavas es fundamental para simular los procesos hidrológicos y sedimentológicos, en la sección 3.1.3.6 se detalla como los modelos de erosión estiman estas relaciones. Además, en el caso de las cárcavas efímeras, se han propuesto relaciones que dependen del caudal y la pendiente que determinan la finalización de las mismas, esto debido a procesos de sedimentación masiva.

\footnotetext{
${ }^{19}$ Tomado de Foster (1986)
} 


\subsubsection{Procesos sedimentológicos en cauces}

Los procesos sedimentológicos predominantes que ocurren en los cauces son el transporte y el depósito de sedimentos. Aunque una fuente importante de sedimentos se da debido al desprendimiento de márgenes y taludes de los cauces, estos procesos dependen básicamente de condiciones locales tales como la presencia de deslizamientos antiguos, discontinuidades en el sustrato litológico (fallas, fracturas), la presencia de macroporos en el suelo, la ubicación de taludes antrópicos (carreteras y obras civiles ubicadas en las inmediaciones del cauce), etc. En la mayoría de modelos de erosión a escala de cuenca se supone que dichos procesos se dan en los surcos y cárcavas que drenan a los cauces (procesos de ladera) y de esta forma se considera que los cauces se encargan de transportar y depositar los sedimentos producidos en la ladera que vierte a ellos. De esta forma es posible aplicar el esquema mostrado en la figura 3.17, determinando que el suministro de sedimentos se presenta en la ladera que vierte al cauce y a los sedimentos aguas arriba de la sección y la capacidad de transporte de sedimentos dependerá de las características hidráulicas del cauce y del caudal que está pasando por su sección. Esta aproximación es adecuada para modelos sedimentológicos distribuidos a escala de cuenca.

Es posible clasificar el caudal sólido que transporta un cauce de tres formas (Julien, 1998):

a) Por el tipo de movimiento: En este caso el caudal total de sedimentos será la suma de los sedimentos transportados como caudal sólido de fondo y los sedimentos transportados como caudal sólido en suspensión. Las partículas de limos y arcillas generalmente viajan en suspensión, mientras que las arenas y gravas se transportan en el fondo del lecho por saltación y arrastre. Julien (1998) define el fondo del lecho como una delgada capa próxima al lecho del cauce con un espesor aproximado de dos veces el diámetro medio de las partículas que componen el lecho, esto es, entre 1 milímetro en cauces con lechos de arenas y limos a decenas de centímetros en cauces con lechos de gravas.

b) Por el método de medida: En este caso el caudal total de sedimentos en el cauce consiste en la suma de el caudal sólido medidos más el caudal sólido no medidos. Esta distinción se justifica puesto que las muestras de sedimentos en suspensión se toman a una distancia, como mínimo, de aproximadamente 10 centímetros arriba de la superficie del lecho. De esta forma el caudal sólido en suspensión medida es sólo una parte de el caudal total de sedimentos en suspensión, puesto que a alturas menores también se presenta transporte de sedimentos en suspensión.

c) Por la fuente de sedimentos: Este caso se esquematiza en la figura 3.17. El caudal total de sedimentos que viaja en un cauce es igual a los sedimentos suministrados que viajan como caudal sólido de lavado, que está limitado 
por el suministro de sedimentos, más el caudal sólido limitados por la capacidad de transporte, que viajan como caudal sólido de fondo. En general la caudal sólido de lavado cubre el intervalo de las partículas finas $\left(d_{s}<d_{10}\right)$ las cuales tienen poca presencia como caudal sólido de fondo, de tal forma se puede considerar que el transporte de sedimentos está limitado por el suministro de sedimentos finos aguas arriba y el transporte de sedimentos como caudal sólido de lavado es posible determinarlo por procesos advectivos (los sedimentos se transportan por el flujo de agua, con lo cual sólo es necesario determinar la concentración de sedimentos en suspensión para calcular el transporte como caudal sólido de lavado). Por otro lado, el caudal sólido de fondo se determina por la capacidad que tiene el flujo para transportar los sedimentos que se encuentran en el lecho, de mayor tamaño.

Si se utiliza la última aproximación para calcular el caudal total de sedimentos que transporta un cauce, es necesario determinar el suministro de sedimentos que recibe dicho cauce y la capacidad de sedimentos que puede transportar. Para calcular ambas cantidades existen numerosas ecuaciones, unas totalmente empíricas y otras con base física.

Por ejemplo, la USLE puede utilizarse para calcular el suministro de sedimentos que recibe una corriente de agua, con los inconvenientes mencionados anteriormente (imposibilidad de validación en condiciones diferentes, factores empíricos de nulo significado físico, agregación temporal anual, o en el caso de su variante para eventos, la MUSLE, la necesidad de utilizar un factor de entrega de sedimentos que depende del área de agregación).

Por otro lado, se han desarrollado ecuaciones para calcular la capacidad de transporte de sedimentos en flujos en ladera con sentido físico, que pueden ser escritas como función exponencial del caudal y la pendiente. Estas ecuaciones se han determinado a partir de estudios sistemáticos en laboratorio (canaletas con lluvias simuladas) y en parcelas experimentales y una característica de estos ensayos es que el flujo, tanto de agua como de sedimentos, se concentra en pequeños surcos. Una recopilación de las ecuaciones desarrolladas se encuentra en Julien y Simons (1985). Tanto los coeficientes como los exponentes de estas ecuaciones se han definido a partir de relaciones empíricas, en las cuales los exponentes (para el caudal y la pendiente) son muy similares, mientras que el coeficiente depende de las condiciones particulares del sitio de medida (canaletas en laboratorio, tipo de suelo, cobertura de vegetación).

En un modelo de erosión distribuido es posible acoplar una red de surcos, con el agua y los sedimentos que generan, a una red de cauces que se encarga de transportarlos (y depositarlos, en el caso de los sedimentos) hacia la salida de la cuenca. Faltará entonces determinar la capacidad de transporte de sedimentos que puede transportar cada tramo de un cauce, con una de las múltiples ecuaciones que se han desarrollado para tal fin, Julien (1998) presenta las ecuaciones más utilizadas, destacando sus limitaciones y posibilidades. Por último será necesario determinar una ecuación que relacione la velocidad del flujo de la sección del 
tramo del cauce analizado con la velocidad de caída o de sedimentación de las partículas de sedimentos que viajan por el cauce. Si se discretiza adecuadamente la cuenca, tanto en el espacio (celdas) como en el tiempo (intervalo temporal) y se aplican estos conceptos para cada discretización es posible determinar la dinámica sedimentológica de una cuenca ante un evento de lluvia.

3.2.2.5.1. Capacidad de transporte de sedimentos en cauces. Para el cálculo de la capacidad de transporte de sedimentos en cauces, ya sean cauces o cárcavas (o incluso surcos), se utilizan diferentes aproximaciones: a) formulaciones basadas en procesos advectivos - difusivos; b) formulaciones basadas en conceptos de energía (o potencia) de la corriente, en las cuales la tasa de trabajo necesario para transportar partículas de sedimentos en flujos turbulentos se relaciona con la tasa de gasto de energía; y c) a partir de ecuaciones empíricas basadas en análisis de regresión y métodos gráficos.

De estas aproximaciones, las más utilizadas por los diferentes modelos son las basadas en la energía de la corriente. Las diferencias fundamentales se encuentran en las magnitudes utilizadas para describir los procesos (volumen, masa o peso).

En textos de hidráulica fluvial se pueden encontrar multitud de ecuaciones para el transporte de sedimentos en cauces fluviales. Las ecuaciones se clasifican por el tipo de movimiento (arrastre de fondo y arrastre en suspensión). Fernández ${ }^{\sim B}$ Bono et al. (1995) efectúan una recopilación de las ecuaciones de transporte de sedimentos en cauces fluviales y recomiendan en que situaciones se deben aplicar algunas de las ecuaciones. Aguirre-Pe et al. (2006) comparan diversos modelos para el transporte de sedimentos en ríos y canales de laboratorio y concluyen que el de mejor desempeño en multitud de situaciones es el propuesto por Engelund y Hansen.

En el parágrafo 3.1.1.2.2 se definió el concepto de energía de la corriente, propuesto inicialmente por Bagnold (1966), quien determinó que la potencia disponible del flujo suministra la energía para el transporte de sedimentos. Dicho autor propone una ecuación de capacidad de transporte de sedimentos resultante de combinar el caudal sólido en suspensión, $q_{s}$, con el caudal sólido de fondo, $q_{b}$, de la siguiente forma:

$$
q_{t}=q_{b}+q_{s}=\frac{\tau_{c} v}{G_{s}-1}\left(e_{B}+0,01 \frac{v}{V_{f}}\right)
$$

donde $q_{t}$ es el caudal de sedimentos expresado en peso seco por unidad de tiempo y ancho en un sistema de unidades consistente; $\tau_{c}$ es el esfuerzo de corte crítico; $v$ es la velocidad promedio; $G_{s}$ es la gravedad específica de los sedimentos; $0,2<e_{B}<0,3$; y $V_{f}$ es la velocidad de sedimentación de los sedimentos.

Engelund y Hansen (1967) ${ }^{20}$ aplican el concepto de energía de la corriente de Bagnold y el principio de similitud para obtener la concentración de sedimentos

\footnotetext{
${ }^{20}$ Tomado de Julien (1998)
} 
por peso, $C_{w}$, según la siguiente ecuación:

$$
C_{w}=0,05\left(\frac{G_{s}}{G_{s}-1}\right) \frac{v S_{f}}{\left[\left(G_{s}-1\right) g d_{s}\right]^{1 / 2}}\left[\frac{R_{h} S_{f}}{\left(G_{s}-1\right) d_{s}}\right]^{0,5}
$$

donde $G_{s}$ es la gravedad específica de los sedimentos, $v$ la velocidad promedio del flujo, $S_{f}$ es el ángulo de fricción (que se supone igual a la pendiente), $g$ es la aceleración debido a la gravedad, $d_{s}$ es el tamaño de las partículas de sedimentos, y $R_{h}$ es el radio hidráulico.

En la ecuación 3.48 el término compuesto por $V S_{F}$ representa la potencia de la corriente, mientras que el término $\left(G_{s}-1\right) d_{s}$ representa el parámetro de Shields $(1936)^{21}$. Dicho autor determinó las condiciones umbrales para el movimiento incipiente de partículas de sedimentos sumergidas en un fluido en movimiento. El parámetro de Shields, $\tau_{\star}$, toma la siguiente forma:

$$
\tau_{\star}=\frac{\tau_{c}}{\left(\gamma_{s}-\gamma_{m}\right) d_{s}}=\frac{\rho_{m} u_{\star}^{2}}{\left(\gamma_{s}-\gamma_{m}\right) d_{s}}
$$

donde $\tau_{c}$ es el esfuerzo de corte crítico, $\rho_{m}$ es la densidad de la mezcla fluido sedimentos, $u_{\star}$ es la velocidad de corte, $\gamma_{s}$ es el peso específico de las partículas de sedimentos, $\gamma_{m}$ es el peso específico de la mezcla fluido - sedimentos, y $d_{s}$ es el tamaño de las partículas.

3.2.2.5.2. Depósito de sedimentos en cauces. Para estimar la cantidad de partículas de sedimentos que se depositan en una sección longitudinal del cauce en un modelo de erosión distribuido a escala de cuenca se utiliza el concepto de reposo de los sedimentos. A partir de este concepto es posible determinar el porcentaje de sedimentos para una fracción de tamaño específica que se deposita en una distancia dada, dependiendo de la velocidad de sedimentación de las partículas, la velocidad del flujo y la profundidad de agua.

Analizando las fuerzas a las que está sometida una partícula de forma esférica cuando se mueve en un fluido, Julien (1998) obtiene dos relaciones, una para los esfuerzos de corte, $F_{D}^{\prime}$, y otra para los esfuerzos perpendiculares a la superficie, $F_{D}^{\prime \prime}$. Estas ecuaciones presenta la forma:

$$
\begin{aligned}
F_{D}^{\prime} & =\int_{0}^{2 \pi} \int_{0}^{\pi}-\tau \sin \theta R^{2} \sin \theta d \theta d \varphi \\
F_{D}^{\prime \prime} & =\int_{0}^{2 \pi} \int_{0}^{\pi}-p_{d} \cos \theta R^{2} \sin \theta d \theta d \varphi
\end{aligned}
$$

donde $\tau$ es el esfuerzo de corte para cada punto de la partícula, $\tau \sin \theta$ es el esfuerzo de corte en la dirección del flujo, $R$ es el radio de la partícula, $R^{2} \sin \theta d \theta d \varphi$ es el diferencial de área, $p_{d}$ es la presión dinámica perpendicular a cada punto de la

\footnotetext{
${ }^{21}$ Tomado de Julien (1998)
} 
partícula, $p_{d} \cos \theta$ es la componente vertical de la presión dinámica, y $\theta$ y $\varphi$ son las coordenadas esféricas.

Las distribuciones de presión y esfuerzo de corte se encuentran analíticamente a partir del tensor de esfuerzos y las ecuaciones de Navier-Stokes en coordenadas esféricas. La solución analítica se expresa de la siguiente forma:

$$
\begin{gathered}
\tau=\tau_{r \theta}=-\frac{3 \nu_{m} u_{\infty}}{2 R}\left(\frac{R}{r}\right)^{4} \sin \theta \\
p_{d}=-\frac{3}{2} \frac{\nu_{m} u_{\infty}}{R}\left(\frac{R}{r}\right)^{2} \cos \theta
\end{gathered}
$$

donde $\nu_{m}$ es la viscosidad cinemática de la mezcla sedimentos - agua, $u_{\infty}$ es la velocidad relativa de la partícula con relación al fluido, $R$ es el radio de la partícula, y $r$ y $\theta$ son las coordenadas esféricas.

Sustituyendo las ecuaciones 3.52 y 3.53 en las integrales 3.50 y 3.51 respectivamente, e integrando sobre toda la superficie de la partícula, se obtiene:

$$
\begin{aligned}
& F_{D}^{\prime}=4 \pi \nu_{m} R u_{\infty} \\
& F_{D}^{\prime \prime}=2 \pi \nu_{m} R u_{\infty}
\end{aligned}
$$

La suma total de fuerzas de arrastre de un fluido viscoso Newtoniano sobre una partícula esférica esta dada por la suma de fuerzas:

$$
F_{D}=F_{D}^{\prime}+F_{D}^{\prime \prime}=4 \pi \nu_{m} R u_{\infty}+2 \pi \nu_{m} R u_{\infty}=6 \pi \nu_{m} R u_{\infty}
$$

La fuerza de empuje $F_{B}$ es la resultante de la distribución de la presión hidrostática sobre la partícula. La fuerza total sobre una partícula en movimiento es:

$$
F=F_{B}+F_{D}=\frac{4}{3} \pi \gamma_{m} R^{3}+6 \pi \mu_{m} R u_{\infty}
$$

donde $\gamma_{m}$ es el peso específico de la mezcla agua - sedimentos.

Partiendo de una análisis dimensional, Julien (1998) demuestra que la fuerza de arrastre de una partícula de diámetro $d_{s}$ que se mueve en un fluido puede expresarse en función del número de Reynolds $R e_{p}=u_{\infty} d_{s} / \nu_{m}$, donde $u_{\infty}$ es la velocidad relativa de la partícula con relación al fluido, y $\nu_{m}$ es la viscosidad cinemática de la mezcla sedimentos - agua. Para encontrar el coeficiente adimensional de arrastre, $C_{D}$, se aplica el análisis dimensional y se substituye $F_{D}$ de la ecuación 3.56 obteniendo:

$$
C_{D}=\frac{8 F_{D}}{\rho_{m} \pi u_{\infty}^{2} d_{s}^{2}}=\frac{24 \nu_{m}}{u_{\infty} d_{s}}=\frac{24}{R e_{p}}
$$

donde $\rho_{m}$ es la densidad de la mezcla. 
Una partícula que está en movimiento en un fluido se está acelerando en la dirección aguas abajo hasta que alcanza una velocidad de equilibrio, o velocidad de sedimentación, $\omega$. La velocidad de sedimentación $\left(\omega=u_{\infty}\right)$ de una pequeña partícula esférica que se deposita por su propio peso $\left(F_{W}=\gamma_{s} V\right.$, donde $\gamma_{s}$ es su peso específico y $V$ es su volumen) en un fluido viscoso, se calcula sustituyendo el peso de la partícula, $F_{W}$, por las fuerzas totales de la ecuación 3.57, de la siguiente forma:

$$
F_{W}=\frac{\pi}{6} d_{s}^{3} \rho_{s} g=\frac{\pi}{6} d_{s}^{3} \rho_{m} g+3 \pi \mu_{m} d_{s} \omega
$$

donde $\rho_{s}$ es la densidad de la partícula.

Resolviendo la ecuación 3.59 para la velocidad de sedimentación, $V_{f}$, como función del diámetro de la partícula, $d_{s}$, se obtiene la ecuación 3.60 para un fluido mezclado (agua - sedimentos) y la ecuación 3.61 para un fluido con agua limpia.

$$
\begin{aligned}
V_{f} & =\frac{1}{18} \frac{\gamma_{s}-\gamma_{m}}{\mu_{m}} d_{s}^{2} \\
V_{f 0} & =\frac{1}{18} \frac{\left(G_{s}-1\right) g}{\nu} d_{s}^{2}
\end{aligned}
$$

donde $\gamma_{s}$ es el peso específico de la partícula, $\gamma_{m}$ es el peso específico de la mezcla, $\nu_{m}$ es la viscosidad cinemática de la mezcla, $G_{s}$ es la gravedad específica de la partícula, $g$ es la aceleración debido a la gravedad, y $\nu$ es la viscosidad cinemática del agua.

Estas ecuaciones son válidas para partículas pequeñas $\left(d_{s}<0,1 \mathrm{~mm}\right)$ que se depositan en un fluido viscoso $\left(R e_{p}<0,1\right)$. Para condiciones más generales, la velocidad de sedimentación se expresa como función del coeficiente de arrastre, $C_{D}$, de las ecuaciones 3.58 y 3.59 después de reemplazar $F_{D}$ por $F_{W}-F_{B}$ con $G=\gamma_{s} / \gamma$, quedando:

$$
\begin{gathered}
V_{f}=\left[\frac{4}{3} \frac{\gamma_{s}-\gamma_{m}}{\rho_{m}} \frac{d_{s}}{C_{D}}\right]^{1 / 2} \text { en una mezcla agua - sedimentos } \\
V_{f 0}=\left[\frac{4}{3}\left(G_{s}-1\right) \frac{g d_{s}}{C_{D}}\right]^{1 / 2} \text { en agua limpia }
\end{gathered}
$$

Engelund y Hansen (1967) ${ }^{22}$ a partir de datos experimentales encuentran una expresión para el coeficiente de arrastre, $C_{D}=\left(24 \nu_{m} / \omega d_{s}\right)+1,5$, que se adapta a gran variedad de tamaños de partículas. De esta forma se puede expresar la velocidad de sedimentación en función del tamaño de las partículas de la siguiente forma:

$$
V_{f}=\frac{8 \nu_{m}}{d_{s}}\left[\left(1+0,0139 d_{\star}^{3}\right)^{0,5}-1\right]
$$

\footnotetext{
${ }^{22}$ Tomado de Julien (1998)
} 
donde $d_{\star}$ es el diámetro de partícula adimensional, definido como:

$$
d_{\star}=d_{s}\left[\frac{\left(G_{s}-1\right) g}{\nu_{m}^{2}}\right]^{1 / 3}
$$

A partir de la ecuación 3.64 es posible estimar la velocidad de sedimentación de diversos tamaños de partículas para un amplio intervalo de números de Reynolds. La tabla 3.2 muestra valores aproximados de velocidades de sedimentación para diversos tamaños de partículas de sedimentos en agua limpia a diferentes temperaturas.

\begin{tabular}{|l|l|l|l|l|}
\hline $\begin{array}{l}\text { Clase } \\
\text { de partículas }\end{array}$ & $\begin{array}{l}\text { Diámetro } \\
(\mathrm{mm})\end{array}$ & $\begin{array}{l}\omega \text { a } 0^{\circ} \mathrm{C} \\
(\mathrm{mm} / \mathrm{s})\end{array}$ & $\begin{array}{l}\omega \text { a } 10^{\circ} \mathrm{C} \\
(\mathrm{mm} / \mathrm{s})\end{array}$ & $\begin{array}{l}\omega \text { a } 20^{\circ} \mathrm{C} \\
(\mathrm{mm} / \mathrm{s})\end{array}$ \\
\hline Bloques & $>256$ & 1919 & 1919 & 1919 \\
\hline Cantos grandes & $>128$ & 1357 & 1357 & 1357 \\
\hline Cantos pequeños & $>64$ & 959 & 959 & 959 \\
\hline Gravas muy gruesas & $>32$ & 678 & 678 & 678 \\
\hline Gravas gruesas & $>16$ & 479 & 479 & 479 \\
\hline Gravas medias & $>8$ & 337 & 338 & 338 \\
\hline Gravas finas & $>4$ & 236 & 237 & 238 \\
\hline Gravas muy finas & $>2$ & 162 & 164 & 167 \\
\hline Arenas muy gruesas & $>1$ & 106 & 109 & 112 \\
\hline Arenas gruesas & $>0,5$ & 61 & 66,4 & 70,3 \\
\hline Arenas medias & $>0,25$ & 25,7 & 31,3 & 36 \\
\hline Arenas finas & $>0,125$ & 7,6 & 10,1 & 12,8 \\
\hline Arenas muy finas & $>0,0625$ & 1,9 & 2,66 & 3,47 \\
\hline Limos gruesos & $>0,031$ & 0,49 & 0,67 & 0,88 \\
\hline Limos medios & $>0,016$ & 0,12 & 0,167 & 0,22 \\
\hline Limos finos & $>0,008$ & 0,031 & 0,042 & 0,055 \\
\hline Limos muy finos & $>0,004$ & 0,0076 & 0,010 & 0,014 \\
\hline Arcillas gruesas & $>0,002$ & $1,9 x 10^{-3}$ & $2,6 x 10^{-3}$ & $3,4 x 10^{-3}$ \\
\hline Arcillas medias & $>0,001$ & $4,8 x 10^{-4}$ & $6,5 x 10^{-4}$ & $8,6 x 10^{-4}$ \\
\hline Arcillas finas & $>0,0005$ & $1,2 x 10^{-4}$ & $1,63 x 10^{-4}$ & $2,1 \times 10^{-4}$ \\
\hline Arcillas muy finas & $>0,00024$ & $2,9 x 10^{-5}$ & $4,1 x 10^{-5}$ & $5,3 x 10^{-5}$ \\
\hline
\end{tabular}

Tabla 3.2. Velocidad de sedimentación en agua limpia para diversos tamaños de partículas, tomado de Julien (1998)

\subsection{La estimación de parámetros}

En esta sección se aborda el problema de integrar el conocimiento previo de las condiciones físicas de la cuenca en el modelo (topografía, características del suelo, condiciones climáticas, usos del suelo, etc.). En la práctica este proceso se conoce 
como estimación de parámetros y es uno de los aspectos fundamentales para el correcto desempeño del modelo. Dicha estimación de parámetros necesariamente debe reflejar la variabilidad espacial, no sólo por razones teóricas, sino y sobre todo, por necesidades prácticas (Puricelli, 2003).

Una de las características más importantes de los modelos ambientales distribuidos es que permiten reflejar la variabilidad espacial del medio que se analiza. Esta ventaja se convierte en una dificultad ante la imposibilidad real de medir cada parámetro que necesita el modelo en todos los elementos de discretización. Además, los valores medidos en campo de las variables que caracterizan el comportamiento hidrológico y sedimentológico sólo dan cuenta de las inmediaciones del sitio de medida y dichas variables adquieren diferentes valores en distancias cortas.

Por tal motivo se hace necesaria la estimación de parámetros, la mayor parte de las veces a partir de información textural de los suelos y basados en análisis estadísticos que a partir de regresiones, permiten inferir el valor de un parámetro hidrológico a partir de otro tipo de información (que se encuentra con más frecuencia), efectuadas con bases de datos de diferentes suelos en regiones diferentes a las del sitio de análisis. Estas funciones, conocidas como funciones de pedotransferencia, muchas veces son la única fuente de información disponible para estimar los parámetros al implementar un modelo ambiental de tipo distribuido.

Puesto que los modelos contienen errores conceptuales y la estimación de parámetros conlleva una incertidumbre, se hace necesario calibrar y validar el modelo. A continuación se exponen brevemente los procesos de estimación de parámetros, calibración y validación del modelo. Es importante que el modelo tenga una estructura coherente en cuanto a los parámetros, esto es, que el usuario tenga claro que parámetros se estiman y cuales son susceptibles de calibrar. Esta estructura se explicará en la formulación del modelo.

\subsubsection{Formas de estimar parámetros en modelos am- bientales distribuidos}

Como se ha mencionado anteriormente, la mayor parte de los flujos de agua ocurren en el interior del suelo y las rocas y la capacidad para medir dichos flujos y los parámetros que los caracterizan es muy limitada puesto que las técnicas de medición actuales solamente reflejan las condiciones de las inmediaciones del sitio de medida. Si a estas limitaciones se le añade la alta variabilidad espacial de los procesos y parámetros se puede concluir que es prácticamente imposible efectuar una medición exhaustiva y rigurosa de las variables que alimentan un modelo hidrológico y geomorfológico.

Por otra parte, es reconocida la brecha que existe entre la escala de los procesos y la escala de observación, lo que hace que necesariamente se estimen parámetros para cada discretización del sistema. Pero para cada elemento de discretización también existe una variabilidad interna que no se puede determinar y lo que sucede 
en aplicaciones prácticas es definir valores efectivos que dan cuenta del comportamiento medio del parámetro al interior del elemento. Al respecto, Beven (1989) señala que los modelos se basan en la física de los procesos a pequeña escala sobre sistemas homogéneos y son aplicados en niveles superiores de generalización, por ejemplo una celda, de esta forma se efectúa un agrupamiento o agregación de las variables sin tener en cuenta la física del proceso en la nueva situación.

En algunos procesos, por ejemplo en la infiltración y el flujo subsuperficial, que ocurren en el nivel más superficial del suelo, la utilización de un valor efectivo para las tasas de conductividad hidráulica es de uso común. De esta forma se ignora el hecho de que durante períodos de recesión dichos procesos se desarrollan en la matriz del suelo, mientras que en períodos de lluvia estos procesos se llevan a cabo por una red interconectada de macroporos. Por tal motivo, es aconsejable la utilización de dos conductividades, las cuales difieren en varios órdenes de magnitud. De cualquier manera, estas conductividades también serán valores efectivos para todo el elemento de discretización que den cuenta del comportamiento medio (por ejemplo, la macroporosidad es esencialmente aleatoria).

Las necesidades planteadas presentan el inconveniente de que en un modelo distribuido se hace indispensable contar con el valor de cada parámetro para cada discretización espacial. Puricelli (2003) propone tres alternativas :

a) Elaborar un sistema de muestreo y monitoreo extensivo y detallado mediante el cual adquirir un gran volumen de datos para procesar y así obtener los valores de los parámetros necesarios en cada lugar.

b) Desarrollar un proceso de estimación basado en modelos estocásticos, por medio del cual, y sobre la base de un volumen limitado de datos puntuales, elaborar campos de parámetros estimados como el producto de realizaciones estocásticas.

c) Aprovechar los datos y la información disponible tanto cartográfica como no cartográfica, proveniente de diferentes fuentes y escalas de análisis, para desarrollar un esquema que respete las relaciones observadas en el terreno y que sean coherentes con el conocimiento existente del tema, a fin de estimar de forma precisa y documentada los valores de los parámetros necesarios para la modelación.

Si se decide por elaborar un proceso de muestreo masivo y detallado de cada parámetro del suelo es necesario contar con una infraestructura suficiente, la cual se limita en la actualidad a pocas parcelas y microcuencas experimentales; además se corre el peligro de obtener información voluminosa y redundante pero no suficiente.

La segunda alternativa se basa en el ajuste matemático óptimo de la variabilidad espacial de una serie de valores puntuales en todo el campo de aplicación. El rigor matemático de las técnicas disponibles no garantizan la variabilidad espacial, mas si se tiene en cuenta que los sistemas naturales presentan una organización que depende de los procesos formadores. De esta forma, en la mayoría de los casos, 
al aplicar técnicas geoestadísticas no se logra el objetivo fundamental, esto es, reflejar la variabilidad espacial de los parámetros que dan cuenta del funcionamiento del sistema.

La tercera alternativa se basa en la convergencia de criterios, esto es, a partir de información variada en escalas, fuentes y criterios de información se desarrolla un proceso analítico que permita inferir que tipo de información es relevante para explicar la variabilidad espacial de un parámetro en particular. De esta forma, se tiene en cuenta todo el conocimiento previo del sistema de análisis que en la práctica se manifiesta en mapas, perfiles de suelos, informes y memorias de investigaciones. Al aplicar esta alternativa se acepta que la variabilidad espacial y temporal de los parámetros es un reflejo de la organización del sistema. En secciones anteriores se ha puesto de manifiesto que el paisaje presenta patrones de organización que dependen de los procesos formadores y por tal motivo es justificable utilizar métodos determinísticos, en vez de métodos estocásticos, para capturar la organización natural del sistema (la cuenca hidrográfica).

Esta última alternativa ha sido desarrollada con anterioridad en la implementación de un modelo hidrológico distribuido (TETIS) en el Departamento de Ingeniería Hidráulica y Medio Ambiente de la Universidad Politécnica de Valencia, en diferentes regiones con resultados satisfactorios. El proceso de análisis y las justificaciones correspondientes se encuentran plasmadas en una tesis doctoral desarrollada por Puricelli (2003).

\subsubsection{Proceso de estimación de parámetros para un modelo ambiental distribuido}

En una cartografía de suelos de una región, las unidades cartográficas de suelos están acompañadas de un perfil característico. A partir de este perfil es posible estimar los valores que van a caracterizar el comportamiento hidrológico y geomorfológico del suelo. Estos valores son estimados con la utilización de funciones de pedotransferencia, las cuales permiten inferir el valor de un parámetro hidrológico a partir de información textural del suelo. La utilización de dichas funciones tienen la ventaja de que es común encontrar mapas de suelos con su memoria asociada, la cual cuenta con perfiles para cada unidad cartográfica con datos texturales de los diferentes niveles del suelo, mientras que los datos hidrológicos se encuentran con poca frecuencia.

Además un mapa de suelos tiene altas connotaciones geomorfológicas. Por ejemplo, en zonas tropicales en donde las variaciones diarias de humedad y temperatura son mayores que las anuales, esto es, el clima no presenta ciclos anuales y la variedad de climas (temperatura y humedad) está determinada por la altitud, un mapa de suelos da cuenta de estas diferencias. Además, un mapa de suelos da cuenta del material parental, ya que no es lo mismo un suelo residual, derivado de la meteorización de una roca antigua (Precuaternaria) que un suelo derivado de un depósito reciente (depósito cuaternario). Esto es debido a que en el proceso 
de elaboración de un mapa de suelos de una región, las unidades cartográficas del suelo se elaboran a partir de criterios fisiográficos (por ejemplo, suelos derivados de la meteorización in situ de rocas vs suelos derivados de depósitos), morfológicos, de tipo de vegetación e hidrológicos .

Los valores estimados a partir de las funciones de pedotransferencia se pueden considerar valores modales ${ }^{23}$ de cada unidad cartográfica de suelos. Pero normalmente los mapas de suelos se elaboran a una escala regional (entre $1: 20000$ y 1 : 200000) y los elementos de discretización de los modelos hidrológicos distribuidos son mucho más pequeños que una unidad cartográfica de suelos. De este modo, con la utilización de valores modales para cada unidad de suelos no se asegura una distribución espacial de parámetros a escala de celda.

Además de los mapas de suelos, para una región particular es normal contar con cartografía de usos del suelo, geología, vegetación y topografía. Esta información es posible relacionarla con los parámetros a estimar y a partir de técnicas analíticas se puede determinar cual información es relevante para explicar la variabilidad espacial de cada parámetro en la zona de estudio.

Como se ha mencionado, los mapas de suelos no dan cuenta de la catena de suelos en cada ladera que comprende una cuenca hidrográfica debido a la escala normal de una cartografía de suelos. Si se utiliza adecuadamente la información derivada de un Modelo de Elevación Digital en el proceso de análisis de la variabilidad espacial de cada parámetro, es posible acercarse a esta variabilidad y definir un valor estimado para cada celda, teniendo en cuenta que dentro de cada ladera los valores de dichos parámetros varían de acuerdo a su posición topográfica relativa.

Estas consideraciones se han demostrado partiendo de estás hipótesis (Puricelli, 2003):

a) El suelo representa a un complejo de efectos superpuestos de diferentes componentes del medio, a diferentes escalas temporales y espaciales. Su distribución espacial y su respuesta hidrológica (y geomorfológica) en cada punto de la superficie del terreno puede ser explicada de forma precisa a partir de su relación con el entorno del que procede.

b) Es posible analizar cuantitativamente y de forma distribuida el comportamiento hidrológico (y geomorfológico) del terreno a partir de la información que normalmente se dispone en un estudio.

c) Es posible, basándose en la información cartográfica con que normalmente se cuenta al inicio de un proyecto, analizar y cuantificar la variabilidad espacial de aquellos atributos del terreno de utilidad para caracterizar el comportamiento hidrológico (y geomorfológico) del mismo.

\footnotetext{
${ }^{23} \mathrm{El}$ valor más frecuente de un parámetro (si es discreto) o la máxima densidad de probabilidad ( si es continuo) en una población (en este caso, en cada unidad cartográfica de suelos)
} 
d) El aprovechamiento completo de la información cartográfica disponible exige de la incorporación de valores numéricos modales asociados a diferentes atributos del terreno sobre la base del conocimiento previo que se posee del tema y de la región estudiada.

De forma genérica para parametrizar o caracterizar una cuenca hidrográfica es necesario conocer (Puricelli, 2003):

a) El patrón o forma con el cual se distribuyen elementos tales como la topografía, la red de drenaje, los suelos, la litología, la cubierta vegetal, los usos del suelo, etc.

b) La forma en que las propiedades de estos afectan a la respuesta hidrológica de la cuenca (retención superficial, condiciones de encharcamiento, etc.).

c) El valor de los parámetros que caracterizan a cada una de las propiedades (permeabilidad, almacenamiento hídrico, etc.).

d) Los tipos de vínculos entre los diferentes componentes del terreno, a fin de poder extrapolar aquellos valores de los cuales no se cuenta con información suficiente.

El proceso práctico para llevar a cabo lo expuesto hasta ahora se puede resumir en los siguientes pasos:

1) Encontrar la distribución de unidades cartográficas que expliquen la variabilidad espacial del parámetro a estimar, esto es, mapas de suelos, vegetación, usos de suelos, topografía.

2) Asignar valores modales para cada una de las variables en cada unidad cartográfica.

3) Desarrollar un análisis que permita determinar cuales de las variables es relevante y cuales no.

4) Encontrar una relación matemática que explique la dependencia de los valores modales de los parámetros con las variables relevantes.

5) Aplicar la relación matemática encontrada en la región de análisis (cuenca hidrográfica).

En la formulación del modelo se explicará con más detalle cada uno de los pasos a seguir. 


\subsubsection{La calibración y validación}

Debido a la incertidumbre inherente en la aplicación de un modelo hidrológico y geomorfológico en una cuenca hidrográfica, se hace necesaria la calibración del modelo y su posterior validación. Estas incertidumbres tienen varias causas entre las cuales se destacan:

a) Los errores del modelo, tanto conceptuales como de su propia estructura.

b) La incertidumbre asociada a los parámetros que alimentan el modelo.

c) Los errores en los datos que alimentan el modelo, en el caso de los modelos hidrológicos y sedimentológicos, los datos de lluvia y caudales (líquidos y sólidos).

La calibración puede ser entendida como un método de ajuste entre los datos observados en la realidad y los simulados por el modelo, mientras que la validación es el proceso de prueba de este ajuste en condiciones diferentes a las utilizadas en la calibración, de esta forma se demuestra o se rechaza que se están simulando apropiadamente los procesos físicos dominantes en un sitio específico. Según Beven (2001b) la calibración de un modelo tiene las mismas características que un ajuste por regresión múltiple, en donde los parámetros óptimos serán tales que minimicen los errores residuales. Si hay residuales implica que existe incertidumbre en la predicción del modelo calibrado. De la misma forma que en una regresión, durante la validación estas incertidumbres son mayores a medida que las condiciones son más extremas o distintas a las empleadas durante la calibración (Vélez, 2003).

Existen varios métodos de calibración, de forma general se pueden clasificar en métodos manuales y métodos automáticos.

\subsubsection{La calibración manual}

Es el método de calibración más utilizado y puede ser concebido como un refinamiento del método de ensayo y error. Por medio de comparaciones visuales de los resultados simulados por el modelo con los datos observados se encuentran los parámetros que más se ajustan al modelo y a las condiciones físicas de la cuenca de análisis. De esta forma, el investigador es quien define cuales parámetros son más sensibles y cuales se determinan a priori, realizando una valoración de la relación existente entre los parámetros, las características del suelo, el tipo de vegetación, etc., haciendo que se reduzca el número de parámetros (Vélez, 2003).

El proceso de calibración manual es importante y en la mayoría de casos necesario, pues puede considerarse un análisis de sensibilidad de cada parámetro a calibrar. De esta forma no solo se reduce el número de parámetros (los poco o nada sensibles), sino que se logra definir los intervalos de variación de los demás parámetros. Esto facilita enormemente una posterior calibración automática, además de permitir al modelador conocer cuales procesos son determinantes en la respuesta hidrológica y sedimentológica de una cuenca. 


\subsubsection{La calibración automática}

La calibración automática se basa en utilizar métodos de optimización que a partir de criterios matemáticos definidos (la función objetivo), encuentren un juego óptimo de parámetros de forma tal que los resultados simulados por el modelo reproduzcan de forma más cercana posible los datos observados. El problema con la calibración automática en hidrología y sedimentología surge por la cantidad de procesos que dan cuenta de la respuesta de una cuenca hidrográfica, y por ende, el alto número de parámetros. De esta forma, no existe un solo juego de parámetros óptimo (por ejemplo, aquel que reproduce con mayor exactitud un evento), o muchos juegos de parámetros producen resultados muy cercanos a los observados. No sólo es necesario utilizar un método de optimización, además se necesita encontrar la incertidumbre asociada al juego, o los juegos de parámetros encontrados.

Vélez (2003) hace un recuento de los diferentes métodos de optimización utilizados en Hidrología, especificando las técnicas utilizadas, sus ventajas e inconvenientes.

\subsection{Aspectos destacados del capítulo}

En el presente capítulo se hace un repaso de los aspectos más importantes que deben considerarse en un modelo de producción, transporte y depósito de sedimentos a escala de cuencas, basado en el estado del arte actual. De este marco conceptual se destacan los siguiente puntos:

- La forma más utilizada para representar la topografía en una cuenca hidrográfica es a partir de Modelos de Elevación Digital. Además de permitir la incorporación de técnicas de resolución de ecuaciones en diferencias finitas en todos los elementos de discretización, se acoplan adecuadamente a datos derivados de imágenes de satélite y permiten desarrollar estrategias de interpolación con facilidad. Por otro lado, es fácil y directo derivar información topográfica útil para modelos hidrológicos y de erosión (pendiente, aspecto, dirección de flujo, índices de humedad y erosión, etc.). Por último a partir de un Modelo de Elevación Digital es posible definir las áreas fuentes para procesos erosivos (su iniciación y finalización).

- Son varios los procesos que dan cuenta de la respuesta hidrológica y sedimentológica de una cuenca hidrográfica. La importancia de estos procesos no solo depende de las condiciones particulares de cada cuenca sino del régimen de humedad a la que está sometida (estados de humedad, períodos de recesión o períodos de lluvia). Los procesos hidrológicos que tienen más relevancia en cuanto a la dinámica sedimentológica son los flujos superficiales y los flujos subsuperficiales de agua en los primeros niveles del suelo, estos procesos se presentan en períodos de lluvia, en los cuales se presenta la movilización de 
sedimentos (producción, transporte y sedimentación), por lo cual deben ser bien entendidos.

- Debido a la gran cantidad de parámetros que es necesario estimar en modelos de erosión con base física para cada elemento de discretización y a la alta incertidumbre de estos parámetros, se justifica utilizar modelos más simples con pocos parámetros, más si el modelo es a escala de cuenca.

- El modelo diseñado debe contar con una estructura coherente en los parámetros, para así asegurar la claridad de que parámetros se estiman y cuales se calibran.

Estas consideraciones se integrarán en la formulación del modelo. 


\section{Parte II}

\section{Formulación del Modelo}





\section{Capítulo 4}

\section{La formulación del modelo}

\subsection{Definición del sistema}

Definir un sistema significa delimitar la frontera que lo separa de su entorno. Para definir una cuenca hidrográfica es necesario tener en consideración los flujos de agua tanto en la superficie como al interior del suelo, puesto que una cuenca hidrográfica está delimitada por la superficie terrestre cuyas aguas fluyen hacia un misma corriente de agua, siendo la divisoria o límite superior las líneas de separación que se pueden trazar entre cuencas o vertientes adyacentes. Estas divisorias coinciden con crestas montañosas en las cuales cada lado conduce sus aguas hacia cauces distintos. En general se acepta que la divisoria de aguas superficiales coincide con la divisoria de aguas subsuperficiales y subterráneas, aunque este hecho no es real en todos los casos.

Si se parte de un Modelo de Elevación Digital es posible, para cada elemento de agregación, definir la dirección de flujo. De esta forma se pueden modelar los flujos laterales en superficie y subsuperficiales, suponiendo que estos se dan básicamente paralelos a la pendiente. Además es posible determinar el número de celdas que drenan hacia él y así determinar la cantidad de flujo que pasa por cada elemento de agregación. Teniendo en cuenta la dirección de flujo y su acumulación, se define para cada elemento de agregación su área de captación, y de esta forma se delimita el sistema a partir de la configuración topográfica de la cuenca hidrográfica.

Para simular los flujos verticales tanto en la vegetación, como en la columna de suelo y el sustrato, para cada celda se puede considerar que cada nivel del conjunto atmósfera - vegetación - suelo - acuífero corresponde a un tanque en el cual se almacena agua y se dan procesos de transferencia de flujo hacia tanques inferiores. De esta forma los almacenamientos en cada tanque son considerados los estados de humedad, esto es, las variables de estado y los flujos de agua las funciones de transferencia entre tanques, que dependen tanto del estado de humedad como de las características físicas del suelo y el sustrato. Así, se pueden simular los diferentes tipos de escorrentía que se dan en una cuenca hidrográfica. 
Combinando adecuadamente un Modelo de Elevación Digital con esquemas de tanques para cada celda se obtiene una representación tridimensional de una cuenca hidrográfica, permitiendo de esta forma considerar tanto los flujos laterales como verticales del agua y de igual forma, los flujos superficiales y los que se dan al interior del suelo y de la roca.

Este esquema ha sido adoptado satisfactoriamente en el modelo TETIS. A continuación se reseñan las características de la definición del sistema.

\subsection{Los elementos del sistema}

El sistema presenta tres elementos diferenciados, definidos por las áreas umbrales para que las diferentes componentes de la escorrentía salgan a la superficie. Además, estas áreas coinciden con la presencia de una incisión permanente en el terreno en donde se concentran los flujos, ya sea en cárcavas o en cauces. En la figura 4.1 se observa un esquema de la relación entre las áreas umbrales para las diferentes componentes de la escorrentía y el área de captación.

\begin{tabular}{|c|c|c|c|}
\hline $\begin{array}{l}\text { Componentes } \\
\text { de la } \\
\text { escorrentía }\end{array}$ & Escorrentía directa & $\begin{array}{l}\text { Escorrentía directa } \\
\text { e interflujo }\end{array}$ & $\begin{array}{l}\text { Escorrentía directa, } \\
\text { interflujo y flujo } \\
\text { base }\end{array}$ \\
\hline \multirow[t]{2}{*}{ Áreas fuente } & Ladera & Celdas con cárcava & $\begin{array}{r}\text { Celdas con cauce } \\
\text { Área de }\end{array}$ \\
\hline & $\begin{array}{l}\text { Áre } \\
\text { para }\end{array}$ & & $\begin{array}{l}\text { ral } \\
\text { base }\end{array}$ \\
\hline
\end{tabular}

Figura 4.1. Elementos del sistema, áreas umbrales y componentes de la escorrentía

\subsubsection{Laderas.}

Está definida por el área máxima para que el flujo superficial en ladera se concentre en una cárcava o un cauce. Como se ha mencionado, la escorrentía superficial en ladera se concentra en áreas muy pequeñas, del orden de metros cuadrados, en pequeños surcos. Estas áreas normalmente son menores al área de la celda en un modelo distribuido a escala de cuenca. De esta forma, todas las celdas presentan flujo superficial y procesos en ladera.

La escorrentía superficial en ladera termina cuando se encuentra un canal, ya sea una cárcava o un cauce. Si se supone que el flujo subsuperficial sale a la superficie (interflujo) por una cárcava efímera, el área máxima para el flujo superficial será igual al área umbral para el interflujo.

Las celdas de ladera no presentan un canal definido y el flujo se da en pequeños surcos, mientras que la transferencia de flujo y sedimentos se da por la ladera, hasta 
que llegue a una celda con cárcava o cauce. En estas áreas la escorrentía superficial es la única componente del flujo de agua.

En celdas de ladera los procesos hidrológicos y sedimentológicos en áreas entre surcos y surcos se tratan de manera conjunta, de esta forma no es necesario tratar de manera implícita las características topológicas y geométricas de los surcos. Este supuesto se justifica por la naturaleza aleatoria de los surcos y por la parsimonia del modelo.

\subsubsection{Cárcavas.}

El inicio de las cárcavas coincide con el área necesaria para que el flujo subsuperficial en ladera retorne a la superficie, proceso conocido como interflujo. El flujo subsuperficial en ladera se presenta en eventos de lluvia y normalmente sale a la superficie cuando se encuentra con una hendidura permanente del terreno, la cual en períodos de recesión no lleva agua. Estas hendiduras, conocidas como cárcavas, marcan el comienzo del interflujo.

La conexión hidrológica entre cárcavas y cauces se presenta en todas las situaciones, mientras que la conexión sedimentológica depende de la capacidad de transporte de cada cárcava y los sedimentos disponibles.

La escorrentía superficial en las celdas con área de captación mayor que el área umbral para el interflujo y menor que el área umbral para el flujo base se da en cárcavas. Esta escorrentía superficial es la suma entre la escorrentía directa y el interflujo.

\subsubsection{Cauces.}

Esta definida por el área necesaria para que el flujo subterráneo en el acuífero alcance la superficie del terreno. El flujo base coincide con la presencia de cauces que permanentemente llevan agua.

En las celdas con área de captación mayor que área umbral para el flujo base, la escorrentía superficial se presenta en cauces y es la suma de la escorrentía directa, el interflujo y el flujo base.

\subsection{La discretización espacial de la cuenca}

Los elementos de discretización corresponden a celdas cuadradas cuya longitud depende del tamaño de la cuenca, la resolución de la información (especialmente del Modelo de Elevación Digital) y los objetivos de la modelación. En términos generales, se considera de forma implícita que el conjunto de procesos que ocurren para que la precipitación se incorpore al flujo en la red de drenaje superficial se dan en cada celda. 
Es recomendable que el tamaño de la celda sea menor que el tamaño medio de las laderas de la cuenca hidrográfica, para de esta forma poder tener en consideración de manera explícita las áreas umbrales necesarias para que se presenten las diferentes componentes de la escorrentía y a la vez se pueda determinar el inicio y la finalización de las áreas fuente para la producción de sedimentos. Si el tamaño de la celda es mayor que el tamaño de las laderas, cada elemento de discretización presentará los diferentes tipos de escorrentía y las diferentes áreas fuente, de esta forma, se agregan todos los procesos y la simulación estará alejada de la realidad.

Vélez (2001) señala que para la definición del tipo de discretización de la cuenca, las celdas cuadradas presentan varios aspectos de facilidad operacional, entre los que destaca:

- La facilidad que desde el punto de vista topológico da el manejo de la malla de celdas donde cada una de ellas se puede definir mediante los índices de fila y de columna.

- La facilidad de conversión de información digital y gráfica a mapas digitales en formato ráster con un tamaño de celda compatible con el que se ha discretizado la cuenca.

- La facilidad para el cambio de escalas.

- Las posibilidades de pre-procesar los mapas en SIG comerciales en formato ráster.

- La facilidad de adaptar la información a un formato compatible con algunos de los SIG más comúnmente utilizados(GRASS, Idrisi, ArcGIS, etc.).

- La comodidad con el manejo del álgebra de mapas.

Así mismo, Vélez (2001) apunta que en la representación de la cuenca por celdas cuadradas, el tamaño de la celda debe estar relacionado con el tamaño característico de las laderas y con el esquema conceptual para la representación del flujo en las celdas. Además, las celdas deben ser tan pequeñas como se requiera para introducir la variabilidad espacial de la precipitación en cada intervalo de tiempo, representar la variabilidad espacial de la cobertura del suelo y diferenciar el tiempo de respuesta desde distintas unidades de producción de escorrentía. A estas consideraciones hay que añadir que el tamaño de las celdas debe reflejar las formas topográficas características, esto es, las zonas en donde converge el flujo (vaguadas), las zonas en donde el flujo diverge (divisorías de aguas), los cambios abruptos de pendiente, etc. Si el tamaño de la celda es mayor que el tamaño medio de las laderas, no es posible diferenciar dichas zonas.

Si la resolución de discretización de la cuenca (definida por el tamaño de celda) es adecuada, es posible diferenciar explícitamente para una unidad geomorfológica homogénea ${ }^{1}$, umbrales que definen el área necesaria para que el flujo subsuperficial

\footnotetext{
${ }^{1}$ Zona con características similares de clima, vegetación y suelos
} 
se incorpore a la red de drenaje. Es importante anotar que el flujo subsuperficial ocurre en eventos de lluvia y en la mayoría de los casos se presenta concentrado en incisiones permanentes del terreno, las cuales en períodos de recesión no llevan agua (cárcavas efímeras). De tal forma es posible asociar dicha área tanto al umbral para la generación del interflujo (escorrentía que retorna a la superficie que se infiltró aguas arriba en la ladera y que fluye a través del subsuelo), con el inicio de las cárcavas efímeras. Análogamente, el área umbral necesaria para que se de el flujo base en una unidad geomorfológica homogénea, se puede relacionar con la presencia de cauces permanente.

En cuanto al área necesaria para que se presenten surcos, se ha mencionado anteriormente que esta es muy pequeña y solo en Modelos de Elevación Digital de alta resolución (del orden de centímetros de tamaño de celda) es posible tratar de manera explícita dichas áreas. Al respecto, Vélez (2001) anota que el flujo que se drena a través de los surcos se forma a partir de un área significativamente pequeña; en la representación por celdas se considera que esta área puede ser representada por una sola celda (en la mayoría de los casos). Cuando se tienen representaciones muy finas con celdas muy pequeñas esta área puede ser representada por un número determinado de celdas acumuladas.

Las áreas umbrales así definidas, representan el área necesaria para que los flujos al interior del suelo (en el caso del flujo subsuperficial, el nivel superior del suelo y en el caso del flujo base, la roca o nivel inferior del suelo, o acuífero), retornen a la superficie, en donde se trasladan en incisiones del terreno, ya sea en cárcavas efímeras o en cauces permanentes. La escorrentía superficial no necesita un área umbral y se puede considerar que ocurre en todas las celdas. Además, la escorrentía superficial fluye sobre pequeños surcos, que como se ha mencionado son básicamente aleatorios y cuyas dimensiones geométricas y densidad se presentan en una escala inferior a la de una celda (más si el modelo es a escala de cuenca).

Por lo mencionado anteriormente se pueden considerar dos niveles de discretización en una cuenca hidrográfica: a) la unidad de discretización elemental (las celdas), y b) las unidades geomorfológicas homogéneas.

\subsubsection{La unidad elemental de discretización, la celda}

Estos elementos presentan una forma y un área homogénea para toda la cuenca y se pueden considerar las unidades más simples en donde se presentan los procesos hidrológicos y sedimentológicos. La variabilidad de parámetros con respecto a las celdas vecinas depende básicamente de aspectos topográficos (pendiente, dirección de flujo, acumulación de flujo, posición topográfica relativa en la ladera).

Para considerar los flujos de agua verticales en una celda, se representa la celda como una serie de tanques de almacenamiento interconectados por funciones de transferencia que dependen tanto del estado de humedad como de las características físicas del suelo. Cada tanque representa un nivel del agregado atmósfera vegetación - suelo - acuífero. De esta forma los parámetros hidrológicos de cada 
tanque están relacionados con la capacidad de almacenamiento, el espesor de cada nivel y con las velocidades de flujo características de cada nivel.

Las salidas de agua para cada celda representan los diferentes mecanismos de producción de escorrentía, y corresponden a la conexión lateral entre celdas. Dependiendo de la posición topográfica de la celda, definida por su área de captación (o lo que es lo mismo, por el número de celdas que drenan hacia ella), estas salidas se efectúan ya sea para el tanque correspondiente de la celda aguas abajo (si el área de captación es menor que el área umbral para determinado flujo al interior del suelo) o para el cauce de la misma celda (si el área de captación es mayor que el área umbral). Para considerar adecuadamente los flujos laterales entre celdas se hace necesario tener en cuenta la distancia que recorre cada flujo, que depende del tamaño de la celda.

Siguiendo este esquema, los flujos de agua tanto laterales como verticales, se consideran y se tratan de forma uni-dimensional. La figura 4.2 es un esquema simplificado de los diferentes niveles de cada celda.

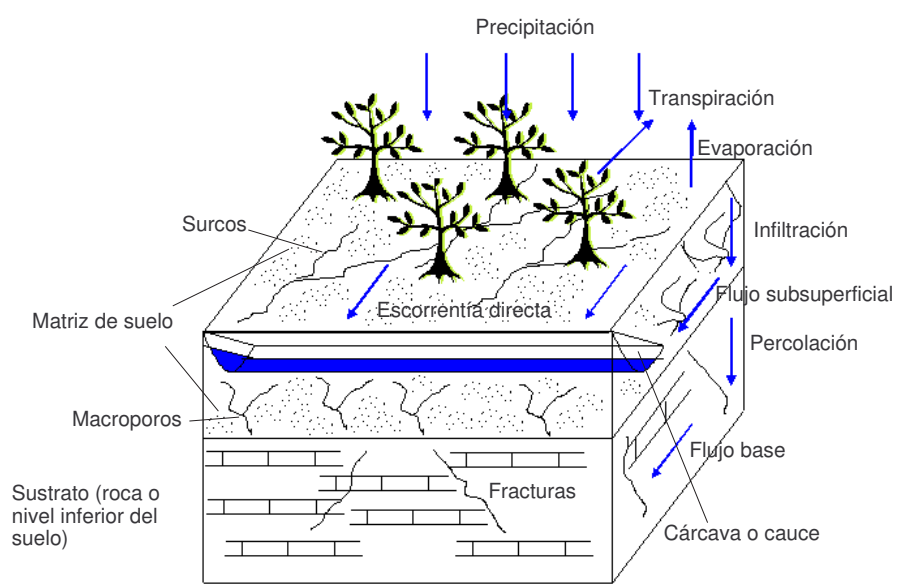

Figura 4.2. Esquema simplificado de una celda

En la figura 4.2 se observan los diferentes procesos hidrológicos que ocurren en un evento de lluvia en cada celda del modelo. Además se bosquejan las rutas preferentes de agua, tanto a nivel superficial (surcos) como al interior del suelo (macroporos y fracturas). Como se ha mencionado, de acuerdo a la posición topográfica de cada celda, las salidas de agua pueden ser a los niveles correspondientes de la celda aguas abajo o al cauce o cárcava perteneciente a la celda. Si la celda no tiene un área de captación suficiente para que posea un canal (cárcava o cauce), la única componente de flujo superficial de agua será la escorrentía directa, la cual se traslada por la ladera a la celda aguas abajo.

En cada intervalo de tiempo de simulación, la precipitación se distribuye entre los diferentes tanques y en cada uno de ellos se determina su contribución a la 
escorrentía. Posteriormente se realiza el balance para actualizar el volumen en cada uno de los tanques.

Vélez (2001) define las celdas interiores de ladera como aquellas que poseen un área de captación menor que el área umbral para el interflujo, teniendo en cuenta que este se realiza en la capa superior del suelo y se incorpora al cauce en la base de la ladera. Análogamente, define las celdas interiores de una subcuenca como aquellas que tienen un área de captación menor que el área umbral para el flujo base. De esta forma las celdas que contribuyen directamente al flujo base presentan un área de captación mayor.

El tamaño de la celda (resolución espacial) tiene efectos en la representación de la topografía y en los procesos hidrológicos y sedimentológicos simulados.

En cuanto a la representación de la topografía, mientras mayor sea el tamaño de la celda, la pendiente tiende a suavizarse. Además se pierde detalle en la representación de las geoformas (crestas, laderas, fondos de valles, vaguadas, depósitos, etc.). Al respecto Kienzle (1996) recomiendan tamaños de celda entre $50 \mathrm{~m}$ y $100 \mathrm{~m}$ para una adecuada representación de geoformas, mientras que con resoluciones mayores que $400 \mathrm{~m}$ no se representan dichas geoformas.

Puesto que los modelos hidrológicos distribuidos basados en Modelos de Elevación Digital utilizan para cada elemento de agregación la pendiente y además se basan en él para representar la topología de la red de drenaje, la dirección de flujo y su acumulación, el efecto de la representación de la topografía se refleja en los resultados arrojados en el modelo. Rojas (2002) hace una recopilación de estudios sobre el efecto del tamaño de la celda en diferentes modelos hidrológicos distribuidos y en la mayoría se coincide en recomendar tamaños menores que $200 \mathrm{~m}$.

Este efecto se hace mayor cuando se simulan procesos erosivos. Según Rojas (2002), varios estudios concluyen que es necesario incluir factores correctores dependientes del tamaño de la celda cuando se simulan procesos erosivos a partir de Modelos de Elevación Digital . Dicha autora, luego de analizar diferentes estudios al respecto recomienda utilizar un tamaño de celda igual o menor que $100 \mathrm{~m}$ en modelos de erosión.

\subsubsection{La conexión lateral entre celdas.}

De acuerdo a lo mencionado hasta ahora la conexión lateral entre celdas depende de las áreas umbrales necesarias para que las diferentes componentes de la escorrentía contribuyan al flujo en la red de drenaje. De esta forma se están involucrando distintas escalas espaciales de este modo (Vélez, 2001):

- El área mínima necesaria para la presencia de un flujo base procedente del acuífero y por encima de la cual los cauces son perennes, determina un umbral de área que se asocia con el tamaño de las subcuencas. Por debajo de este umbral de área el flujo subterráneo se transfiere en la ladera hacia la celda vecina de acuerdo a la dirección definida previamente para el flujo. 
- El área mínima para que el flujo subsuperficial salga a la red de drenaje, se asocia a un umbral de área tal que el flujo subsuperficial encuentra un cauce que corresponde a una incisión suficientemente profunda en el terreno. Por debajo de este umbral de área el flujo subsuperficial se transfiere de una celda a otra aguas abajo en la dirección predefinida del flujo.

- El área máxima de drenaje para la transferencia del flujo superficial en la ladera de una celda a otra, se define como umbral de área de flujo superficial, a partir del cual la transferencia es hacia los elementos de la red de drenaje.

En cuanto al área máxima para que se de flujo superficial en ladera, se puede considerar que esta es menor que el tamaño de la celda para un modelo a escala de cuenca, desde este punto de vista su definición puede ser innecesaria. Otra posibilidad es considerar que esta área coincide con el área mínima para el flujo subsuperficial, teniendo en cuenta que esta área coincide con la presencia de una incisión profunda del terreno (cárcava efímera), la cual sería la finalización del flujo superficial en ladera. En cualquiera de las dos opciones, sólo se necesitan dos áreas umbrales (una para el interflujo y otra para el flujo base).

La figura 4.3 muestra el esquema de las celdas y su conexión entre los elementos de la ladera.

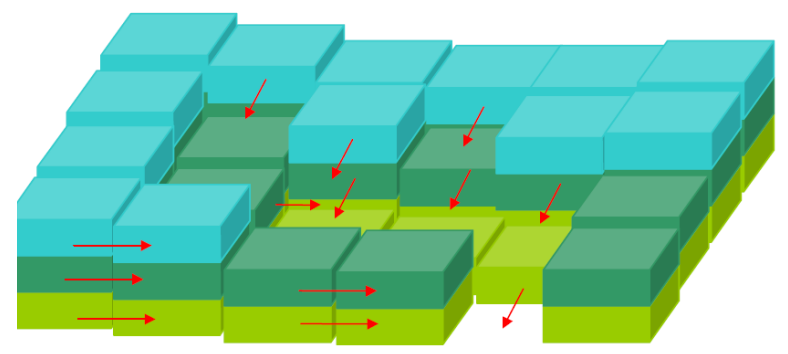

Figura 4.3. Esquema de las celdas y su conexión lateral, figura tomada de Vélez (2001)

\subsubsection{Los tanques en el modelo TETIS y su conexión vertical.}

La conexión vertical entre tanques da cuenta de los procesos hidrológicos fundamentales, representados por funciones de transferencia simples y con sentido físico. En la figura 4.4 se observa el esquema de conexión entre tanques.

El agua que entra a la celda es la suma entre la lluvia caída y la nieve fundida, la cual se almacena en el tanque $H_{0}$.

El tanque $H_{1}$ corresponde al almacenamiento estático, esto es, el agua que se encuentra en el nivel superior del suelo y que es utilizada por las plantas para sus ciclos vitales. Además, en este tanque se incluye el agua que se retiene en charcos 


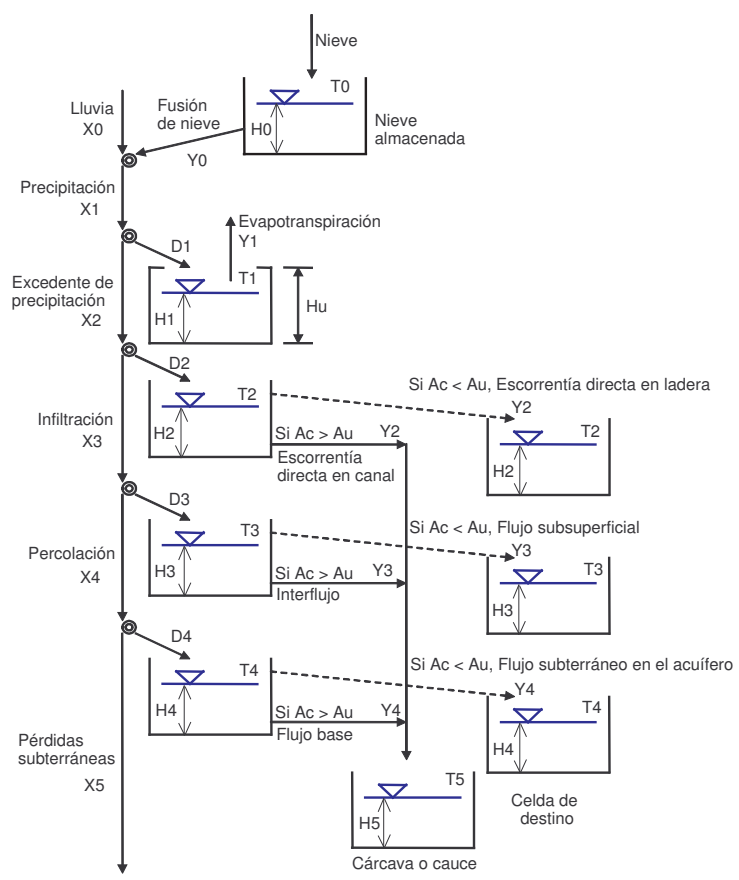

Figura 4.4. Esquema de conexión hidrológica entre tanques, adaptado de Vélez (2001)

y depresiones del terreno y la que es interceptada por las plantas. En este tanque la única salida posible es por evapotranspiración. El parámetro $H_{u}$ es la máxima capacidad de almacenamiento de agua y es función de las características del suelo y la profundidad de la zona de raíces.

El excedente de precipitación se distribuye entre el tanque $H_{2}$ y el agua que se infiltra en el suelo. El tanque $H_{2}$ representa el almacenamiento del agua mientras fluye superficialmente por la ladera. Así, el agua que sale de este tanque corresponde a la escorrentía directa.

Si se considera que el área umbral para que la escorrentía directa se canalice es menor que el área de una celda, la traslación de escorrentía directa entre celdas se hará por la red de cauces y de esta forma se supone que la red de pequeños surcos al interior de la celda se puede representar como un canal equivalente. En este caso, ninguna celda de la cuenca aportará escorrentía directa al tanque correspondiente de la celda aguas abajo.

Si el área umbral es mayor que el área de una celda, por ejemplo, en el caso de que esta área sea igual a la del inicio de cárcavas efímeras, la escorrentía directa se traslada por la ladera hasta que llegue a una celda con área de captación mayor que el área umbral (en este caso, será igual al área umbral para el interflujo).

$\mathrm{El}$ agua que se infiltra se distribuye entre el tanque $H_{3}$ y el agua que se percola al nivel inferior del suelo. El tanque $H_{3}$ representa el almacenamiento gravitatorio, 
esto es, el almacenamiento del agua mientas fluye lateralmente a través de la capa superior del suelo y hacia la red de drenaje. En este tanque se da el flujo subsuperficial y las salidas pueden ser al tanque correspondiente de la celda aguas abajo o a la red de drenaje como interflujo. Estas dos opciones dependen del área umbral para el interflujo ( $A_{u}$ en la figura 4.4) y el área de captación de la celda ( $A_{c}$ en la figura 4.4).

El agua que se percola se distribuye entre el tanque $H_{4}$ y las pérdidas subterráneas. El tanque $H_{4}$ representa el nivel inferior del suelo o el sustrato rocoso, esto es el acuífero, y el agua que se almacena es el nivel de flujo base o flujo subterráneo. Las salidas de este tanque pueden ser directamente al cauce de la celda (como flujo base) o al nivel correspondiente de la celda aguas abajo (como flujo subterráneo en el acuífero), dependiendo de la relación entre el área de captación de la celda y el área umbral para el flujo base.

Una vez se simulan los flujos de agua, se calculan los procesos sedimentológicos para cada celda, basados en la aproximación desarrollada en el CASC2D-SED (Rojas, 2002).

De acuerdo con la capacidad de transporte de sedimentos del caudal que pasa por cada celda, ya sea en ladera o en canal, y la cantidad de sedimentos disponibles para cada tamaño de grano considerado, se calcula inicialmente los sedimentos transportados por suspensión. Si aún queda capacidad de transporte se utiliza para transportar los sedimentos como caudal sólido de fondo. Si todavía queda capacidad de transporte, esta es utilizada para erosionar sedimentos en ladera, de acuerdo con el porcentaje de tamaños de grano del primer nivel del suelo.

Los sedimentos generados se trasladan al nivel correspondiente de sedimentos en suspensión de la celda de destino, donde posteriormente se depositan según la velocidad del flujo, la altura de agua y la velocidad de sedimentación de cada fracción de tamaño analizada. En los cauces no se dan procesos de erosión, de esta forma la capacidad de transporte remanente no se utiliza. La figura 4.5 es un esquema de los procesos sedimentológicos en ladera y la figura 4.6 es un esquema de los procesos sedimentológicos en canal.

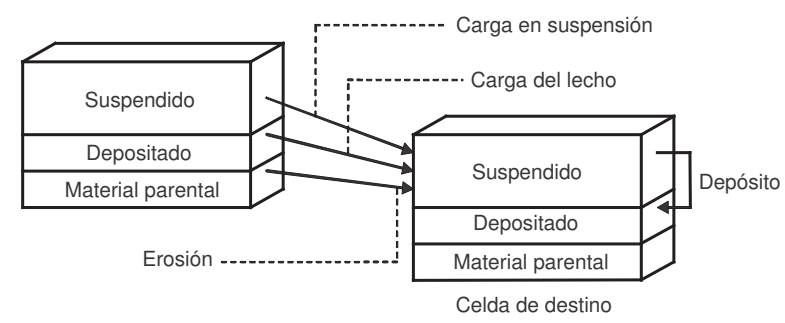

Figura 4.5. Esquema de procesos sedimentológicos en ladera para cada celda 


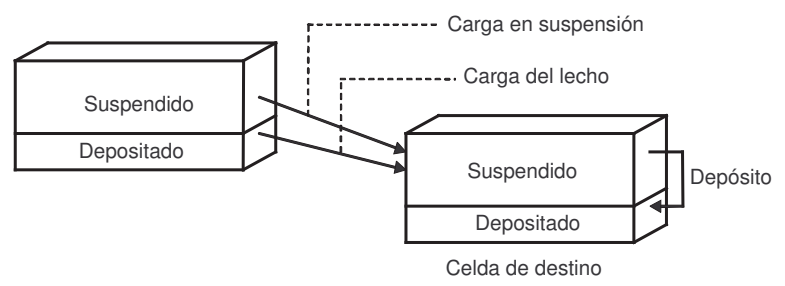

Figura 4.6. Esquema de procesos sedimentológicos en canal para cada celda

\subsubsection{Las unidades geomorfológicas homogéneas}

El otro nivel de discretización corresponde a zonas en donde las condiciones climáticas, de suelos, de vegetación y de usos del suelo son similares. De esta forma, las características geomorfológicas de estas zonas serán similares. El modelo presenta una serie de parámetros geomorfológicos que caracterizan la red de drenaje, entre ellas hacen parte las áreas umbrales para el interflujo (o la iniciación de cárcavas efímeras) y el flujo base (o la iniciación de cauces permanentes). Estas unidades geomorfológicas homogéneas se diferencian por que sus parámetros geomorfológicos son constantes.

\subsection{La discretización temporal de los proce- sos}

Para cada intervalo de simulación se aplican las relaciones funcionales de transferencia de flujos entre tanques y entre celdas y se actualizan los almacenamientos.

El intervalo temporal de simulación depende de los objetivos de la modelación y del tamaño de la cuenca hidrográfica. Si el objeto es simular eventos de lluvia intensos, el intervalo debe ser del orden de minutos, puesto que en estos eventos se dan procesos rápidos de transferencia lluvia - escorrentía, tales como la escorrentía hortoniana. El tamaño de la cuenca influye en el intervalo temporal de simulación, debido a que este debe estar relacionado con el tiempo de concentración de la cuenca.

Si el objeto de la modelación es simular el comportamiento anual se recomienda un intervalo temporal de simulación del orden de horas o como máximo un día. Si se quieren modelar comportamientos multianuales (por ejemplo, para la gestión de recursos hídricos) el intervalo de simulación es del orden de días.

Puesto que la respuesta hidrológica y sedimentológica de una cuenca comprende diferentes escalas temporales es recomendable que el modelo considere diferentes intervalos temporales de simulación. Por ejemplo, en eventos de lluvias intensas se debe utilizar intervalos temporales de simulación cortos (del orden de minutos), mientras que en períodos de recesión o en lluvias de poca intensidad, se reco- 
miendan intervalos temporales de simulación largos (horas o días). De esta forma se asegura que el modelo reproduzca los procesos determinantes de la respuesta hidrológica adecuadamente y a la vez se logra una mejor eficiencia computacional.

Una práctica habitual al simular eventos de lluvia es considerar las condiciones climáticas en períodos anteriores para estimar las condiciones de humedad precedente. Por ejemplo, se simula un evento de lluvia con duración de cinco horas con un intervalo temporal de simulación de cinco minutos; para estimar las condiciones de humedad precedente se tiene en cuenta la precipitación en los últimos dos meses antes del evento con simulaciones con un intervalo temporal de un día.

Un aspecto que se debe tener en consideración es que los parámetros del modelo tienen relación con el intervalo temporal de simulación, por lo que normalmente se deben efectuar calibración para cada intervalo temporal de simulación utilizado.

\subsection{Los procesos y el funcionamiento del mo- delo}

Una vez definido el sistema y la forma como se conectan los diferentes elementos, se detalla en este capítulo la forma de simular los procesos, esto es, las relaciones funcionales de transferencia. Además se detalla el funcionamiento del modelo, reseñando las variables de estado, los algoritmos utilizados para actualizar dichas variables en cada intervalo temporal de simulación y en cada elemento de agregación espacial.

\subsubsection{Los procesos hidrológicos}

Para cada intervalo temporal de simulación y para cada celda se efectúa un balance hidrológico aplicando diferentes relaciones funcionales para cada proceso de transferencia entre los diferentes tanques que componen cada celda. A continuación se detallan los procesos que ocurren entre los tanques, tal como se reseñan en el parágrafo 4.3.1.2 (ver figura 4.4).

\subsubsection{El almacenamiento estático}

Corresponde al segundo tanque de almacenamiento del modelo $\left(T_{1}\right)$. El almacenamiento estático representa el agua que transita por la cuenca y que no se infiltra ni escurre superficialmente y sale de la cuenca por evapotranspiración, esto es las abstracciones iniciales. En este tanque se representan los procesos de intercepción de la lluvia por la cubierta de vegetación, la detención del agua en charcos y depresiones de la topografía y el agua que se retiene en el nivel superior del suelo por fuerzas capilares y que es utilizada por las plantas para sus ciclos vitales.

Para calcular la lluvia $\left(X_{0}\right)$ que cae en la celda se tiene en cuenta los registros de precipitación de las $n$ estaciones más cercanas, utilizando el método de 
interpolación espacial del inverso de la distancia. Además, es posible considerar el efecto orográfico, con la inclusión de un factor corrector lineal que tiene en cuenta el cambio en la lluvia debido a la diferencia de altura entre la celda y las estaciones de precipitación. La expresión utilizada es:

$$
X_{0}=\sum_{j=1}^{n} \varpi_{j}\left[X_{1, j}+\beta\left(z-z_{j}\right)\right]
$$

donde $\varpi_{j}$ es el factor de ponderación del inverso de la distancia, $X_{1, j}$ es la precipitación registrada en la estación $j, z$ es la altura de la celda, $z_{j}$ es la altura de la estación $j, \mathrm{y} \beta$ es el parámetro que caracteriza el incremento de precipitación debido a la diferencia de altitud.

La suma de la lluvia y la cantidad de nieve fundida corresponde a la precipitación $\left(X_{1}=Y_{0}+X_{0}\right)$, la cual entra al conducto del que se deriva una cantidad $D_{1}$ para el tanque del almacenamiento estático. Se supone que este tanque tiene una capacidad máxima de almacenamiento $H_{u}^{\star}$, igual a la suma de la capacidad de almacenamiento capilar del suelo, el almacenamiento de agua en depresiones del terreno y la capacidad de la cobertura de vegetación para almacenar agua.

La capacidad de almacenamiento capilar del suelo está relacionada con la cantidad de agua que hay que agregar a una columna de suelo con contenido de humedad igual al punto de marchitez hasta alcanzar el mayor almacenamiento posible sin que el agua fluya por la acción de la gravedad, esto es, la humedad a capacidad de campo. El almacenamiento capilar del suelo depende de la profundidad de raíces, la textura de los niveles del suelo en dicha profundidad y el contenido de materia orgánica.

La cantidad de agua que no ingresa al almacenamiento estático corresponde al excedente de precipitación, $X_{2}$, y depende del contenido de humedad del suelo, representado por la cantidad almacenada en el tanque de almacenamiento estático, $H_{1}$, de la capacidad máxima de almacenamiento, $H_{u}^{\star}$, y la precipitación, $X_{1}$, de acuerdo con la expresión:

$$
X_{2}=\operatorname{Max}\left\{0 ; X_{1}-H_{u}^{\star}+H_{1}\right\}
$$

Lo cual es equivalente a suponer una capacidad de infiltración infinita hasta que el tanque de almacenamiento estático se llene.

Aunque la evapotranspiración no es relevante en períodos de lluvia intensos, en el modelo se tiene en cuenta. Esto debido a que puede llegar a ser importante en cuencas grandes. Además es relevantes en períodos de recesión y es necesario tenerla en cuenta para estimar los estados de humedad al inicio de un evento.

La cantidad de agua que sale por evapotranspiración $\left(Y_{1}\right)$, se calcula como función del agua disponible en el tanque de almacenamiento estático $H_{1}$, la evapotranspiración potencial ETP, y el índice de cobertura vegetal, $\lambda^{\star}(m)$, de la siguiente forma:

$$
Y_{1}=\operatorname{Min}\left\{\operatorname{ETP} \cdot \lambda^{\star}(m) ; H_{1}\right\}, \quad m=1, \ldots, 12
$$


La ETP se estima para cada celda por el método de interpolación del cuadrado de la distancia teniendo en cuenta un número limitado de estaciones cercanas, sin el uso de un factor corrector por la altitud.

El índice de cobertura vegetal, $\lambda^{\star}(m)$, varía a lo largo del año según las condiciones particulares de desarrollo de cada cobertura, ya sea natural o cultivada y toma un valor diferente para cada mes $m$. Es un índice adimensional y toma valores entre 0 y 1 y se puede entender como una medida de la disponibilidad de humedad según la cobertura y la época del año, siendo 0 en condiciones de nula disponibilidad y 1 con máxima disponibilidad.

El agua que no ingresa al tanque del almacenamiento estático, hace parte del excedente de precipitación e ingresa al suelo o se mueve superficialmente en la ladera.

\subsubsection{El almacenamiento superficial}

Se trata del tercer tanque de almacenamiento del modelo $\left(T_{2}\right)$. Las salidas de agua de este tanque representan el agua que se mueve superficialmente por la ladera, por escorrentía directa $\left(Y_{2}\right)$, y la que se infiltra en el suelo $\left(X_{3}\right)$. Se supone que la escorrentía directa viaja sobre la ladera como escorrentía laminar que se concentra rápidamente en pequeños surcos hasta alcanzar un elemento de la red de drenaje. De esta forma, tanto las cantidades almacenadas como el tiempo de residencia debe ser acorde con las laderas reales.

En cuanto a la cantidad que se infiltra en el suelo, se supone que la capa superior del suelo tiene una conductividad hidráulica representativa que depende de la textura y estructura del mismo y de la cobertura de vegetación y las prácticas de manejo del suelo. Puesto que el tanque inmediatamente superior da cuenta del agua que es utilizada por las plantas y se tiene en cuenta el almacenamiento debido a las fuerzas capilares (almacenamiento estático), esta conductividad hidráulica se puede considerar para suelos en condiciones de saturación $\left(k_{s}^{\star}\right)$ y la infiltración se debe a las fuerzas gravitatorias. De esta forma, la cantidad que se infiltra se calcula según la siguiente relación:

$$
X_{3}=\operatorname{Min}\left\{X_{2} ; \Delta t \cdot k_{s}^{\star}\right\}
$$

Para simular la escorrentía directa se puede suponer que la ladera se representa como un canal equivalente, cuyas características se determinan en función de la morfología y la cobertura de cada celda. Si se aplica la ecuación de continuidad y se supone una velocidad constante, la escorrentía directa se representa mediante un embalse lineal:

$$
Y_{2}=\alpha \cdot H_{2}
$$

donde $\alpha$ es el coeficiente de descarga y toma la siguiente forma: 


$$
\alpha=1-\frac{\Delta x}{\Delta x+v^{\star} \cdot \Delta t}
$$

Para la velocidad de flujo en ladera se considera que $v^{\star}=1,4 \cdot S_{0}^{0,5}$, donde $S_{0}$ es la pendiente de la celda y el coeficiente 1,4 corresponde a una estimación previa realizada para asegurar que el intervalo de velocidades se encuentre entre 1 y $0,01 \mathrm{~m} / \mathrm{s}$ para un amplio intervalo de pendientes. El coeficiente de descarga aumenta a medida que se aumenta el intervalo temporal o se disminuye el tamaño de la celda.

\subsubsection{El almacenamiento gravitatorio}

Corresponde al cuarto tanque de almacenamiento del modelo $\left(T_{3}\right)$ y representa el agua gravitatoria almacenada en el suelo. En este tanque el agua tiene dos posibles salidas, una hacia el nivel inferior del suelo o de la roca subyacente por medio de la percolación $\left(X_{4}\right)$ y la otra fluyendo lateralmente (paralela a la pendiente) en el subsuelo como flujo subsuperficial $\left(Y_{3}\right)$, la cual sale a la superficie como interflujo.

$\mathrm{Al}$ igual que la infiltración, se supone que la capa inferior del suelo a escala de celda tiene una capacidad de percolación característica, la cual se puede asociar a la textura y estructura del sustrato (ya sea suelo o roca).

La cantidad de agua que se percola $\left(X_{4}\right)$ se asocia al excedente de infiltración $\left(X_{3}\right)$ y a la conductividad hidráulica del suelo en condiciones de saturación $\left(k_{s}^{\star}\right)$ de acuerdo a la siguiente relación:

$$
X_{4}=\operatorname{Min}\left\{X_{3} ; \Delta t \cdot k_{s}^{\star}\right\}
$$

Para el cálculo del flujo subsuperficial se efectúa una formulación análoga a la presentada en el almacenamiento superficial, obteniéndose la siguiente relación lineal:

$$
Y_{3}=\alpha \cdot H_{3}
$$

donde:

$$
\alpha=1-\frac{\Delta x}{\Delta x+k_{s s}^{\star} \cdot \Delta t}
$$

en donde $k_{s s}^{\star}$ representa la conductividad hidráulica horizontal del suelo, definida por la estructura de macroporos del suelo.

\subsubsection{El almacenamiento subterráneo, el acuífero}

Corresponde al quinto tanque de almacenamiento $\left(T_{4}\right)$ y representa el almacenamiento subterráneo. Las salidas posibles son por pérdidas subterráneas $\left(X_{5}\right)$ o como flujo subterráneo en el acuífero $\left(Y_{4}\right)$, el cual cuando encuentra un cauce pasa a formar el flujo base. 
Al igual que los tanques de almacenamiento superiores, se pretende que tanto la cantidad almacenada como el tiempo de residencia, sean coherentes con el comportamiento de los flujos de agua en los acuíferos de la cuenca. El agua que ingresa por percolación puede derivarse o a las pérdidas subterráneas, las cuales no regresan ni a la superficie ni a los cauces, o al almacenamiento subterráneo.

Las pérdidas subterráneas $\left(X_{5}\right)$ se asocian a la percolación $\left(X_{4}\right)$, a la conductividad hidráulica de la roca en condiciones de saturación $\left(k_{p p}^{\star}\right)$, y al estado del tanque, de la siguiente forma:

$$
X_{5}=\operatorname{Min}\left\{X_{4} ; \Delta t \cdot k_{p p}^{\star}\right\}
$$

Para la representación del flujo a través del acuífero, se utiliza la ecuación de continuidad y una ecuación que relaciona la tasa de flujo que sale de este almacenamiento con la cantidad de agua almacenada. Las salidas de almacenamiento subterráneo se calculan de acuerdo a la siguiente ecuación:

$$
Y_{4}=\alpha \cdot H_{4}
$$

donde:

$$
\alpha=1-\frac{\Delta x}{\Delta x+k_{b}^{\star} \cdot \Delta t}
$$

donde $k_{b}^{\star}$ es la conductividad hidráulica horizontal de la roca o el nivel inferior del suelo.

$\mathrm{Al}$ simular el flujo subterráneo en crecidas, es posible reproducir adecuadamente las recesiones del flujo en los cauces.

\subsubsection{La traslación del flujo, la Onda Cinemática Geomorfológi- ca}

Una vez el modelo realiza el balance hidrológico en cada celda y se calculan las salidas de escorrentía en sus diferentes componentes (escorrentía directa, interflujo y flujo base), se procede a trasladar el agua a través de la red de drenaje, compuesta por cárcavas y cauces.

Cada componente de la escorrentía fluye, ya sea por la ladera en pequeños surcos (escorrentía directa), por el nivel superior del suelo (flujo subsuperficial), o por el acuífero (flujo subterráneo); hasta alcanzar un cauce o cárcava, según las áreas umbrales para cada flujo superficial y el área de captación de cada celda. Cuando el agua llega a la red de drenaje natural de la cuenca, comienza a circular por la red de drenaje en sí.

La traslación se realiza por medio de la onda cinemática, que como se ha visto, es una simplificación de las ecuaciones de flujo de Saint Vennant, en la cual se desprecian los términos correspondientes a los efectos inerciales y de presión en la ecuación de conservación de energía.

Suponiendo un canal prismático con una sección constante a lo largo de cada tramo de discretización de longitud $\Delta x$ y para cada intervalo de simulación $\Delta t$, 
la ecuación de continuidad se puede expresar en término de dos incógnitas, la velocidad de flujo $v_{t}^{\star}$ y el área de la sección transversal $A_{t}$, de acuerdo con la siguiente relación:

$$
A_{t} \Delta x+v_{t}^{\star} A_{t} \Delta t=I_{t}+S_{t-1}
$$

donde $S$ representa el volumen de agua que sale del tramo del cauce e $I_{t}$ son los flujos de entrada de las laderas (escorrentía superficial en ladera, interflujo y/o flujo base) y de los tramos de cauce aguas arriba.

Las características hidráulicas de los cauces, para cada celda, se obtienen con base en parámetros geomorfológicos de cada región homogénea, los cuales se obtienen de forma fácil y directa a partir de información de campo (o de literatura en su defecto). Esta metodología fue desarrollada por Vélez (2001) denominándola Onda Cinemática Geomorfológica, cuyas características se exponen a continuación.

La red de drenaje y la geometría hidráulica. La red de drenaje y su topología se obtiene a partir del Modelo de Elevación Digital, a partir de las direcciones de flujo y su acumulación en cada celda. De este modo, la calidad de representación de la red de drenaje depende de la resolución y la calidad del Modelo de Elevación digital y los algoritmos utilizados en su procesamiento.

Para obtener las características geométricas de la sección del canal (para cada celda) por donde se traslada el flujo se utilizan relaciones de la geometría hidráulica, previa validación de sus parámetros para cada región geomorfológica homogénea de la cuenca. Estas relaciones fueron propuestas inicialmente por Leopold y Maddock (1953), quienes relacionaron las dimensiones de la sección de flujo con el caudal en el cauce mediante las siguientes ecuaciones de tipo potencial:

$$
\begin{gathered}
h=b \cdot Q^{\beta} \\
W=c \cdot Q^{\alpha} \\
v=p \cdot Q^{\lambda}
\end{gathered}
$$

donde $h$ es la profundidad; $W$ es el ancho; $v$ es la velocidad del flujo; $Q$ es el caudal en el cauce; $b, c$, y $p$ son coeficientes empíricos; y $\beta, \alpha, \mathrm{y} \lambda$ son los exponentes empíricos de validez regional.

De acuerdo con fuertes evidencias empíricas se han determinado dos grupos de valores para los coeficientes y exponentes que han sido denominados "para la estaciónz "para aguas abajo". Los valores "para aguas abajo" predicen las variaciones de la geometría hidráulica a lo largo de un cauce natural y están basadas en caudales con un nivel de referencia geomorfológico común. La mayor evidencia empírica se ha obtenido para la sección del cauce expuesta como una cicatriz permanente en el terreno conocido como "caudal a sección llena", el cual se puede relacionar con un caudal con período de retorno definido (según las condiciones climáticas y geomorfológicas particulares), esta caudal también se puede relacionar con "el caudal formador".

Según Leopold et al. (1964) existe una relación entre el caudal a sección llena $Q_{b}$ en cada punto de la red de drenaje y el área de captación de la cuenca que 
drena a este punto $\Lambda$. Esta relación se da en regiones con condiciones climáticas y morfológicas homogéneas de la siguiente forma:

$$
\begin{gathered}
Q_{b} \propto \Lambda^{\varphi} \\
Q_{b}=\kappa \Lambda^{\varphi}
\end{gathered}
$$

donde $\kappa$ y $\varphi$ son parámetros que se presentan constantes en una región geomorfológica homogénea.

La rugosidad. De forma general, la variación de la rugosidad con la posición e incluso con el flujo, se da según la siguiente ecuación:

$$
n=\Omega \Lambda^{\sigma_{1}} h^{\sigma_{2}} S^{\sigma_{3}}
$$

donde $\Lambda$ es el área de drenaje, $h$ es la profundidad del flujo, y $S$ es la pendiente de la línea de energía del cauce.

El valor del coeficiente $\Omega$ y los exponentes $\sigma_{1}, \sigma_{2}, \sigma_{3}$ dependen de cada caso en particular y pueden ser regionalizados. En la práctica se determinan a partir del criterio experto del analista.

La velocidad del flujo. Para el cálculo de la velocidad del flujo se utilizan expresiones que relacionan la velocidad con el radio hidráulico de la sección $R_{h}$, la pendiente de la línea de energía $S$ y coeficientes empíricos de rugosidad o resistencia al flujo.

Si se utiliza la onda cinemática se supone que durante cada intervalo temporal de simulación $\Delta t$ y a lo largo de cada elemento de discretización $\Delta x$ la pendiente de la línea de energía es igual a la pendiente del terreno $\left(S=S_{0}\right)$. De esta forma, la velocidad y la profundidad del flujo se pueden relacionar mediante una ecuación de pérdida de energía, como la ecuación de Manning.

$\mathrm{Al}$ suponer un canal suficientemente ancho se tiene que:

$$
R_{h}=\frac{A_{t}}{W}
$$

donde $R_{h}$ es el radio hidráulico, $A_{t}$ es el área de la sección del flujo, y $W$ es el ancho de la sección.

La velocidad del flujo se puede expresar en función del área de la sección $A_{t}$, la pendiente $S_{0}$, el ancho $W$, y el coeficiente de rugosidad $n$, de la siguiente forma:

$$
v=\frac{1}{n}\left[\frac{A_{t}}{W}\right]^{2 / 3} S_{0}^{1 / 2}
$$

De acuerdo con estas expresiones es posible determinar de manera aproximada, razonable y representativa las condiciones de flujo para cualquier elemento de la red de drenaje de una región geomorfológica homogénea.

La ecuación de continuidad. La ecuación de continuidad asegura que en el modelo se mantiene el balance de masas. Si se supone que el flujo no está controlado aguas abajo, el volumen que se entrega aguas abajo de cada elemento de 
discretización depende únicamente de esta variable de estado. Además, se puede suponer una sección constante para toda la longitud del elemento, esto es, se considera un canal prismático en donde el almacenamiento es constante en toda su longitud. Con estos supuestos, la ecuación de continuidad se expresa de la siguiente forma:

$$
\begin{gathered}
A_{t} \Delta x+Q_{t} \Delta t=\sum_{j} I_{j, t}+S_{t-1} \\
A\left(\frac{\Delta x}{\Delta t}+v\right)=\frac{1}{\Delta t}\left(\sum_{j} I_{j, t}+S_{t-1}\right)
\end{gathered}
$$

Reemplazando la ecuación deducida para la velocidad se obtiene la siguiente expresión:

$$
A\left(\frac{\Delta x}{\Delta t}+\frac{A^{\varpi_{2}} s^{\varpi_{3}} \Lambda^{\varpi_{4}}}{B^{\varpi_{1}}}\right)=\frac{1}{\Delta t}\left(\sum_{j} I_{j, t}+S_{t-1}\right)
$$

donde:

$$
\begin{gathered}
B=\Omega\left(c_{1} \kappa^{\left(\alpha_{1}-\alpha_{2}\right)}\right)^{\left(2 / 3-\sigma_{2}\right)} \\
\varpi_{1}=\left(\frac{1}{1+\alpha_{2}\left(2 / 3-\sigma_{2}\right)}\right) \\
\varpi_{2}=\left(2 / 3-\sigma_{2}\right)\left(1-\alpha_{2}\right) \varpi_{1} \\
\varpi_{3}=\left(1 / 2-\sigma_{3}\right) \varpi_{1} \\
\varpi_{4}=\left(\varphi\left(2 / 3-\sigma_{2}\right)\left(\alpha_{2}-\alpha_{1}\right)+\sigma_{1}\right) \varpi_{1}
\end{gathered}
$$

La ecuación 4.23 es no lineal, pero es posible resolverla numéricamente, encontrando el área por un proceso iterativo. El coeficiente $B$ y los exponentes $\varpi_{1}, \varpi_{2}$, $\varpi_{3}, \varpi_{4}$ dependen de condiciones geomorfológicas, homogéneas para una región, de esta forma no dependen de condiciones locales ni del tiempo. La pendiente y el área de drenaje varían para cada elemento de discretización (celda), pero son conocidas (a partir del Modelo de Elevación Digital). El término de la derecha varía para cada elemento y para cada intervalo temporal. De esta forma, una vez obtenida el área se reemplaza en la ecuación de velocidad para finalmente obtener la descarga para cada elemento de la red de drenaje.

\subsubsection{Los procesos sedimentológicos}

Una vez el modelo efectúa el balance hidrológico en cada celda y calcula la traslación del flujo para todos los elementos de la red de drenaje, se simulan los procesos sedimentológicos. Para cada celda, se dan procesos de producción, transporte y depósito de sedimentos en ladera, mientras que en los elementos de la red de drenaje se presenta el transporte y depósito de sedimentos. 
El submodelo sedimentológico está basado en la formulación desarrollada en el CASC2D-SED, desarrollado en el Engineering Research Center de la Colorado State University en Fort Collins, USA, específicamente en la versión de Rojas (2002). El CASC2D-SED simula los procesos de sedimentos en ladera en dos dimensiones, mientras que en canales la aproximación es unidimensional. En el nuevo modelo desarrollado, tanto los procesos en ladera como en canales son unidimensionales, en el sentido de la pendiente.

Una vez una partícula de suelo es erosionada, esta comienza a hacer parte del flujo y es transportada aguas abajo. Una partícula que pasa sobre cualquier punto de control de la cuenca necesariamente se erosionó aguas arriba y ha sido transportada por el flujo (Einstein, 1950) ${ }^{2}$. Las tasas de producción, transporte y depósito están controladas por dos características: la disponibilidad de sedimentos en la cuenca y la capacidad de transporte de la corriente. Normalmente los materiales finos que son fácilmente transportados en grandes cantidades por el flujo, están limitados por la disponibilidad de sedimentos en la cuenca. Los materiales gruesos son más difíciles de transportar por la corriente, así la tasa de movimiento está limitada por la capacidad de transporte del flujo (ver figura 3.17).

Se supone que el caudal sólido viaja a lo largo del sistema por las corrientes. Las fracciones gruesas se mueven como caudal sólido de fondo. El caudal total de sedimentos consiste tanto en el caudal sólido de fondo como en el caudal sólido en suspensión. La velocidad necesaria para que una partícula se mueva a través de la corriente depende del tamaño de la partícula, siendo pequeña para limos y arcillas en suspensión y alta para el caso de las arenas y gravas (Francis, 1973) ${ }^{3}$. Este hecho es importante para predecir el movimiento de tamaños diferentes de partículas en el flujo. Los algoritmos de producción, transporte y depósito de sedimentos, tanto en laderas como en canales, han sido desarrollados para simular el proceso descrito.

\subsubsection{Los procesos sedimentológicos en ladera}

En la parte correspondiente a las laderas, para cada celda, se determinan los procesos de producción, transporte y depósito de sedimentos. Si la celda presenta un canal, ya sea una cárcava o un cauce, los sedimentos producidos se añaden a dicho canal y se transportan por el canal a la celda aguas abajo. Si la celda es de ladera, los sedimentos producidos se transportan por la ladera a la parte correspondiente a la ladera de la celda aguas abajo, hasta que se encuentre una celda con canal.

Sobre la ladera, el modelo utiliza la ecuación de Kilinc y Richardson (1973) de capacidad de transporte, que depende del caudal y la pendiente del terreno. Si se tienen mapas distribuidos con los factores de la USLE (erosionabilidad, prácticas de manejo y prácticas de conservación) se puede utilizar la ecuación modificada de Kilinc y Richardson, propuesta por Julien (1998).

\footnotetext{
${ }^{2}$ Tomado de Rojas (2002)

${ }^{3}$ Tomado de Rojas (2002)
} 
Las partículas pequeñas como limos y arcillas se mueven principalmente por suspensión mientras que las fracciones de arena se mueven como caudal sólido de fondo. Este hecho es utilizado en el concepto de reposo de partícula y el transporte de caudal sólido en suspensión por procesos advectivos. Las arenas presentan altas velocidades de sedimentación por lo cual se depositan rápidamente, mientras los finos permanecen en suspensión debido a las bajas velocidades de sedimentación. Una vez están en suspensión, las partículas se mueven por advección. El flujo advectivo describe el transporte de sedimentos según la velocidad de la corriente (Julien, 1998).

La capacidad de exceso de transporte se define como la capacidad del flujo para mover el caudal sólido de fondo y erosionar el suelo in situ. Primero, la capacidad de exceso de transporte se usa para mover los sedimentos por fracción de tamaño de acuerdo con el porcentaje presente en el material del lecho. Luego, si aún queda capacidad de transporte una vez el caudal sóliso en suspensión y el caudal sólido de fondo han sido transportados, el suelo es erosionado proporcionalmente al porcentaje de la fracción de tamaño correspondiente en el suelo in situ.

Julien y Simons (1985) derivan una relación general a partir del análisis dimensional y que puede escribirse como una función de potencia de la pendiente y el caudal (ver parágrafo 3.2.2.3.3). El caudal unitario de sedimentos, $q_{s}\left(m^{2} / s\right)$, toma la siguiente forma:

$$
q_{s}=\alpha S^{\beta} q^{\gamma}
$$

donde $\alpha$ es un coeficiente empírico; $S$ es la pendiente del terreno $(\mathrm{m} / \mathrm{m}) ; q$ es el caudal unitario de agua $\left(\mathrm{m}^{2} / \mathrm{s}\right)$, definido por el caudal de agua $\left(\mathrm{m}^{3} / \mathrm{s}\right)$ sobre la unidad de ancho $(m)$; y $\beta$ y $\gamma$ son exponentes empíricos.

Kilinc y Richardson (1973) efectuaron estudios experimentales y analíticos de los mecanismos de erosión en canaletas de laboratorio con suelos arenosos desprovistos de vegetación utilizando un simulador de lluvia. El objeto principal de estas investigaciones fue estudiar el factor más importante que afecta la erosión de suelos y desarrollar una ecuación de predicción de pérdidas de suelos. Los datos recogidos fueron la concentración de sedimentos, la velocidad superficial del flujo sobre ladera, el caudal de agua, la temperatura de agua, la tasa de infiltración, la densidad del suelo, la pendiente, la intensidad de lluvia y la geometría del canal. Estos autores llegaron a la siguiente ecuación:

$$
q_{s}=25500 \cdot S^{1,664} q^{2,035}
$$

donde $q_{s}$ se da en $($ tons $/ m \cdot s)$.

La ecuación 4.25 es consistente con muchas de las ecuaciones que predicen el transporte de sedimentos (Julien y Simons, 1985). Julien (1998) modificó la ecuación original de Kilinc y Richardson para considerar los efectos de los usos del suelo, las prácticas de cultivo y las características de los suelos, llegando a la siguiente relación: 


$$
q_{s}=23210 \cdot S^{1,66} q^{2,035} \frac{K}{0,15} C \cdot P
$$

donde $K$ es el factor de erosionabilidad del suelo, $C$ es el factor de cultivo y $P$ es el factor de prácticas de conservación, según la Ecuación Universal de Pérdida de Suelos (Renard et al., 1997) y 23210 es una constante empírica.

El factor 0,15 en el denominador de la ecuación 4.26 proviene del hecho de que la ecuación 4.25 fue desarrollada para arenas con suelo desnudo y 0,15 es la erosionabilidad máxima para arenas según la USLE.

Puesto que la ecuación de Kilinc y Richardson se derivó a partir de mediciones en canaletas de laboratorio con lluvias simuladas, de manera explícita tiene en cuenta la erosión pluvial por salpicadura de las gotas de lluvia, de esta forma no es necesario considerar la energía cinética de las precipitaciones.

Como se ha mencionado, los factores de la USLE no tienen un significado físico y se pueden considerar factores de seguridad. La utilización de la ecuación 4.26 sólo se justifica si en la zona de estudio se han efectuado mapas con los factores de la USLE según criterios expertos y en áreas en donde dichos factores estén calibrados adecuadamente.

Si no se cuenta con mapas de los factores de la USLE, es recomendable utilizar la ecuación 4.25, teniendo en cuenta que el coeficiente da cuenta de las condiciones de las parcelas experimentales utilizadas para el desarrollo de la ecuación. Además, dicho coeficiente al ser utilizado en modelos distribuidos tiene dependencia de la escala espacial y el intervalo temporal de simulación. Por estas consideraciones, se recomienda utilizar dicho coeficiente como factor corrector de calibración en el modelo.

La erosión superficial total es:

$$
E_{t}=\int_{\text {tiempo }} \int_{\text {ancho }} q_{s} \cdot d x \cdot d t
$$

Para una celda de tamaño $x$ y para un intervalo de tiempo $\Delta t$, el volumen total de sedimentos $Q_{s_{K R}}\left(m^{3}\right)$ que produce la celda se calcula como:

$$
Q_{s_{K R}}=\alpha \cdot S^{1,66} q^{2,035} \cdot x \cdot \Delta t
$$

y si se cuenta con mapas de los factores de la USLE, como:

$$
Q_{s_{K R}}=\alpha \cdot S^{1,66} q^{2,035} \cdot K \cdot C \cdot P \cdot x \cdot \Delta t
$$

donde $\alpha$ es el factor corrector de calibración.

En el modelo no se consideran las condiciones de inicio de movimiento de las partículas sólidas en ladera, de esta forma se está suponiendo que una vez haya agua escurriendo los sedimentos comienzan a transportarse. Una forma de considerar estas condiciones de inicio es incluir un término en las ecuaciones 4.28 y 4.29 en el caudal, de esta forma $\left(q-q_{0}\right)^{2,035}$. El término $q_{0}$ es el caudal necesario 
para que una partícula inicie su movimiento. La justificación de no incluir este término es su poca sensibilidad, que sólo es apreciable cuando el caudal es muy pequeño. Esta justificación se basa en el trabajo de Velleux (2005).

La tasa de sedimentos transportados por procesos advectivos, $Q_{s_{A D V_{i}}}\left(\mathrm{~m}^{3} / \mathrm{s}\right)$, se obtiene del producto de la concentración de sedimentos por fracción de tamaño en suspensión, $C_{i}\left(\mathrm{~m}^{3} / \mathrm{m}^{3}\right)$, y la velocidad de flujo promedio, $V(\mathrm{~m} / \mathrm{s})$, para cada fracción de tamaño $i$, de la siguiente forma:

$$
\frac{Q_{s_{A D V_{i}}}}{A}=V \cdot C_{i}
$$

donde $A$ es el área de flujo $\left(m^{2}\right)$.

Simplificando la ecuación 4.30 e integrando para un paso de tiempo $\Delta t$, el volumen de sedimentos en suspensión por fracción de tamaño $i\left(m^{3}\right)$ que puede ser transportado por procesos advectivos es:

$$
Q_{s_{S U S_{i}}}=\operatorname{SusVol}_{i} \frac{V \cdot \Delta t}{x}
$$

donde $\mathrm{SusVol}_{i}$ es el volumen de sedimentos en suspensión para cada fracción de tamaño $\left(m^{3}\right)$, y $x$ es el tamaño de la celda $(m)$.

Finalmente, el volumen de sedimentos en suspensión que puede ser transportado para cada fracción de tamaño $i$, es:

$$
Q_{s_{S U S_{i}}}=\left\{\begin{array}{lrl}
\operatorname{Max}\left(Q_{s_{S U S_{i}}} ; Q_{s_{K R}} \frac{\text { SusVol }_{i}}{\sum_{i=1}^{3} \text { SusVol }_{i}}\right) & \text { si } & Q_{s_{K R}}<\sum_{i=1}^{3} \text { SusVol }_{i} \\
\text { SusVol }_{i} & \text { si } & Q_{s_{K R}} \geqslant \sum_{i=1}^{3} \text { SusVol }_{i}
\end{array}\right.
$$

La ecuación 4.32 corresponde al cálculo de el caudal sólido en suspensión que se traslada al tanque correspondiente de la celda de destino (ver figura 4.5).

El exceso de capacidad de transporte $(\operatorname{ExcCapML})$ para transportar sedimentos como caudal sólido de fondo se calcula como:

$$
\operatorname{ExcCapML}=\operatorname{Max}\left(0 ; Q_{s_{K R}}-\sum_{i=1}^{3} Q_{s_{S U S_{i}}}\right)
$$

Y el volumen $\left(\mathrm{m}^{3}\right)$ transportado como caudal sólido de fondo para cada fracción de tamaño $i$, se calcula como:

$$
Q_{s_{M L_{i}}}=\left\{\begin{array}{lrl}
\operatorname{ExcCap} M L \frac{M L V o l_{i}}{\sum_{i=1}^{3} M L V l_{i}} & \text { si } & \text { ExcCapML }<\sum_{i=1}^{3} M L V o l_{i} \\
M L V o l_{i} & \text { si } & \text { ExcCapML } \geqslant \sum_{i=1}^{3} M L V o l_{i}
\end{array}\right.
$$

donde $M L V o l_{i}$ es el volumen de la fracción de tamaño $i$ que se encuentra como material de fondo. 
La ecuación 4.34 es la utilizada para calcular el caudal sólido del lecho que recibe el tanque de sedimentos suspendidos de la celda de destino (ver figura 4.5).

Una vez se transportan los sedimentos en suspensión y como caudal sólido de fondo, si aún queda capacidad de transporte, el suelo se erosiona proporcionalmente al porcentaje de cada fracción de tamaño $i$ del suelo in situ, de acuerdo con la siguiente ecuación:

$$
Q_{s_{E R O S_{i}}}=P_{i}\left(\text { ExcCapML }-\sum_{i=1}^{3} Q_{s_{M L_{i}}}\right)
$$

donde $Q_{s_{E R O S_{i}}}$ es el volumen que se erosiona del suelo in situ para cada fracción de tamaño, y $P_{i}$ es el porcentaje que se encuentra de cada fracción de tamaño $i$.

La ecuación 4.35 se utiliza para calcular la erosión del suelo in situ en cada celda, el cual se traslada al tanque de material suspendido de la celda de destino (ver figura 4.5).

\subsubsection{Los procesos sedimentológicos en canales}

El material producido en las laderas de la cuenca es transportado a la salida siguiendo los canales de la misma, ya sean cárcavas o cauces. En los canales no se permite la erosión, de esta forma no se utiliza la capacidad de transporte remanente luego de transportar los sedimentos en suspensión y como caudal sólido de fondo. Se utiliza la ecuación de Engelund y Hansen (1967) ${ }^{4}$ para calcular la capacidad de transporte de sedimentos en canales. Esta ecuación predice la capacidad de transporte dependiendo del diámetro por fracción de tamaño, las condiciones de flujo y la geometría hidráulica del canal y puede usarse para estimar la capacidad de transporte de fracciones de arenas, limos y arcillas que provienen de áreas aguas arriba.

Según lo visto en el parágrafo 3.2.2.5.1, Engelund y Hansen aplican el concepto de energía de la corriente de Bagnold y el principio de similitud para obtener la concentración de sedimentos por peso, $C_{w}$, según la siguiente ecuación:

$$
C_{w}=0,05\left(\frac{G_{s}}{G_{s}-1}\right) \frac{V S_{f}}{\left[\left(G_{s}-1\right) g d_{s}\right]^{1 / 2}}\left[\frac{R_{h} S_{f}}{\left(G_{s}-1\right) d_{s}}\right]^{0,5}
$$

donde $G_{s}$ es la gravedad específica de los sedimentos, $V$ la velocidad promedio del flujo, $S_{f}$ es el ángulo de fricción (que se supone igual a la pendiente), $g$ es la aceleración debido a la gravedad, $d_{s}$ es el tamaño de las partículas de sedimentos, y $R_{h}$ es el radio hidráulico.

$\mathrm{Al}$ igual que en la ladera, el modelo no considera las condiciones de inicio de movimiento de las partículas sólidas en canales. Una forma de considerar estas condiciones de inicio es incluir un término en la ecuación 4.36 en la velocidad del flujo, de esta forma $\left(V-V_{0}\right)$. El término $V_{0}$ es la velocidad necesaria para

\footnotetext{
${ }^{4}$ Tomado de Julien (1998)
} 
que una partícula inicie su movimiento. La justificación de no incluir este término es su poca sensibilidad, que sólo es apreciable cuando el caudal es muy pequeño (Velleux, 2005).

El volumen que puede ser transportado para cada fracción de tamaño $i$ durante el intervalo de tiempo $\Delta t$ se calcula como:

$$
Q_{s_{E H_{i}}}=\frac{Q \cdot C_{w_{i}} \cdot \Delta t}{2,65}
$$

donde $Q$ es el caudal de flujo que pasa por el canal $\left(\mathrm{m}^{3} / \mathrm{s}\right)$, y $C_{w_{i}}$ es la concentración por peso de sedimentos para cada fracción de tamaño $i$.

El volumen de sedimentos en suspensión para cada fracción de tamaño $i$ que se transporta en el canal por procesos advectivos es:

$$
Q_{s_{S U S_{i}}}=\operatorname{SusVol}_{i} \frac{V \cdot \Delta t}{x}
$$

donde $\mathrm{SusVol}_{i}$ es el volumen de sedimentos en suspensión que se encuentra en el canal, $V$ es la velocidad de flujo, $\Delta t$ es el intervalo temporal y $x$ es la longitud del canal.

La ecuación 4.38 se utiliza para calcular el caudal sólido en suspensión que se traslada al tanque correspondiente de la celda de destino (ver figura 4.6).

La capacidad de transporte en exceso que se utiliza para transportar la caudal sólido de fondo, para cada fracción de tamaño $i$, es:

$$
\operatorname{ExcCapML} L_{i}=\operatorname{Max}\left(0 ; Q_{s_{E H_{i}}}-Q_{s_{S U S_{i}}}\right)
$$

El volumen de material de fondo que puede ser transportado por procesos advectivos en el canal, para cada fracción de tamaño $i$, es proporcional a:

$$
\operatorname{MLVOl}_{i} \frac{V \cdot \Delta t}{x}
$$

donde $M L V o l_{i}$ es el volumen de sedimentos que se encuentran como material de fondo para cada fracción de tamaño $i$.

Finalmente, el volumen de sedimentos transportado como caudal sólido de fondo, para cada fracción de tamaño $i$, será el mínimo entre la capacidad de transporte en exceso y el caudal sólido de fondo que puede ser transportado por procesos advectivos:

$$
Q_{s_{M L_{i}}}=\operatorname{Min}\left(\operatorname{ExcCapML} L_{i} ; \operatorname{MVol}_{i} \frac{V \cdot \Delta t}{x}\right)
$$

La ecuación 4.41 calcula el volumen de sedimentos como caudal sólido del lecho que se trasladan al tanque de sedimentos suspendidos de la celda de destino (ver figura 4.6). 


\subsubsection{El depósito de sedimentos}

En el modelo se utiliza el concepto de reposo de sedimentos, repasado en el parágrafo 3.2.2.5.2. Según este concepto las fracciones de arenas, limos y arcillas pueden depositarse proporcionalmente según sus velocidades de sedimentación, así se permite un tratamiento diferencial del transporte de sedimentos por fracción de tamaño. La tabla 3.2 muestra velocidades de sedimentación para diferentes tamaños de grano y temperatura en agua limpia. El depósito de sedimentos se efectúa tanto en la parte correspondiente a la ladera de la celda como al canal.

Después de transportar los sedimentos de una celda a otra receptora, los sedimentos en suspensión permanecen en reposo. El modelo supone un tipo de partícula discreta en reposo en la cual las partículas tienden a depositarse independientemente de cada una de las otras partículas discretas. El porcentaje de sedimentos en suspensión que puede depositarse para cada fracción de tamaño $i$, PorcenDep $_{i}$, para un incremento de tiempo, $\Delta t$, depende de la velocidad de sedimentación de la partícula, $V_{f}$, y la profundidad de agua en la celda, $h$, de acuerdo con la siguiente relación:

$$
\text { PorcenDep }_{i}=\left\{\begin{array}{lll}
V_{f} \frac{\Delta t}{h} & \text { si } & h>\omega_{i} \cdot \Delta t \\
1 & \text { si } & h \leqslant \omega_{i} \cdot \Delta t
\end{array}\right.
$$

El volumen de sedimentos en suspensión que se deposita en un intervalo de tiempo dado se sustrae de la porción de sedimentos en suspensión y se añade al depositado, tal como se observa en las figuras 4.5 y 4.6.

\subsection{Los parámetros del modelo}

Los parámetros de un modelo expresan de forma numérica las características principales del sistema, según la conceptualización y la estructura propia del modelo. En modelos hidrológicos y geomorfológicos, los parámetros deben tener en consideración los errores en el modelo y en las entradas, y los efectos de escala temporal y espacial. Además, si se trata de un modelo distribuido, los parámetros deben reflejar la variabilidad espacial del medio físico.

El modelo, en su parte hidrológica, utiliza una estructura de parámetros dividida en dos niveles:

- Las características hidrológicas estimadas según la información disponible, con sentido físico y que no tiene en cuenta los errores debido a efectos de escala.

- Las funciones correctoras.

Las características hidrológicas se estiman para cada celda y dan cuenta de la variabilidad espacial de los parámetros en la cuenca hidrográfica, además poseen 
un significado físico de acuerdo con la conceptualización del sistema, las escalas espaciales y temporales y los procesos tenidos en cuenta.

Las funciones correctores también se denominan factores correctores, dan cuenta de los errores en el modelo y en las entradas, de los efectos de escala espacial y temporal, y de los errores en las estimación en las características hidrológicas. Es razonable suponer que las funciones correctoras son comunes para toda la cuenca, o al menos para un número limitado de regiones dentro de la cuenca (Francés et al., 2007). Además, por tratarse de un modelo distribuido en celdas de igual tamaño, todas las celdas presentan los mismos efectos de escala.

La estructura de parámetros dividida se expresa según la ecuación (Francés et al., 2007):

$$
\theta_{i j}^{\star} \sim R_{i} \theta_{i j}, \quad j=1, \ldots n ; \quad i=1, \ldots, p
$$

donde $\theta_{i j}^{\star}$ es el parámetro efectivo $i$-enésimo para la celda $j, R_{i}$ es el factor corrector común para todas las celdas, $\theta_{i j}$ es el parámetro estimado para la celda $j, n$ es el número total de celdas, y $p$ es el número total de parámetros por celda.

Francés et al. (2007) recalcan que una consecuencia importante de esta estructura desde el punto de vista de la calibración, es que el número de variables que deben ser ajustadas se reduce notablemente, siendo sólo necesario calibrar los $p$ factores correctores, en vez del producto $(n p)$, de $p$ parámetros por $n$ número de celdas.

El primer paso para llevar a cabo esta estructura es determinar los mapas de parámetros según un criterio experto. Estos mapas deben reflejar la variabilidad espacial de cada parámetro y su estimación debe acercarse a una media areal según el tamaño de la celda y el intervalo temporal de simulación.

Los parámetros hidrológicos a estimar para cada celda son:

- El índice mensual de cobertura de vegetación para la evapotranspiración, $\lambda(m)$.

- La capacidad de almacenamiento hídrico del suelo, $H_{u}$.

- La conductividad hidráulica saturada del suelo, $K_{s}$.

- La conductividad hidráulica saturada del sustrato del suelo, $K_{p}$.

El procedimiento para estimar los parámetros hidrológicos para cada celda teniendo en cuenta su variabilidad espacial se detalla posteriormente y fue diseñado por Puricelli (2003).

Para los procesos de propagación de flujo en canales, se utiliza un solo factor corrector que afecta directamente la velocidad para cada celda y para cada intervalo temporal, de esta forma no es necesario calibrar todos los parámetros geomorfológicos. Para tener en consideración la variación de la precipitación con la altitud en el proceso de calibración del modelo, se tiene en cuenta el factor corrector $\beta$ de la ecuación 4.1 . 
El índice de cobertura de vegetación para la evapotranspiración se estima a partir de mapas de vegetación y usos del suelo, mientras que la velocidad del flujo superficial en ladera $u$ se estima a partir de la pendiente de cada celda $S_{0}$, derivada del Modelo de Elevación Digital, usando la siguiente expresión:

$$
u=1,4 S_{0}^{0,5}
$$

Debido a la ausencia de información suficiente en la práctica hidrológica y a la alta correlación entre parámetros, el resto de parámetros se basan en los parámetros $K_{s}$ y $K_{p}$, según la tabla 4.1. En esta tabla se resume la estructura dividida de parámetros para el modelo.

\begin{tabular}{|l|l|}
\hline Parámetro para cada celda & Descomposición \\
\hline Capacidad de almacenamiento hídrico & $H_{u}^{\star}=R_{1} H_{u}$ \\
\hline Índice de cobertura de vegetación, para cada mes $m$ & $\lambda^{\star}(m)=R_{2} \lambda(m), m=1, \ldots, 12$ \\
\hline Capacidad de infiltración & $K_{s}^{\star}=R_{3} K_{s}$ \\
\hline Velocidad del flujo superficial & $u^{\star}=R_{4} u$ \\
\hline Capacidad de percolación & $K_{p}^{\star}=R_{5} K_{p}$ \\
\hline Velocidad del flujo subsuperficial & $K_{s s}^{\star}=R_{6} K_{s}$ \\
\hline Capacidad de percolación profunda & $K_{p p}^{\star}=R_{7} K_{p}$ \\
\hline Velocidad de flujo base & $K_{b}^{\star}=R_{8} K_{p}$ \\
\hline Velocidad del flujo en canal en el tiempo $t$ & $v^{\star}(t)=R_{9} v(t)$ \\
\hline
\end{tabular}

Tabla 4.1. Estructura de parámetros según la conceptualización del modelo, tomado de Francés et al. (2007)

\subsubsection{La variabilidad espacial de los parámetros}

Al tratarse de un modelo distribuido, los parámetros del modelo exigen que reflejen su variabilidad espacial natural dentro de la cuenca. Como se ha mencionado, no es posible determinar por medio de mediciones de campo los valores de los parámetros para cada discretización espacial, por tal motivo se hace necesario estimarlos. Esta variabilidad presenta dos tendencias generales:

- Regional, definida por unidades cartográficas de suelos. Para cada unidad de suelos es posible determinar un valor modal para cada parámetro. Este valor modal representa el valor más probable, el cual se estima de acuerdo al perfil (o perfiles) característico de dicha unidad. Este nivel de variabilidad comprende una o varias laderas, o geoformas a escala regional en la cual se encuentran numerosas celdas, las cuales presentan el mismo valor modal.

- Local, definida por la posición topográfica relativa (catena de suelos en cada ladera) de cada elemento de discretización, esto es, la celda. Este nivel local también puede estar determinado por otras variables ambientales con representación cartográfica (usos del suelo, vegetación, geología, geomorfología). 
De este modo, la variabilidad interna de las unidades cartográficas se puede explicar por medio de variables ambientales con representación cartográfica. El objetivo es determinar de forma analítica la tendencia de la variabilidad en el ámbito de estudio (la cuenca hidrográfica o una región en particular), esto es, diseñar un procedimiento que permita definir cuales de las variables ambientales tienen relevancia en explicar dicha variabilidad. Así, además de encontrar la tendencia regional de variabilidad, se puede utilizar dicha tendencia para estimar el valor de cada parámetro a escala de celda.

El modelo propuesto para la tendencia regional se basa en el establecimiento de una relación funcional de dependencia entre las variables principales y ambientales. La relación más simple es la lineal (Puricelli, 2003):

$$
y_{c}=\beta_{0}+\sum_{j=1}^{k} \beta_{j} x_{c j}
$$

donde $y_{c}$ es el valor de la variable principal $y$ en la celda $c, \beta_{0}$ es el valor de $y$ cuando $x_{c j}=0, \beta_{j}$ es el coeficiente de ajuste lineal para cada variable ambiental $j$, con $j=1,2, \ldots, k$, siendo $k$ el número total de variables ambientales incluidas en el análisis, y $x_{c j}$ es el valor de la variable ambiental $j$ en la celda $c$.

La figura 4.7 es un esquema de la variabilidad espacial de los parámetros, tanto a nivel regional como a nivel local. La parte a) de la figura es una vista en planta de tres unidades cartográficas de suelos con diferentes valores modales del parámetro a analizar. La parte b) es una gráfica con la variabilidad espacial del parámetro, tanto a nivel regional (valores modales) como a nivel local (representada por la línea discontinua).

Las variables principales son aquellas cuya distribución espacial se pretende estimar a escala de celda, esto es, los parámetros del modelo. Las variables ambientales son las demás variables con representación cartográfica que explican la variabilidad espacial de los parámetros, esto es, las variables que representan diferentes características del terreno, relacionadas con la naturaleza y génesis de los suelos que se encuentran presentes en el sector analizado.

Debido al amplio intervalo de valores que presentan las variables principales en la naturaleza, estas variables se transforman para permitir que sus valores se distribuyan más simétricamente alrededor de un valor medio. La transformación se hace de la siguiente forma:

- La capacidad de almacenamiento hídrico del suelo se transforma a su raíz cuadrada.

- La conductividad hidráulica saturada del suelo se transforma a su logaritmo natural.

- La conductividad hidráulica saturada del sustrato del suelo se transforma a su logaritmo natural. 


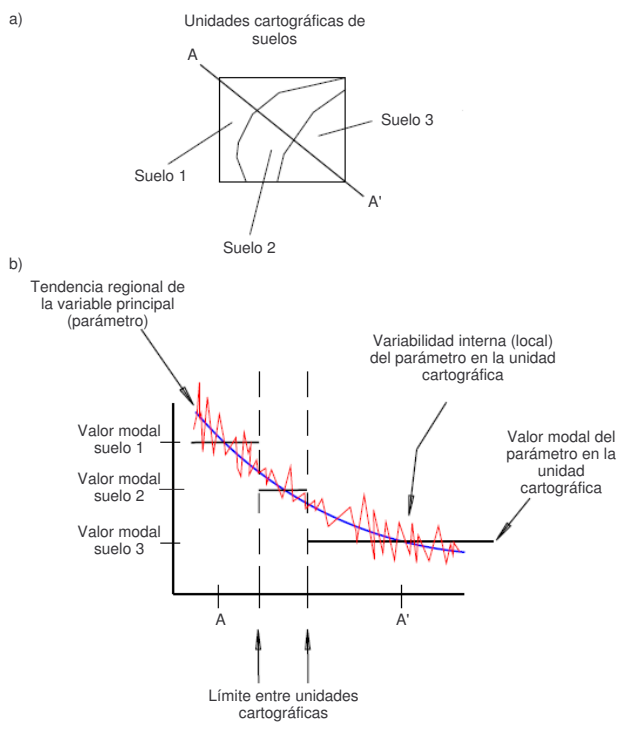

Figura 4.7. Esquema de la variabilidad espacial de parámetros, adaptado de Puricelli (2003)

Las variables ambientales pueden ser categóricas (por ejemplo, cualidades de unidades de suelos con comportamiento hidrológico contrastado), o continuas.

Las variables ambientales continuas son los atributos topográficos que describen la morfología del terreno y pueden ser derivados de un Modelo de Elevación Digital. Al definir la tendencia regional de variabilidad espacial de un parámetro, debe existir al menos una variable ambiental continua para asegurar que cada celda posea un valor diferente. Las variables ambientales continuas son: la pendiente, el aspecto, la curvatura, y los índices topográficos (ver parágrafos 3.1.1.1 y 3.1.1.2).

Las variables ambientales continuas son transformadas linealmente con el objeto de que queden expresadas en una escala continua entre 0 y 1 . De esta forma se garantiza que dichas variables presentan un intervalo de variación similar y no se den problemas en la solución debido a variables con órdenes de magnitud diferentes. La normalización se efectúa según la siguiente ecuación:

$$
x_{n}=\frac{x-M i n}{M a x-M i n}
$$

donde $x_{n}$ es la variable ambiental continua normalizada, $x$ es el valor en cada celda de la variable ambiental continua a normalizar, Max y Min son los valores máximos y mínimos absolutos de la variable ambiental continua a normalizar.

Las variables cualitativas o categóricas se incorporan como variables mudas ${ }^{5}$. Estas variables mudas representan comportamientos contrastados en la variable

\footnotetext{
${ }^{5}$ En Inglés, dummy variables
} 
principal y toman valores de 0 y 1 , según corresponda o no a la categoría o intervalo seleccionado. Además es posible definir una nueva variable muda como la interacción o combinación de dos variables mudas.

Se enmarcan en el grupo de las variables cualitativas los mapas cualitativos de usos del suelo, vegetación, litología y características de los suelos. Con el análisis de dichos mapas se pretende definir variables ambientales mudas. Por ejemplo, en el caso de un mapa de suelos, es posible separar suelos con presencia de una costra impermeable de suelos sin presencia de costra impermeable.

Cada variable, tanto principal como ambiental tiene representación cartográfica. Las variables continuas presentan un intervalo de variación continua, mientras que las variables mudas sólo presentan dos valores.

El proceso de estimación comienza con la intersección de todas las unidades cartográficas de variables ambientales cualitativas, como se describe en la figura 4.8. Las unidades cartográficas obtenidas a partir de la intersección se denominan Unidades Cartográficas de Muestreo (UCMs).

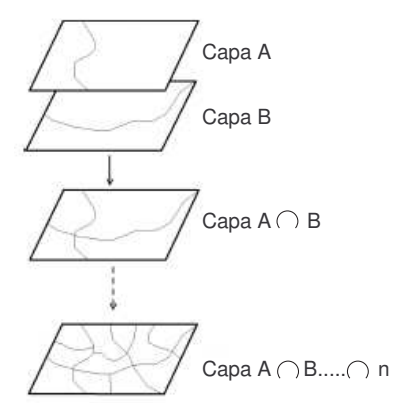

Figura 4.8. Intersección entre variables ambientales, figura tomada de Puricelli (2003)

A partir de la intersección de las variables ambientales se determina el valor modal de cada una de las UCMs obtenidas y el factor de ponderación. Dicho factor será el área con que cada una de las unidades cartográficas de suelos afecta a las unidades obtenidas en la intersección.

El paso siguiente es la obtención de los coeficientes de ajuste lineal siguiendo un esquema multivariado por el método de los mínimos cuadrados ponderados. De esta forma, la función objetivo a minimizar es:

$$
\sum_{i=1}^{n} \omega_{i}\left(y_{i}-\beta_{0}-\sum_{j=1}^{k} \beta_{j} x_{i j}\right)
$$

donde $\omega_{i}$ es el factor de ponderación, o peso que afecta a cada estimación de la variable principal en cada UCM; $y_{i}$ es el valor modal de la variable principal asignada a la $i$-ésima $\mathrm{UCM}$, con $i=1,2, \ldots, n$, donde $n$ es el número total de UCMs; $\beta_{0}$ es el valor de la estimación cuando todas las variables ambientales son 
nulas; $\beta_{j}$ es el factor de multiplicación de la $i$-ésima variable ambiental; y $x_{i j}$ es el valor de la variable ambiental $j$, de la $i$-ésima UCM.

Para encontrar el juego de variables ambientales óptimo es necesario efectuar pruebas estadísticas para determinar cual de las variables es determinante o no en la explicación de la variabilidad espacial. Son varias las pruebas que se pueden aplicar, entre las que se destacan el coeficiente de determinación, que mide la magnitud de la reducción de la variabilidad estimada a partir del empleo de las variables ambientales para el ajuste, es decir, es un indicador del grado de variabilidad observada que el modelo ajustado puede explicar.

El coeficiente de determinación es un indicador global y no determina si una variable en particular es significativa en la mejora del ajuste o no. Por tal motivo es necesario efectuar pruebas para determinar, para cada variable, si es estadísticamente significativa o no. Una forma es analizar los residuales para cada variable ambiental.

Una vez obtenido el ajuste óptimo se aplica una corrección con el fin de conservar los valores modales de las variables principales en cada una de las unidades cartográficas de suelos. De esta forma se asegura que los valores modales obtenidos por medio del ajuste sean los mismos que los valores modales originales. Esto se logra con la aplicación de la siguiente relación:

$$
y_{c}^{\star}=y_{c}+\left[E\left(y_{c}\right)-y^{u}\right]
$$

donde $y_{c}^{\star}$ es el valor de la variable principal estimada en cada celda $c ; y_{c}$ es el valor de la variable principal estimada mediante el ajuste de la tendencia regional, para cada celda $c ; E\left(y_{c}\right)$ es el valor medio de la variable principal para cada unidad cartográfica de suelo, calculado a partir de los valores de todas las celdas incluidas dentro de dicha unidad cartográfica; y $y^{u}$ es el valor modal original de la variable principal, asignado a cada unidad cartográfica.

La capa temática así construida corresponde a la estimación distribuida de la variable principal en el área de análisis, la cual conserva la coherencia con la distribución de los valores modales y presenta un valor para cada celda de acuerdo con la relación funcional con las diferentes variables ambientales. En este punto es importante anotar que para asegurar un valor para cada celda es necesario que en la ecuación de ajuste obtenida se encuentre al menos una variable ambiental continua.

\subsubsection{Los parámetros hidrológicos}

Según la estructura de parámetros, el modelo necesita de tres características hidrológicas a estimar para cada celda:

a) La capacidad de almacenamiento hídrico útil del suelo, $H_{u}$. Se conceptualiza como la diferencia entre el contenido de humedad del suelo a capacidad de campo y el punto de marchitez permanente. 
En la práctica, la capacidad de almacenamiento hídrico se calcula inicialmente para cada horizonte de suelo en el cual se encuentran raíces, de acuerdo con la siguiente ecuación:

$$
H_{u}=\frac{\rho_{b} \cdot p \cdot\left(H_{c c}-H_{p m p}\right)}{\rho_{w} \cdot 100}
$$

donde $H_{u}$ es el contenido de agua útil para el horizonte $(\mathrm{mm}) ; \rho_{b}$ es la densidad aparente del suelo seco $\left(\mathrm{gr} / \mathrm{cm}^{3}\right) ; \rho_{w}$ es la densidad del agua $\left(\mathrm{gr} / \mathrm{cm}^{3}\right)$; $p$ es el espesor del horizonte de suelo $(\mathrm{m}) ; H_{c c}$ es el contenido de humedad a capacidad de campo (\%); y $H_{p m p}$ es el contenido de humedad en el punto de marchitez permanente (\%).

Para un perfil de suelo compuesto por $i$ horizontes de suelos con presencia de raíces, la capacidad de almacenamiento hídrico, $C A H$, es:

$$
C A H=\sum_{i} H_{u_{i}}
$$

La capacidad de almacenamiento hídrico del suelo es un término eficiente en función de que sea considerado como el valor de referencia del intervalo en el cual el suelo puede actuar como un reservorio dinámico de agua (Puricelli, 2003).

Puesto que las propiedades físicas del suelo que definen la capacidad de almacenamiento hídrico sólo se miden en muy pocas situaciones, es necesario el uso de funciones de pedotransferencia que las estimen a partir de información textural del suelo, la cual se encuentra normalmente en la descripción de los perfiles de suelos.

b) La conductividad hidráulica saturada del suelo, $K_{s}$. Se define como la capacidad de los medios porosos en condiciones de saturación para transmitir agua de un punto a otro. Sus unidades son de velocidad.

La conductividad hidráulica presenta una alta variabilidad espacial y depende de la anisotropía, el grado de consolidación del medio, la fracturación, el grado de selección de los materiales y la heterogeneidad del mismo.

c) La conductividad hidráulica saturada del sustrato del suelo, $K_{p}$. El sustrato del suelo puede ser una roca, un saprolito (roca meteorizada), un paleosuelo o un depósito. Dependiendo de las características físicas del sustrato varía su conductividad hidráulica. Una de las mayores fuentes de variabilidad es la presencia de fracturas y diaclasas, especialmente si se trata de rocas consolidadas.

La estimación de este parámetro presenta la mayor incertidumbre, puesto que la información acerca del sustrato del suelo suele ser escasa. Además dicho parámetro presenta un intervalo de variación de varios órdenes de magnitud. 


\subsubsection{Los parámetros geomorfológicos}

El modelo necesita de parámetros geomorfológicos, los cuales son comunes para una región (denominada región geomorfológica homogénea). A diferencia de los parámetros hidrológicos y sedimentológicos, los parámetros geomorfológicos tienen aplicación regional, de esta forma, todas las celdas que pertenecen a una región geomorfológica homogénea presentan parámetros geomorfológicos comunes. Una región geomorfológica homogénea está definida por condiciones climáticas, vegetación y tipo de suelo similares. Los parámetros geomorfológicos son:

a) Las áreas umbrales para flujos superficiales. Se trata de las áreas necesarias para que las diferentes componentes de la escorrentía salgan a la superficie. Se supone que los flujos se presentan canalizados una vez llegan a la superficie, ya sea en cárcavas o cauces.

Según lo reseñado en la definición del sistema es necesario definir dos áreas umbrales para flujos superficiales:

- Área umbral para el interflujo. Las áreas necesarias para el interflujo se pueden determinar a partir de mapas topográficos y fotografías aéreas, ubicando la cabecera de las cárcavas y midiendo su área de captación. La finalización de las cárcavas corresponde al inicio de los cauces.

- Área umbral para el flujo base. El área para el flujo base se determina a partir de mapas topográficos y fotografías áreas, ubicando la cabecera de los cauces permanentes.

b) Los parámetros de la propagación del flujo. Se trata de los coeficientes y exponentes de las relaciones geomorfológicas para determinar las características geométricas de los canales para cada región geomorfológica homogénea. Como se ha mencionado (ver parágrafo 3.1.3.6.1) los elementos de la red de drenaje de una cuenca hidrográfica, ya sean surcos, cárcavas y cauces, presentan relaciones entre su geometría, su caudal y el área de captación de la sección. En el modelo es necesario determinar los coeficientes y exponentes para cárcavas y cauces de las siguientes relaciones de la geometría hidráulica:

- Área de captación $\Lambda$ y caudal a sección llena $Q_{b}$ :

$$
\Lambda=\kappa \cdot Q_{b}^{\varphi}
$$

- Ancho de la sección transversal a sección llena $W_{b}$ y caudal a sección llena $Q_{b}$ :

$$
W_{b}=a_{1} \cdot Q_{b}^{\alpha_{1}}
$$


- Ancho de la sección transversal $W$ y caudal que pasa por la sección $Q$ :

$$
W=Q^{\alpha_{2}}
$$

- Diámetro del sedimento $d$, pendiente $S$ y profundidad del flujo $h$ :

$$
d=c_{d} \cdot(S \cdot h)^{\theta}
$$

- Coeficiente de rugosidad $n$ y diámetro del sedimento $d$ :

$$
n=c_{n} \cdot d^{\xi}
$$

Los coeficientes $\kappa, a_{1}, c_{d}, \mathrm{y} c_{n} ; \mathrm{y}$ los exponentes $\varphi, \alpha_{1}, \alpha_{2}, \theta, \mathrm{y} \xi$ pueden estimarse utilizando regresiones lineales a partir de un número pequeños de secciones transversales, medidas en campo para cada región geomorfológica homogénea. La tabla 4.2 muestra los intervalos de variación de los exponentes y coeficientes en cauces naturales, según la literatura.

\begin{tabular}{|c|c|}
\hline Parámetro de propagación & Intervalo de variación \\
\hline Coeficiente $\kappa$ & $0,5-0,75$ \\
\hline Exponente $\varphi$ & $0,65-0,8$ \\
\hline Coeficiente $a_{1}$ & $0,5-5,75$ \\
\hline Exponente $\alpha_{1}$ & $0,34-0,55$ \\
\hline Exponente $\alpha_{2}$ & $0,05-0,2$ \\
\hline Coeficiente $c_{d}$ & $0,5-50,0$ \\
\hline Exponente $\theta$ & $0,5-2,75$ \\
\hline Coeficiente $c_{n}$ & $0,025-0,07$ \\
\hline Exponente $\xi$ & $0,125-0,18$ \\
\hline
\end{tabular}

Tabla 4.2. Intervalos de variación de los parámetros de propagación, tomado de Francés et al. (2007)

\subsubsection{Los parámetros sedimentológicos}

El módulo sedimentológico requiere de los siguientes parámetros para cada celda para su correcto funcionamiento:

a) La textura del nivel superior del suelo. Para los procesos sedimentológicos el modelo diferencia tres tamaños de grano: arenas, limos y arcillas. En la parte correspondiente a los procesos en ladera, la capacidad de transporte de sedimentos se utiliza para transportar los sedimentos en suspensión y como caudal sólido de fondo y el remanente de dicha capacidad se utiliza para erosionar el suelo in situ de acuerdo con el porcentaje de cada fracción de tamaño. El modelo supone que el material disponible para la erosión corresponde al nivel superior del suelo, por lo tanto, es necesario suministrar el valor para cada celda de los porcentajes de arenas, limos y arcillas. 
b) Los factores de la USLE. El modelo utiliza tres factores de la USLE: a) el factor de erosionabilidad del suelo, factor $K$, b) el factor de cultivo, factor $C, \mathrm{c}$ ) y el factor de prácticas de conservación $P$. La utilización de dichos factores mejora la estimación de la variabilidad espacial de los procesos erosivos siempre y cuando se cuente con mapas adecuados de estos factores. Cabe anotar que dichos factores son factores de seguridad y dependen de criterios expertos.

Aún con la utilización de los mapas de factores de la USLE es necesario calibrar la producción de sedimentos con la utilización del factor corrector $\alpha$ de la ecuación 4.29 .

Si no se cuenta con mapas de factores de la USLE, el factor corrector $\alpha$ de la ecuación 4.28 da cuenta de las características del suelo, la vegetación, el tipo de cultivo y las escalas (espacial y temporal) de aplicación de la ecuación.

\subsubsection{Las condiciones iniciales del modelo}

Para simular un evento es necesario definir las condiciones iniciales de las variables de estado hidrológicas y sedimentológicas. Según la conceptualización del modelo, las variables de estado son las siguientes:

- El nivel del almacenamiento estático, tanque $H_{1}$.

- El nivel del almacenamiento superficial, tanque $H_{2}$.

- El nivel del almacenamiento gravitatorio, tanque $H_{3}$.

- El nivel del almacenamiento subterráneo, tanque $H_{4}$.

- El caudal en los canales, tanque $H_{5}$.

- El volumen de sedimentos en suspensión.

- El volumen de sedimentos depositados.

- El volumen de sedimentos erosionados.

Los niveles iniciales de los tanques de almacenamiento de la parte hidrológica del modelo son comunes para toda la cuenca. Una posibilidad para considerar niveles distribuidos en el espacio (un valor para cada celda) es definir los valores iniciales de humedad como los arrojados por una simulación anterior. El modelo presenta las dos opciones.

El nivel del almacenamiento estático presenta una capacidad máxima, definida por la capacidad de almacenamiento hídrico del suelo $H_{u}$. El modelo necesita como dato de entrada la condición inicial del tanque de almacenamiento estático representada por el porcentaje del total de la capacidad de almacenamiento hídrico del suelo. 
Con respecto a los niveles del almacenamiento superficial, gravitatorio y subterráneo, el valor inicial de entrada se da como la altura de agua en milímetros de cada tanque. Para el caudal en los canales, se define el valor inicial como el porcentaje del caudal a banca llena.

Con respecto a los volúmenes de sedimentos el único valor que se define al inicio del evento es el volumen de sedimentos depositados. Puesto que el depósito de sedimentos presenta una alta variabilidad espacial, concentrándose en depresiones del terreno, y tramos de la red de canales con poca pendiente, no tiene sentido definir condiciones iniciales homogéneas para toda la cuenca. Una forma de considerar las condiciones iniciales de los sedimentos depositados de forma adecuada, esto es, respetando la variabilidad espacial del depósito de sedimentos es iniciar la simulación con los valores arrojados por una simulación anterior. Esta última opción es posible en el modelo.

\subsubsection{La calibración y validación}

Debido a los errores en la conceptualización y la estructura del modelo, a los errores en las entradas y a la alta incertidumbre inherente a la estimación de parámetros es necesario calibra el modelo en la cuenca hidrográfica analizada. En general, los métodos de calibración se componen de un algoritmo de optimización, una función objetivo y un juego de variables a calibrar. Las variables de calibración corresponden a los factores correctores.

\subsubsection{Los factores correctores de calibración}

Se trata de los factores que se necesita ajustar en el proceso de calibración del modelo en una cuenca natural. Según lo visto en la descripción de la estructura de parámetros, estos factores correctores son comunes para una cuenca, o al menos para un número limitado de regiones dentro de la cuenca.

De acuerdo con la conceptualización del sistema y las escalas espaciales y temporales, estos factores presentan intervalos de valores característicos. Estos intervalos se definen a priori, según el conocimiento previo de las condiciones hidrológicas particulares de la cuenca de análisis. Una vez definidos los intervalos de variación de los factores correctores se aplica un proceso de calibración automática con el objetivo de encontrar los valores óptimos a partir de los intervalos iniciales.

Con la estructura dividida de parámetros es posible determinar los intervalos generales de variación de los factores correctores. Por ejemplo, se espera que los factores correctores de la capacidad de almacenamiento hídrico $R_{1}$, la evapotranspiración $R_{2}$, la velocidad del flujo superficial en ladera $R_{4}$ y la velocidad de flujo en canales $R_{9}$, estén cercanos a un valor de 1 .

Debido al al alto grado de no linealidad en los procesos que dependen de un umbral de capacidad, los efectos de escalas hacen que los factores correctores de 
la capacidad de infiltración $R_{3}$ y la capacidad de percolación $R_{5}$ tomen valores menores que 1.

Puesto que la conductividad hidráulica horizontal es mayor que la conductividad hidráulica vertical en varios órdenes de magnitud, se espera que los factores que dan cuenta de los flujos laterales al interior del suelo, esto es, para la velocidad del flujo subsuperficial $R_{6}$ sea entre 10 y 1000, mientras que para la velocidad del flujo base $R_{8}$ esté entre 1 y 1000 . Una explicación para estos valores se da por el hecho que dichos flujos siguen fracturas y macroporos.

El factor corrector de las pérdidas subterráneas $R_{7}$ varía entre 0 y 10 y su estimación se puede determinar de acuerdo con un conocimiento a priori del balance hidrológico en la cuenca hidrográfica.

En la tabla 4.3 se proponen intervalos de variación de los factores correctores, de acuerdo con su significado físico.

\begin{tabular}{|l|c|c|}
\hline Factor corrector & Límite inferior & Límite superior \\
\hline$R_{1}$, Almacenamiento estático & 0,5 & 2,0 \\
\hline$R_{2}$, Evapotranspiración & 0,5 & 2,0 \\
\hline$R_{3}$, Infiltración & 0,0 & 1,0 \\
\hline$R_{4}$, Velocidad del flujo en ladera & 0,1 & 2,0 \\
\hline$R_{5}$, Percolación & 0,0 & 1,0 \\
\hline$R_{6}$, Velocidad del flujo subsuperficial & 10,0 & 1000,0 \\
\hline$R_{7}$, Pérdidas subterráneas & 0,0 & 10,0 \\
\hline$R_{8}$, Velocidad del flujo base & 1,0 & 1000,0 \\
\hline$R_{9}$, Velocidad del flujo en canales & 0,5 & 1,5 \\
\hline$\beta$, Precipitación & 0,0 & 1,0 \\
\hline
\end{tabular}

Tabla 4.3. Intervalos de variación propuestos para los factores correctores

\subsubsection{El algoritmo de optimización}

El algoritmo de optimización utilizado en el modelo es el propuesto inicialmente por Duan et al. (1992), denominado SCE-UA ${ }^{6}$ y modificado por Sorooshian et al. (1993).

Este método de optimización de búsqueda de un óptimo global se basa en cuatro conceptos básicos (Vélez, 2003):

- Combinación de aproximaciones determinísticas y probabilísticas.

- Evolución sistemática de un complejo de puntos que se extienden en el espacio de los parámetros en la dirección del mejoramiento global.

- Evolución competitiva

\footnotetext{
${ }^{6}$ En Ingles, Shuffled Complex Evolution - University of Arizona
} 
- Barajado de los complejos.

El algoritmo de optimización SCE-UA se utilizó inicialmente en modelos hidrológicos agregados con buenos resultados. Posteriormente se utilizó en modelos semidistribuidos. La primera vez que se utilizó en un modelo hidrológico distribuido fue por Senerath et al. (2000) ${ }^{7}$, para calibrar de forma automática el modelo CASC2D, con resultados satisfactorios. Para el CASC2D sólo se calibraron los parámetros más sensibles del modelo, determinados previamente mediante calibración manual, y se consideraron constantes en el espacio.

\subsubsection{La función objetivo}

Son numerosos los criterios para evaluar el desempeño de modelos en simulación hidrológica, dichos criterios se utilizan como función objetivo. En general, los criterios de evaluación se basan en algún tipo de comparación entre los resultados simulados por el modelo y los datos observados en una estación de aforo en la cuenca hidrográfica de estudio.

Como función objetivo se utiliza el error cuadrático medio o $R M S E^{8}$. Como criterios de evaluación, tanto para la calibración como para las validaciones se utiliza el coeficiente de eficiencia de Nash y Sutcliffe $E$ y el error en el balance $B E$ para cada evento simulado. La función objetivo y los criterios de evaluación presentan las siguientes expresiones (Francés et al., 2007):

$$
\begin{gathered}
R M S E=\sqrt{\frac{\sum_{t=1}^{T}\left(Q_{t, o b s}-Q_{t, s i m}\right)^{2}}{T}} \\
E=1-\sum_{t=1}^{T} \frac{\left(Q_{t, s i m}-Q_{t, o b s}\right)^{2}}{\left(Q_{t, o b s}-\bar{Q}\right)^{2}} \\
B E=100 \times \frac{V_{s i m}-V_{o b s}}{V_{o b s}}
\end{gathered}
$$

donde $T$ es la duración total del período de calibración, $Q_{t, o b s}$ es el caudal observado en el tiempo $t$ y $Q_{t, \text { sim }}$ es el caudal simulado en el tiempo $t, \bar{Q}$ es el valor medio de los caudales observados, $V_{o b s}$ es el volumen total observado durante todo el período de calibración, y $V_{\text {sim }}$ es el volumen total simulado durante todo el período de calibración.

\subsubsection{La validación}

Para comprobar la validez del modelo y su correcta aplicación es necesario validarlo en condiciones diferentes a las del período de calibración.

\footnotetext{
${ }^{7}$ Tomado de Vélez (2003)

${ }^{8}$ En Ingles, root mean square error
} 
Una ventaja de los modelos hidrológicos distribuidos es que permiten simular el comportamiento en todos los puntos de una cuenca hidrográfica. De esta forma, es posible además de validar el modelo en eventos diferentes (validación temporal), validarlo en estaciones de aforo diferentes a la utilizada en la calibración (validación espacial). Así es posible analizar la consistencia al interior de la cuenca del modelo y la posibilidad de utilizar los resultados simulados en otros puntos de la cuenca.

En las validaciones es donde se refleja de forma adecuada el desempeño del modelo. Tanto los mapas de parámetros, como los factores correctores deben ser comunes para todos los eventos de validación. Los estados iniciales de humedad para cada evento analizado se pueden estimar por medio de una optimización automática o por medio de un calentamiento del modelo, esto es, una simulación previa al evento con el objeto de estimar las condiciones iniciales de humedad.

Para analizar el desempeño del modelo en las validaciones se utilizan los criterios de evaluación reseñados en la sección anterior, esto es, el coeficiente de eficiencia de Nash y Sutcliffe (ecuación 4.57) y el error en el balance (ecuación $4.58)$.

\subsection{Los resultados del modelo}

Puesto que el modelo es distribuido, las series de resultados se pueden generar para todos los puntos de la cuenca. Además es posible observar el comportamiento espacial y temporal de todas las variables de estado para cualquier tiempo.

En una nueva versión del modelo, actualmente en desarrollo, se generarán series temporales de las variables de estado en forma de animaciones de mapas. Esto permitirá visualizar el comportamiento de la cuenca de manera didáctica.

Para las estaciones de control (estaciones de aforo, puntos de interés) el modelo genera las siguientes series temporales:

- Hidrograma simulado.

- Sedimentograma simulado para cada fracción de tamaño.

- Caudal de sedimentos en suspensión para cada fracción de tamaño.

- Caudal de sedimentos como carga de fondo para cada fracción de tamaño.

- Concentración de sedimentos en suspension para cada fracción de tamaño.

Además de un resumen de los volúmenes de agua y sedimentos que salen de la cuenca definida por la estación de control y algunos indicadores del comportamiento general del modelo, cuando dicha estación tiene aforos líquidos y de sedimentos.

En la aplicación del modelo se pueden observar las salidas del modelo para la cuenca de Goodwin Creek y los análisis que se pueden hacer de las mismas. 


\section{Parte III}

Aplicación del Modelo 



\section{Capítulo 5}

\section{La Cuenca de Goodwin Creek}

En este capítulo se detallan las características físicas de la cuenca de Goodwin Creek, específicamente las que determinan su comportamiento hidrológico, geomorfológico y sedimentológico. Además se reseñan los antecedentes históricos de la cuenca y se expone brevemente el sistema de instrumentación instalado y su funcionamiento. A partir del análisis de las características físicas de la cuenca se estiman los parámetros necesarios para el funcionamiento del modelo.

\subsection{Aspectos generales}

La Cuenca de Goodwin Creek se ubica en el estado de Mississippi, USA, en el condado de Panola, cerca de la localidad de Batesville (figura 5.1). Cubre un área de aproximadamente $21,3 \mathrm{~km}^{2}$ y es un afluente de la Long Creek, la cual hace parte de la cuenca del río Yazoo que desemboca en el río Mississippi. La desembocadura de la cuenca se localiza a los $89^{\circ} 54^{\prime} 50^{\prime \prime}$ de latitud y $34^{\circ} 13^{\prime} 55^{\prime \prime}$ de longitud. Los intervalos de altura de la cuenca están entre 71 metros y 128 metros. La red de drenaje está altamente incisa y presenta una pendiente media de 0,004. En la actualidad cerca del $13 \%$ de la cuenca se encuentra cultivado (principalmente cultivos de algodón), el $60 \%$ en pastos y el $26 \%$ en reforestación de bosques de pino.

Está operada desde el año 1981 por el National Sedimentation Laboratory del Agricultural Research Service del Departamento de Agricultura de Estados Unidos (United States Department of Agriculture, USDA). La cuenca se encuentra extensivamente instrumentada para apoyar investigaciones en erosión en laderas, transporte y depósito de sedimentos en canales e hidrología de cuencas. La totalidad de información de la cuenca se encuentra disponible en la página web oficial del Agricultural Research Service del USDA ${ }^{1}$.

Según Kuhnle et al. (1996) la cuenca de Goodwin Creek proporciona un caso

\footnotetext{
${ }^{1}$ http://ars.usda.gov
} 


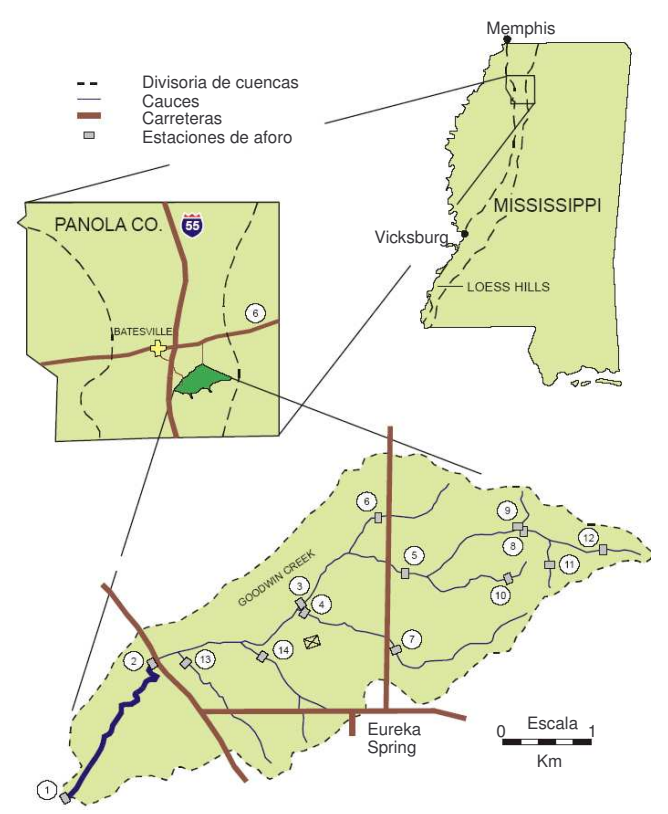

Figura 5.1. Localización de la cuenca de Goodwin Creek

instructivo de como los cambios en los usos del suelo y las características hidrológicas y geomorfológicas afecta la producción de sedimentos y la calidad de las aguas. A principios del siglo $X I X$ la cuenca se encontraba en su totalidad en bosques mientras que a principios del siglo $X X$ se encontraba deforestada y cultivada y a partir de este momento las tasas de erosión se hicieron excesivas.

La cuenca está dividida en 14 subcuencas definidas por estaciones de aforo de caudales líquidos y de sedimentos, las cuales presentan un intervalo de áreas entre $0,6 \mathrm{~km}^{2}$ y $21,3 \mathrm{~km}^{2}$ (figura 5.1). Posee una red de 32 estaciones de precipitación uniformemente distribuidas, tanto adentro de la cuenca como en sus inmediaciones. La precipitación promedio anual es de $1440 \mathrm{~mm}$ y el caudal medio anual medido en el punto de desagüe de la cuenca es de $14 \times 10^{6} \mathrm{~m}^{3}$ (datos del período entre 1982 - 1992). En la figura 5.2 se observan un modelo de elevación digital de la cuenca con tamaño de celda de 30 metros de lado y la red de drenaje generada a partir del MED.

Las estaciones de aforo se diseñaron para operar en régimen supercrítico con el objeto de evitar el depósito de sedimentos. Además se tuvo en cuenta los afluentes internos más importantes de la cuenca. Así para cada punto de conjunción de dos afluentes importantes, se estableció una estación de aforo.

La instrumentación en cada estación, tanto de aforo como de precipitación, incluye un sistema telemétrico de adquisición de datos electrónico que se encarga de colectar, almacenar y transmitir los datos a un ordenador central ubicado en la sede del National Sedimentation Laboratory en donde se procesan y archivan los 


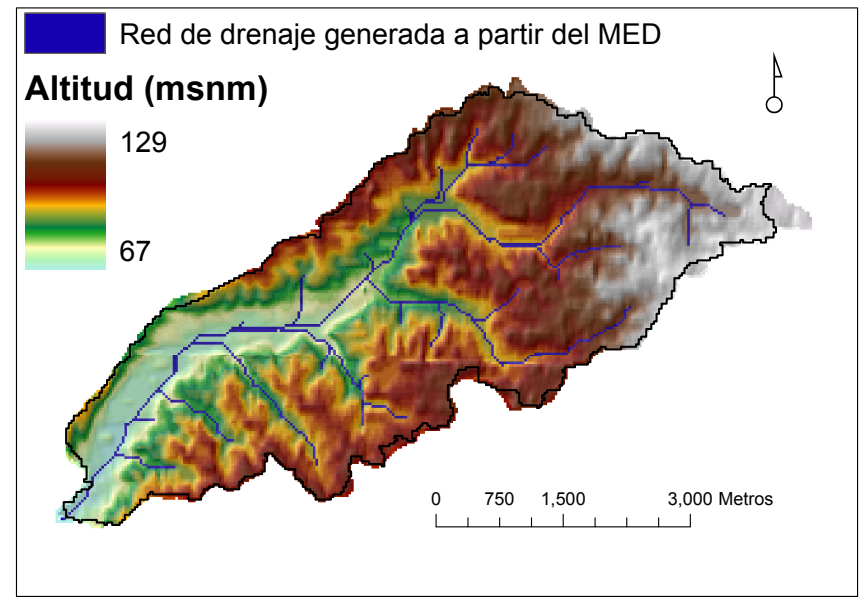

Figura 5.2. Modelo de Elevación Digital y red de drenaje

datos. Los datos colectados incluyen el nivel de agua, muestras de transporte de sedimentos, temperatura del agua y del aire, precipitación y parámetros climáticos. Durante eventos de lluvias se toman muestras de la carga total de sedimentos en algunas estaciones previamente seleccionadas, con la utilización de un muestreador Helley-Smith para la carga del lecho y un muestreador de carga en suspensión $D H$ 48.

Para conocer los cambios en la cobertura de vegetación y la superficie topográfica se efectúan campañas periódicas de toma de fotografías aéreas e imágenes de satélite.

La cuenca de Goodwin Creek se ubica en una zona en donde se presentan tasas de erosión y degradación del suelo muy altas, la región conocida como las colinas Bluff (Bluff Hills). Los sedimentos generados se depositan en las planicies aluviales del río Mississippi y en el propio cauce del río, ocasionando graves problemas de colmatación con la consecuente necesidad de dragado sistemático del río para evitar problemas en la navegación.

Una vez ubicada la fuente de sedimentos, el National Sedimentation Laboratory vio la necesidad de establecer una cuenca experimental para el conocimiento de los mecanismos y procesos causantes de la erosión. Los criterios de selección de dicha cuenca, que cumplía la Goodwin Creek, fueron:

- Que se ubicara en las colinas Bluff.

- Facilidad de dividir la cuenca en subcuencas. Este criterio responde a la necesidad de analizar subcuencas con diversas características de suelos y vegetación, con el fin de poder relacionarlas con la pérdida de suelos.

- Que no tuviera una presa o embalse en la red de drenaje. 
- Que estuviera cerca del National Sedimentation Laboratory

Debido a la disponibilidad de la información y a la calidad y cantidad de datos, la cuenca de Goodwin Creek se cuenta como una de las más estudiadas del mundo, con cientos de publicaciones e investigaciones en temas tales como hidrometeorología, procesos de erosión, erosión en cárcavas, transporte de sedimentos, geomorfología fluvial, estabilización y restauración de cauces, entre otros. La cuenca de Goodwin Creek ha llamado la atención de científicos de la $N A S A^{2}$ y la $N O A A^{3}$ que trabajan en proyectos hidroclimáticos de gran escala, tales como el proyecto internacional de escala continental GEWEX ${ }^{4}$ y el $W C R P^{5}$ de la $W M O{ }^{6}$.

\subsection{El sistema de instrumentación}

Los criterios de diseño de la red de estaciones de aforo se basaron en conclusiones arrojadas por investigaciones hidrológicas anteriores. Dichos criterios son:

- La sección del cauce debe ser adecuada para el análisis del fluido que pasa, esto es, debe tener una sección bien definida y estable.

- El área de drenaje de la sección se puede dividir en subcuencas las cuales deben ser relativamente homogéneas en cuanto a los usos del suelo, suelos y geología.

- La sección debe estar ubicada en un sitio asequible para su construcción y mantenimiento.

- Las áreas de drenaje deben tener un mínimo de áreas urbanas.

En el diseño de la red de instrumentación en la cuenca se tuvo en cuenta que los eventos extremos, en los cuales hay movilización de sedimentos, se presentan con poca frecuencia, pero que es necesario que la escala temporal de registro sea de intervalos de tiempo cortos (minutos). Así la red debe operar durante largos periodos de tiempo pero con una resolución temporal corta, para registrar adecuadamente los eventos cortos.

En cada estación de aforo se construyó una sección de canal en régimen supercrítico, para asegurar que el agua que pasa tenga la capacidad de carga necesaria para transportar toda la carga de sedimentos. Todas las secciones de control se han construido en concreto reforzado. La totalidad de secciones de control de las estaciones de aforo se han construido en forma de $V$, excepto las estaciones 1,

\footnotetext{
${ }^{2}$ National Aeronautics and Space Administration

${ }^{3}$ National Oceanographic and Atmospheric Administration

${ }^{4}$ Global Energy and Water Cycle Experiment

${ }^{5}$ World Climate Research Program

${ }^{6}$ World Meteorological Organization
} 
2 y 3 que se construyeron en forma de $U$. Además para asegurar que todos los sedimentos pasan por la sección de control, la pendiente longitudinal es de $4 \%$.

Las medidas de carga total de sedimentos no son totalmente automáticas, debido a la carencia de una tecnología apropiada. Los métodos de medidas son convencionales, esto es, es necesaria la intervención de operadores de campo.

En los inicios de la instrumentación de la cuenca se dio énfasis a la medición automática de la carga de sedimentos de fracciones finas (limos y arcillas) y arenas. Así, se emplazaron celdas de densidad para obtener concentraciones de sedimentos en tiempo real, junto con el caudal líquido. Sin embargo, esta metodología de medición tuvo muchos problemas causados por la baja sensibilidad del método que imposibilitaba su utilidad para las concentraciones normales que se presentan en eventos de crecidas en la cuenca, en las cuales hay presencia de sedimentos de grano grueso (arenas gruesas y gravas).

Posteriormente, se completó la instrumentación con la utilización de muestreadores físicos y controles computarizados. La carga de sedimentos finos $(<$ $0,062 \mathrm{~mm}$ ) se mide adecuadamente de forma sistemática, pero para tamaños de grano mayores es necesario la presencia de personal para mediciones manuales, lo cual es inviable para medidas sistemáticas. Así, sólo en las estaciones 1 y 2 se encuentran medidas manuales y ocasionalmente en la estación 3.

La carga de gravas se mide con la utilización de bedload box samplers en las estaciones 2, 13 y 14 y el Helley smith sampler en la parte baja de la estación 2. Desafortunadamente dichos muestreadores operan hasta cuando se llenan, lo cual ocurre en pocos minutos en un evento de crecida.

Durante los eventos de tormentas intensas, se toman muestreos manuales de la carga total de sedimentos en las estaciones 1 y 2 usando bedload and depthintegrating suspended sediment samplers.

En resumen, la carga de sedimentos está medida sistemáticamente usando un pumping sampler, un equal transit rate sampler y un Helley Smith sampler. Estos métodos son usados para medir las tasas de transporte de materiales finos $(<$ $0,062 \mathrm{~mm})$, arenas $(0,062-2 \mathrm{~mm})$ y gravas $(>2,0 \mathrm{~mm})$.

La estación 1 se ubica en el punto más bajo de la cuenca, sin ser afectada por el efecto remanso de la confluencia con la Long Creek. La estación 2 se localiza aguas abajo de una carretera, justo cuando el cauce presenta un régimen estable.

Las estaciones 13 y 14 presentan un área de drenaje muy pequeña, su construcción se debe a que aunque son pequeños afluentes, el material del lecho se compone de gravas, las cuales en eventos extremos se removilizan aguas abajo.

Las estaciones 3 y 4 se ubican justo aguas arriba de los dos afluentes más importantes de la cuenca, mientras que la ubicación de las estaciones 5,6 y 7 se debe a su cercanía a la carretera que cruza la cuenca en sentido norte - sur.

El área de captación de las estaciones 8 y 9 se encuentra en una zona que estuvo cultivada con intensidad y presenta carcavamiento grave, siendo una zona con alta contribución de sedimentos. 
El área de captación de la estación 10 se encuentra totalmente en bosque cultivado mientras que el área de drenaje de la estación 11 consiste básicamente en pastos, de esta forma dan cuenta de las características hidrológicas y sedimentológicas de dichos usos del suelo. La estación 12 se encuentra en la parte más alta de la cuenca (con respecto a las demás estaciones de aforo), aguas abajo de dicha estación los canales cambian drásticamente en tamaño y profundidad.

\subsection{Características físicas de la cuenca}

En esta sección se describen las características físicas de la cuenca, que determinan su comportamiento hidrológico y sedimentológico. Las características físicas de la cuenca son tomadas de Blackmarr (1995).

\subsubsection{Condiciones climáticas}

El clima de la zona es húmedo, con veranos cálidos e inviernos suaves. La temperatura media anual es de aproximadamente $17^{\circ} \mathrm{C}$ y la precipitación media anual es de $1400 \mathrm{~mm}$. La figura 5.3 muestra la precipitación media mensual de la cuenca durante el período comprendido entre los años 1981 y 1993.

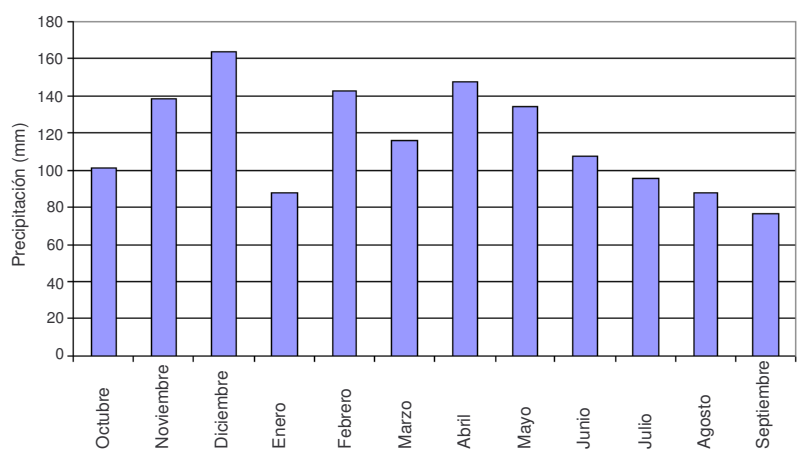

Figura 5.3. Precipitación media mensual de la cuenca Goodwin Creek entre 1981 y 1993

En la cuenca de Goodwin Creek los eventos de crecidas son altamente variables y las cargas de sedimentos se producen y movilizan durante eventos extremos, los cuales normalmente ocurren al finalizar el verano y a principios del otoño y se encuentran asociados a las tormentas tropicales generadas en el Golfo de México. Ocasionalmente, las lluvias se asocian a masas de alta humedad provenientes del Océano Pacífico.

En general, las precipitaciones son el resultado de corrientes convectivas ocasionadas por el choque de masas de aire cálidas y con gran humedad provenientes del 
sur con masa de aire frío proveniente del norte, ocasionando un frente de choque en la zona. Dichos frentes son comunes en el verano y la primavera. La precipitación en forma de nieve es muy escasa.

Es usual que sólo dos o tres eventos extremos sean los que contribuyan a la carga anual de sedimentos en la cuenca. El transporte de sedimentos en la red de drenaje toma tiempos largos para reactivarse, además aunque la inestabilidad de márgenes es intensa, se presenta esporádicamente.

\subsubsection{Geología}

La cuenca de Goodwin Creek se localiza en la provincia fisiográfica de la planicie costera (Coastal Plain Physiographic Province), con los dos tercios oeste de la cuenca perteneciente a la Subprovincia de colinas Bluff (Bluff Hills Subprovince) y el tercio este en la Subprovincia de las colinas centrales del norte (North Central Hills Subprovince). La Bluff Hill Subprovince está cubierta de loess ${ }^{7}$, con un relieve relativamente alto al este de la planicie aluvial del Mississippi, casi plana, mientras que la North Central Hills es un área de relieve moderado. Las capas de loess se presentan en los interfluvios, desapareciendo gradualmente en la dirección oeste - este, mientras que los depósitos aluviales holocénicos se encuentran en los valles.

La columna estratigráfica de la zona se compone de formaciones terciarias y cuaternarias, tal como se observa en la columna estratigráfica general de la figura 5.4 .

\begin{tabular}{|c|c|c|c|}
\hline SISTEMA & SERIE & FORMACIÓN & MIEMBRO \\
\hline \multirow{3}{*}{ Cuaternario } & Holoceno & Aluviones recientes & \\
\cline { 2 - 4 } & Pleistoceno & Loess & \\
\hline \multirow{4}{*}{ Terciario } & Plioceno & Citronelle & \\
\cline { 3 - 4 } & & Kosciusko & \\
\cline { 3 - 4 } & \multirow{2}{*}{ Eoceno } & Zilpha & \\
\cline { 3 - 4 } & & Winona & \\
\cline { 3 - 4 } & & Tallahatta & Neshoba \\
\cline { 3 - 4 } & & & Basic City \\
\hline
\end{tabular}

Figura 5.4. Columna estratigráfica generalizada de la cuenca Goodwin Creek

Las características principales de las formaciones geológicas son:

La formación Tallahatta. Se compone de arenas, limos, areniscas y limolitas. El miembro Neshoba presenta arenas finas amarillas y grises con matriz arcillosa y laminar, este miembro se presenta ocasionalmente cementado. El miembro Basic

\footnotetext{
${ }^{7}$ Limos transportados y depositados por el viento, de origen glacial. Se encuentran extendidos en masas continentales en latitudes medias, afectadas por glaciaciones en el Pleistoceno
} 
City es arcilloso, con contenidos micaceos y con láminas de material orgánico, frecuentemente aparece cementado.

La formación Winona. Presenta arenas, limos, arcillas y arcillolitas. Es una formación micácea y carbonacea con colores variables. Las arcillas son laminares. Cuando se oxida presenta colores rojos y cafés.

La formación Zilpha. Contiene arcillas, areniscas limosas, lignitas, areniscas y limolitas. Los sedimentos son carbonaceos de color café y negro cuando están húmedos. Presenta concreciones de marcasita laminares.

La formación Kosciusko. Contiene arenas, areniscas y arcillas retrabajadas. Las arenas son finas a gruesas y presentan colores variables. Las arcillas tienen alta presencia de nódulos y bolos.

La formación Citronella. Está compuesta por arenas, areniscas, gravas y arcillas. Las arenas son gruesas a finas, con estratificación cruzada y ocasionalmente se presentan cementadas. Las gravas se encuentran esparcidas y aparecen en láminas delgadas. Las arcillas son lenticulares.

\subsubsection{Geomorfología y Geología del Cuaternario}

\subsubsection{Formaciones superficiales}

En la cuenca de Goodwin Creek se pueden identificar siete unidades litológicas del Holoceno, que se dividen en tres secuencias depositacionales según la edad (Holoceno temprano, Holoceno medio y Holoceno tardío). El Pleistoceno se manifiesta por la presencia de un manto de depósitos de loess de espesor variable (entre 10 metros y 30 metros). La figura 5.5 es un corte litológico idealizado de las formaciones superficiales.

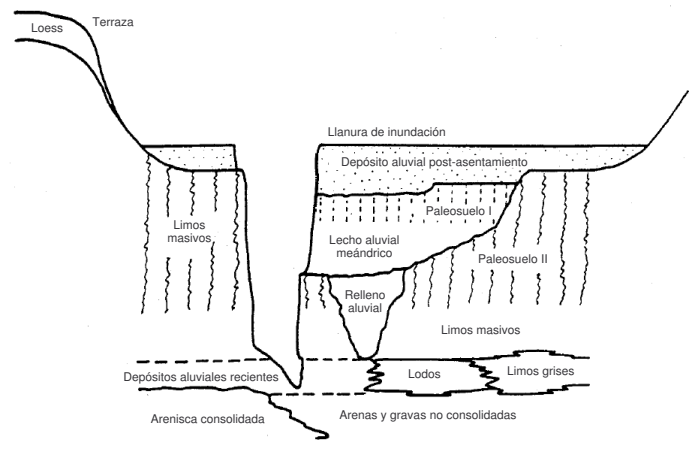

Figura 5.5. Corte litológico idealizado de las formaciones superficiales

La secuencia depositacional del Holoceno temprano. Contiene dos miembros. El más joven está compuesto por limos masivos de textura fina, densa y con $\mathrm{pH}$ entre neutro y alcalino. Este miembro se sobreimpone a tres unidades con 
contacto discontinuo a gradacional. Es común la presencia de materia orgánica en todas las unidades, excepto en los limos masivos. Los limos masivos rellenan los valles con depósitos de aproximadamente 4 metros de espesor. La meteorización de estos limos está representada por el Paleosuelo II, el cual no presenta horizonte $A 1$, el horizonte $A 2$ es delgado, mientras que presenta un horizonte $B 2$ espeso y bien desarrollado.

El miembro más antiguo del Holoceno temprano contiene limos grises no consolidados, lodos y depósitos aluviales. Los depósitos aluviales presentan una textura relativamente gruesa y los lodos son esencialmente orgánicos. Ambas unidades son altamente erosionables, mientras que los limos grises son relativamente estables debido a su alta densidad, su contenido de arcillas cohesivas, su alto contenido de humedad y su estructura poligonal. Este miembro tiene una edad media estimada de 10000 años.

La secuencia del Holoceno medio. Consiste en rellenos aluviales que fueron depositados en un corto período. Los materiales presentan una textura gruesa con poca o ninguna cohesión y son altamente erosionables. El perfil de meteorización es poco definido. Estos depósitos se presentan en los valles con poca frecuencia. La edad media ronda los 5000 años.

La secuencia depositacional del Holoceno tardío. Incluye dos unidades litológicas, los depósitos aluviales post-asentamiento y el lecho aluvial meándrico. Los depósitos aluviales post-asentamiento son el resultado de la erosión de los loess ubicados en las laderas debido a la intensa actividad agrícola que se dio en la cuenca a finales del siglo diez y nueve y principios del siglo veinte. Dichos depósitos cubre prácticamente todas las llanuras de inundación con un espesor que varía entre 1 metro y 4 metros. Son altamente permeables excepto cuando se ubican en zonas dedicadas a la agricultura, debido a la compatación de la maquinaria agrícola. No se encuentran meteorizados, presentando un perfil de tipo $A_{p}$ sobreimpuesto al horizonte $C$.

Los depósitos de lecho aluvial meándrico poseen una edad máxima de 3000 años. Se formaron por la erosión de sedimentos antiguos y su depósito en una red de meandros bien definida. El material está compuesto por limos finos a arenas medias y está poco meteorizado. El perfil de meteorización se representa por el Paleosuelo I, el cual es relativamente fértil y bien drenado. Posee un horizonte $A 1$ con espesor entre un par de centímetros y 25 centímetros que se sobreimpone a un horizonte $B$ poco desarrollado. El horizonte $A 1$ se formó en un ecosistema de gramíneas.

\subsubsection{Morfología de la red de drenaje}

En la cuenca de Goodwin Creek, la red de drenaje consiste en valles estrechos y cauces incisados. La incisión en los cauces deja al descubierto depósitos de loess, mientras que los fondos de los valles están rellenos de depósitos aluviales derivados de la erosión grave producida por los primeros asentamientos de europeos en la 
zona, en la década de 1830.

Luego de la llegada de los primeros europeos, comenzó una deforestación y posterior cultivo, ocasionando erosión grave en las laderas y depósito acelerado en los valles. Los fondos de los valles fueron cubiertos por varios metros de sedimentos erosionados de las laderas y las condiciones fangosas de los sedimentos hizo que se desarrollara una red de drenaje irregular. Esta erosión grave se ha observado en loess de diferentes partes del mundo, por ejemplo en China (Hessel, 2002) y Europa (Lang et al., 2003), producida por la deforestación y el posterior cultivo.

La respuesta de los dueños de las tierras ante dichas condiciones fue la canalización de las corrientes y la construcción de zanjas, entre los períodos de 1840 y 1930. Estos esfuerzos fueron insuficientes e inefectivos.

Entre 1930 y 1960 se efectuó una segunda canalización y la construcción de embalses para el control de inundaciones en los canales. Debido a la alteración de los canales, la posición actual de la red de drenaje no corresponde a los depósitos del Holoceno y a la red de meandros naturales. Como resultado, la red de drenaje de la cuenca respondió a la canalización con una fuerte incisión. Esta incisión es normal en puntos de quiebre aguas arriba de los tramos canalizados. En la actualidad, la incisión está aun en progreso en muchos tramos de la red de drenaje, ocasionando problemas de inestabilidad de las márgenes, con altos costos económicos.

\subsubsection{Estabilidad de lechos y márgenes de la red de cauces}

Los materiales de los lechos que controlan la estabilidad incluyen depósitos aluviales y meandros generados posteriormente al asentamiento de los colonos europeos, los limos masivos del Holoceno temprano y las capas superficiales de depósitos aluviales no consolidados de textura limosa.

La inestabilidad de los depósitos aluviales y meandros post-asentamiento se presenta por estrés gravitatorio, acentuado por el desarrollo de grietas de tensión. Las grietas de tensión son verticales y paralelas a los taludes de las márgenes del lecho. El desprendimiento de material en los limos masivos es el resultado de estrés gravitatorio con el plano de falla definido por una estructura poligonal debido a la meteorización del material holoceno. La frecuencia de la inestabilidad se relaciona con la incisión del margen, que incrementa la altura y la inclinación del talud y deja expuesto material fangoso en el pie del talud. Una vez desecado dicho material, se forman grietas de tensión, fácilmente erosionables. De esta forma, tanto en períodos de lluvia como en períodos secos se presentan procesos de inestabilidad del talud de las márgenes del lecho.

En la cuenca de Goodwin Creek se encuentran amplias zonas con carcavamiento remontante ( $15 \%$ del área la cuenca) que se explican por los mecanismos descritos anteriormente.

Los puntos de quiebre en la parte baja de la red de drenaje (cambios de pendiente) poseen lechos de arena y gravas y la estabilidad de estos tramos depende básicamente del suministro de sedimentos y las propiedades hidráulicas del siste- 
ma. Además, la presencia de materiales relativamente duros en el lecho, tales como areniscas consolidadas pre-holocénicas, inhiben la migración de puntos de quiebre y permiten la presencia de zonas de acumulación de materiales gruesos (arenas y gravas) con la consecuente estabilización del lecho en dichos tramos.

\subsubsection{Suelos}

En la cuenca de Goodwin Creek se diferencian 7 series de suelos (figura 5.6). El material parental corresponde al manto de loess con presencia esporádica de arenas y arcillas provenientes de sedimentos de la planicie costera del Eoceno y de los depósitos aluviales del Plioceno y Pleistoceno del río Mississippi. Los suelos en general presentan una textura limosa y son fácilmente erosionables cuando se remueve la cubierta de vegetación, ocasionando carcavamiento intenso.

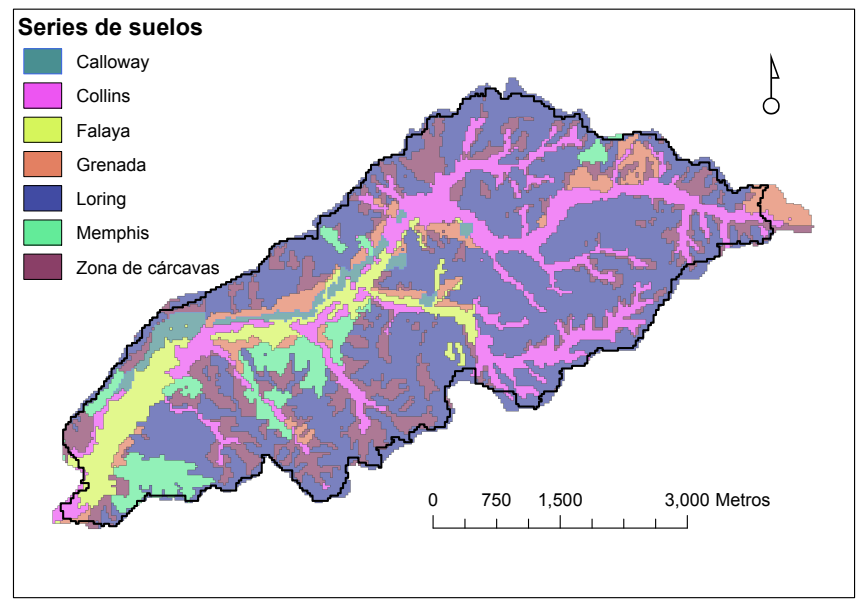

Figura 5.6. Series de suelos en la cuenca Goodwin Creek

Se han observado dos tipos de ciclos geomorfológicos que determinan el ambiente sobre los cuales se desarrollan los suelos durante el Holoceno, el ciclo de incisión de canales y el ciclo de agradación de canales.

El ciclo de incisión ocurre cuando los sedimentos que llegan aguas arriba son el factor limitante. Actualmente se presenta un ciclo de incisión, iniciado por el asentamiento de los colonos europeos entre los años 1840 y 1880 . Una vez se deforesta la vegetación nativa y se cultiva, los mantos de loess comienzan a erosionarse hasta que se alcanza un nivel arenoso, más resistente a la erosión. El efecto sobre la red de drenaje es un relleno de materiales de arenas y limos, tanto en las llanuras de inundación como en los abanicos aluviales. Este ciclo es el cuarto ciclo de incisión que se ha dado en la cuenca durante el Holoceno. 
Los suelos se han clasificado en series ${ }^{8}$ y asociaciones ${ }^{9}$. En la cuenca se han cartografiado dos asociaciones, la Collins - Falaya - Grenada - Calloway ubicada en terrazas y llanuras de inundación. Esta asociación es básicamente limosa, pobre a moderadamente bien drenada e incluye la mayor parte de los cultivos en la cuenca. La otra asociación de suelos, la Loring - Grenada - Memphis se desarrolla en las laderas. Se trata de suelos bien a moderadamente drenados, con pendientes suaves a abruptas y en la actualidad se encuentran con pastos y bosques. Esta asociación fue la que se deforestó con la llegada de los primeros pobladores y posteriormente se abandonó o se forestó.

Las características principales de las series de suelos son:

La serie Calloway. Se compone de limos finos y mixtos del tipo thermic Glossaquic Fragiudalfs; los suelos son pobremente drenados, fuertemente ácidos a medio ácidos. Los suelos se han formado en terrazas y llanuras de inundación.

La serie Collins. Presenta limos gruesos y mixtos del tipo thermic Aquic Udifluvents; son suelos moderadamente bien drenados, fuertemente ácidos a medio ácidos, los cuales se han formado en aluviones o en el piedemonte de las laderas. Estos suelos se localizan a lo largo de la red de drenaje y se encuentran cultivados.

La serie Falaya. Contiene limos gruesos, mixtos, ácidos y son del tipo thermic Aeric Fluvaquents. Son suelos pobremente drenados, fuertemente a muy fuertemente ácidos desarrollados en aluviones y cerca del pie de las laderas. En su mayoría se encuentran cultivados.

La serie Grenada. Consiste en limos finos, mixtos del tipo thermic Glossic Fragiudalfs. Son suelos moderadamente bien drenados, de fuerte a fuertemente ácidos desarrollados sobre depósitos de loess en terrazas y las partes altas de la ladera.

La serie Loring. Se compone de limos finos, mixtos del tipo thermic Typic Fragiudalfs. La serie consiste en suelos bien drenados, de fuerte a muy fuertemente ácidos desarrollados en las laderas.

La serie Memphis. Contiene limos finos, mixtos del tipo thermic Typic Hapludalfs. Se trata de suelos bien drenados, de fuerte a fuertemente ácidos desarrollados en las partes altas de las laderas. Se encuentra bajo bosques.

Las zonas con cárcavas. Consisten en suelos gravemente erosionados y con carcavamiento. La parte más superficial del suelo se ha removido. Estas zonas fueron deforestadas, cultivadas y luego abandonadas. En la actualidad se encuentran árboles diseminados, rastrojos y pastos. No es apta para el cultivo.

\subsubsection{Usos del suelo}

La cuenca presentaba en el período de aplicación del modelo tres usos del suelo: cultivos, bosques y pastos. La distribución espacial de los usos del suelo se muestra en la figura 5.7.

\footnotetext{
${ }^{8}$ Grupo de suelos que tiene un perfil similar

${ }^{9}$ Grupo de suelos con localización y arreglo similar
} 


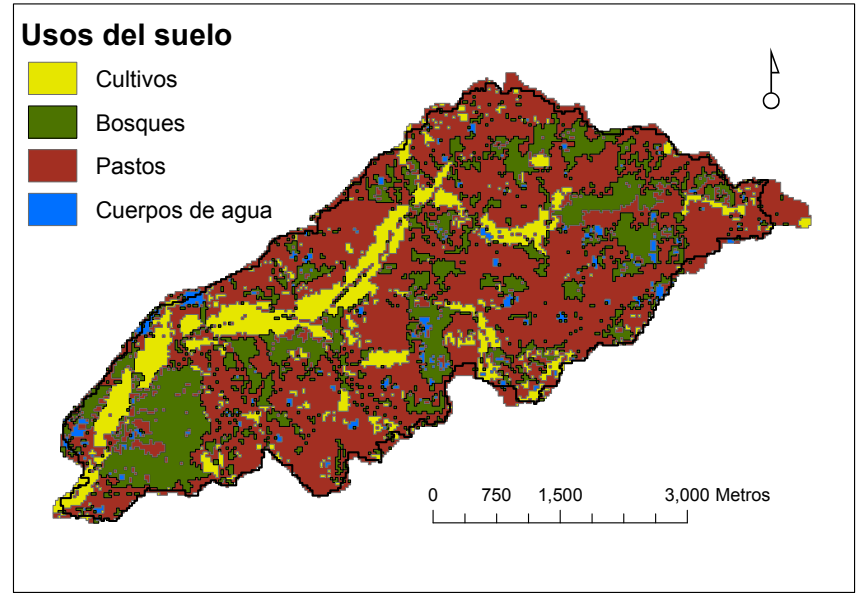

Figura 5.7. Usos del suelo en la cuenca Goodwin Creek

Los cultivos incluyen algodón, soja y pequeños granos, los pastos incluyen zonas de rastrojo y los bosques son en su totalidad cultivados. Los cuerpos de agua son pequeños embalses y zonas de encharcamiento.

\subsubsection{Características topográficas}

A partir del modelo de elevación digital (figura 5.2) se derivan las características topográficas de la cuenca, las cuales se presentan en las figuras 5.8 - 5.11.

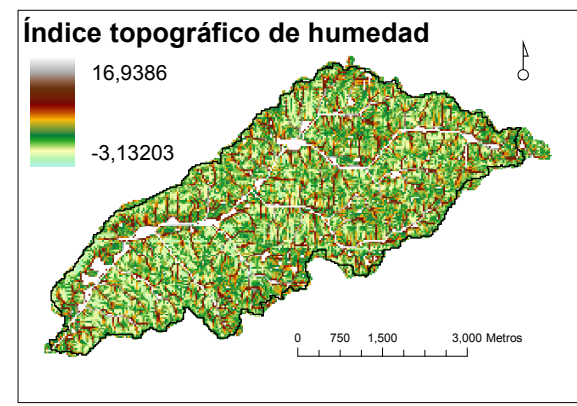

Figura 5.8. Mapa del índice topográfico de humedad 

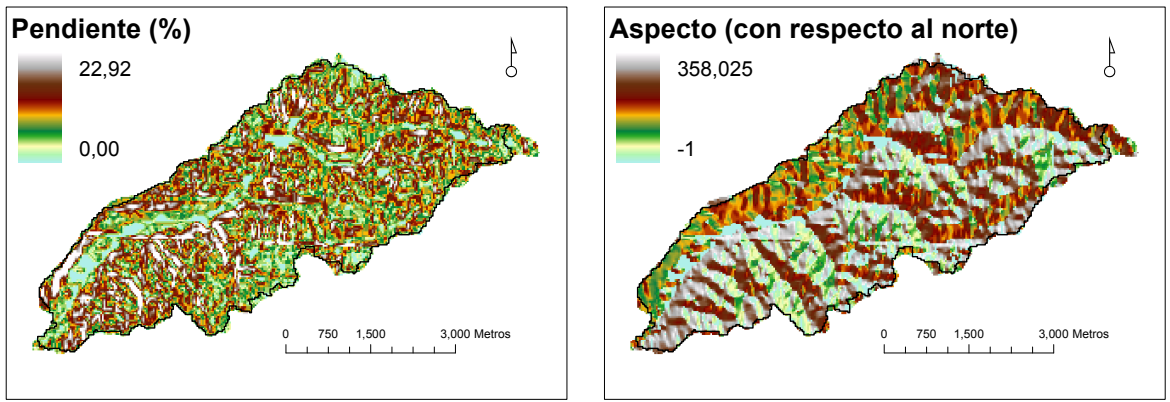

Figura 5.9. Mapas de pendientes en porcentaje y aspecto en grados
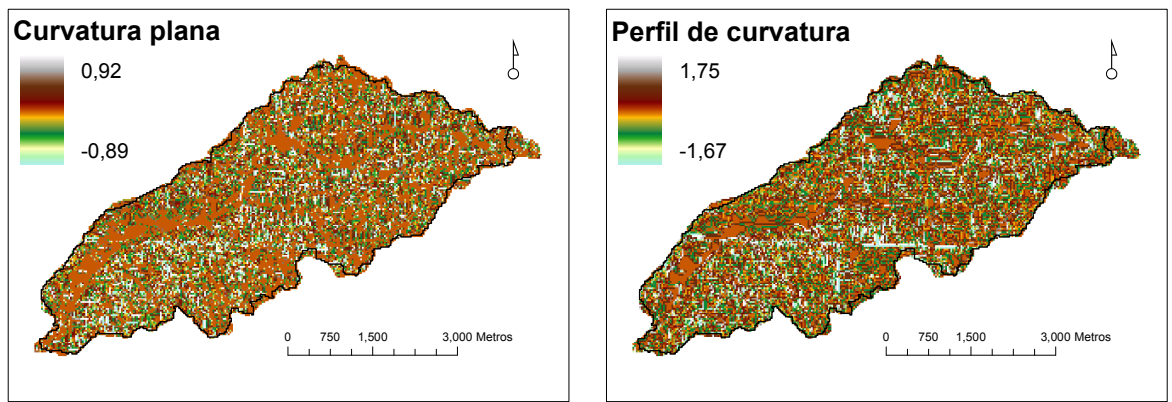

Figura 5.10. Mapas de la curvatura horizontal y el perfil de curvatura
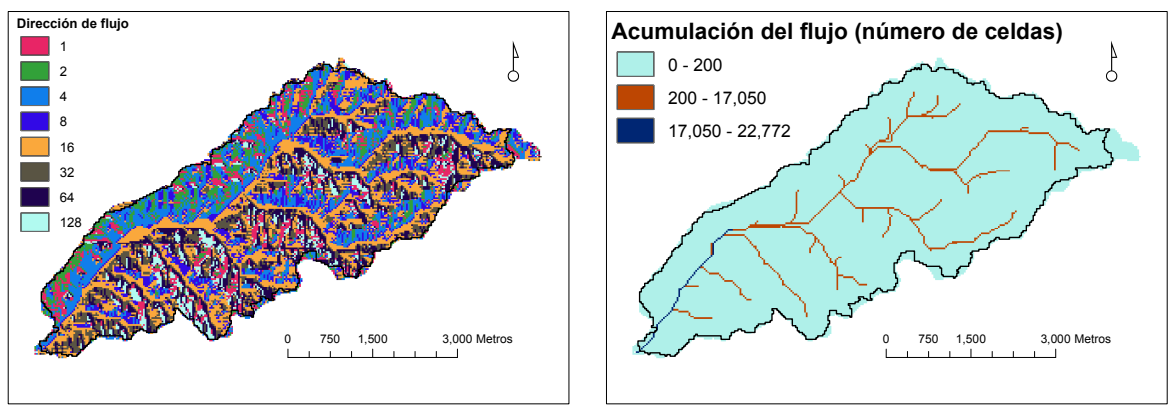

Figura 5.11. Mapas de la dirección y acumulación del flujo 


\section{Capítulo 6}

\section{Estimación de parámetros}

En este capítulo se estiman los parámetros necesarios para la implementación del modelo en la cuenca de Goodwin Creek. Se explican las simplificaciones en algunos parámetros y los análisis efectuados tendientes a encontrar la variabilidad espacial.

\subsection{Los parámetros hidrológicos}

Debido a que el modelo se aplicará en eventos extremos de lluvia, en los cuales se presenta producción y movilización de sedimentos, el índice de cobertura de vegetación para la evapotranspiración carece de relevancia.

Según Ogden y Heilig (2001) las aguas subterráneas no contribuyen significativamente al caudal en la cuenca de Goodwin Creek. El flujo base en la salida de la cuenca es menor que $0,05 \mathrm{~m}^{3} / \mathrm{s}$. A partir de mediciones de los niveles de las aguas subterráneas tomadas en las inmediaciones del cauce principal, se observa que el nivel freático se presenta muchos metros debajo de la superficie, mientras que las fluctuaciones del nivel freático durante eventos de lluvia son del orden de centímetros (entre 5 y 10 centímetros). Estas observaciones, añadidas a la textura fina de los suelos, indican que el mecanismo dominante en el comportamiento hidrológico de la cuenca se debe a la escorrentía por exceso de infiltración del suelo. Debido a esto, la conductividad hidráulica saturada del sustrato del suelo no es un parámetro significativo y se puede considerar que el comportamiento hidrológico se debe escencialmente a la escorrentía directa y al flujo subsuperficial.

\subsubsection{Conductividad hidráulica saturada del sustrato del suelo}

Como se ha mencionado, el flujo subterráneo es una componente irrelevante en el comportamiento hidrológico de la cuenca. De esta forma, no es necesario efectuar 
un análisis exhaustivo de la conductividad hidráulica saturada del sustrato del suelo. Los valores fueron estimados de acuerdo con las características texturales de las formaciones geológicas presentes en la cuenca. El mapa de $K_{p}$ se muestra en la figura 6.1.

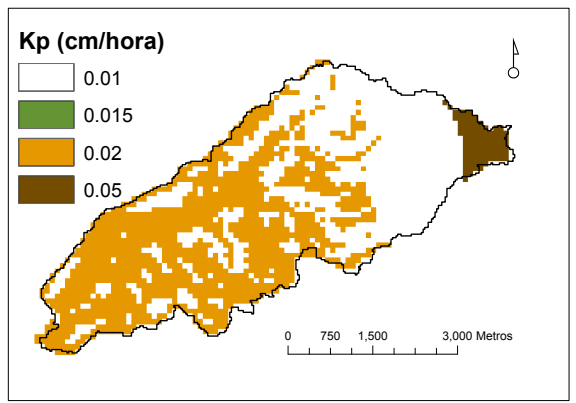

Figura 6.1. Mapa de la conductividad hidráulica del sustrato del suelo

\subsubsection{Conductividad hidráulica saturada del suelo}

Para estimar la conductividad hidráulica saturada del suelo se calcula el tiempo de viaje sobre los niveles del suelo que se encuentran en la zona de raíces. Para cada nivel de las series de suelos se tiene la permeabilidad, en $\mathrm{cm} /$ hora (Blackmarr, 1995). El tiempo de viaje es el producto de esta permeabilidad por el espesor del nivel. Al sumar los tiempos de viaje por todos los niveles que se encuentran en la zona de raíces se obtiene el tiempo de viaje total. La división del espesor de la zona de raíces sobre el tiempo de viaje total es la conductividad hidráulica media del perfil. En la tabla 6.1 se muestran los valores obtenidos para las unidades cartográficas resultantes.

\subsubsection{Capacidad de almacenamiento hídrico del suelo}

Para estimar los valores modales de la capacidad de almacenamiento hídrico del suelo, $H_{u}$, se tuvo en cuenta el contenido de agua disponible para los diferentes niveles del suelo en los cuales se encuentran raíces. De tal forma es necesario estimar la profundidad de raíces según los diferentes usos del suelo de la cuenca. Se ha estimado que la profundidad de raíces para los cultivos es de $100 \mathrm{~cm}$, para los bosques es de $200 \mathrm{~cm}$, y para los pastos es de $40 \mathrm{~cm}$.

Para cada unidad de suelos se tiene el contenido de agua disponible, en $\mathrm{mm} / \mathrm{mm}$, y el espesor de cada nivel de suelo, en $m m$ (Blackmarr, 1995). La capacidad de almacenamiento hídrico de cada nivel es el producto entre el contenido de agua disponible y el espesor $(\mathrm{mm})$. La capacidad de almacenamiento hídrico del perfil 


\begin{tabular}{l|c|c|c}
\hline Uso del suelo & Serie de suelo & Identificador & $\begin{array}{c}\text { Conductividad hidráulica } \\
\text { saturada }(\mathrm{cm} / \text { hora })\end{array}$ \\
\hline \multirow{5}{*}{ Cultivos } & Calloway & 11 & 0,21 \\
& Collins & 12 & 4,191 \\
& Falaya & 13 & 4,191 \\
& Grenada & 14 & 0,293 \\
& Cárcavas & 15 & 4,191 \\
& Loring & 16 & 0,678 \\
& Memphis & 17 & 4,191 \\
\hline \multirow{5}{*}{ Bosques } & Calloway & 21 & 0,283 \\
& Collins & 22 & 4,191 \\
& Falaya & 23 & 4,191 \\
& Grenada & 24 & 0,177 \\
& Cárcavas & 25 & 4,191 \\
& Loring & 26 & 0,214 \\
& Memphis & 27 & 4,191 \\
\hline \multirow{5}{*}{ Pastos } & Calloway & 31 & 4,191 \\
& Collins & 32 & 4,191 \\
& Falaya & 33 & 4,191 \\
& Grenada & 34 & 4,191 \\
& Cárcavas & 35 & 4,191 \\
& Loring & 36 & 4,191 \\
& Memphis & 37 & 4,191 \\
\hline
\end{tabular}

Tabla 6.1. Identificador y conductividad hidráulica saturada para las unidades cartográficas

de cada unidad de suelos es la suma de la capacidad de almacenamiento hídrico de cada nivel, hasta que se alcanza la profundidad de raíces. En las tablas $6.2-$ 6.3 se muestran los valores obtenidos para las unidades cartográficas.

\subsubsection{Variabilidad espacial de los parámetros hidrológi- $\cos$}

El procedimiento comienza con la unión de los mapas de suelos y usos del suelo, obteniendo en total 21 unidades cartográficas ( 7 tipos de suelos y 3 usos del suelo), cada una de las cuales presenta un valor modal de los parámetros $H_{u}$ y $K_{s}$. La figura 6.2 muestra el mapa resultante de unir los tipos de suelos con los usos del suelo y la tabla 6.1 reseña el identificador para cada unidad cartográfica resultante.

Para definir la variabilidad espacial de la capacidad de almacenamiento hídrico del suelo y la conductividad hidráulica, al interior de las unidades cartográficas, se supone que el índice topográfico y la curvatura son las variables ambientales que más intervienen en la explicación de dicha variabilidad. Estas suposiciones se basa 


\begin{tabular}{|c|c|c|c|c|c|}
\hline \multirow[t]{2}{*}{ Nivel } & \multirow{2}{*}{$\begin{array}{c}\text { Profundidad } \\
\text { en la base } \\
(\mathrm{mm})\end{array}$} & \multirow{2}{*}{$\begin{array}{c}\text { Agua } \\
\text { disponible } \\
(\mathrm{mm} / \mathrm{mm})\end{array}$} & \multicolumn{3}{|c|}{$\begin{array}{l}\text { Contenido de agua disponible } \\
\qquad(\mathrm{mm})\end{array}$} \\
\hline & & & Cultivo & Bosque & Pasto \\
\hline Ca-A & 152,4 & 0,116 & 17,68 & 17,68 & 17,68 \\
\hline \multirow[t]{4}{*}{$\mathrm{Ca}-\mathrm{B}$} & 279,4 & 0,116 & 14,73 & 14,73 & 14,73 \\
\hline & 406,4 & 0,1 & 12,7 & 12,7 & 12,06 \\
\hline & 1270 & 0,1 & 59,36 & 86,36 & \\
\hline & $>4000$ & 0,1 & & 73 & \\
\hline \multicolumn{3}{|c|}{ Capacidad de almacenamiento hídrico $(\mathrm{mm})$} & 104,47 & 204,47 & 44,47 \\
\hline $\mathrm{C}-\mathrm{m}$ & 152,4 & 0,125 & 19,05 & 19,05 & 19,05 \\
\hline \multirow[t]{2}{*}{$\mathrm{C}-\mathrm{O}$} & 609,6 & 0,116 & 53,04 & 53,04 & 28,72 \\
\hline & $>4000$ & 0,116 & 45,29 & 161,29 & \\
\hline \multicolumn{3}{|c|}{ Capacidad de almacenamiento hídrico $(\mathrm{mm})$} & 117,37 & 233,37 & 47,77 \\
\hline F-a & 177,8 & 0,125 & 22,23 & 22,23 & 22,23 \\
\hline F-l & $>4000$ & 0,125 & 102,78 & 227,78 & 27,78 \\
\hline \multicolumn{3}{|c|}{ Capacidad de almacenamiento hídrico $(\mathrm{mm})$} & 125 & 250 & 50 \\
\hline
\end{tabular}

Tabla 6.2. Capacidad de almacenamiento hídrico para las unidades cartográficas. Calloway (Ca), Collins (C), Falaya (F)

en las conclusiones obtenidas por Moore et al. (1993a) y Gessler et al. (1995).

El índice topográfico de humedad (Beven y Kirkby, 1979) es una medida de la posición topográfica relativa de la celda en cada ladera, esto es, la catena de suelos en la ladera. La capacidad de almacenamiento hídrico del suelo depende del espesor del nivel superior del suelo, específicamente el que se encuentra en la zona de raíces.

Valores altos del índice topográfico indican zonas con baja pendiente y área de drenaje alta, esto es, zonas en el piedemonte de la ladera, en vaguadas, valles, abanicos aluviales, llanuras de inundación. En estas zonas se presenta acumulación de los niveles superiores del suelo, con presencia de suelo orgánico y por lo tanto suelos aptos para el desarrollo de la vegetación. De otra parte, en zonas con pendientes altas y poca área de drenaje, los niveles superiores del suelo suelen ser poco profundos. De esta forma se puede esperar que la capacidad de almacenamiento hídrico aumente directamente proporcional al índice topográfico.

En relación con la conductividad hidráulica saturada, se espera que esta presente una relación inversamente proporcional al índice topográfico. Valores altos del índice topográfico indican zonas de acumulación, tanto de agua como de finos, además la red de macroporos al interior del suelo disminuye, de esta forma la conductividad hidráulica del suelo disminuye. Por otro lado en zonas con pendientes altas y poca área de acumulación, el suelo suele ser bien drenado y con textura más gruesa y la densidad de macroporos aumenta, de esta forma, al disminuir el índice topográfico de humedad se espera que aumente la conductividad hidráulica del suelo. 


\begin{tabular}{|c|c|c|c|c|c|}
\hline \multirow[t]{2}{*}{ Nivel } & \multirow{2}{*}{$\begin{array}{c}\text { Profundidad } \\
\text { en la base } \\
(\mathrm{mm})\end{array}$} & \multirow{2}{*}{$\begin{array}{c}\text { Agua } \\
\text { disponible } \\
(\mathrm{mm} / \mathrm{mm})\end{array}$} & \multicolumn{3}{|c|}{$\begin{array}{l}\text { Contenido de agua disponible } \\
\qquad(\mathrm{mm})\end{array}$} \\
\hline & & & Cultivo & Bosque & Pasto \\
\hline Gr-A & 127 & 0,116 & 14,73 & 14,73 & 14,73 \\
\hline Gr-B & 584,2 & 0,15 & 68,58 & 68,58 & 40,95 \\
\hline Gr-B2 & $>4000$ & 0,058 & 24,12 & 82,12 & \\
\hline \multicolumn{3}{|c|}{ Capacidad de almacenamiento hídrico $(\mathrm{mm})$} & 107,43 & 165,43 & 55,68 \\
\hline Lo-B2 & 127 & 0,116 & 14,73 & 14,73 & 14,73 \\
\hline Lo-B3 & 838,2 & 0,141 & 100,28 & 100,28 & 38,49 \\
\hline $\mathrm{Lo}-\mathrm{C}$ & $>4000$ & 0,15 & 24,27 & 174,27 & \\
\hline \multicolumn{3}{|c|}{ Capacidad de almacenamiento hídrico $(\mathrm{mm})$} & 139,28 & 289,28 & 53,23 \\
\hline Mi-F2 & 152,4 & 0,116 & 17,68 & 17,68 & 17,68 \\
\hline \multirow[t]{3}{*}{ Mi-F3 } & 635 & 0,116 & 55,98 & 55,98 & 28,72 \\
\hline & 1244,6 & 0,15 & 54,75 & 91,44 & \\
\hline & $>4000$ & 0,15 & & 113,31 & \\
\hline \multicolumn{3}{|c|}{ Capacidad de almacenamiento hídrico $(\mathrm{mm})$} & 128,41 & 278,41 & 46,4 \\
\hline $\mathrm{Gu}$ & 1000 & 0,116 & 23,2 & 34,8 & 11,6 \\
\hline \multicolumn{3}{|c|}{ Capacidad de almacenamiento hídrico $(\mathrm{mm})$} & 23,2 & 34,8 & 11,6 \\
\hline
\end{tabular}

Tabla 6.3. Capacidad de almacenamiento hídrico para las unidades cartográficas. Grenada (Gr), Loring (Lo), Memphis (Mi) y Zonas con cárcavas $(\mathrm{Gu})$

La curvatura horizontal es determinante en la propensión del agua a converger o divergir. Cuando el valor de la curvatura horizontal es negativa el flujo diverge y la celda se ubica en zonas altas y divisorias de aguas, mientras que cuando la curvatura es positiva el flujo tiene a converger y la celda se ubica en valles y vaguadas. La relación entre la curvatura y la capacidad de almacenamiento hídrico del suelo es inversamente proporcional, mientras que la relación entre la curvatura y la conductividad hidráulica saturada del suelo es directamente proporcional.

La curvatura horizontal presenta un intervalo de aplicación más local que el índice topográfico de humedad, ya que se basa en la comparación de la altitud de la celda con su vecindario.

Puesto que las unidades cartográficas construidas para los valores modales de la capacidad de almacenamiento hídrico y la conductividad hidráulica saturada del suelo se derivan de la unión entre las series de suelos y los usos del suelo de la cuenca y además la cuenca es relativamente homogénea (la totalidad de suelos son derivados de loess y depósitos de loess, se encuentran sólo tres usos del suelo, las características climáticas y geomorfológicas no varían) no se pueden identificar variables ambientales que expliquen un comportamiento hidrológico contrastado. Esto justifica la no inclusión de variables ambientales dummies en el análisis de la variabilidad espacial de los parámetros hidrológicos.

Siguiendo la metodología descrita en la sección 4.6.1 se obtiene el siguiente 


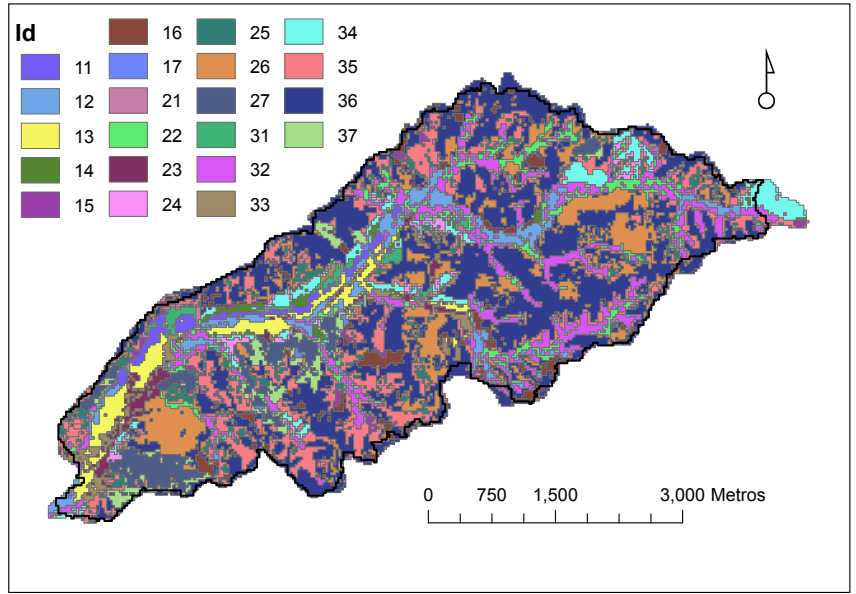

Figura 6.2. Unidades cartográficas derivadas de la unión entre los suelos y los usos del suelo

modelo de regresión para la raíz cuadrada de la capacidad de almacenamiento hídrico del suelo:

$$
\sqrt{H_{u}}=9,2788+1,3895 \times I T_{\text {nor }}-0,8966 \times C U R V A_{\text {nor }}
$$

El p-valor de la regresión es inferior a 0,01, de este modo existe una relación estadísticamente significativa entre las variables para un nivel de confianza del $99 \%$. El estadístico R-cuadrado es de $24 \%$, indicando que el modelo explica un $24 \%$ de la variabilidad de $\sqrt{H_{u}}$. En cuanto al p-valor de las variables dependientes, la constante y el coeficiente de $I T_{n o r}$ toma un valor de 0 , de esta forma son estadísticamente significativos para un nivel de confianza del $99 \%$; mientras que el p-valor del coeficiente de $C U R V A_{n o r}$ es de 0,11 , señalando que este término no es significativamente estadístico para un nivel de confianza del $90 \%$ o superior.

Y el siguiente modelo de regresión para el logaritmo natural de la conductividad hidráulica saturada del suelo:

$$
\ln K_{s}=0,6524-0,689 \times I T_{\text {nor }}+0,4137 \times C U R V A_{\text {nor }}
$$

El p-valor de la regresión es inferior a 0,01, de este modo existe una relación estadísticamente significativa entre las variables para un nivel de confianza del $99 \%$. El estadístico R-cuadrado es de 74,7\%, indicando que el modelo explica un $74,7 \%$ de la variabilidad de $\ln K_{s}$. En cuanto al p-valor de las variables dependientes, la constante y el coeficiente de $I T_{n o r}$ toma un valor de 0 , de esta forma son estadísticamente significativos para un nivel de confianza del $99 \%$; mientras que el p-valor del coeficiente de $C U R V A_{\text {nor }}$ es de 0,0034 , señalando que este término es significativamente estadístico para un nivel de confianza del $99 \%$. 
En las ecuaciones 6.1 y 6.2 , las variables dependientes toman la siguiente forma:

$$
I T_{n o r}=\frac{I T-M i n}{M a x-M i n}
$$

y

$$
C U R V A_{\text {nor }}=\frac{C U R V A-M i n}{M a x-M i n}
$$

donde $I T_{n o r}$ y $C U R V A_{n o r}$ son el índice topográfico y la curvatura horizontal normalizados, respectivamente, IT y $C U R V A$ son los valores en cada celda del índice topográfico y la curva plana, respectivamente, y Max y Min son los valores máximos y mínimos absolutos de las variables respectivas.

Luego de aplicar los modelos de regresión de las ecuaciones 6.1 y 6.2 en todas las celdas y corregir el ajuste según la ecuación 4.48 con el fin de asegurar que los valores modales obtenidos por medio del ajuste sean los mismos que los valores modales originales se obtiene los mapas distribuidos de $H_{u}$ y $K_{s}$ para la cuenca, los cuales se observan en las figuras 6.3 y 6.5. En las figuras 6.4 y 6.6 se muestran los histogramas de los parámetros.

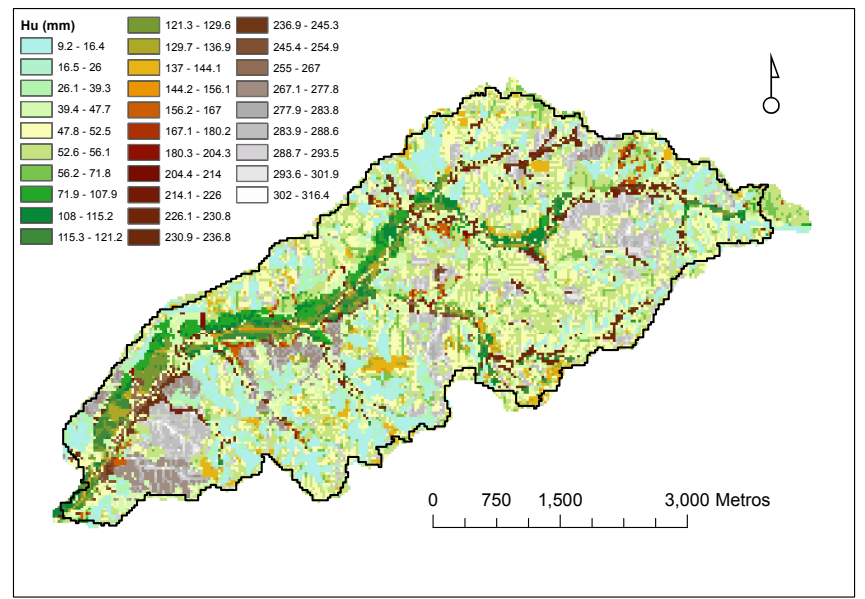

Figura 6.3. Mapa de la capacidad de almacenamiento hídrico estimada

\subsection{Los parámetros geomorfológicos}

Los cauces de la cuenca de Goodwin Creek se caracterizan por ser efímeros en casi su totalidad. El flujo base sólo se presenta en la parte baja, esencialmente en los últimos tres kilómetros y con un caudal muy bajo (Kuhnle et al., 1996). Las zonas con cárcavas se presentan en las inmediaciones de la red de drenaje en toda su extensión. 


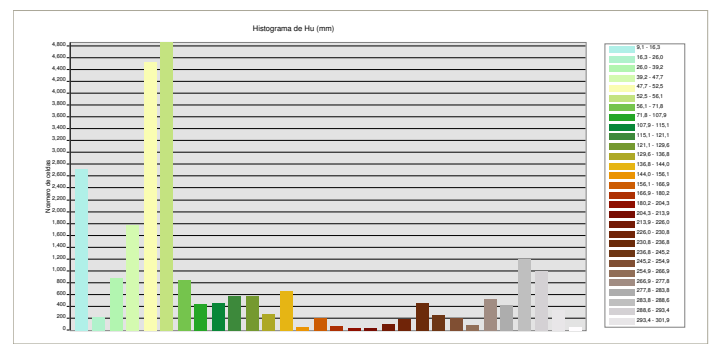

Figura 6.4. Histograma de la capacidad de almacenamiento hídrico estimada

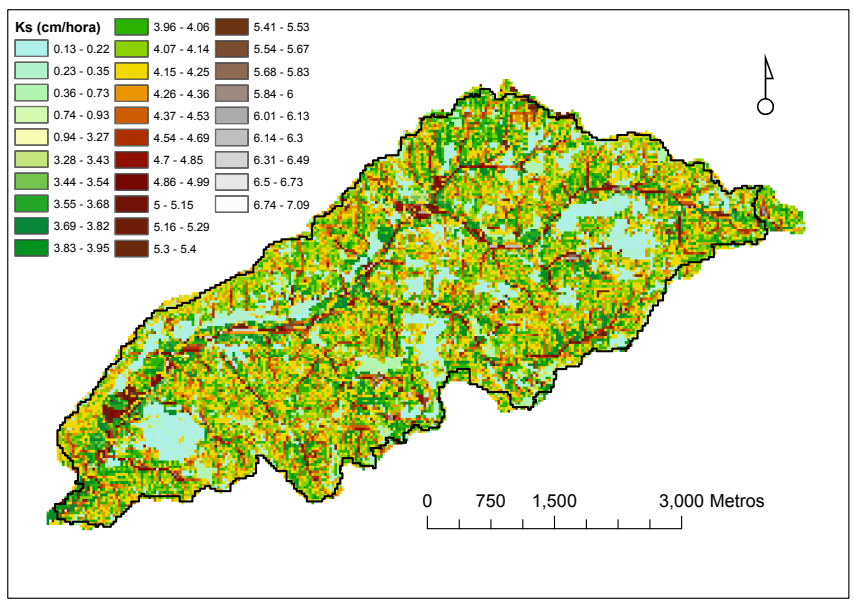

Figura 6.5. Mapa de la conductividad hidráulica del suelo

Para ubicar el comienzo de las cárcavas se probaron diferentes áreas umbrales y se compararon de forma visual con el mapa de suelos, en el cual se especifican las zonas con cárcavas, de esta forma se determinó el área umbral para el interflujo en $0,01 \mathrm{~km}^{2}$ (una hectárea).

El comienzo de las cárcavas coincide con la finalización del flujo en ladera, el cual se concentra en las cárcavas, y el comienzo del interflujo, esto es, la zona en la cual el flujo subsuperficial llega a la superficie. En la figura 6.7 se muestra la red de cárcavas determinada a partir de las celdas acumuladas derivadas del modelo de elevación digital de $30 \mathrm{~m}$ de lado, sobreimpuesta a la zona de cárcavas del mapa de suelos de la cuenca.

El comienzo del flujo base marca el final de las zonas de cárcavas. Para determinar este umbral se tuvo en cuenta el área de drenaje en el punto ubicado a tres kilómetros aguas arriba del punto de desagüe de la cuenca. En la figura 6.7 se muestra el punto en el cual el cauce comienza a presentar flujo base, el cual 


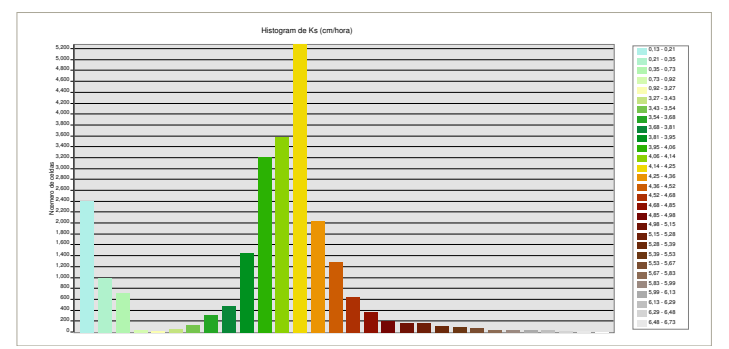

Figura 6.6. Histograma de la conductividad hidráulica del suelo

presenta un área de drenaje de $15,35 \mathrm{Km}^{2}$. Además se muestra las celdas que pertenecen a laderas (área de captación menor que el área umbral para el interflujo), en las cuales la única componente del caudal es la escorrentía directa; celdas con cárcavas (área de captación menor que el área umbral para el flujo base y mayor que el área umbral para el interflujo), en estas celdas las componentes del caudal son la escorrentía directa y el interflujo; y celdas con cauce, en las cuales el caudal se compone de escorrentía directa, interlujo y flujo base.

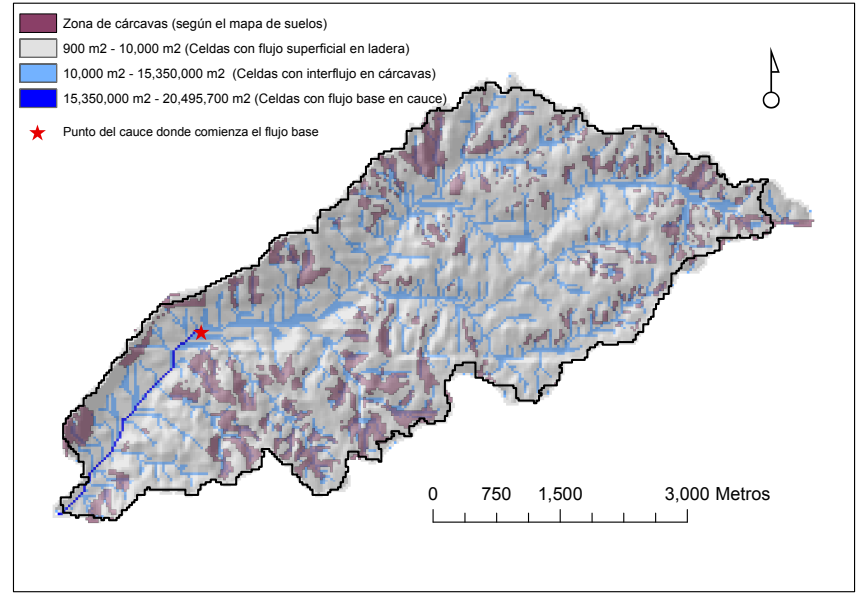

Figura 6.7. Mapa de las áreas para las diferentes componentes de la escorrentía

Los parámetros geomorfológicos necesarios para las relaciones de la geometría hidráulica se tomaron de Molnár y Ramírez (1998). Dichos autores basados en la hipótesis de que los cauces de los sistemas fluviales naturales se ajustan a un estado óptimo de energía en el cual la disipación de la energía es constante a lo largo de toda la red de drenaje, encuentran las relaciones geomorfológicas para la cuenca de Goodwin Creek. En su trabajo demuestran que las desviaciones locales a dicho ajuste se representan en tramos del cauce inestables o potencialmente inestables, 
basados en la red de cauces de la cuenca.

Molnár y Ramírez (1998) proponen un área umbral que determina el comienzo de las secciones fluviales activas de la red de drenaje de $0,18 \mathrm{~km}^{2}$. Aunque esta área es mayor que la determinada para el inicio de las cárcavas, se supone que los parámetros de propagación se pueden aplicar tanto a la red de cárcavas como a la red de cauces, que como se ha mencionado, sólo se presenta en la parte más baja de la cuenca.

En la tabla 6.4 se muestran los parámetros de propagación utilizados para la cuenca de Goodwin Creek, esto es, los exponentes y coeficientes de las ecuaciones $4.51-4.55$.

\begin{tabular}{|c|c|}
\hline Parámetro de propagación & Valor \\
\hline Coeficiente $\kappa$ & 0,8684 \\
\hline Exponente $\varphi$ & 0,95 \\
\hline Coeficiente $a_{1}$ & 6,516 \\
\hline Exponente $\alpha_{1}$ & 0,48 \\
\hline Exponente $\alpha_{2}$ & 0,2 \\
\hline Coeficiente $c_{d}$ & 15,0 \\
\hline Exponente $\theta$ & 1,0 \\
\hline Coeficiente $c_{n}$ & 0,047 \\
\hline Exponente $\xi$ & 0,1667 \\
\hline
\end{tabular}

Tabla 6.4. Parámetros de propagación para la cuenca de Goodwin Creek

\subsection{Los parámetros sedimentológicos}

La textura del nivel superior del suelo, esto es los porcentajes de arenas, limos y arcillas se tomaron de la información de las series de suelos disponible en Blackmarr (1995). Las figuras 6.8 y 6.9 muestran los mapas con la distribución espacial de los porcentajes de arenas, limos y arcillas.

Los mapas con los factores de la USLE fueron tomados de Rojas (2002) y se muestran en la figura 6.10. El factor de erosionabilidad del suelo, factor $K$, se determinó a partir de las características de las series de suelos presentes en la cuenca. El factor del cultivo, factor $C$, se determinó a partir de los usos del suelo. El factor de las prácticas de conservación, factor $P$ no es relevante en la cuenca, de tal forma toma un valor de 1 para toda la cuenca. 

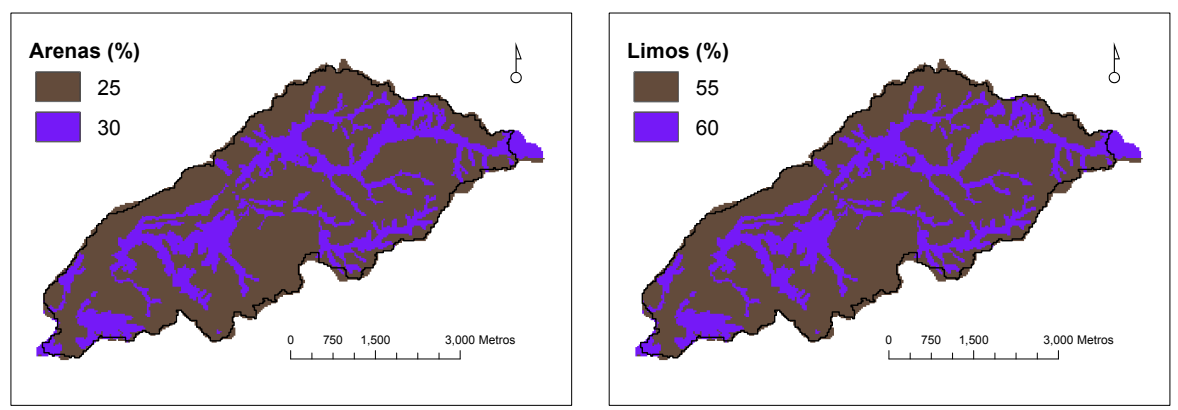

Figura 6.8. Mapas de porcentajes de arenas y limos

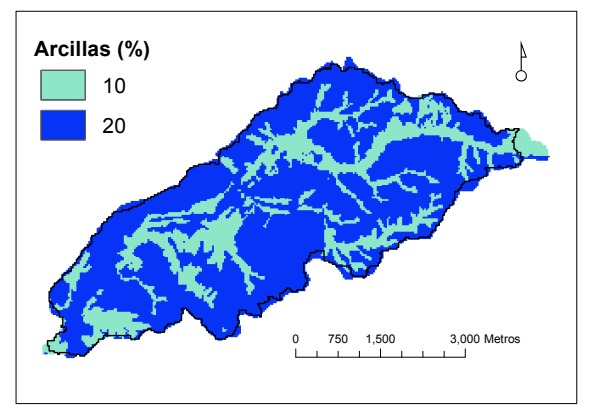

Figura 6.9. Mapa de porcentajes de arcillas
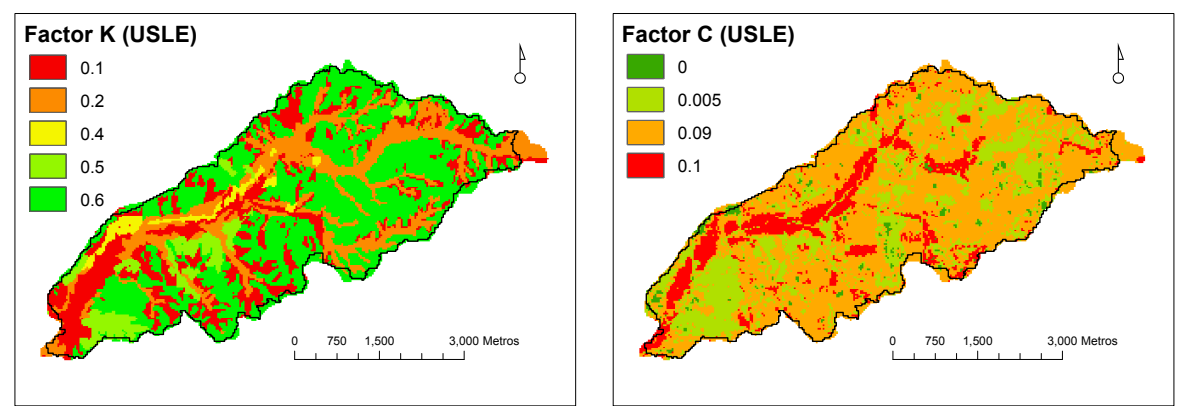

Figura 6.10. Mapas de los factores $K$ y $C$ de la USLE 


\section{Capítulo 7}

\section{Calibración y Validación}

En este capítulo se calibra y valida el modelo. La calibración del modelo se efectúa en un evento de lluvia intenso y en la estación de aforo de la salida de la cuenca. Para validar el modelo se tienen en cuenta dos eventos de lluvia intensos con condiciones diferentes al evento de calibración y se utilizan diferentes estaciones de aforo, de este modo, la validación no sólo es temporal sino espacial.

La calibración del modelo consiste en encontrar el juego de factores correctores tales que los hidrogramas y los sedimentogramas simulados por el modelo sean lo más cercano posible a los observados. Dicho juego de factores correctores debe ser coherente con las condiciones físicas de la cuenca, de tal forma, antes de efectuar una calibración automática es necesario realizar un análisis de sensibilidad de cada factor corrector y su influencia en el comportamiento hidrológico y sedimentológico. De dicho análisis se determinan a priori los factores correctores relevantes y sus intervalos de variación iniciales para la calibración automática. Además, es necesario determinar las condiciones iniciales de las variables de estado, tanto para el evento de calibración como para los eventos de validación.

Los datos de lluvia se tomaron de 16 estaciones de precipitación (figura 7.1), con una resolución temporal de 5 minutos, igual al intervalo temporal de simulación del modelo. La escala espacial utilizada para la aplicación del modelo en la cuenca corresponde a celdas cuadradas de 30 metros de lado. De las 14 estaciones de aforo presentes en la cuenca se seleccionaron 6 estaciones para la aplicación del modelo. En la figura 7.1 se muestran las estaciones con su área de captación.

En la tabla 7.1 se reseñan las coordenadas de las estaciones de aforo y sus áreas de drenaje. Las coordenadas de las estaciones de aforo utilizadas en el modelo difieren un poco de las coordenadas reales, esto se debe a que las coordenadas del modelo deben coincidir con el centro de una celda con un número de celdas acumuladas similar al área de captación real. De igual forma, las áreas de captación derivadas del modelo de elevación digital difieren de las áreas de captación real. 


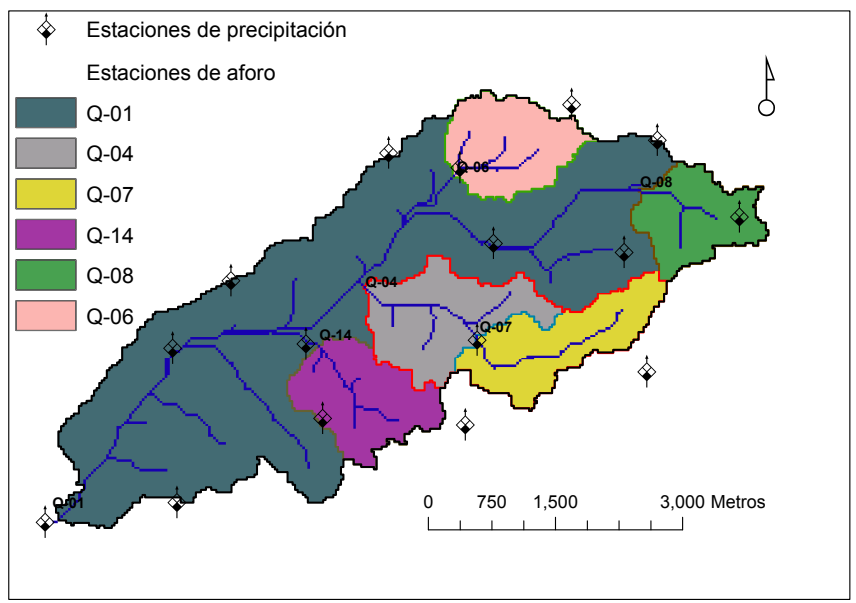

Figura 7.1. Estaciones de aforo seleccionadas y su área de captación

\begin{tabular}{|c|c|c|c|c|c|c|}
\hline \multirow{2}{*}{ Estación } & \multicolumn{4}{|c|}{ Coordenadas } & \multicolumn{2}{c|}{ Área de captación en $\mathrm{km}^{2}$} \\
\cline { 2 - 7 } & \multicolumn{2}{|c|}{ Según NSL } & \multicolumn{2}{c|}{ Según MED } & Según NSL & Según MED \\
\hline & X & Y & X & Y & & \\
\hline Q-01 & 231568,7 & 3791553,7 & 231720 & 3791580 & 21,39 & 20,48 \\
\hline Q-04 & 235367,3 & 3794280,5 & 235320 & 3794310 & 3,57 & 3,52 \\
\hline Q-06 & 236459,3 & 3795732,9 & 236370 & 3795630 & 1,19 & 1,51 \\
\hline Q-07 & 236662,9 & 3793699,9 & 236640 & 3793740 & 1,60 & 1,69 \\
\hline Q-08 & 238577,9 & 3795483,8 & 238560 & 3795450 & 1,55 & 1,30 \\
\hline Q-14 & 234644,4 & 3793655,0 & 234780 & 3793620 & 1,63 & 1,63 \\
\hline
\end{tabular}

Tabla 7.1. Coordenadas y áreas de captación de las estaciones de aforo

\subsection{Calibración del modelo}

El evento de calibración corresponde al ocurrido el 17 de octubre de 1981. El evento comenzó a las 21:10 con una duración total de 4,8 horas. La precipitación antecedente es muy poca (en los dos meses anteriores al evento la precipitación es casi nula), por lo que la cuenca se encontraba con poco contenido de humedad. La lluvia total en las estaciones de precipitación varía entre $66 \mathrm{~mm}$ y 78,7 $\mathrm{mm}$ con promedio de 73,6 $\mathrm{mm}$. La intensidad de precipitación tiene un máximo de $51,6 \mathrm{~mm} /$ hora con un promedio de 14,7 $\mathrm{mm} /$ hora. La calibración se efectuó en la estación de aforo ubicada en el punto de desagüe de la cuenca (estación Q-01).

El evento de calibración ocurrió a principios del otoño, luego de un verano seco y cálido. De una revisión de los registros de lluvia de los dos meses anteriores al evento, de las estaciones de precipitación de la cuenca, se observa que la cantidad 
de lluvia caída es muy poca, con lluvias cortas y con poca intensidad. Debido a que estas lluvias cayeron en la época más caliente del verano se puede suponer que esta cantidad de lluvia se evapotranspiró. De esta forma, los estados de humedad de los tanques del modelo al inicio del evento se pueden considerar vacíos y no se calibran.

Inicialmente se calibra el modelo en su parte hidrológica. Teniendo en cuenta las características físicas de la cuenca y su relación con el comportamiento hidrológico, es de esperarse que los factores correctores más sensibles del modelo correspondan a los que dan cuenta de la escorrentía superficial y subsuperficial. Este hecho observable se comprueba en el modelo variando los factores correctores de las pérdidas subterráneas $R_{7} \mathrm{y}$ el flujo base $R_{8}$. Aun efectuando cambios drásticos, de varios ordenes de magnitud en estos dos factores, el hidrograma simulado varía imperceptiblemente. Además, al tratarse de un evento extremo, la evapotranspiración no debe incidir en el hidrograma simulado. De igual forma, al cambiar drásticamente el factor corrector de la evapotranspiración $R_{2}$, el hidrograma simulado no cambia. Los demás factores correctores tienen relevancia en el hidrograma simulado, de esta forma son los factores a calibrar. En la tabla 7.2 se muestran los límites para la calibración automática del modelo en la cuenca, sus valores iniciales y los resultados arrojados.

\begin{tabular}{|c|c|c|c|c|}
\hline \multirow{2}{*}{ Factor corrector } & \multicolumn{2}{|c|}{ Límites } & \multirow{2}{*}{$\begin{array}{l}\text { Valor } \\
\text { inicial }\end{array}$} & \multirow{2}{*}{$\begin{array}{l}\text { Resultado } \\
\text { calibración }\end{array}$} \\
\hline & Inferior & Superior & & \\
\hline$R_{1}$, Almacenamiento estático & 0,1 & 1,5 & 0,5 & 0,207 \\
\hline$R_{3}$, Infiltración & 0,00001 & 1,0 & 0,1 & 0,00103 \\
\hline$R_{4}$, Velocidad del flujo en ladera & 0,1 & 1,5 & 0,5 & 0,11267 \\
\hline$R_{5}$, Percolación & 0,1 & 1,0 & 0,5 & 0,3954 \\
\hline$R_{6}$, Velocidad del flujo subsuperficial & 1,0 & 1000,0 & 100,0 & 53,989 \\
\hline$R_{9}$, Velocidad del flujo en canales & 0,1 & 0,8 & 0,4 & 0,3126 \\
\hline
\end{tabular}

Tabla 7.2. Límites, valor inicial y factores resultantes de la calibración automática

Una vez calibrada la parte hidrológica del modelo se efectúa la calibración del factor corrector para la erosión en ladera (ver ecuaciones 4.28 y 4.29). El factor de la ecuación de Kilinc y Richardson se ha calibrado considerando el volumen total de sedimentos que salen de la cuenca en el evento de calibración. Con un factor corrector igual a 76000,0 el volumen total de sedimentos simulados que salen de la cuenca se hace muy cercano al observado.

En la figura 7.2 se observan los hidrogramas y sedimentogramas observados y simulados en el evento de calibración en la estación de aforo ubicada en el punto de desagüe de la cuenca y las series temporales de el caudal sólido. La componente principal del hidrograma simulado por el modelo corresponde a la escorrentía directa, mientras que el interflujo sólo aporta al caudal en el final de la recesión, 
además no se presenta flujo base y la evapotranspiración es nula. La totalidad de agua que se percola no entra al acuífero y pasa a ser pérdidas subterráneas. El almacenamiento superficial se llena rápidamente (tanque $H_{1}$ del modelo), esto es, el nivel superior del suelo se satura, de esta forma se simula adecuadamente la componente principal del caudal y el comportamiento hidrológico de la cuenca corresponde a escorrentía directa por exceso de saturación. La tabla 7.3 presenta el resumen de resultados del modelo.
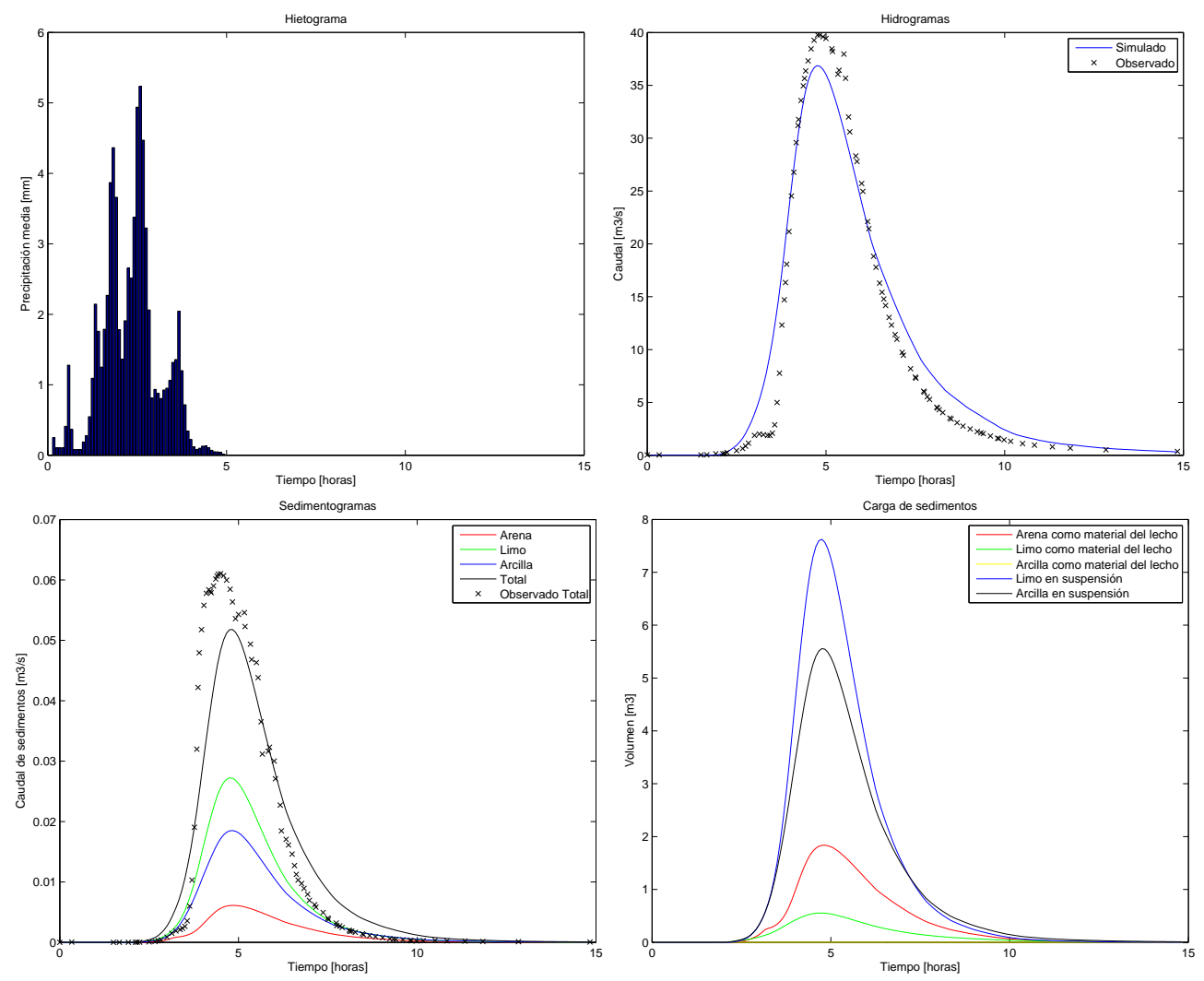

Figura 7.2. Series temporales simuladas en la calibración para la estación Q-01

En la tabla 7.4 se muestra el desempeño del modelo y su comparación con los datos observados en la estación Q-01. Todos los indicadores del comportamiento general del modelo muestran que la calibración es adecuada.

En la figura 7.3 se muestra la relación entre los caudales líquidos y de sedimentos, tanto los simulados como los observados para el evento de calibración. En los bucles de histéresis se observa que la dinámica del evento se simula, en general, adecuadamente. El modelo presenta mejores desempeños en el inicio del evento, mientras que una vez se alcanza el caudal pico, la relación caudal - sedimentos simulada se aleja de los observados, específicamente, los sedimentos observados 


\begin{tabular}{|c|c|c|c|}
\hline \multicolumn{2}{|c|}{ Almacenamiento estático } & \multicolumn{2}{c|}{ Sedimentos erosionados } \\
\hline Nivel medio en la cuenca $[\mathrm{mm}]$ & 18,94725 & Arena erosionada $\left[\mathrm{m}^{3}\right]$ & 324,95 \\
\hline Entrada por lluvia $\left[\mathrm{Hm}^{3}\right]$ & 1,51938 & Limo erosionado $\left[\mathrm{m}^{3}\right]$ & 702,09 \\
\hline Flujo de salida de ET $\left[\mathrm{Hm}^{3}\right]$ & 0 & Arcilla erosionada $\left[\mathrm{m}^{3}\right]$ & 230,1 \\
\hline \multicolumn{2}{|c|}{ Agua en superficie } & \multicolumn{2}{c|}{ Sedimentos depositados } \\
\hline Nivel medio en la cuenca $[\mathrm{mm}]$ & 1,25138 & Arena depositada $\left[\mathrm{m}^{3}\right]$ & 260,58 \\
\hline Excedente de Ppt $\left[\mathrm{Hm}^{3}\right]$ & 1,08395 & Limo depositado $\left[\mathrm{m}^{3}\right]$ & 460,18 \\
\hline Escorrentia directa $\left[\mathrm{Hm}^{3}\right]$ & 1,08044 & Arcilla depositada $\left[\mathrm{m}^{3}\right]$ & 50,21 \\
\hline \multicolumn{2}{|c|}{ Almacenamiento gravitatorio } & \multicolumn{2}{c|}{ Sedimentos producidos } \\
\hline Nivel medio en la cuenca $\left[\mathrm{mm}^{3}\right]$ & 0,06023 & Arena producida $\left[\mathrm{m}^{3}\right]$ & 64,37 \\
\hline Cantidad de infiltración $\left[\mathrm{Hm}^{3}\right]$ & 0,00348 & Limo producido $\left[\mathrm{m}^{3}\right]$ & 241,89 \\
\hline Salida por interflujo $\left[\mathrm{Hm}^{3}\right]$ & 0,00025 & Arcilla producida $\left[\mathrm{m}^{3}\right]$ & 179,59 \\
\hline Perdidas subterráneas $\left[\mathrm{Hm}^{3}\right]$ & 0,00164 & Producción total $\left[\mathrm{m}^{3}\right]$ & 485,85 \\
\hline Error en balance $[\%]$ & $-0,000083$ & Error en balance $[\%]:$ & $-0,00003125$ \\
\hline
\end{tabular}

Tabla 7.3. Resumen de resultados en la calibración para la estación Q-01

\begin{tabular}{|c|c|c|c|}
\hline & Observado & Simulado & Error [\%] \\
\hline Caudal máximo $\left[\mathrm{m}^{3} / \mathrm{s}\right]$ & 39,764 & 36,86 & $-7,303$ \\
\hline Tiempo al pico $[$ horas $]$ & 4,83 & 4,75 & $-1,656$ \\
\hline Volumen de agua $\left[\mathrm{Hm}^{3}\right]$ & 0,395 & 0,431 & 9,114 \\
\hline Volumen de sedimentos $\left[\mathrm{m}^{3}\right]$ & 485,26 & 485,85 & 0,122 \\
\hline Índice de Nash & 0,9645 & RMSE & 2,244 \\
\hline
\end{tabular}

Tabla 7.4. Desempeño del modelo en la calibración para la estación Q-01

se hacen mayores en la recesión del hidrograma simulado. Las diferencias en los resultados se encuentran en intervalos aceptables con los datos observados.

\subsection{Validación temporal}

La validación temporal corresponde a la aplicación del modelo en eventos distintos al utilizado en la calibración. Los factores correctores del modelo son los determinados en la calibración, pero los estados de humedad inicial varían, dependiendo de las condiciones climáticas antecedentes a los eventos. Una forma de estimar las condiciones iniciales de la cuenca es a partir de una calibración automática, en la cual se fijan los factores correctores y sólo se calibran los estados de humedad inicial. 


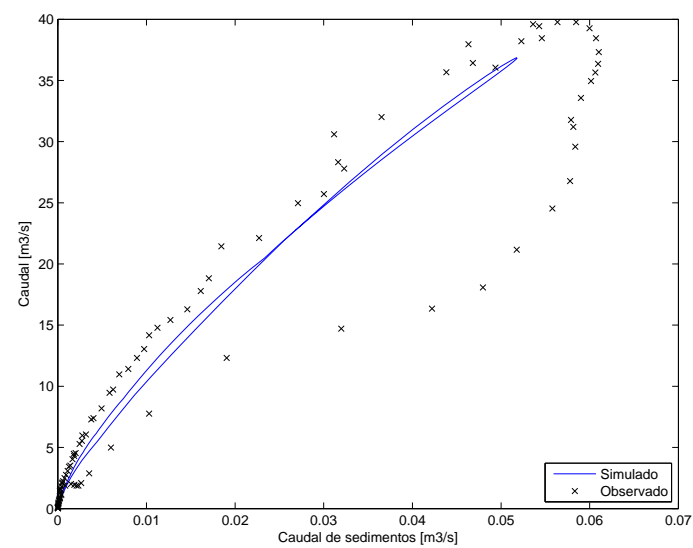

Figura 7.3. Relación entre el caudal líquido y el sólido para el evento de calibración

\subsubsection{Evento de validación 2}

Ocurrió el 20 de septiembre de 1983, con una lluvia total dos veces mayor que la caída en el evento de calibración y con muy poca precipitación antecedente. La duración total del evento es de 9,8 horas, con un precipitación total promedio de $147,5 \mathrm{~mm}$, variando entre $135,4 \mathrm{~mm}$ y $154,9 \mathrm{~mm}$ para las diferentes estaciones de precipitación. La intensidad de precipitación presenta un máximo de $65,5 \mathrm{~mm} /$ hora con un promedio de 10,1 $\mathrm{mm} /$ hora. En la tabla 7.5 se muestran los límites para la calibración automática de los estados de humedad inicial, sus valores iniciales y los resultados arrojados.

\begin{tabular}{|l|c|c|c|c|}
\hline Estado de humedad inicial & \multicolumn{2}{|c|}{ Límites } & Valor & Resultado \\
& Inferior & Superior & inicial & calibración \\
\hline$H_{1}$, Almacenamiento estático [\%] & 0,0 & 100,0 & 50,0 & 0,0036 \\
\hline$H_{5}$, Cauce a sección llena [\%] & 0,0 & 100,0 & 50,0 & 0,17053 \\
\hline
\end{tabular}

Tabla 7.5. Límites, valor inicial y factores resultantes de la calibración automática de los estados de humedad inicial para el evento 2

En la figura 7.4 se observan los hidrogramas y sedimentogramas observados y simulados en el evento de validación temporal 2 en la estación de aforo ubicada en el punto de desagüe de la cuenca y las series temporales de el caudal sólido. Los niveles medios y las componentes de la escorrentía presentan un comportamiento similar al observado en el evento de calibración. La tabla 7.6 presenta un resumen de los resultados de la simulación.

En la tabla 7.7 se muestra el comportamiento general del modelo en el evento de validación temporal 2 . Los resultados del modelo son adecuados, aunque tanto 

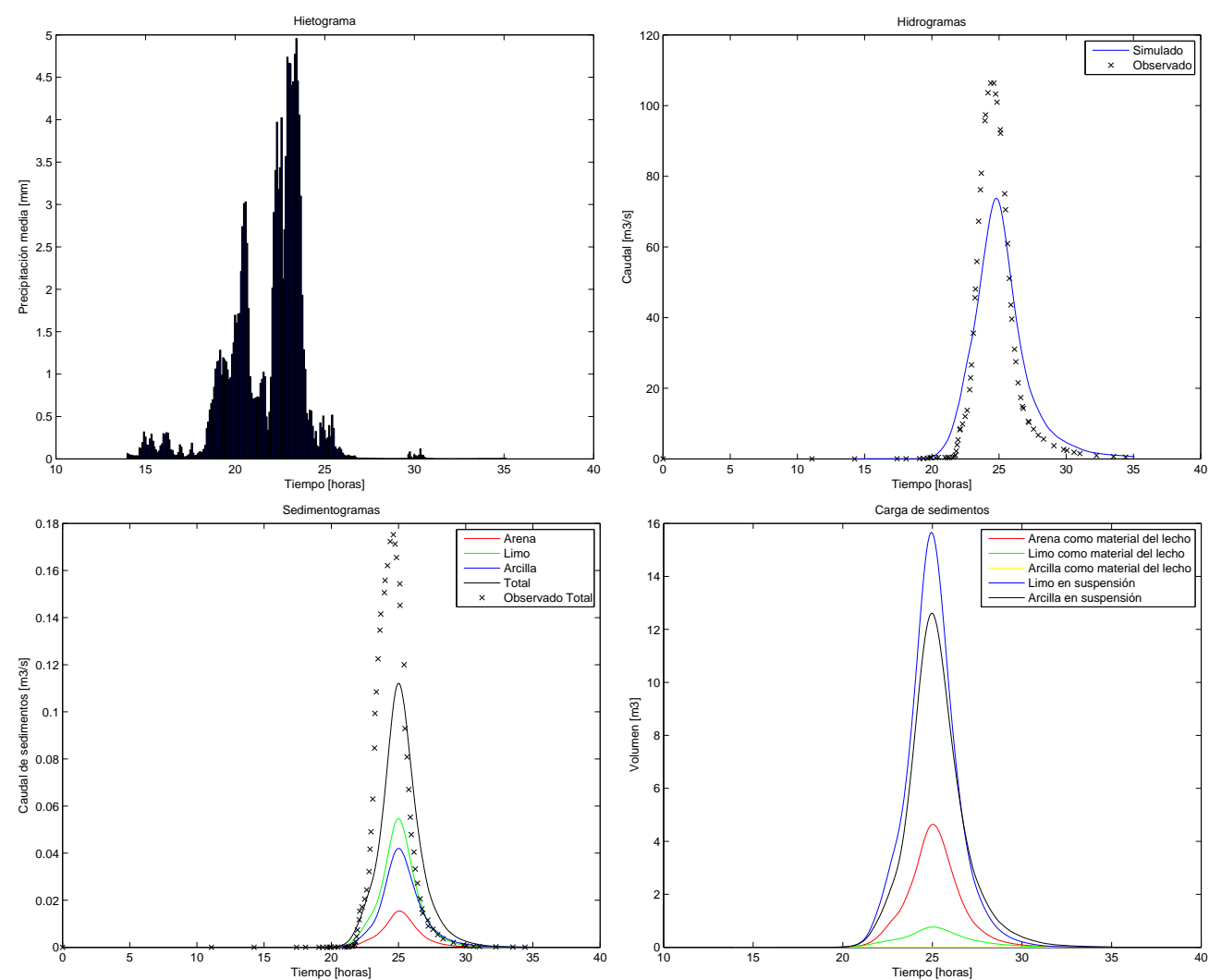

Figura 7.4. Series temporales simuladas en el evento 2 para la estación Q-01

el hidrograma como la producción de sedimentos simulados presentan valores por debajo de los observados. Esta subvaloración de los resultados es mayor en la producción de sedimentos.

En la figura 7.5 se muestra la relación entre los caudales líquidos y de sedimentos, tanto los simulados como los observados para el evento de validación 2 . En los bucles de histéresis se observa que la dinámica del evento se simula adecuadamente. En este caso se observa con claridad que los resultados del modelo presentan una subvaloración en el pico del del evento. Este hecho se puede explicar debido a que el evento analizado presenta una lluvia total dos veces mayor que la del evento de calibración. Al igual que en el evento de calibración las diferencias entre los resultados y los datos observados son aceptables.

\subsubsection{Evento de validación 3}

Ocurrió el 28 de agosto de 1982 con una precipitación similar al evento de calibración pero con alta humedad precedente, producida por lluvias anteriores al 


\begin{tabular}{|c|c|c|c|}
\hline \multicolumn{2}{|c|}{ Almacenamiento estático } & \multicolumn{2}{c|}{ Sedimentos erosioandos } \\
\hline Nivel medio en la cuenca $[\mathrm{mm}]$ & 10,42878 & Arena erosionada $\left[\mathrm{m}^{3}\right]$ & 784,7 \\
\hline Entrada por lluvia $\left[\mathrm{Hm}^{3}\right]$ & 3,05335 & Limo erosionado $\left[\mathrm{m}^{3}\right]$ & 1695,58 \\
\hline Flujo de salida de ET $\left[\mathrm{Hm}^{3}\right]$ & 0 & Arcilla erosionada $\left[\mathrm{m}^{3}\right]$ & 555,97 \\
\hline \multicolumn{2}{|c|}{ Agua en superficie } & \multicolumn{2}{c|}{ Sedimentos depositados } \\
\hline Nivel medio en la cuenca $[\mathrm{mm}]$ & 1,28016 & Arena depositada $\left[\mathrm{m}^{3}\right]$ & 612,75 \\
\hline Excedente de Ppt $\left[\mathrm{Hm}^{3}\right]$ & 2,61792 & Limo depositado $\left[\mathrm{m}^{3}\right]$ & 1106,31 \\
\hline Escorrentia directa $\left[\mathrm{Hm}^{3}\right]$ & 2,60649 & Arcilla depositada $\left[\mathrm{m}^{3}\right]$ & 76,86 \\
\hline \multicolumn{2}{|c|}{ Almacenamiento gravitatorio } & \multicolumn{2}{c|}{ Sedimentos producidos } \\
\hline Nivel medio en la cuenca $\left[\mathrm{mm}^{3}\right]$ & 0,06627 & Arena producida $\left[\mathrm{m}^{3}\right]$ & 171,96 \\
\hline Cantidad de infiltración $\left[\mathrm{Hm}^{3}\right]$ & 0,01104 & Limo producido $\left[\mathrm{m}^{3}\right]$ & 589,22 \\
\hline Salida por interflujo $\left[\mathrm{Hm}^{3}\right]$ & 0,00065 & Arcilla producida $\left[\mathrm{m}^{3}\right]$ & 478,66 \\
\hline Perdidas subterráneas $\left[\mathrm{Hm}^{3}\right]$ & 0,00554 & Producción total $\left[\mathrm{m}^{3}\right]$ & 1239,84 \\
\hline Error en balance $[\%]$ & 0,000048 & Error en balance $[\%]:$ & $-0,00008493$ \\
\hline
\end{tabular}

Tabla 7.6. Resumen de resultados en el evento 2 para la estación Q-01

\begin{tabular}{|c|c|c|c|}
\hline & Observado & Simulado & Error [\%] \\
\hline Caudal máximo $\left[\mathrm{m}^{3} / \mathrm{s}\right]$ & 106,353 & 73,762 & $-30,644$ \\
\hline Tiempo al pico $\left[\mathrm{horas}^{\prime}\right]$ & 25,08 & 24,83 & $-0,997$ \\
\hline Volumen de agua $\left[\mathrm{Hm}^{3}\right]$ & 1,075 & 1,053 & $-2,047$ \\
\hline Volumen de sedimentos $\left[\mathrm{m}^{3}\right]$ & 1611,58 & 1239,84 & $-23,067$ \\
\hline Índice de Nash & 0,8327 & RMSE & 9,476 \\
\hline
\end{tabular}

Tabla 7.7. Desempeño del modelo en el evento 2 para la estación Q-01

evento. Presentó una duración de 6 horas, con un total de lluvia de 61,7 $\mathrm{mm}$ en promedio, con un intervalo de variación entre $39,1 \mathrm{~mm}$ y $91,7 \mathrm{~mm}$ para las diferentes estaciones de precipitación. La intensidad tuvo un máximo de 90,3 $\mathrm{mm} /$ hora con un promedio de 10,3 $\mathrm{mm} /$ hora. En la tabla 7.8 se muestran los límites para la calibración automática de los estados de humedad inicial, sus valores iniciales y los resultados arrojados.

En la figura 7.6 se observan los hidrogramas y sedimentogramas observados y simulados en el evento de validación temporal 3 en la estación de aforo ubicada en el punto de desagüe de la cuenca y las series temporales de el caudal sólido.

$\mathrm{Al}$ igual que en el evento de validación 2, los niveles medios y las componentes de la escorrentía presentan un comportamiento similar al observado en el evento de calibración. La tabla 7.10 presenta los resultados de la simulación.

El comportamiento general se presenta en la tabla 7.9. El comportamiento hidrológico del modelo es muy cercano al observado, especialmente el volumen total de agua. En este evento el modelo subvalora la producción de sedimentos, especialmente en los intervalos de tiempo cercanos al caudal pico. De esta forma el volumen de sedimentos simulado está por debajo del observado, aunque con un 


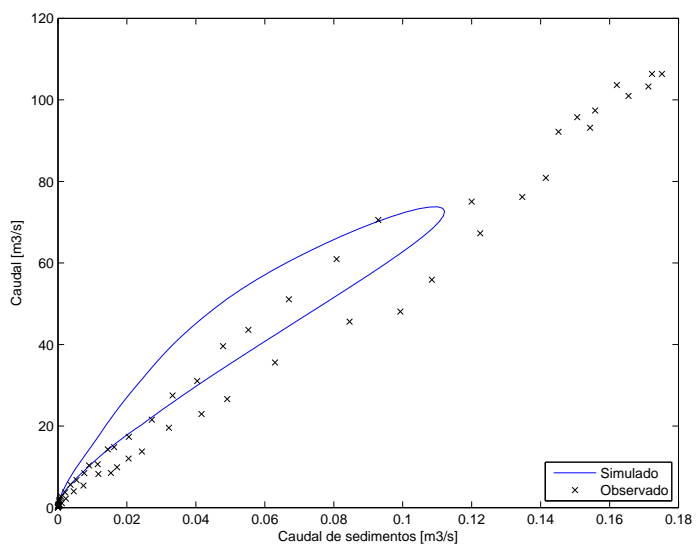

Figura 7.5. Relación entre el caudal líquido y el sólido para el evento de validación 2

\begin{tabular}{|c|c|c|c|c|}
\hline \multirow[t]{2}{*}{ Estado de humedad inicial } & \multicolumn{2}{|c|}{ Límites } & \multirow{2}{*}{$\begin{array}{l}\text { Valor } \\
\text { inicial }\end{array}$} & \multirow{2}{*}{$\begin{array}{l}\text { Resultado } \\
\text { calibración }\end{array}$} \\
\hline & Inferior & Superior & & \\
\hline$H_{1}$, Almacenar & 0,0 & 100,0 & 50,0 & 39,2 \\
\hline $\mathrm{H}_{2}$, Agua en superficie $[\mathrm{mm}]$ & 0,0 & 20, & 5,0 & 0,02957 \\
\hline$H_{5}$, Cauce a sección llena [\%] & 0,0 & 100,0 & 50,0 & 6,58932 \\
\hline
\end{tabular}

Tabla 7.8. Límites, valor inicial y factores resultantes de la calibración automática de los estados de humedad inicial para el evento 3

valor permisible.

En la figura 7.7 se muestra la relación entre los caudales líquidos y de sedimentos, tanto los simulados como los observados para el evento de validación 3 . En los bucles de histéresis se observa que la dinámica del evento se simula adecuadamente. En este caso se observa el mismo comportamiento que en el evento de calibración, antes del pico del evento el modelo simula bien la relación caudal sedimentos, mientras que en la recesión, el modelo subvalora el caudal sólido.

\subsection{Validación espacial}

La validación espacial corresponde a la aplicación del modelo en estaciones de aforo diferentes a la escogida para la calibración con el mismo evento. Los factores correctores y las condiciones de humedad inicial no cambian. Cuando la validación se efectúa con un evento diferente al de calibración, esta validación será espacio temporal. 

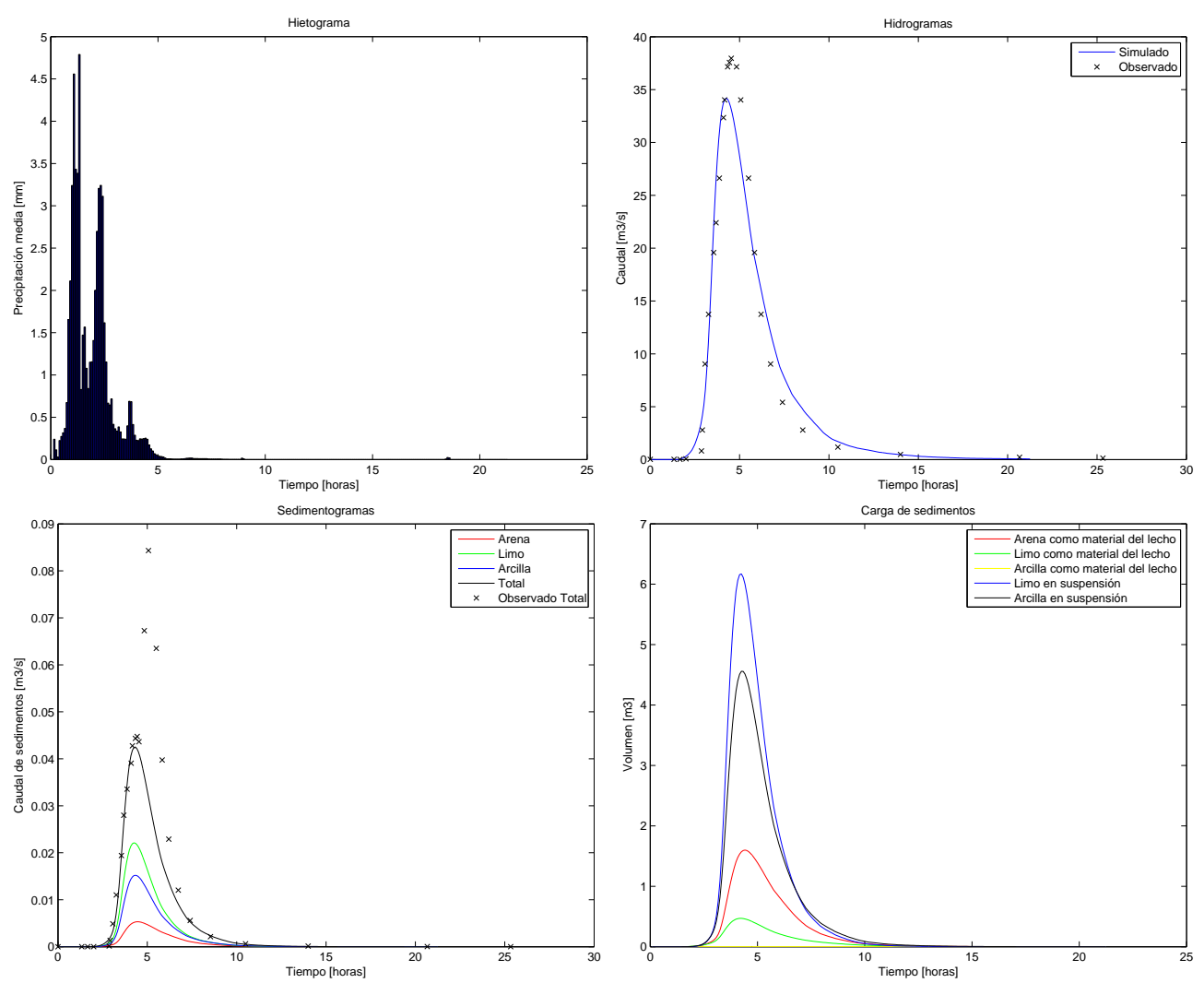

Figura 7.6. Series temporales simuladas en el evento 3 para la estación Q-01

\subsubsection{Estación de aforo 04}

La estación Q-04 se ubica aguas arriba de la confluencia de los dos afluentes más importante de la cuenca. Su área de captación es de $3,57 \mathrm{~km}^{2}$ y posee una estación de aforo interior (Q-07). La distribución de usos del suelo es similar a la que presenta la cuenca, predominando los pastos. La serie de suelos predominante es la Loring y presenta pocas zonas afectadas por carcavamiento.

La figura 7.8 muestra los hidrogramas y sedimentogramas para el evento de calibración. El hidrograma simulado es muy cercano al observado mientras que la producción de sedimentos simulada está por debajo de los observados, especialmente cuando se presenta el caudal pico. Los volúmenes totales simulados, tanto de agua como de sedimentos, presentan valores admisibles con respecto a los observados, tal como se observa en la tabla 7.11.

La figura 7.9 muestra los resultados del evento de validación temporal 2 para la estación de aforo Q-04. Tanto los hidrogramas como los sedimentogramas simulados presentan un comportamiento similar a los observados y sólo en el caudal pico se observa un diferencia, en este caso una subvaloración de los resultados del 


\begin{tabular}{|c|c|c|c|}
\hline & Observado & Simulado & Error [\%] \\
\hline Caudal máximo $\left[\mathrm{m}^{3} / \mathrm{s}\right]$ & 37,829 & 34,19 & $-9,620$ \\
\hline Tiempo al pico $\left[\mathrm{horas}^{3}\right.$ & 4,58 & 4,25 & $-7,205$ \\
\hline Volumen de agua $\left[\mathrm{Hm}^{3}\right]$ & 0,397 & 0,404 & 1,763 \\
\hline Volumen de sedimentos $\left[\mathrm{m}^{3}\right]$ & 541,61 & 372,66 & $-31,194$ \\
\hline İ́ndice de Nash & 0,9697 & RMSE & 1,589 \\
\hline
\end{tabular}

Tabla 7.9. Desempeño del modelo en el evento 3 para la estación Q-01

\begin{tabular}{|c|c|c|c|}
\hline \multicolumn{2}{|c|}{ Almacenamiento estático } & \multicolumn{2}{c|}{ Sedimentos erosionados } \\
\hline Nivel medio en la cuenca $[\mathrm{mm}]$ & 20,71257 & Arena erosionada $\left[\mathrm{m}^{3}\right]$ & 236,78 \\
\hline Entrada por lluvia $\left[\mathrm{Hm}^{3}\right]$ & 1,26616 & Limo erosionado $\left[\mathrm{m}^{3}\right]$ & 513,27 \\
\hline Flujo de salida de ET $\left[\mathrm{Hm}^{3}\right]$ & 0 & Arcilla erosionada $\left[\mathrm{m}^{3}\right]$ & 171,58 \\
\hline \multicolumn{2}{|c|}{ Agua en superficie } & \multicolumn{2}{c|}{ Sedimentos depositados } \\
\hline Nivel medio en la cuenca $[\mathrm{mm}]$ & 0,67706 & Arena depositada $\left[\mathrm{m}^{3}\right]$ & 181,77 \\
\hline Excedente de Ppt $\left[\mathrm{Hm}^{3}\right]$ & 1,00142 & Limo depositado $\left[\mathrm{m}^{3}\right]$ & 330,57 \\
\hline Escorrentia directa $\left[\mathrm{Hm}^{3}\right]$ & 0,99663 & Arcilla depositada $\left[\mathrm{m}^{3}\right]$ & 36,62 \\
\hline \multicolumn{2}{|c|}{ Almacenamiento gravitatorio } & \multicolumn{2}{c|}{ Sedimentos producidos } \\
\hline Nivel medio en la cuenca $[\mathrm{mm}]$ & 0,09287 & Arena producida $\left[\mathrm{m}^{3}\right]$ & 55,01 \\
\hline Cantidad de infiltración $\left[\mathrm{Hm}^{3}\right]$ & 0,00539 & Limo producido $\left[\mathrm{m}^{3}\right]$ & 182,7 \\
\hline Salida por interflujo $\left[\mathrm{Hm}^{3}\right]$ & 0,00072 & Arcilla producida $\left[\mathrm{m}^{3}\right]$ & 134,95 \\
\hline Perdidas subterráneas $\left[\mathrm{Hm}^{3}\right]$ & 0,0027 & Producción total $\left[\mathrm{m}^{3}\right]$ & 372,66 \\
\hline Error en balance $[\%]$ & $-0,000477673$ & Error en balance $[\%]:$ & $-0,00003808$ \\
\hline
\end{tabular}

Tabla 7.10. Resumen de resultados en el evento 3 para la estación Q-01

modelo. En la tabla 7.12 se aprecia que los volúmenes totales de agua y sedimentos simulados se encuentran muy cercanos a los observados.

En la figura 7.10 se observan los hidrogramas y sedimentogramas simulados y observados para el evento de validación 3 . El hidrograma simulado es cercano al observado pero la producción de sedimentos simulada está muy por debajo de la observada, especialmente en los caudales máximos. La tabla resumen 7.13 muestra como el volumen de sedimentos simulado es casi tres veces menor que el volumen de sedimentos observado.

\subsubsection{Estación de aforo 07}

La estación de aforo Q-07 se encuentra al interior de la cuenca definida por la estación Q-04 y posee un área de captación de 1,60 $\mathrm{km}^{2}$. La mayor parte de la cuenca se encuentra en pastos y las series de suelos que predominan son la Loring en las laderas y la Collins en los depósitos aluviales. Las áreas con cárcavas son pocas. El comportamiento del modelo es similar al presentado en la estación Q-04, con hidrogramas y sedimentogramas simulados inferiores a los observados. 


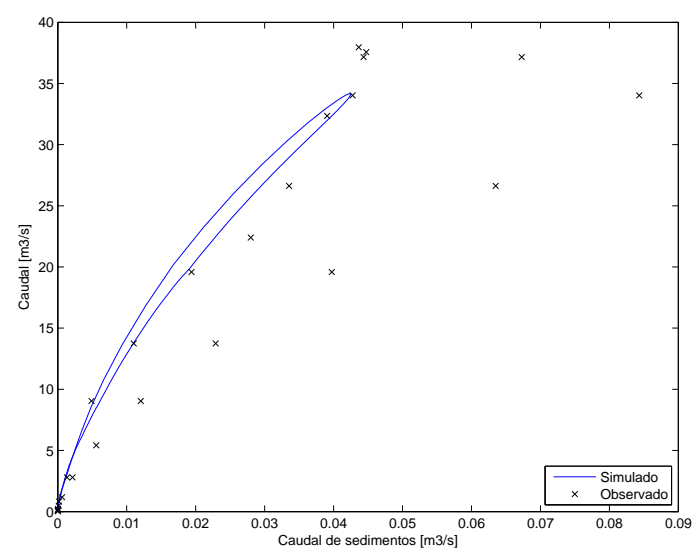

Figura 7.7. Relación entre el caudal líquido y el sólido para el evento de validación 3

\begin{tabular}{|c|c|c|c|}
\hline & Observado & Simulado & Error [\%] \\
\hline Caudal máximo $\left[\mathrm{m}^{3} / \mathrm{s}\right]$ & 9,826 & 9,546 & $-2,850$ \\
\hline Tiempo al pico $\left[\mathrm{horas}^{3}\right.$ & 3,58 & 3,33 & $-6,983$ \\
\hline Volumen de agua $\left[\mathrm{Hm}^{3}\right]$ & 0,071 & 0,077 & 8,451 \\
\hline Volumen de sedimentos $\left[\mathrm{m}^{3}\right]$ & 152,54 & 105,4 & $-30,903$ \\
\hline İndice de Nash & 0,8648 & RMSE & 0,963 \\
\hline
\end{tabular}

Tabla 7.11. Desempeño del modelo en el evento 1 para la estación Q-04

La figura 7.11 muestra los hidrogramas y sedimentogramas simulados y observados para el evento de calibración. Aunque el hidrograma y el volumen de agua simulados son muy cercanos a los observados, los sedimentogramas y el volumen total de sedimentos simulados presentan valores más bajos que los observados (tabla 7.14).

En la figura 7.12 se observan los hidrogramas y sedimentogramas simulados y observados para el evento de validación 2. En este caso los hidrogramas y sedimentogramas y los volúmenes de agua y sedimentos simulados se encuentran por debajo que los observados (tabla 7.15).

Igual comportamiento se observa en los hidrogramas y sedimentogramas simulados para el evento de validación 3, cuyos resultados se muestran en la figura 7.13 y se resumen en la tabla 7.16.

Es claro que el modelo no valida adecuadamente en la estación Q-07, especialmente en el comportamiento sedimentológico. Este hecho puede explicar que la estación Q-04 presente valores simulados menores que los observados. 

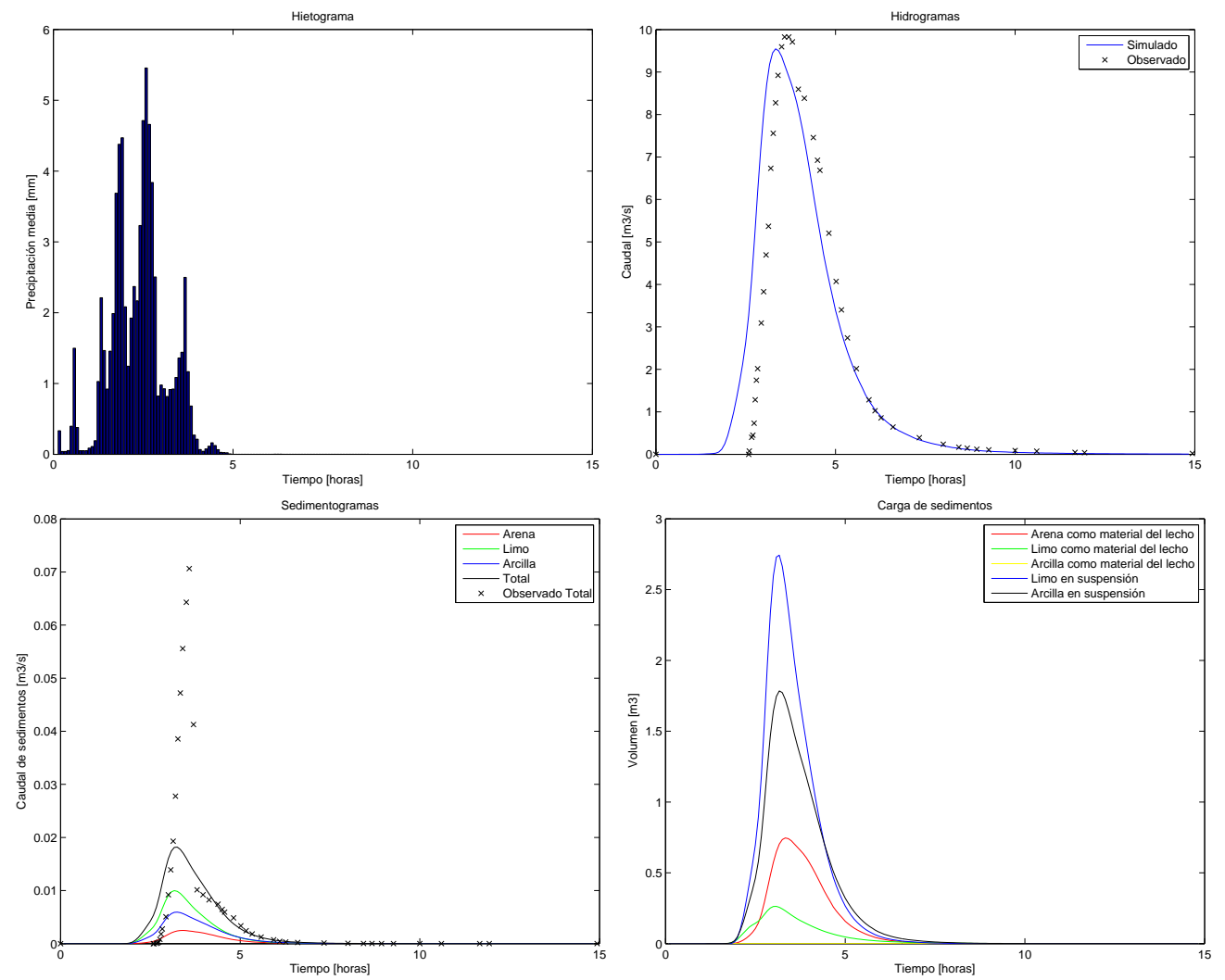

Figura 7.8. Series temporales simuladas en el evento 1 para la estación Q-04

\begin{tabular}{|c|c|c|c|}
\hline & Observado & Simulado & Error [\%] \\
\hline Caudal máximo $\left[\mathrm{m}^{3} / \mathrm{s}\right]$ & 31,227 & 18,193 & $-41,740$ \\
\hline Tiempo al pico $\left[\mathrm{horas}^{\prime}\right]$ & 24,17 & 23,83 & $-1,407$ \\
\hline Volumen de agua $\left[\mathrm{Hm}^{3}\right]$ & 0,208 & 0,189 & $-9,135$ \\
\hline Volumen de sedimentos $\left[\mathrm{m}^{3}\right]$ & 282,98 & 265,07 & $-6,329$ \\
\hline Índice de Nash & 0,7683 & RMSE & 2,64 \\
\hline
\end{tabular}

Tabla 7.12. Desempeño del modelo en el evento 2 para la estación Q-04 

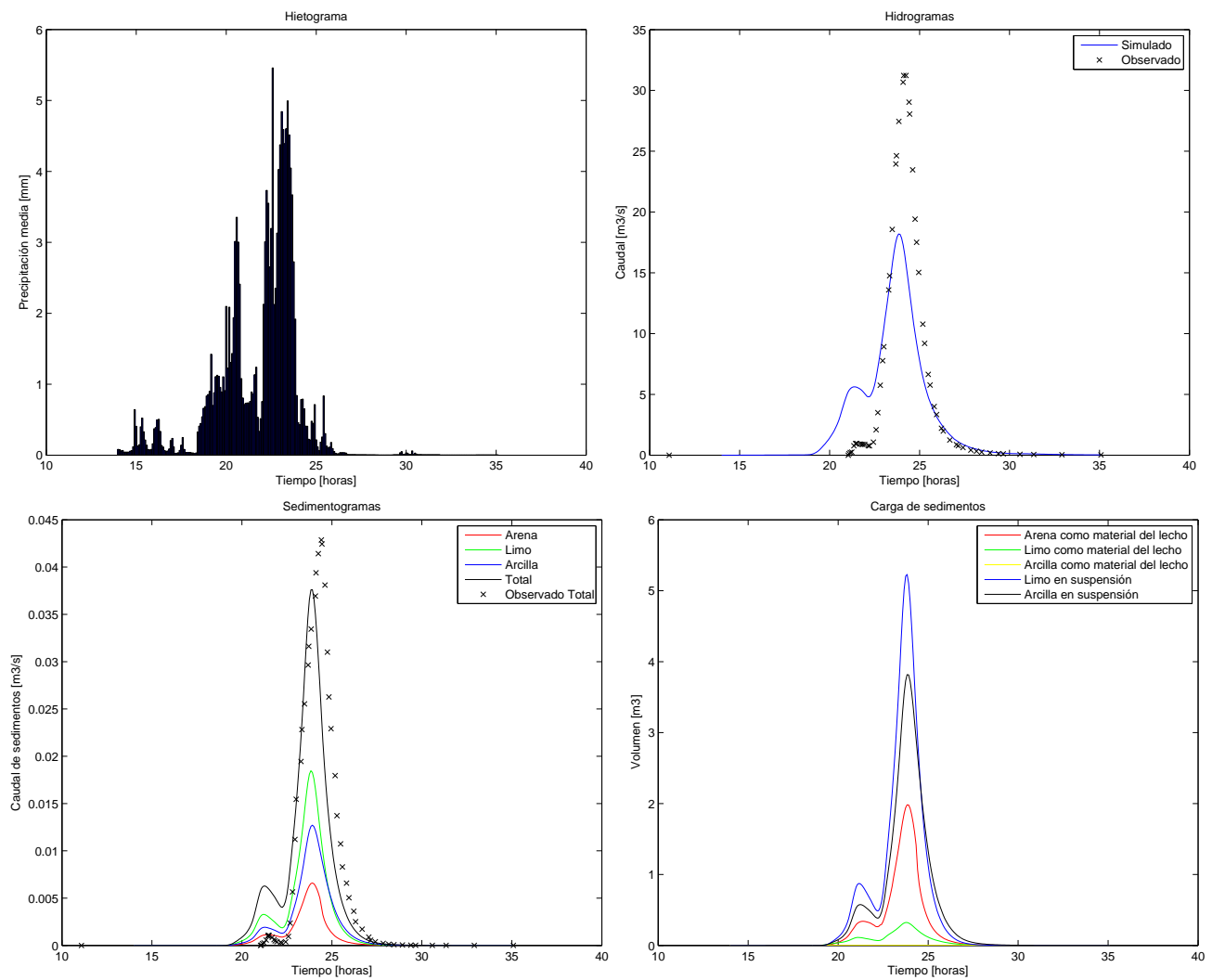

Figura 7.9. Series temporales simuladas en el evento 2 para la estación Q-04

\begin{tabular}{|c|c|c|c|}
\hline & Observado & Simulado & Error [\%] \\
\hline Caudal máximo $\left[\mathrm{m}^{3} / \mathrm{s}\right]$ & 14,737 & 10,327 & $-29,925$ \\
\hline Tiempo al pico $\left[\mathrm{horas}^{\prime}\right]$ & 3,33 & 2,75 & $-17,417$ \\
\hline Volumen de agua $\left[\mathrm{Hm}^{3}\right]$ & 0,111 & 0,089 & $-19,820$ \\
\hline Volumen de sedimentos $\left[\mathrm{m}^{3}\right]$ & 357,71 & 105,04 & $-70,635$ \\
\hline Índice de Nash & 0,789 & RMSE & 1,441 \\
\hline
\end{tabular}

Tabla 7.13. Desempeño del modelo en el evento 3 para la estación Q-04 

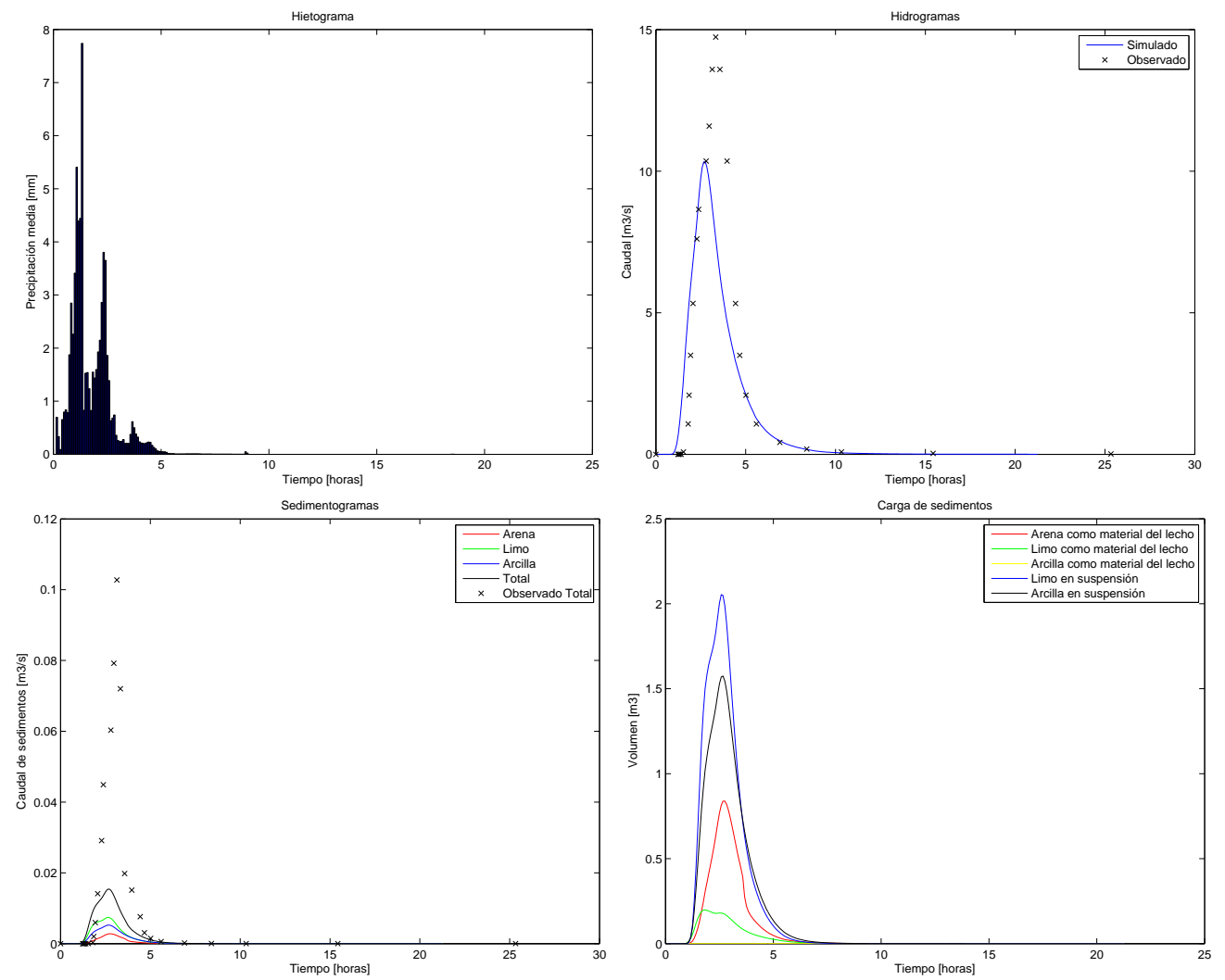

Figura 7.10. Series temporales simuladas en el evento 3 para la estación Q-04

\begin{tabular}{|c|c|c|c|}
\hline & Observado & Simulado & Error [\%] \\
\hline Caudal máximo $\left[\mathrm{m}^{3} / \mathrm{s}\right]$ & 5,206 & 5,146 & $-1,153$ \\
\hline Tiempo al pico $\left[\mathrm{horas}^{\prime}\right]$ & 3,83 & 3,08 & $-19,582$ \\
\hline Volumen de agua $\left[\mathrm{Hm}^{3}\right]$ & 0,036 & 0,037 & 2,778 \\
\hline Volumen de sedimentos $\left[\mathrm{m}^{3}\right]$ & 58,14 & 38,55 & $-33,695$ \\
\hline Índice de Nash & 0,6297 & RMSE & 0,808 \\
\hline
\end{tabular}

Tabla 7.14. Desempeño del modelo en el evento 1 para la estación Q-07 

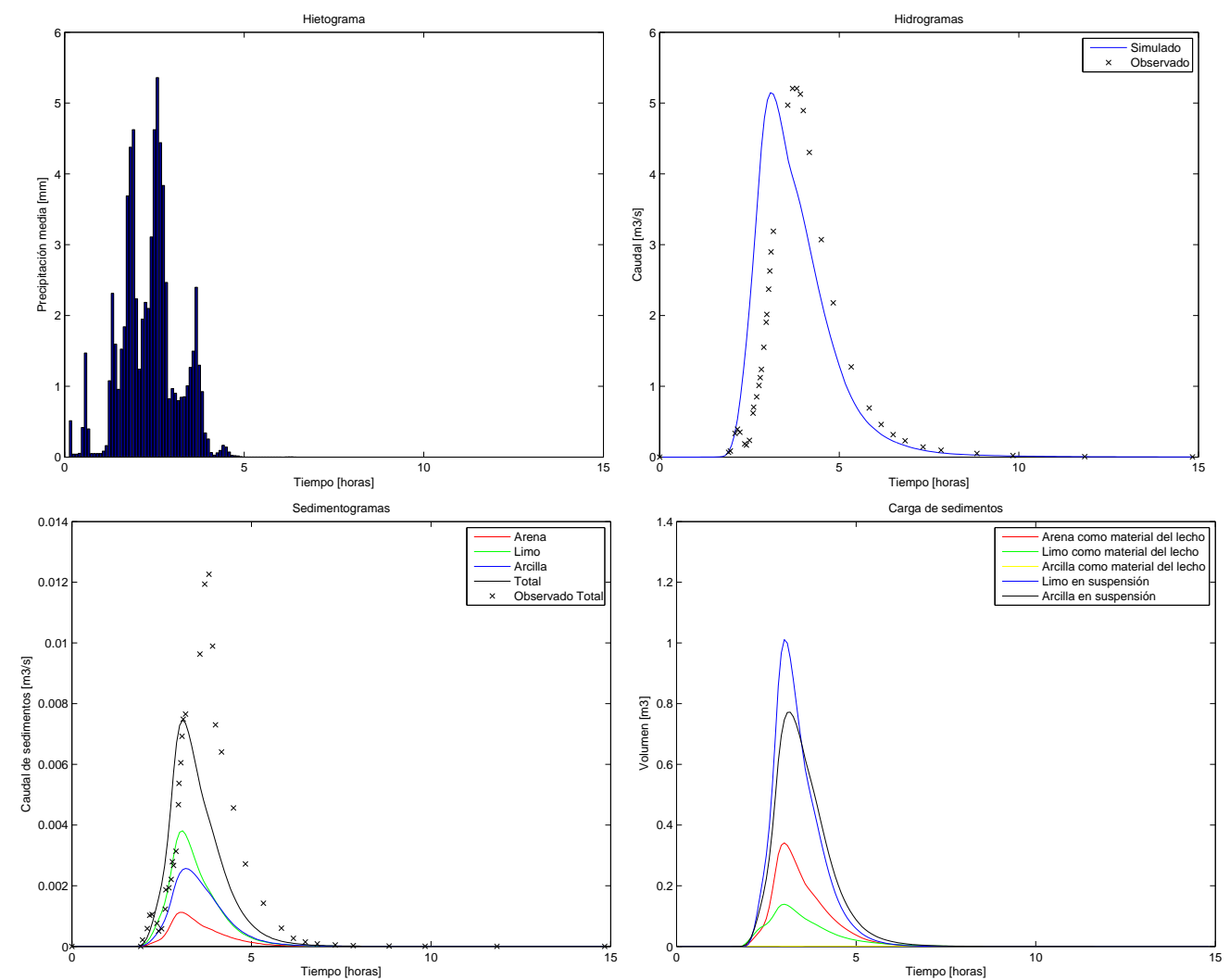

Figura 7.11. Series temporales simuladas en el evento 1 para la estación Q-07

\begin{tabular}{|c|c|c|c|}
\hline & Observado & Simulado & Error [\%] \\
\hline Caudal máximo $\left[\mathrm{m}^{3} / \mathrm{s}\right]$ & 26,58 & 8,615 & $-67,588$ \\
\hline Tiempo al pico $\left[\mathrm{horas}^{\prime}\right]$ & 24,08 & 23,83 & $-1,038$ \\
\hline Volumen de agua $\left[\mathrm{Hm}^{3}\right]$ & 0,134 & 0,088 & $-34,328$ \\
\hline Volumen de sedimentos $\left[\mathrm{m}^{3}\right]$ & 271,74 & 98,54 & $-63,737$ \\
\hline Índice de Nash & 0,5397 & RMSE & 2,661 \\
\hline
\end{tabular}

Tabla 7.15. Desempeño del modelo en el evento 2 para la estación Q-07 

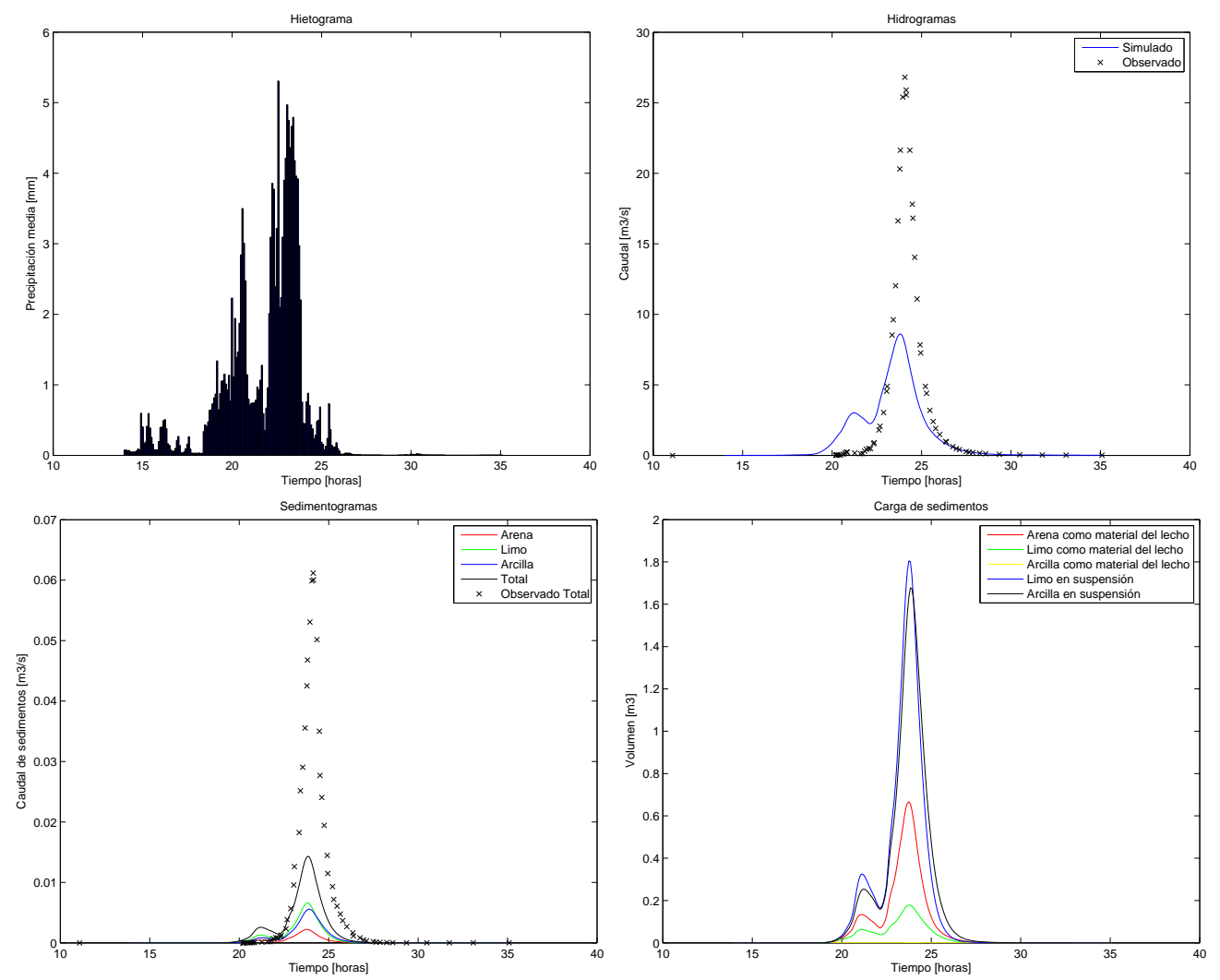

Figura 7.12. Series temporales simuladas en el evento 2 para la estación Q-07

\begin{tabular}{|c|c|c|c|}
\hline & Observado & Simulado & Error [\%] \\
\hline Caudal máximo $\left[\mathrm{m}^{3} / \mathrm{s}\right]$ & 10,366 & 4,984 & $-51,920$ \\
\hline Tiempo al pico $\left[\mathrm{horas}^{3}\right]$ & 2,33 & 2,5 & 7,296 \\
\hline Volumen de agua $\left[\mathrm{Hm}^{3}\right]$ & 0,08 & 0,044 & $-45,000$ \\
\hline Volumen de sedimentos $\left[\mathrm{m}^{3}\right]$ & 103,19 & 46,16 & $-55,267$ \\
\hline Índice de Nash & 0,671 & RMSE & 1,33 \\
\hline
\end{tabular}

Tabla 7.16. Desempeño del modelo en el evento 3 para la estación Q-07 

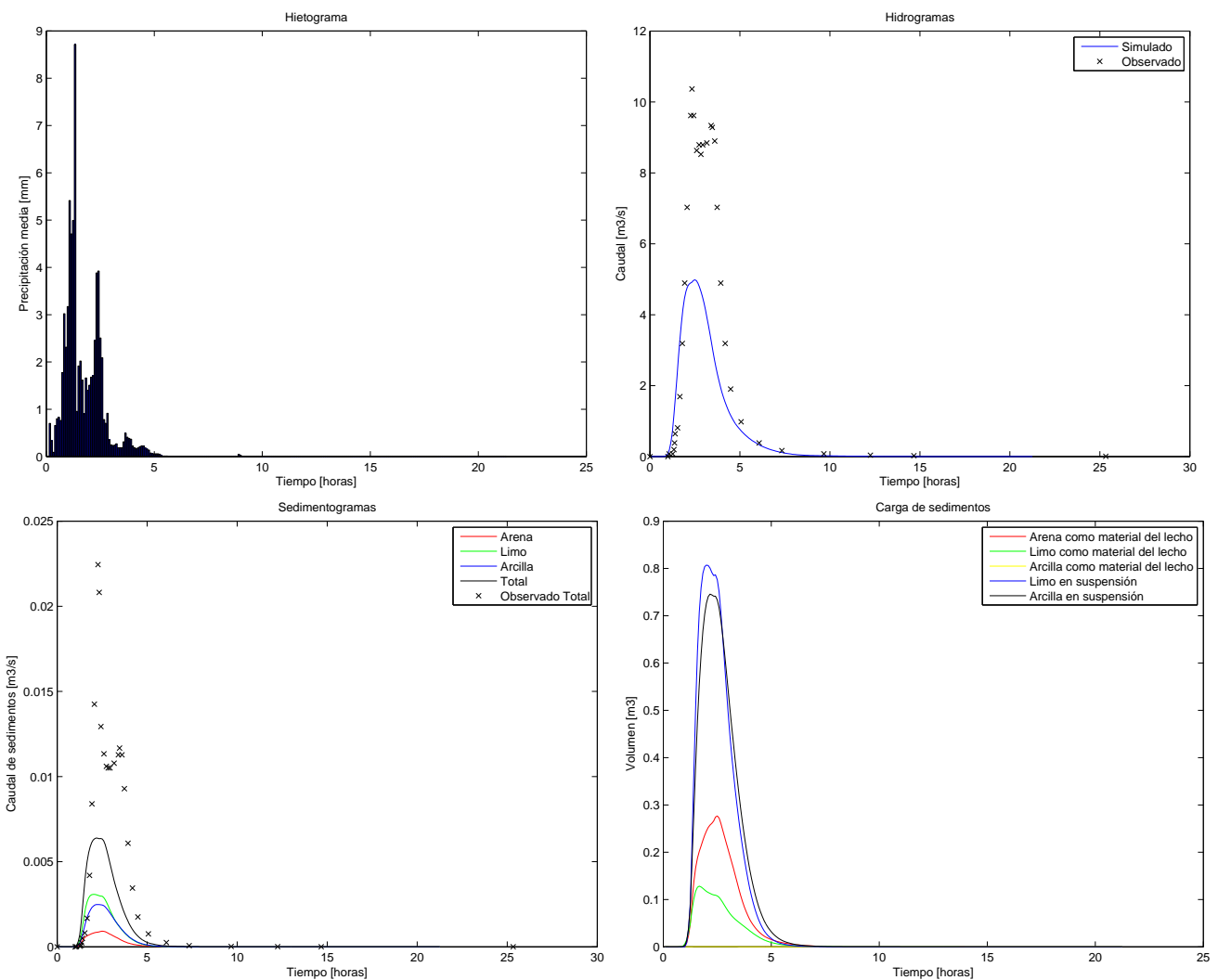

Figura 7.13. Series temporales simuladas en el evento 3 para la estación Q-07 


\subsubsection{Estación de aforo 06}

La estación de aforo 06 posee un área de captación de $1,19 \mathrm{~km}^{2}$ siendo la de menor área de las escogidas para la validación espacial, de esta forma es una estación que puede indicar el funcionamiento del modelo en cuanto a los procesos en ladera. El uso del suelo predominante son los pastos y bosques, con pequeñas zonas dedicadas al cultivo. Las series de suelos presentes son la Loring en zonas de ladera y la Collins en depósitos aluviales, además de presentar zonas con cárcavas.

La figura 7.14 muestra los hidrogramas y sedimentogramas simulados y observados para el evento de calibración. Aunque el hidrograma y el volumen de agua simulados son muy cercanos a los observados, los sedimentogramas y el volumen total de sedimentos simulados presentan valores más altos que los observados (tabla 7.17).

En la figura 7.15 se observan los hidrogramas y sedimentogramas simulados y observados para el evento de validación 2. En este caso los hidrogramas y sedimentogramas y los volúmenes de agua y sedimentos simulados se encuentran ligeramente por debajo que los observados (tabla 7.18).

Igual comportamiento se observa en los hidrogramas y sedimentogramas simulados para el evento de validación 3, cuyos resultados se muestran en la figura 7.16 y se resumen en la tabla 7.19.

Los hidrogramas y sedimentogramas simulados en esta estación para los diferentes eventos no permiten sacar conclusiones precisas en cuanto al funcionamiento del modelo, puesto que en uno los valores simulados son menores que los observados y en otros son mayores.

\begin{tabular}{|c|c|c|c|}
\hline & Observado & Simulado & Error [\%] \\
\hline Caudal máximo $\left[\mathrm{m}^{3} / \mathrm{s}\right]$ & 3,922 & 4,111 & 4,819 \\
\hline Tiempo al pico $\left[\mathrm{horas}^{3}\right]$ & 3,17 & 2,92 & $-7,886$ \\
\hline Volumen de agua $\left[\mathrm{Hm}^{3}\right]$ & 0,025 & 0,031 & 24,000 \\
\hline Volumen de sedimentos $\left[\mathrm{m}^{3}\right]$ & 14,23 & 32,95 & 131,553 \\
\hline Índice de Nash & 0,6155 & RMSE & 0,596 \\
\hline
\end{tabular}

Tabla 7.17. Desempeño del modelo en el evento 1 para la estación Q-06

\subsubsection{Estación de aforo 08}

La estación de aforo Q-08 presenta un área de 1,55 $\mathrm{km}^{2}$. El uso del suelo está casi en su totalidad en pastos y presenta un área importante con cárcavas. En los tres eventos, los resultados arrojados por el modelo son menores que los observados, especialmente en la parte sedimentológica.

La figura 7.17 muestra los hidrogramas y sedimentogramas simulados y observados para el evento de calibración. Tanto el hidrograma como los sedimentogramas 

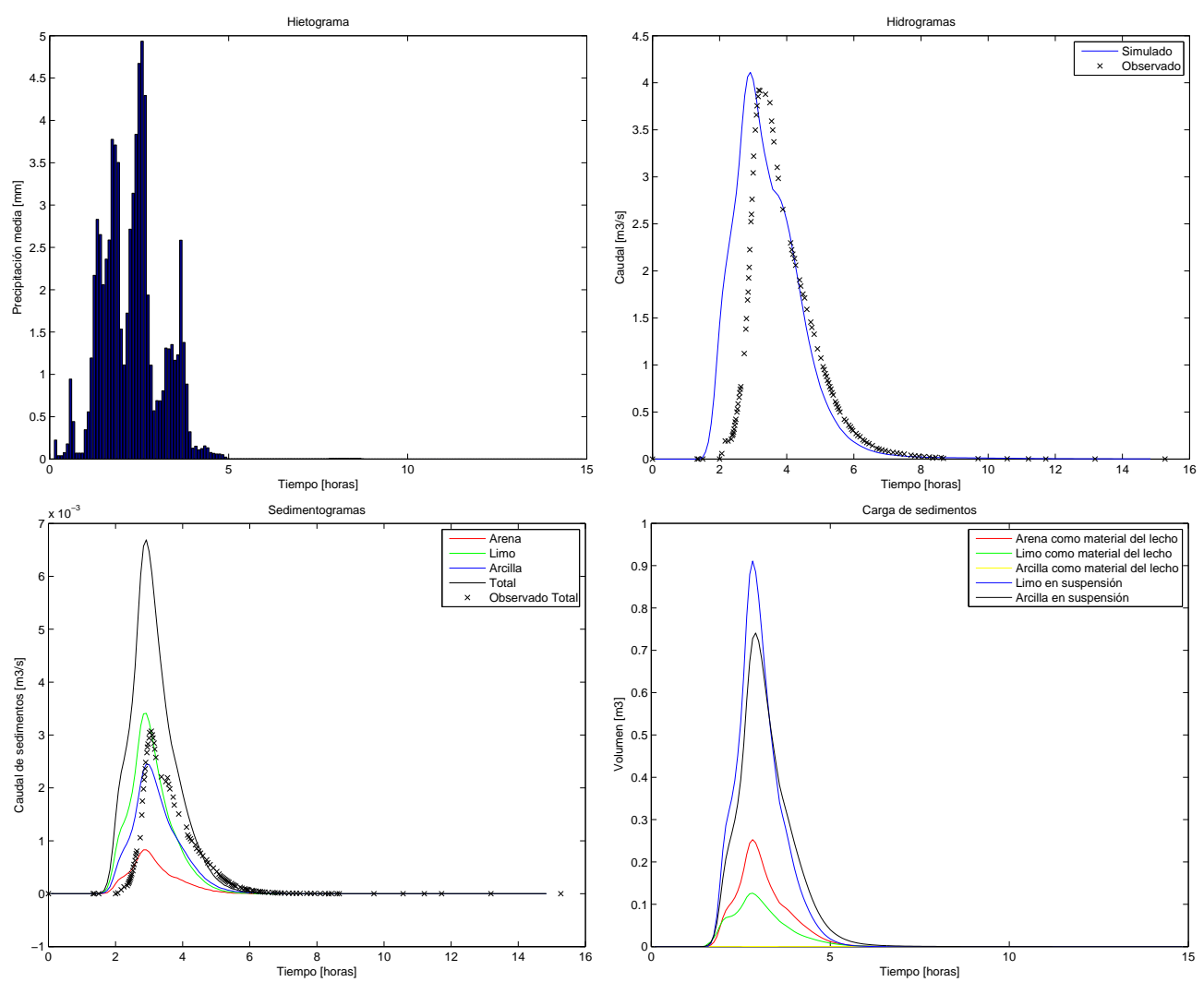

Figura 7.14. Series temporales simuladas en el evento 1 para la estación Q-06

y los volúmenes totales de sedimentos simulados presentan valores más bajos que los observados (tabla 7.20). Igual comportamiento se observa en los eventos de validación temporal (tablas 7.21 y 7.22 y figuras 7.18 y 7.19 )

\subsubsection{Estación de aforo 14}

La estación de aforo Q-14 posee un área de captación de $1,63 \mathrm{~km}^{2}$. El uso del suelo es predominantemente en pastos y presente zonas con carcavamiento en las inmediaciones de la red de drenaje. Al igual que en la mayoría de las estaciones de aforo analizadas anteriormente, la producción de sedimentos que simula el modelo es menor que los observados. 

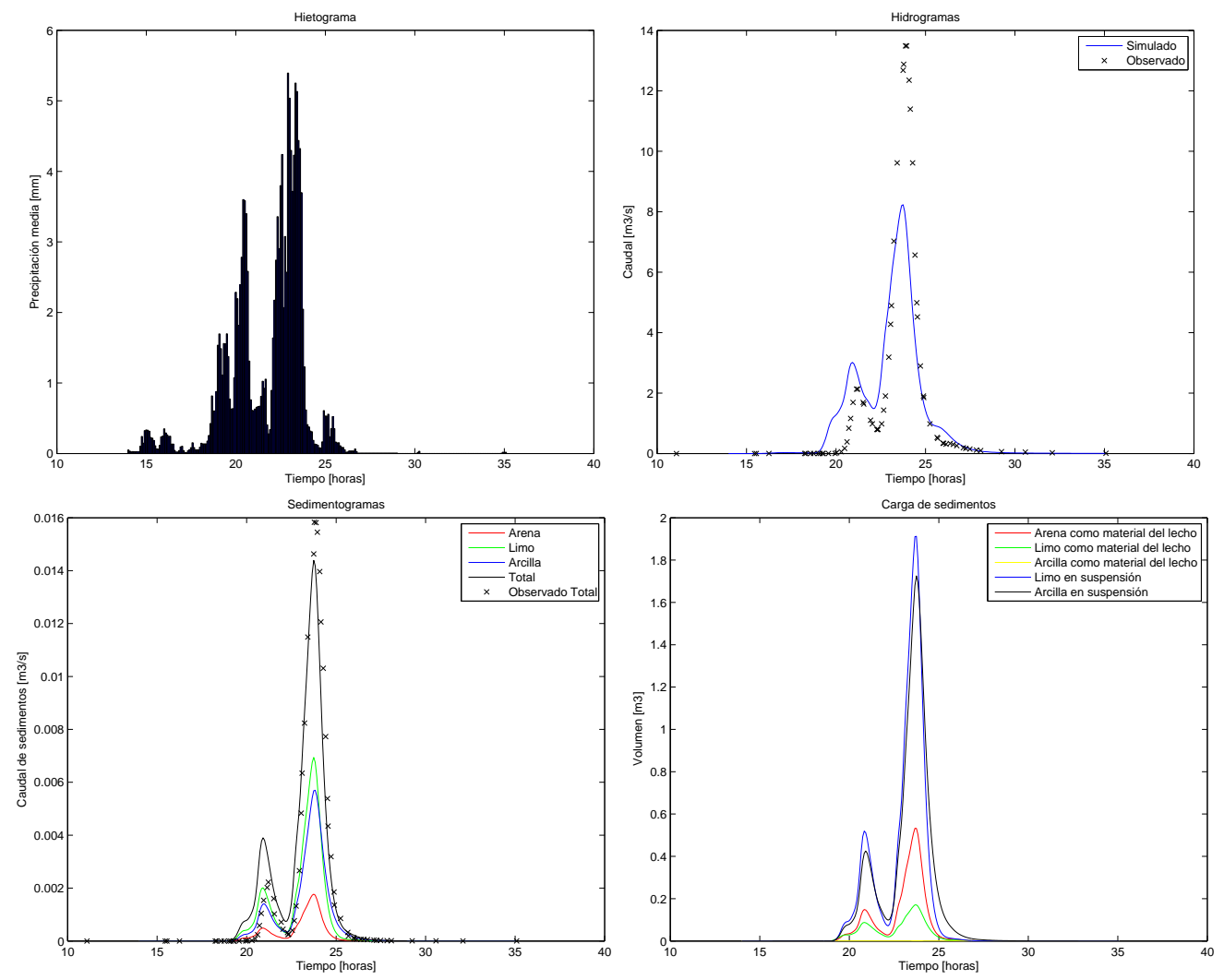

Figura 7.15. Series temporales simuladas en el evento 2 para la estación Q-06

\begin{tabular}{|c|c|c|c|}
\hline & Observado & Simulado & Error [\%] \\
\hline Caudal máximo $\left[\mathrm{m}^{3} / \mathrm{s}\right]$ & 13,488 & 8,231 & $-38,975$ \\
\hline Tiempo al pico $\left[\mathrm{horas}^{\prime}\right]$ & 23,92 & 23,75 & $-0,711$ \\
\hline Volumen de agua $\left[\mathrm{Hm}^{3}\right]$ & 0,076 & 0,074 & $-2,632$ \\
\hline Volumen de sedimentos $\left[\mathrm{m}^{3}\right]$ & 78,79 & 84,88 & 7,729 \\
\hline Índice de Nash & 0,8067 & RMSE & 0,919 \\
\hline
\end{tabular}

Tabla 7.18. Desempeño del modelo en el evento 2 para la estación Q-06 

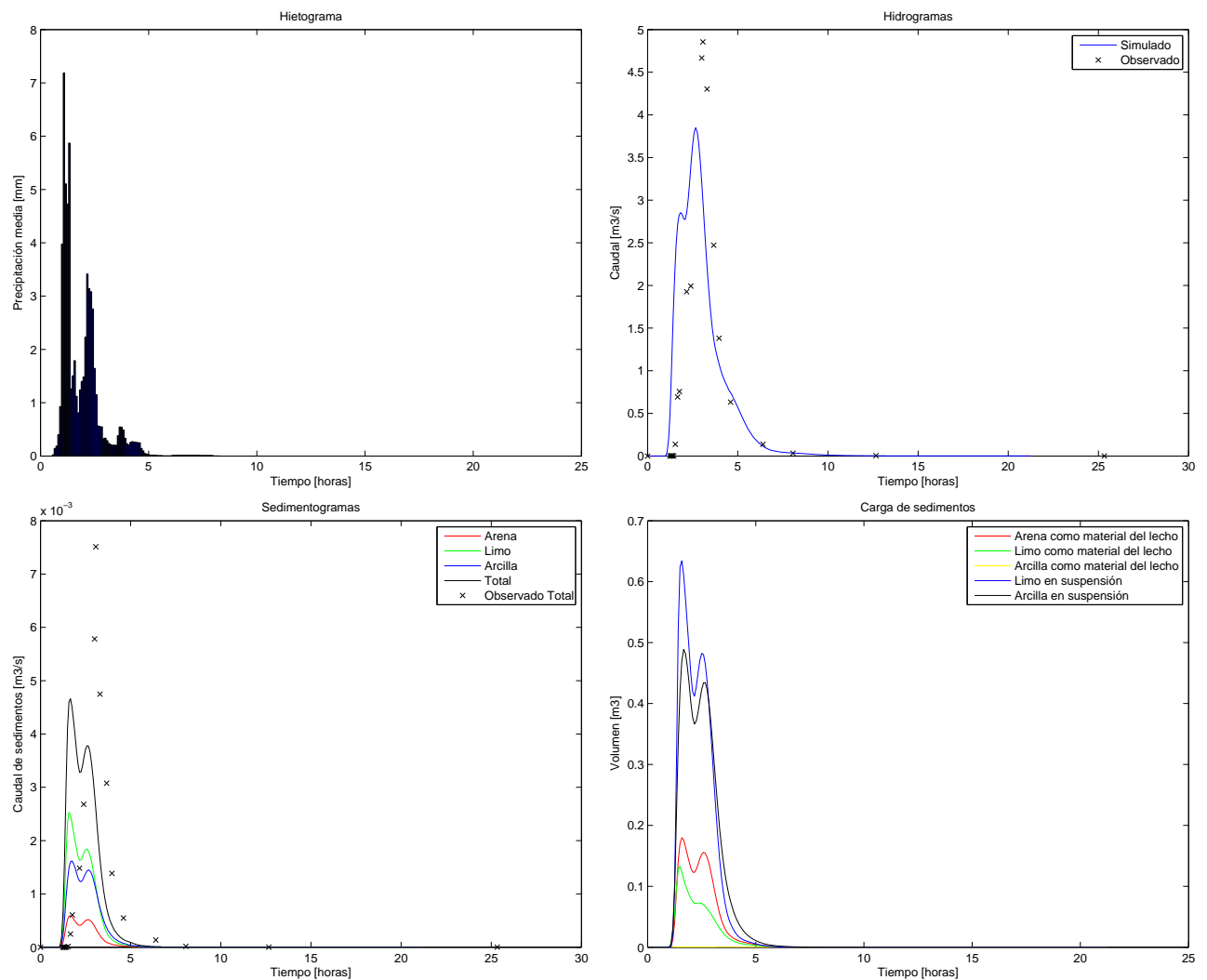

Figura 7.16. Series temporales simuladas en el evento 3 para la estación Q-06

\begin{tabular}{|c|c|c|c|}
\hline & Observado & Simulado & Error [\%] \\
\hline Caudal máximo $\left[\mathrm{m}^{3} / \mathrm{s}\right]$ & 4,816 & 3,849 & $-20,079$ \\
\hline Tiempo al pico $\left[\mathrm{horas}^{\prime}\right]$ & 3,08 & 2,67 & $-13,312$ \\
\hline Volumen de agua $\left[\mathrm{Hm}^{3}\right]$ & 0,028 & 0,03 & 7,143 \\
\hline Volumen de sedimentos $\left[\mathrm{m}^{3}\right]$ & 30,81 & 28,05 & $-8,958$ \\
\hline Índice de Nash & 0,7025 & RMSE & 0,474 \\
\hline
\end{tabular}

Tabla 7.19. Desempeño del modelo en el evento 3 para la estación Q-06 

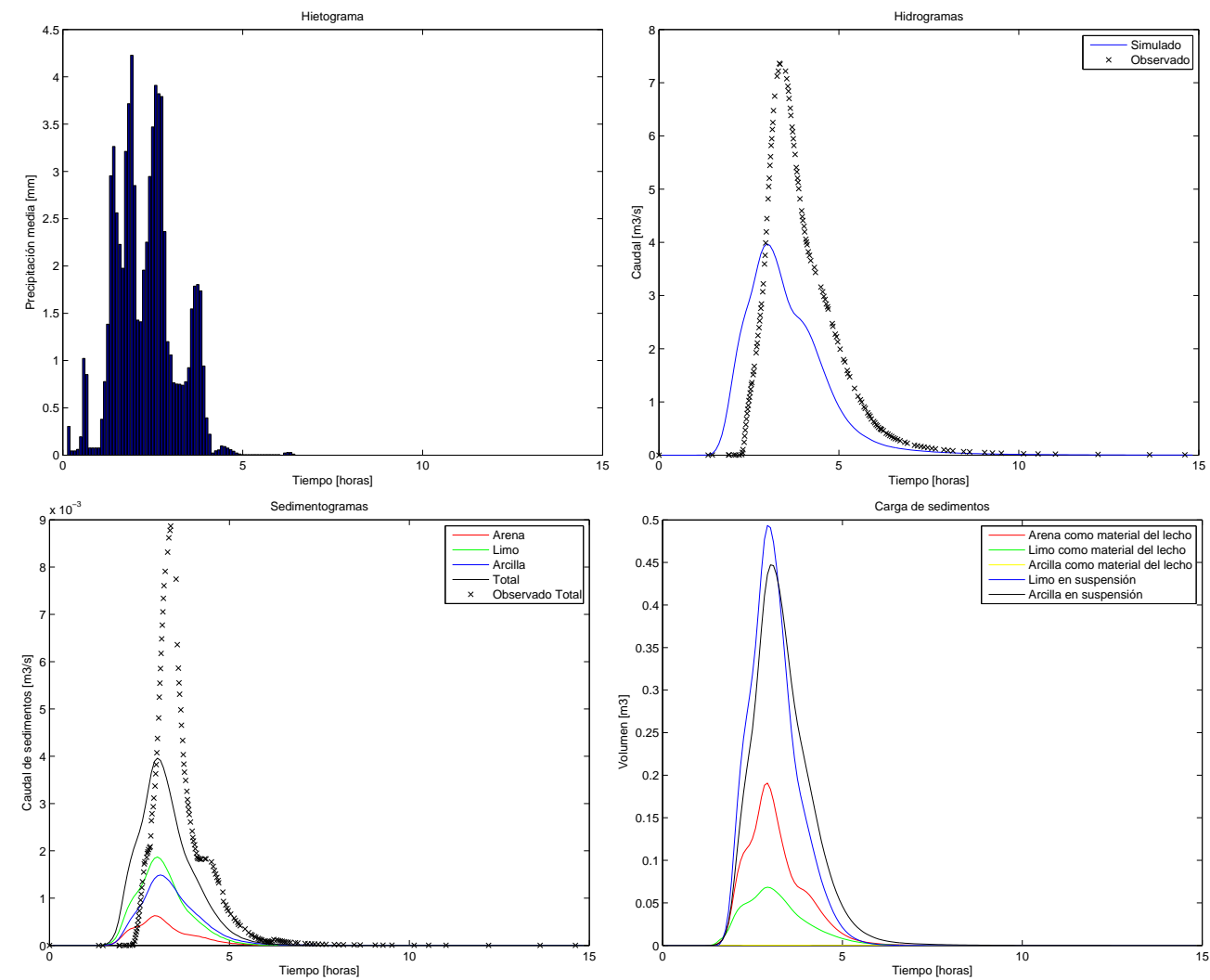

Figura 7.17. Series temporales simuladas en el evento 1 para la estación Q-08

\begin{tabular}{|c|c|c|c|}
\hline & Observado & Simulado & Error [\%] \\
\hline Caudal máximo $\left[\mathrm{m}^{3} / \mathrm{s}\right]$ & 7,305 & 3,969 & $-45,667$ \\
\hline Tiempo al pico $\left[\mathrm{horas}^{\prime}\right]$ & 3,42 & 3 & $-12,281$ \\
\hline Volumen de agua $\left[\mathrm{Hm}^{3}\right]$ & 0,045 & 0,032 & $-28,889$ \\
\hline Volumen de sedimentos $\left[\mathrm{m}^{3}\right]$ & 30,89 & 23,01 & $-25,510$ \\
\hline Índice de Nash & 0,6436 & RMSE & 1,029 \\
\hline
\end{tabular}

Tabla 7.20. Desempeño del modelo en el evento 1 para la estación Q-08 

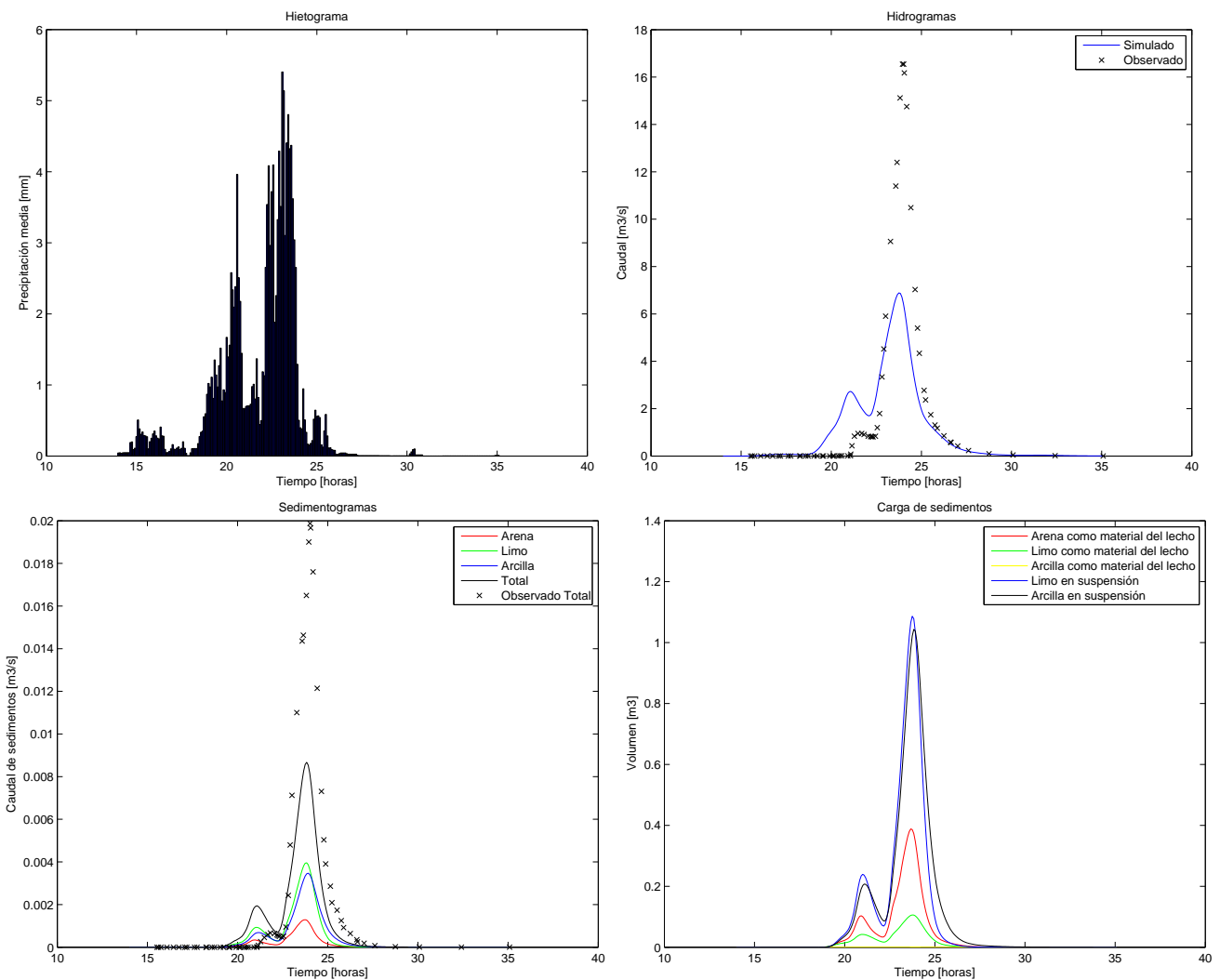

Figura 7.18. Series temporales simuladas en el evento 2 para la estación Q-08

\begin{tabular}{|c|c|c|c|}
\hline & Observado & Simulado & Error [\%] \\
\hline Caudal máximo $\left[\mathrm{m}^{3} / \mathrm{s}\right]$ & 16,545 & 6,888 & $-58,368$ \\
\hline Tiempo al pico $\left[\mathrm{horas}^{\prime}\right]$ & 24 & 23,75 & $-1,042$ \\
\hline Volumen de agua $\left[\mathrm{Hm}^{3}\right]$ & 0,096 & 0,073 & $-23,958$ \\
\hline Volumen de sedimentos $\left[\mathrm{m}^{3}\right]$ & 101,48 & 58,95 & $-41,910$ \\
\hline Índice de Nash & 0,658 & RMSE & 1,518 \\
\hline
\end{tabular}

Tabla 7.21. Desempeño del modelo en el evento 2 para la estación Q-08 

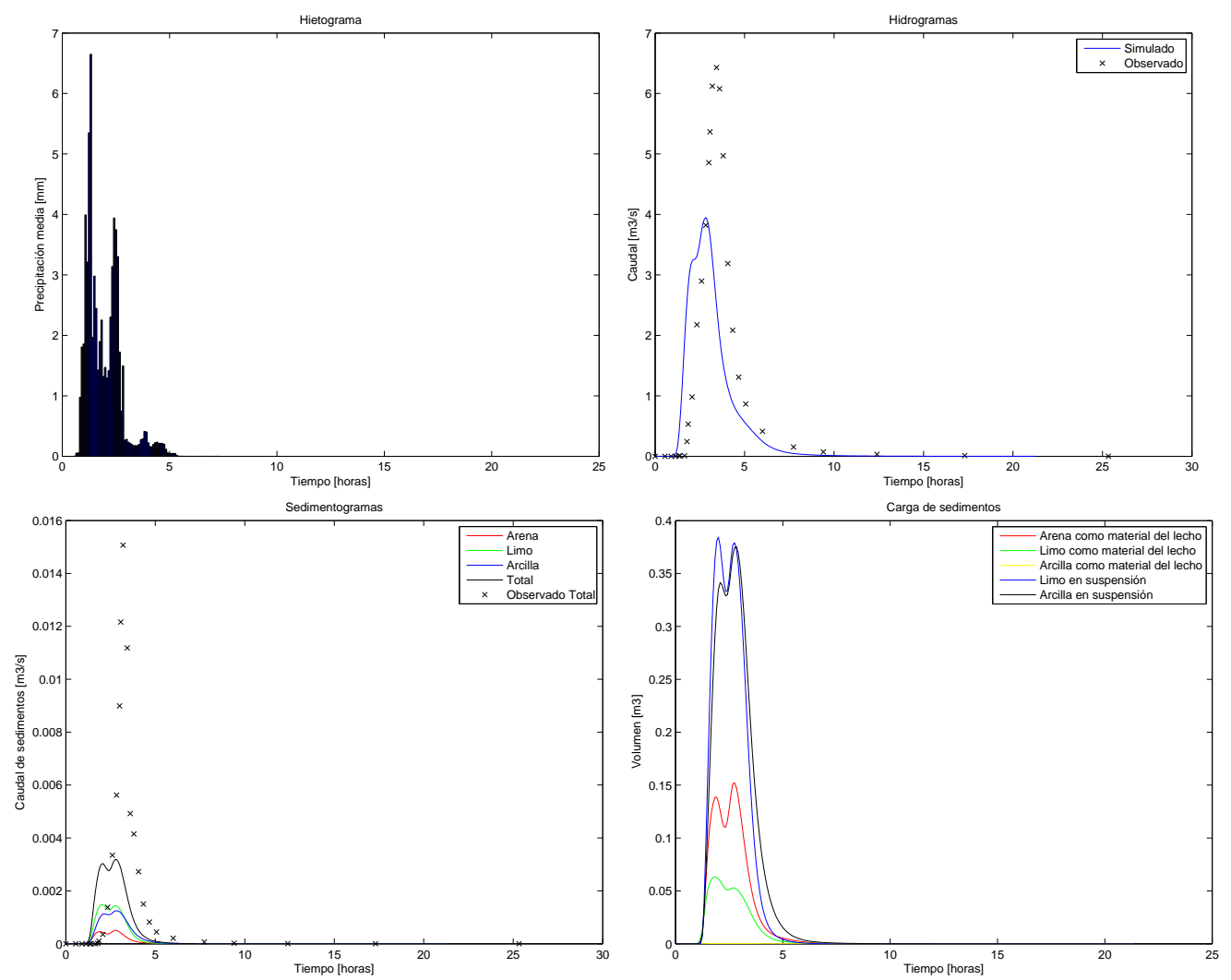

Figura 7.19. Series temporales simuladas en el evento 3 para la estación Q-08

\begin{tabular}{|c|c|c|c|}
\hline & Observado & Simulado & Error [\%] \\
\hline Caudal máximo $\left[\mathrm{m}^{3} / \mathrm{s}\right]$ & 6,408 & 3,949 & $-38,374$ \\
\hline Tiempo al pico $\left[\mathrm{horas}^{\prime}\right]$ & 3,42 & 2,83 & $-17,251$ \\
\hline Volumen de agua $\left[\mathrm{Hm}^{3}\right]$ & 0,043 & 0,032 & $-25,581$ \\
\hline Volumen de sedimentos $\left[\mathrm{m}^{3}\right]$ & 47,5 & 22,51 & $-52,611$ \\
\hline Índice de Nash & 0,5876 & RMSE & 0,798 \\
\hline
\end{tabular}

Tabla 7.22. Desempeño del modelo en el evento 3 para la estación Q-08 

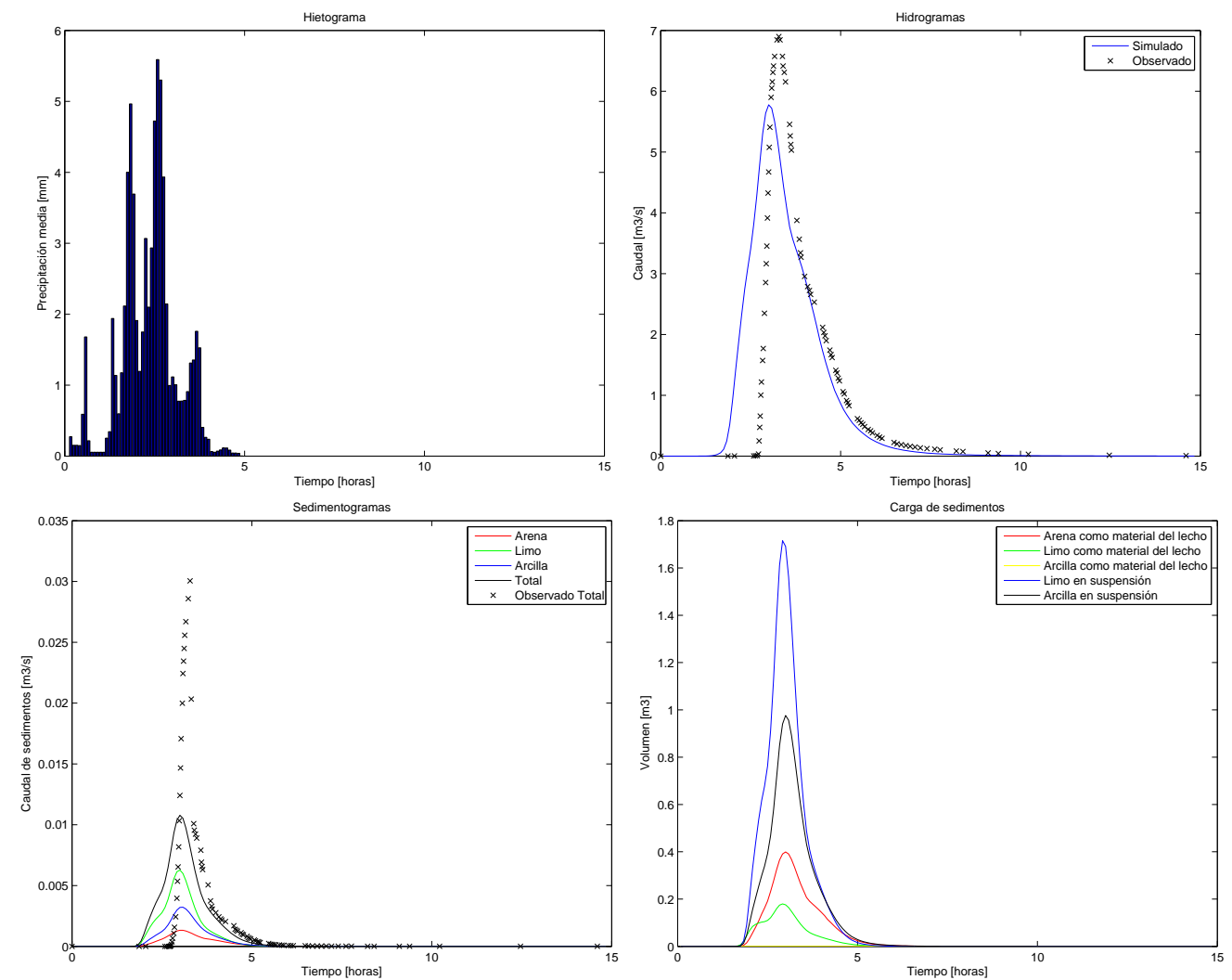

Figura 7.20. Series temporales simuladas en el evento 1 para la estación Q-014

\begin{tabular}{|c|c|c|c|}
\hline & Observado & Simulado & Error [\%] \\
\hline Caudal máximo $\left[\mathrm{m}^{3} / \mathrm{s}\right]$ & 6,863 & 5,777 & $-15,824$ \\
\hline Tiempo al pico $\left[\mathrm{horas}^{\prime}\right]$ & 3,25 & 3 & $-7,692$ \\
\hline Volumen de agua $\left[\mathrm{Hm}^{3}\right]$ & 0,033 & 0,037 & 12,121 \\
\hline Volumen de sedimentos $\left[\mathrm{m}^{3}\right]$ & 52,72 & 45,3 & $-14,074$ \\
\hline Índice de Nash & 0,6326 & RMSE & 0,877 \\
\hline
\end{tabular}

Tabla 7.23. Desempeño del modelo en el evento 1 para la estación Q-014 

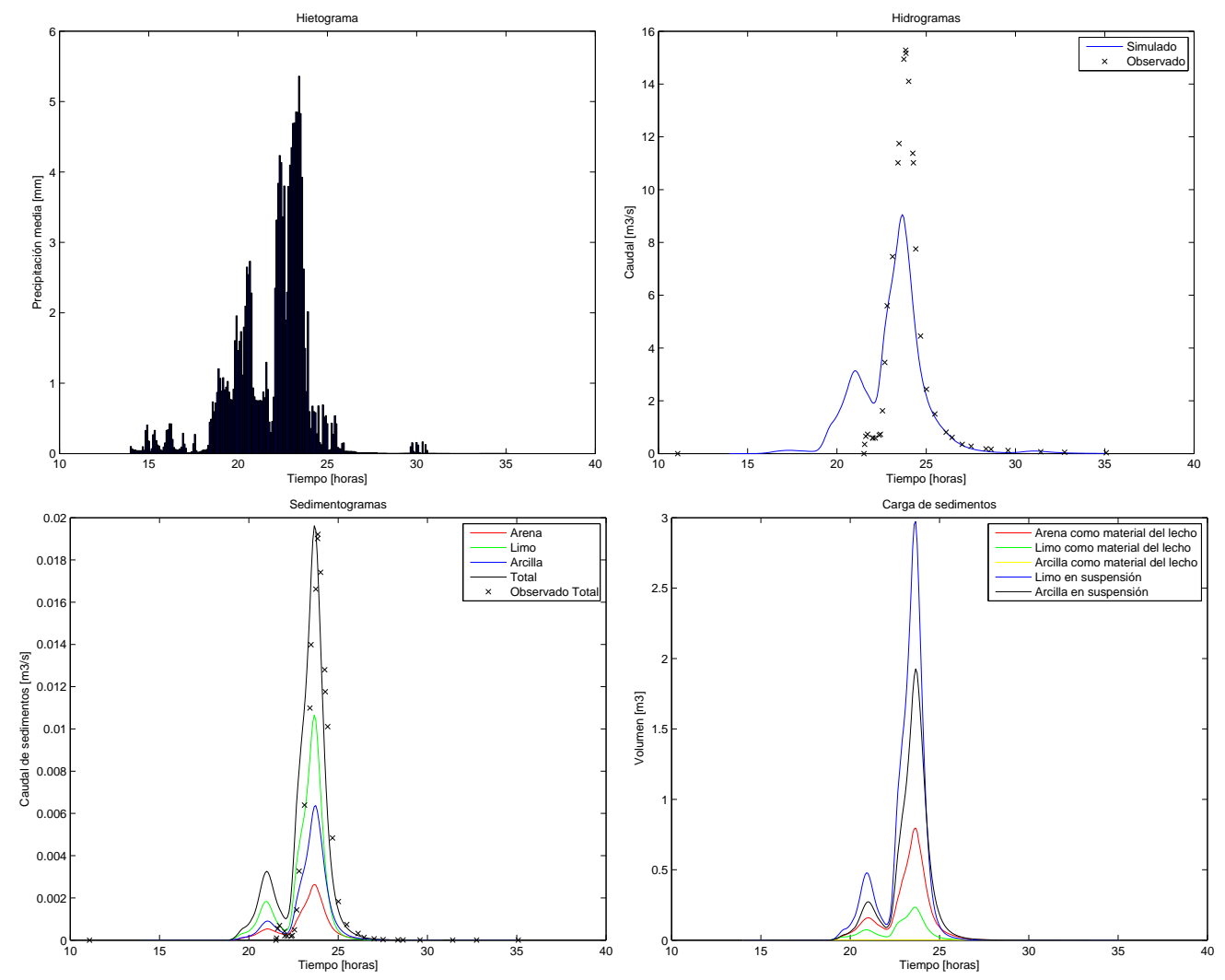

Figura 7.21. Series temporales simuladas en el evento 2 para la estación Q-014

\begin{tabular}{|c|c|c|c|}
\hline & Observado & Simulado & Error [\%] \\
\hline Caudal máximo $\left[\mathrm{m}^{3} / \mathrm{s}\right]$ & 15,227 & 9,057 & $-40,520$ \\
\hline Tiempo al pico $\left[\mathrm{horas}^{\prime}\right]$ & 23,83 & 23,67 & $-0,671$ \\
\hline Volumen de agua $\left[\mathrm{Hm}^{3}\right]$ & 0,09 & 0,088 & $-2,222$ \\
\hline Volumen de sedimentos $\left[\mathrm{m}^{3}\right]$ & 85,35 & 112,35 & 31,634 \\
\hline Índice de Nash & 0,7756 & RMSE & 1,164 \\
\hline
\end{tabular}

Tabla 7.24. Desempeño del modelo en el evento 2 para la estación Q-014 

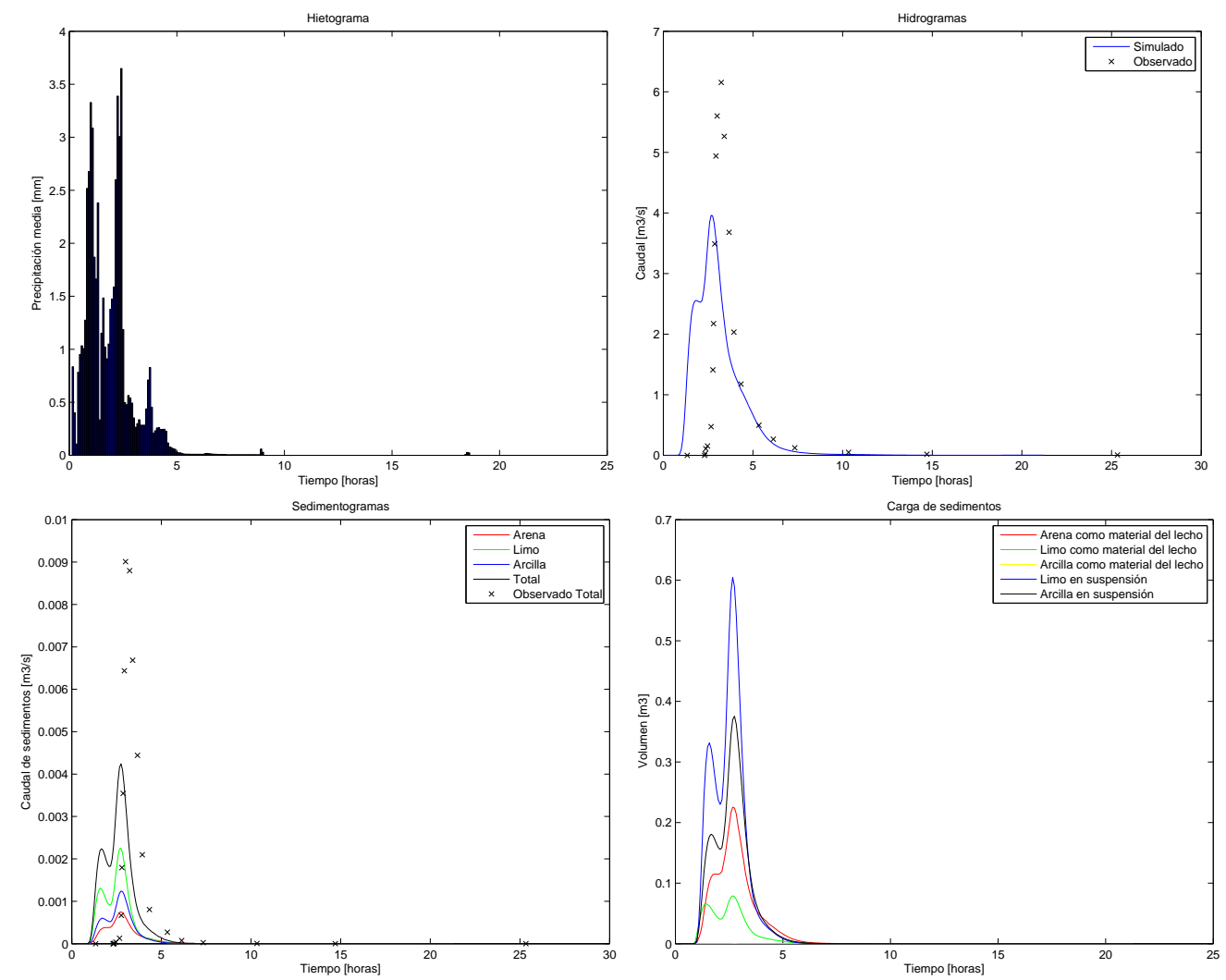

Figura 7.22. Series temporales simuladas en el evento 3 para la estación Q-014

\begin{tabular}{|c|c|c|c|}
\hline & Observado & Simulado & Error [\%] \\
\hline Caudal máximo $\left[\mathrm{m}^{3} / \mathrm{s}\right]$ & 6,065 & 3,96 & $-34,707$ \\
\hline Tiempo al pico $\left[\mathrm{horas}^{\prime}\right]$ & 3,25 & 2,67 & $-17,846$ \\
\hline Volumen de agua $\left[\mathrm{Hm}^{3}\right]$ & 0,028 & 0,032 & 14,286 \\
\hline Volumen de sedimentos $\left[\mathrm{m}^{3}\right]$ & 25,34 & 23,03 & $-9,116$ \\
\hline Índice de Nash & 0,2945 & RMSE & 0,827 \\
\hline
\end{tabular}

Tabla 7.25. Desempeño del modelo en el evento 3 para la estación Q-014 


\section{Capítulo 8}

\section{Resultados y análisis}

En este capítulo se muestran los resultados del modelo y se comparan con los datos observados en la cuenca de Goodwin Creek. Además se efectúan algunos análisis de su comportamiento en relación con sus aspectos novedosos y relevantes.

\subsection{Comportamiento general del modelo}

De acuerdo con los resultados mostrados en el capítulo anterior, se considera que el desempeño del modelo es adecuado, de esta forma se valida la hipótesis de trabajo formulada en esta tesis. Al contrastar los resultados del modelo, específicamente el comportamiento sedimentológico, con otras aplicaciones en la cuenca de Goodwin Creek (por ejemplo, Ogden y Heilig (2001) y Rojas (2002)) se observa que, en general, el modelo simula con buen desempeño tanto el comportamiento hidrológico como el sedimentológico de la cuenca en eventos de lluvia.

En las figuras 8.1 y 8.2 se muestra el comportamiento general del modelo. El desempeño hidrológico se muestra relacionando el índice de eficiencia de Nash (hidrogramas observados versus hidrogramas simulados) contra el área de captación de las diferentes estaciones de aforo en las cuales se aplicó el modelo. El desempeño sedimentológico se observa relacionando los volúmenes totales producidos tanto observados como simulados para los tres eventos y las seis estaciones de aforo.

Tomando en cuenta la complejidad inherente a las dinámicas hidrológicas y sedimentológica, las diferencias entre los resultados del modelo y los datos observados en los hidrogramas y sedimentogramas de salida de los eventos y en las estaciones de aforo analizadas son asumibles.

La validación de la hipótesis es necesario matizarla, puesto que en algunos casos los resultados arrojados por el modelo son algo alejados de los observados en la cuenca de Goodwin Creek. Por ejemplo, según los resultados simulados por el modelo en las estaciones de aforo en las cuales se efectuó la validación espacial, es claro que el modelo subvalora la producción de sedimentos en ladera. Este hecho 


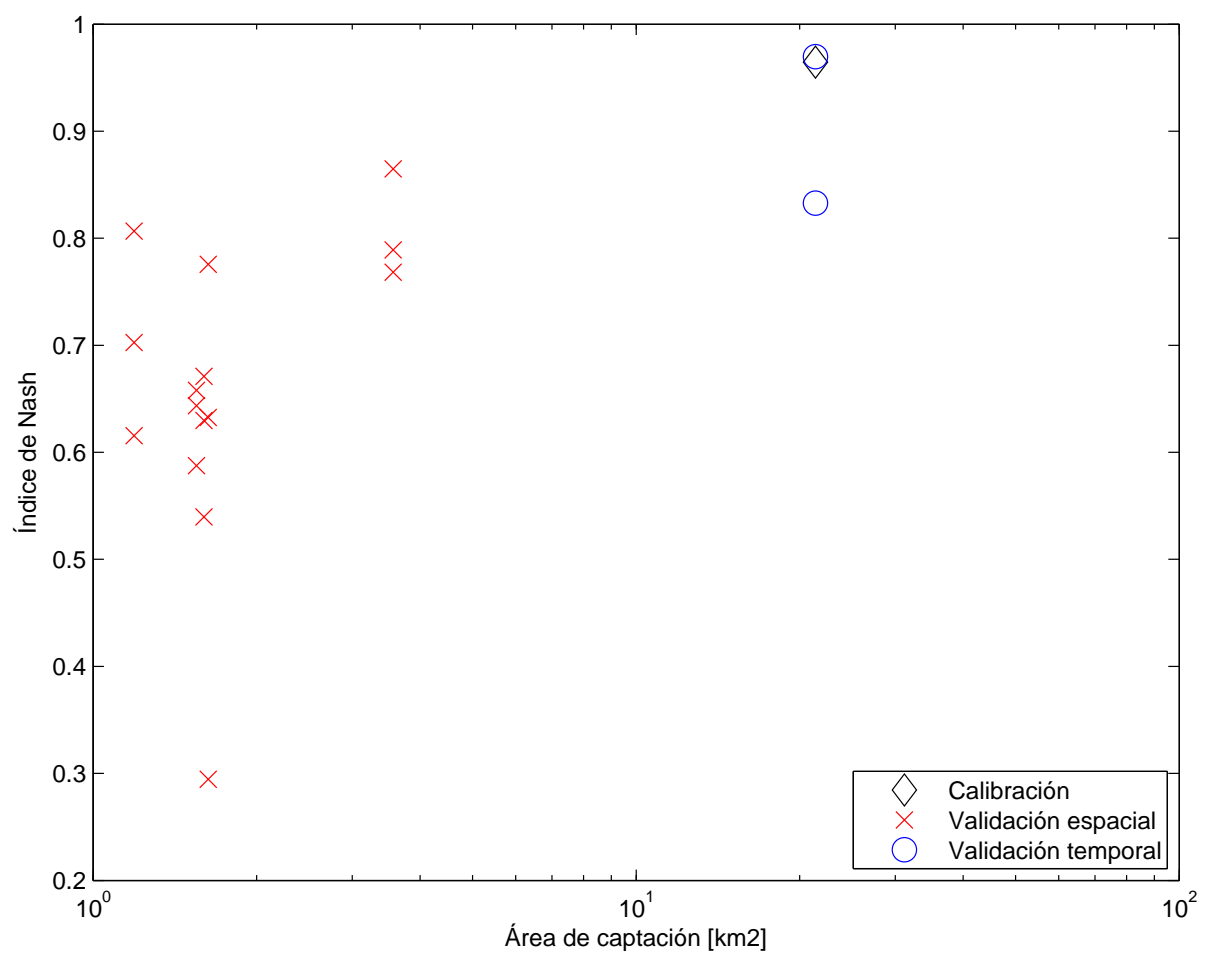

Figura 8.1. Comportamiento hidrológico del modelo

se hace evidente al contrastar los valores simulados en las estaciones de aforo con poca área de captación (estaciones Q-06, Q-07, Q-08 y Q-14).

El factor de la ecuación original de Kilinc y Richardson es de 25500 y considerando los factores de la USLE es de 23310 (Julien, 1998), dicho factor se ajusta a las condiciones de las canaletas de laboratorio en donde se efectuaron los ensayos. Rojas (2002) utiliza un factor de 58390 al aplicar el modelo CASC2D-SED en la cuenca de Goodwin Creek.

En este caso, el factor de la ecuación de Kilinc y Richardson se ha calibrado considerando el volumen total de sedimentos que salen de la cuenca en el evento de calibración. Con un factor corrector igual a 76000 el volumen total de sedimentos simulados que salen de la cuenca se hace muy cercano al observado.

El factor de calibración de la ecuación de Kilinc y Richardson se calibró en la salida de la cuenca, de esta forma da cuenta del comportamiento medio de la cuenca en cuanto a la producción de sedimentos en ladera. Este hecho significa que el depósito real en la red de drenaje es apreciablemente superior que el que está simulando el modelo.

En la figura 8.3 se contrasta el comportamiento del modelo con otras aplicaciones de modelos sedimentológicos en la cuenca de Goodwin Creek. Ambas apli- 


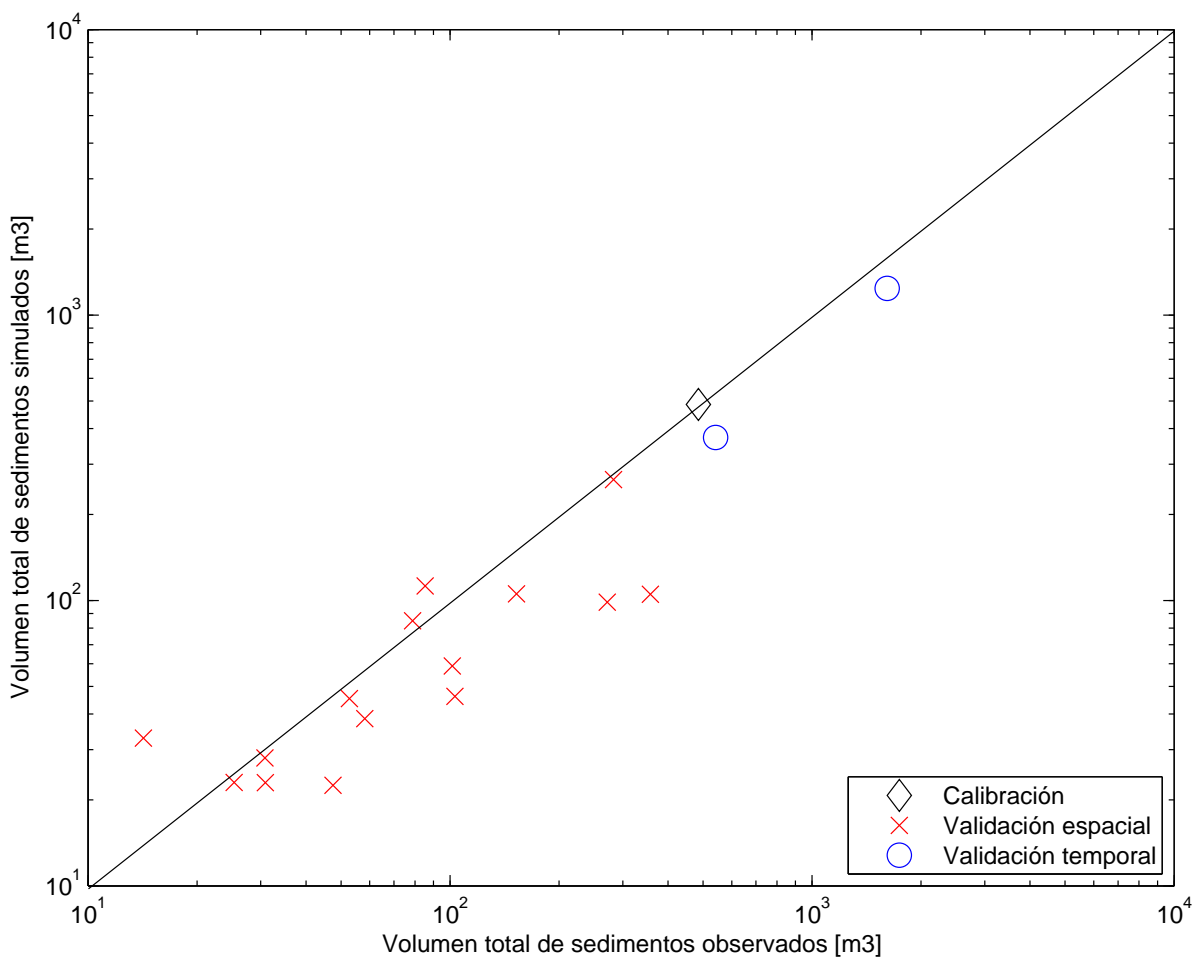

Figura 8.2. Comportamiento sedimentológico del modelo

caciones corresponden al modelo CASC2D-SED (Ogden y Heilig, 2001), (Rojas, 2002). El estudio efectuado por Ogden y Heling se efectuó en diferentes eventos y se utilizaron diferentes estaciones de aforo, aún así, los resultados sirven para comparar el desempeño del modelo, mientras que los resultados de Rojas corresponden a los mismos eventos y estaciones de aforo.

Aunque no se puede determinar cual de los modelos presenta mejores desempeños, es de destacar que en el modelo propuesto en esta tesis presenta un sólo elemento de calibración en la parte sedimentológica, mientras que en las aplicaciones reseñadas se calibran los factores de la USLE. Además, se comprueba que con la conceptualización de la cuenca propuesta en esta tesis es posible efectuar simulaciones adecuadas.

\subsection{Las áreas fuentes y los sumideros de se- dimentos}

En la figura 8.4 se muestra la distribución espacial del volumen de sedimentos erosionados y depositados para el evento de calibración. En estos mapas se aprecian 


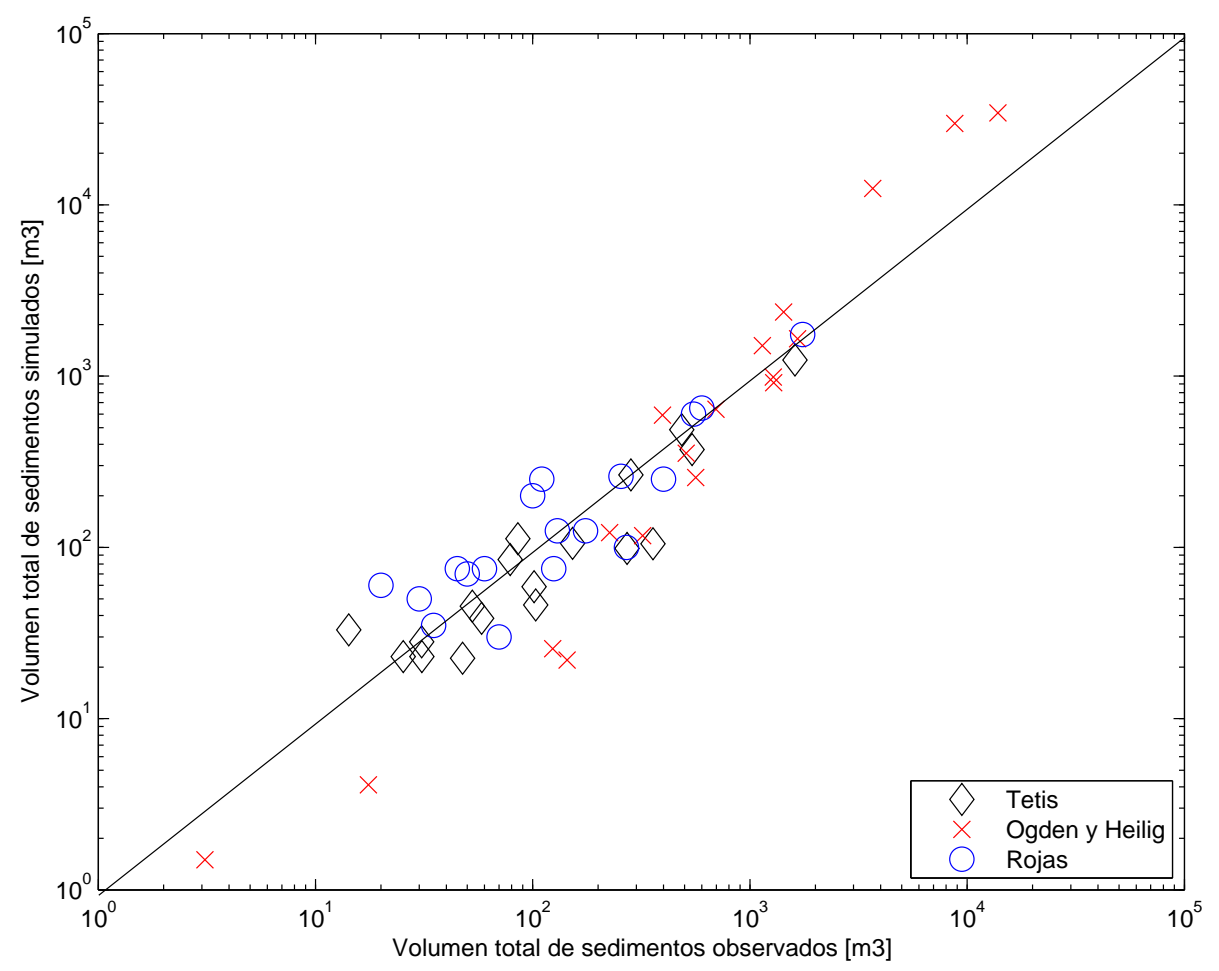

Figura 8.3. Comparación del comportamiento sedimentológico

las zonas de producción y depósito de sedimentos, esto es las áreas fuentes de sedimentos y los sumideros.

Es fácil diferenciar zonas con altas tasas de producción de sedimentos, en algunos casos se pueden asociar con zonas de cárcavas, según el mapa de suelos de la cuenca. Al efectuar una observación rápida de los mapas de usos del suelo, se puede determinar que las zonas ubicadas en pastos son las que presentan tasas de erosión más altas.

En la figura 8.5 se muestra la distribución espacial del volumen de sedimentos erosionados y depositados para el evento de validación 2 .

En la figura 8.6 se muestra la distribución espacial del volumen de sedimentos erosionados y depositados para el evento de validación 3.

Una observación importante al comparar los mapas de los diferentes eventos es las diferencias que se observan en las zonas de erosión y depósito. Una explicación a estas diferencias se debe a las diferencias en la distribución espacial de las lluvias analizadas, tal como se observa en los mapas de la distribución espacial de los sedimentos erosionados. En estas figuras se muestra además la distribución espacial de las lluvias, representada por isoyetas de la precipitación acumulada para todo el evento (en milímetros). 

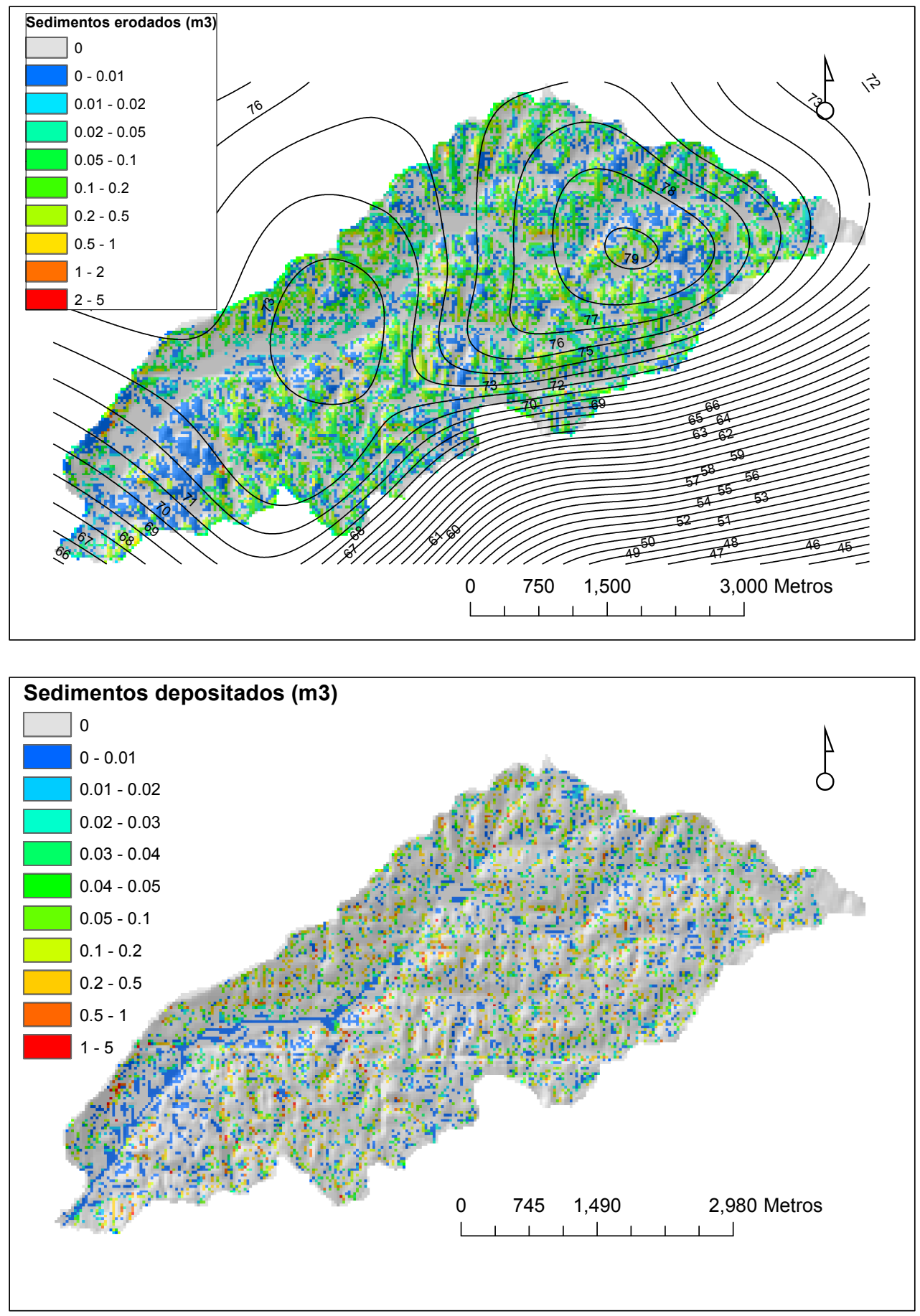

Figura 8.4. Distribución espacial de sedimentos erosionados y depositados para el evento de calibración, volúmenes por celda. Las líneas negras son isoyetas de precipitación acumulada para el evento (en milímetros) 

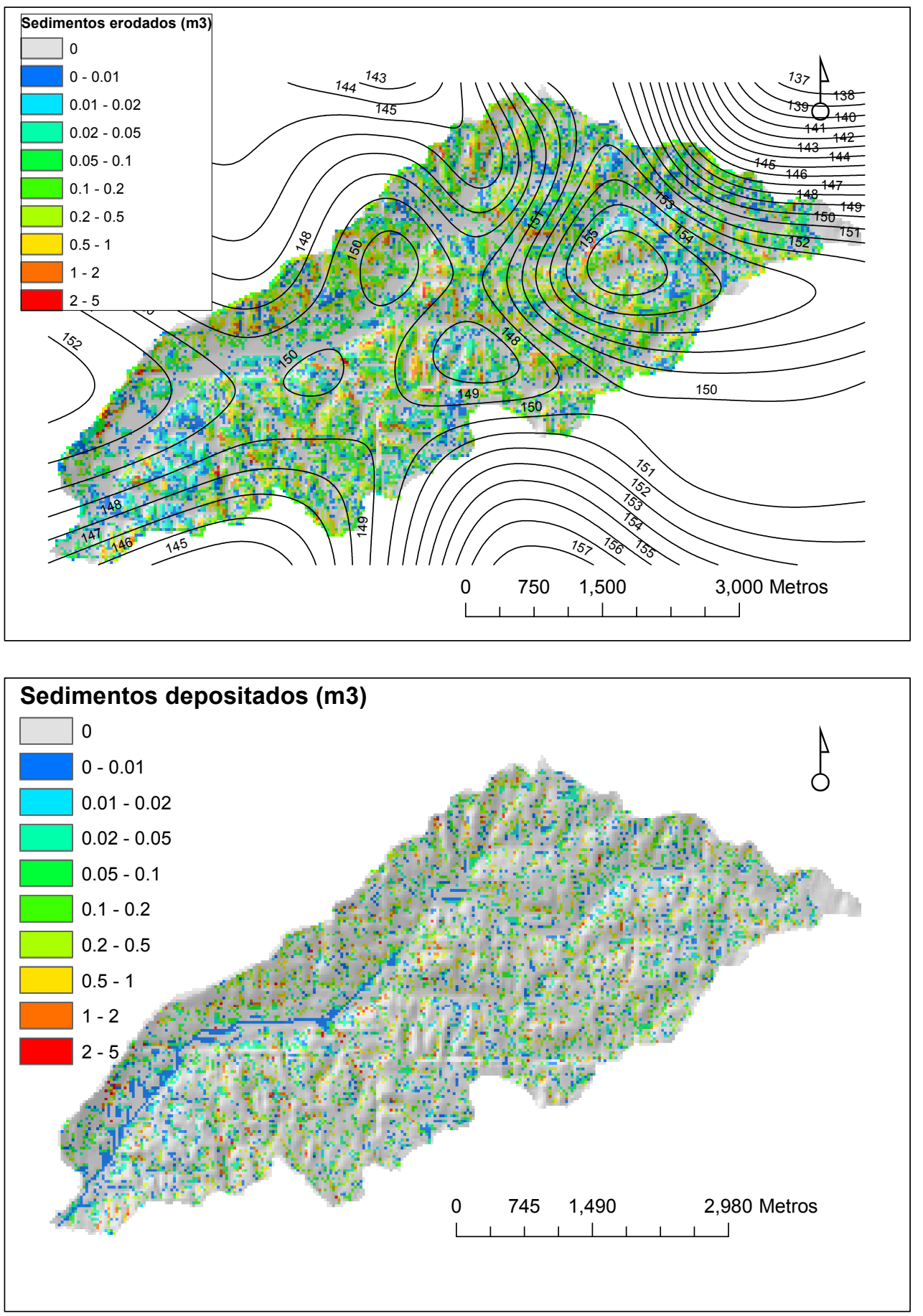

Figura 8.5. Distribución espacial de sedimentos erosionados y depositados para el evento de validación 2, volúmenes por celda. Las líneas negras son isoyetas de precipitación acumulada para el evento (en milímetros) 

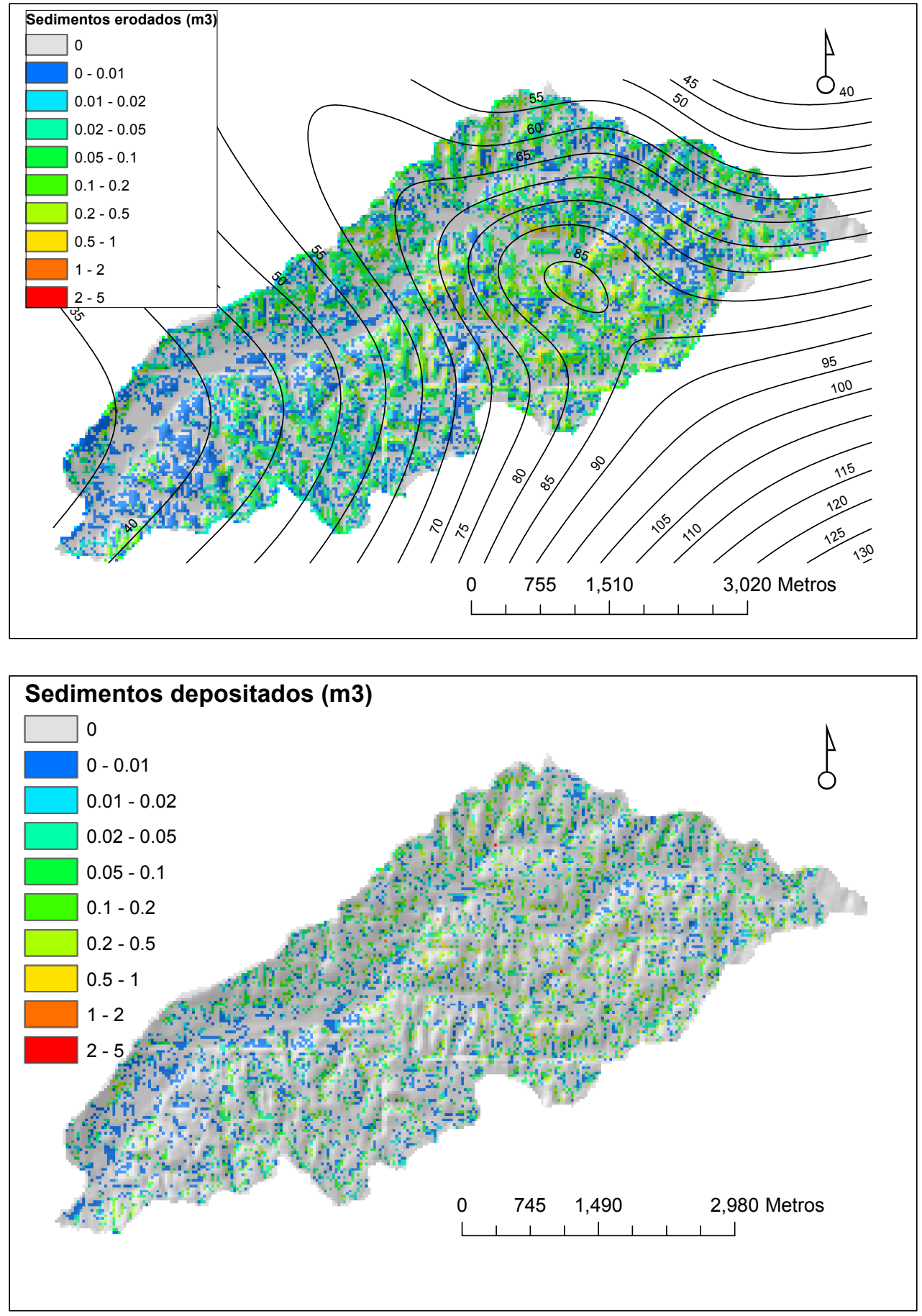

Figura 8.6. Distribución espacial de sedimentos erosionados y depositados para el evento de validación 3, volúmenes por celda. Las líneas negras son isoyetas de precipitación acumulada para el evento (en milímetros) 


\subsection{Las condiciones iniciales de sedimentos}

Para determinar la sensibilidad del modelo ante las condiciones iniciales de sedimentos se han efectuado dos simulaciones con condiciones iniciales de sedimentos depositados diferente de cero: a) con condiciones iniciales iguales a las condiciones finales del mismo evento, y b) con condiciones iniciales iguales a las condiciones finales multiplicadas por un factor de 100.

De esta forma se supone que al iniciar el evento, los tanques correspondientes a los sedimentos depositados, tanto en ladera como en cauces, presentan sedimentos previamente depositados. La utilización del factor multiplicativo responde a la necesidad de asegurar que los sedimentos depositados no sean el factor limitante para los procesos erosivos.

En la figura 8.7 se observan los sedimentogramas totales simulados para los tres escenarios analizados en la estación ubicada en la salida de la cuenca y en el evento de calibración.

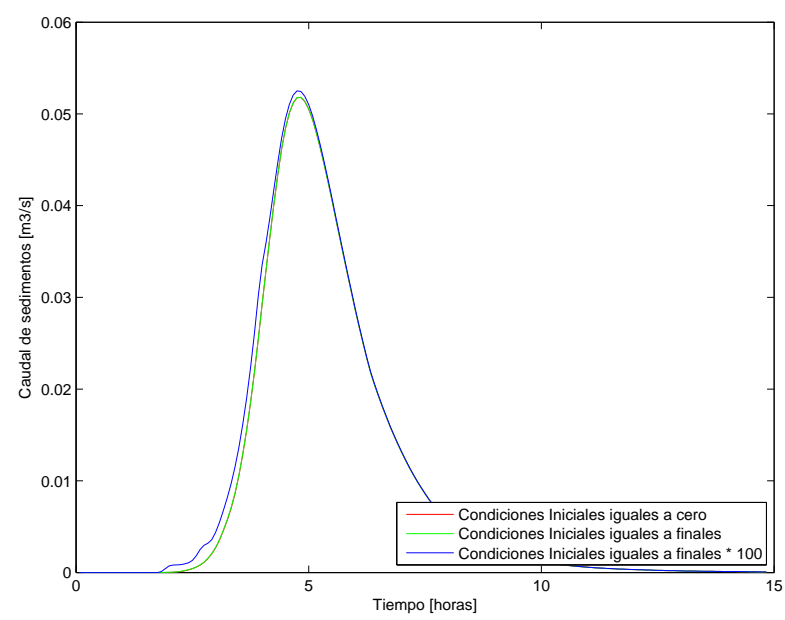

Figura 8.7. Sedimentogramas totales variando las condiciones iniciales de sedimentos en la estación de desagüe y en el evento de calibración

El volumen total de sedimentos generados cuando las condiciones iniciales son iguales a cero es de $485,85 \mathrm{~m}^{3}$, cuando las condiciones iniciales son iguales a las finales es de $486,3 \mathrm{~m}^{3}$ y en el caso de que las condiciones iniciales son iguales a las finales multiplicadas por 100 es de $508,23 \mathrm{~m}^{3}$

El modelo es poco sensible ante las condiciones iniciales de sedimentos y las diferencias sólo son perceptibles al iniciar el evento. La explicación ante este comportamiento se da por el hecho que cuando comienza a encontrarse capacidad de transporte con condiciones iniciales de sedimentos diferentes de cero, dicha capacidad se encargará de removilizar los sedimentos previamente depositados y la capacidad de transporte será el factor limitante, no los sedimentos disponibles. 
Este análisis sólo se tiene sentido en los sedimentos depositados en cauces, puesto que en la ladera la capacidad de transporte del flujo remanente (esto es, luego de transportar los sedimentos depositados) se utiliza para erosionar el suelo in situ.

La utilidad práctica de conservar los sedimentos depositados en un evento e iniciar una simulación con dichos sedimentos es que de esta forma es posible determinar volúmenes depositados para varios eventos. Esta utilidad puede ser implementada para los sedimentos erosionados, de esta forma se agregan los sedimentos y se puede determinar la producción de sedimentos en períodos de tiempo largos.

\subsection{La importancia de la conceptualización del sistema}

Uno de los aspectos novedosos del modelo es la conceptualización del sistema. Al definir áreas umbrales para la iniciación de las diferentes componentes de la escorrentía (escorrentía directa, interflujo y flujo base) y al relacionar estas áreas con la iniciación y finalización de los diferentes elementos del sistema (ladera, cárcava y cauce) se ha logrado una mejora en la respuesta hidrológica y sedimentológica.

Esta afirmación se basa en la comparación de resultados de versiones anteriores del modelo, en las cuales se consideraba que en cada celda se daban todas las componentes de la escorrentía y cada celda presentaba un canal que se encargaba de transportar el agua total producida.

Para comprobar dicha mejora, se efectuó una simulación con áreas umbrales menores que el tamaño de la celda. De esta forma todas las celdas presentan cauce, por el cual se trasladan las tres componentes de la escorrentía (escorrentía directa, interflujo y flujo base).

Las figuras 8.8 y 8.9 muestran los hidrogramas y sedimentogramas simulados para dos escenarios: a) con área umbral para el interflujo de $0,01 \mathrm{~km}^{2}$ y con área umbral para el flujo base de $15,35 \mathrm{Km}^{2}$ y b) con área umbral para el interflujo de $0,002 \mathrm{Km}^{2}$. Puesto que en el caso de la cuenca de análisis las características geomorfológicas de los cauces y las cárcavas no difieren, el modelo no es sensible a los cambios en el área umbral para el flujo base.

En la tabla 8.1 se muestran los resultados de dicha simulación, los cuales se pueden comparar con la tabla 7.3.

El comportamiento del modelo es altamente sensible al área umbral para el interflujo, especialmente en su parte sedimentológica. Puesto que la producción de sedimentos se presenta en ladera, la acumulación del flujo en ladera, teniendo en cuenta un área umbral consecuente con la longitud de las laderas (esto es, el área umbral para el interflujo), asegura una correcta simulación.

Al disminuir el área umbral para el interflujo tanto la erosión como el depósito disminuyen, esto se debe al hecho de que no se acumula el agua en ladera. La 


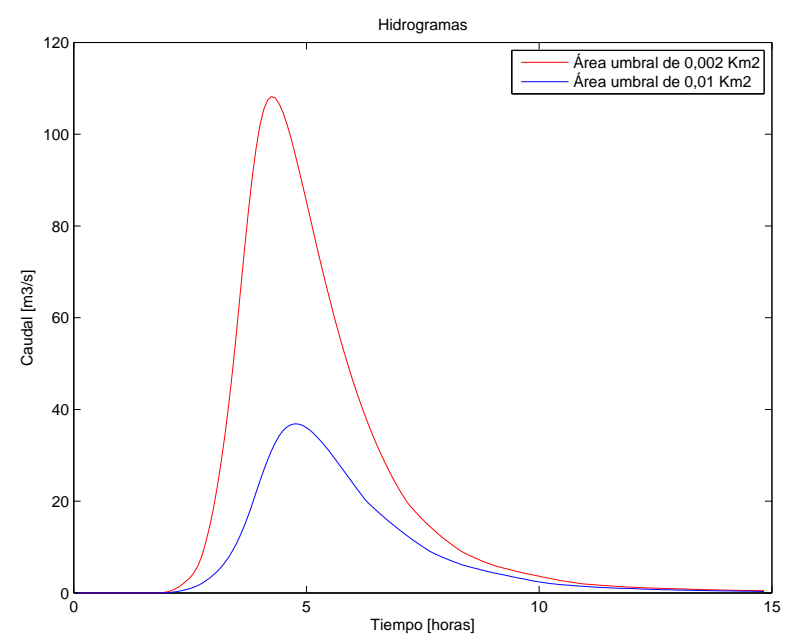

Figura 8.8. Hidrogramas con áreas umbrales para el interflujo (tamaño de ladera) diferentes, en la estación de desagüe y en el evento de calibración

producción total, esto es, los sedimentos que salen de la cuenca son mayores, puesto que la disminución en la erosión es menor que la disminución en el depósito.

Por medio de una recalibración de los factores correctores es posible conseguir hidrogramas y sedimentogramas similares, pero de esta forma, el modelo se aleja de la realidad y posiblemente la validación no sea adecuada.

\subsection{Análisis de cambios ambientales}

Con el modelo es posible efectuar análisis de cambios ambientales y su relación con las dinámicas hidrológicas y sedimentológicas de la cuenca. Con el objeto de mostrar esta aplicación, se simulará el evento de calibración con condiciones ambientales diferentes, específicamente con cambios en los usos del suelo (cambios antrópicos).

Los dos escenarios son:

- La totalidad de la cuenca se encuentra en bosque. Estas eran las condiciones ambientales de la cuenca antes de la llegada de los primeros colonos europeos, a principios del siglo $X I X$. Se espera que las tasas de erosión sean bajas.

- La totalidad de la cuenca se encuentra en pastos. Esta es la situación más adversas desde el punto de vista de la erosión del suelo, en donde se espera que las tasas de erosión sean altas y puede asemejarse a las condiciones anteriores a la repoblación de bosques en la cuenca, esto es a principios del siglo $X X$. 


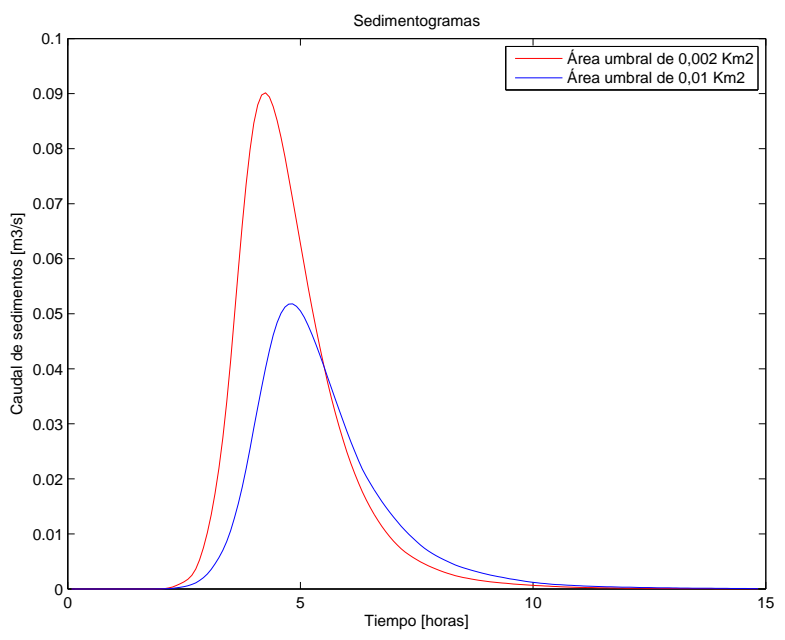

Figura 8.9. Sedimentogramas con áreas umbrales para el interflujo (tamaño de ladera) diferentes, en la estación de desagüe y en el evento de calibración

Estos cambios ambientales se traducen en el modelo en cambios en los mapas de parámetros, específicamente en los mapas de la capacidad de almacenamiento hídrico del suelo y en la conductividad hidráulica saturada del suelo. Los cambios más drásticos se notan en la capacidad de almacenamiento hídrico del suelo, puesto que esta depende de la profundidad de raíces.

En el supuesto de que la cuenca se encuentra en su totalidad en bosques, se estima que la profundidad de raíces es de $200 \mathrm{~cm}$, mientras que cuando se encuentra en pastos es de $40 \mathrm{~cm}$.

En la tabla 8.2 se muestran los valores modales para la capacidad de almacenamiento hídrico del suelo, $H_{u}$ y para la conductividad hidráulica saturada del suelo, $K_{s}$ para las series de suelos de la cuenca de Goodwin Creek en las dos situaciones.

Para encontrar la variabilidad espacial de los parámetros se sigue la metodología descrita en la sección 4.6.1, suponiendo que la curvatura y el índice topográfico (Beven y Kirkby, 1979) son las variables ambientales que dan cuenta de dicha variabilidad.

Para la situación en la que toda la cuenca se encuentra en bosque, el modelo de regresión para la raíz cuadrada de la capacidad de almacenamiento hídrico del suelo es:

$$
\sqrt{H_{u}}=12,95+0,8321 \times I T_{\text {nor }}-3,272 \times C U R V A_{\text {nor }}
$$

El p-valor de la regresión es inferior a 0,01, de este modo existe una relación estadísticamente significativa entre las variables para un nivel de confianza del $99 \%$. El estadístico R-cuadrado es de 19,23\%, indicando que el modelo explica un $19,23 \%$ de la variabilidad de $\sqrt{H_{u}}$. En cuanto al p-valor de las variables dependientes, la constante y los coeficientes toman un valor de 0 , de esta forma son 


\begin{tabular}{|c|c|c|c|}
\hline \multicolumn{2}{|c|}{ Almacenamiento estático } & \multicolumn{2}{c|}{ Sedimentos erosionados } \\
\hline Nivel medio en la cuenca $[\mathrm{mm}]$ & 18,94725 & Arena erosionada $\left[\mathrm{m}^{3}\right]$ & 196,61 \\
\hline Entrada por lluvia $\left[\mathrm{Hm}^{3}\right]$ & 1,51938 & Limo erosionado $\left[\mathrm{m}^{3}\right]$ & 425,67 \\
\hline Flujo de salida de ET $\left[\mathrm{Hm}^{3}\right]$ & 0 & Arcilla erosionada $\left[\mathrm{m}^{3}\right]$ & 141,24 \\
\hline \multicolumn{2}{|c|}{ Agua en superficie } & \multicolumn{2}{c|}{ Sedimentos depositados } \\
\hline Nivel medio en la cuenca $[\mathrm{mm}]$ & 1,25138 & Arena depositada $\left[\mathrm{m}^{3}\right]$ & 50,96 \\
\hline Excedente de Ppt $\left[\mathrm{Hm}^{3}\right]$ & 1,08395 & Limo depositado $\left[\mathrm{m}^{3}\right]$ & 11,34 \\
\hline Escorrentia directa $\left[\mathrm{Hm}^{3}\right]$ & 1,08044 & Arcilla depositada $\left[\mathrm{m}^{3}\right]$ & 0,0 \\
\hline \multicolumn{2}{|c|}{ Almacenamiento gravitatorio } & \multicolumn{2}{c|}{ Sedimentos producidos } \\
\hline Nivel medio en la cuenca $[\mathrm{mm}]$ & 0,04393 & Arena producida $\left[\mathrm{m}^{3}\right]$ & 145,65 \\
\hline Cantidad de infiltración $\left[\mathrm{Hm}^{3}\right]$ & 0,00348 & Limo producido $\left[\mathrm{m}^{3}\right]$ & 414,32 \\
\hline Salida por interflujo $\left[\mathrm{Hm}^{3}\right]$ & 0,00025 & Arcilla producida $\left[\mathrm{m}^{3}\right]$ & 141,22 \\
\hline Perdidas subterráneas $\left[\mathrm{Hm}^{3}\right]$ & 0,00164 & Producción total $\left[\mathrm{m}^{3}\right]$ & $701,, 20$ \\
\hline Error en balance $[\%]$ & $-0,000084$ & Error en balance $[\%]:$ & $-0,00001917$ \\
\hline
\end{tabular}

Tabla 8.1. Resumen de resultados con área umbral para el interflujo de $0,002 \mathrm{Km}^{2}$, en la estación de desagüe y en el evento de calibración

\begin{tabular}{|c|c|c|c|c|}
\hline \multirow{2}{*}{ Serie de suelo } & \multicolumn{2}{|c|}{$H_{u}[\mathrm{~mm}]$} & \multicolumn{2}{c|}{$K_{s}[\mathrm{~cm} /$ hora $]$} \\
\cline { 2 - 5 } & Bosque & Pasto & Bosque & Pasto \\
\hline Calloway & 204,47 & 44,47 & 0,283 & 4,191 \\
\hline Collins & 233,37 & 47,77 & 4,191 & 4,191 \\
\hline Falaya & 250,0 & 50,0 & 4,191 & 4,191 \\
\hline Grenada & 165,43 & 55,68 & 0,177 & 4,191 \\
\hline Loring & 289,28 & 53,23 & 0,214 & 4,191 \\
\hline Memphis & 278,41 & 46,4 & 4,191 & 4,191 \\
\hline Zonas con cárcavas & 34,8 & 11,6 & 4,191 & 4,191 \\
\hline
\end{tabular}

Tabla 8.2. Valores de la capacidad de almacenamiento hídrico $\left(H_{u}\right)$ y la conductividad hidráulica saturada del suelo $\left(K_{s}\right)$ para los dos escenarios

estadísticamente significativos para un nivel de confianza del $99 \%$.

Y el modelo de regresión para el logaritmo natural de la conductividad hidráulica saturada del suelo es:

$$
\ln K_{s}=-0,1173-2,144 \times I T_{\text {nor }}+1,014 \times C U R V A_{\text {nor }}
$$

El p-valor de la regresión es inferior a 0,01, de este modo existe una relación estadísticamente significativa entre las variables para un nivel de confianza del $99 \%$. El estadístico R-cuadrado es de 44,1\%, indicando que el modelo explica un 44,1\% de la variabilidad de $\ln K_{s}$. En cuanto al p-valor de las variables dependientes, los coeficiente de $I T_{\text {nor }}$ y de $C U R V A_{\text {nor }}$ toman un valor de 0 , de esta forma son estadísticamente significativos para un nivel de confianza del $99 \%$; mientras que el p-valor de la constante es de 0,2035, señalando que este término no es significa- 
tivamente estadístico para un nivel de confianza del $80 \%$ o superior.

Para la situación en la que toda la cuenca se encuentra en pastos, el modelo de regresión para la raíz cuadrada de la capacidad de almacenamiento hídrico del suelo es:

$$
\sqrt{H_{u}}=6,020+0,5476 \times I T_{\text {nor }}-1,003 \times C U R V A_{\text {nor }}
$$

El p-valor de la regresión es inferior a 0,01, de este modo existe una relación estadísticamente significativa entre las variables para un nivel de confianza del $99 \%$. El estadístico R-cuadrado es de 32,16\%, indicando que el modelo explica un $32,16 \%$ de la variabilidad de $\sqrt{H_{u}}$. En cuanto al p-valor de las variables dependientes, la constante y los coeficientes toman un valor de 0 , de esta forma son estadísticamente significativos para un nivel de confianza del $99 \%$.

En las ecuaciones $8.1-8.3, I T_{n o r}$ y $C U R V A_{n o r}$ son como están definidas en las ecuaciones 6.3 y 6.4 .

En el caso de la conductividad hidráulica saturada del suelo cuando la cuenca se encuentra totalmente en pastos, no es posible determinar un modelo de regresión para la variabilidad espacial, puesto que en toda la cuenca se presenta el mismo valor modal. Para este caso el valor asignado para toda la cuenca es de $4,191 \mathrm{~cm} /$ hora.

Los estados de humedad inicial para los dos escenarios son los mismos que para el evento de calibración, esto es, todos los tanques se encuentran vacíos y no se modificaron los factores correctores de calibración.

La figura 8.10 muestra los hidrogramas simulados para los tres escenarios (bosque, pastos y actual).

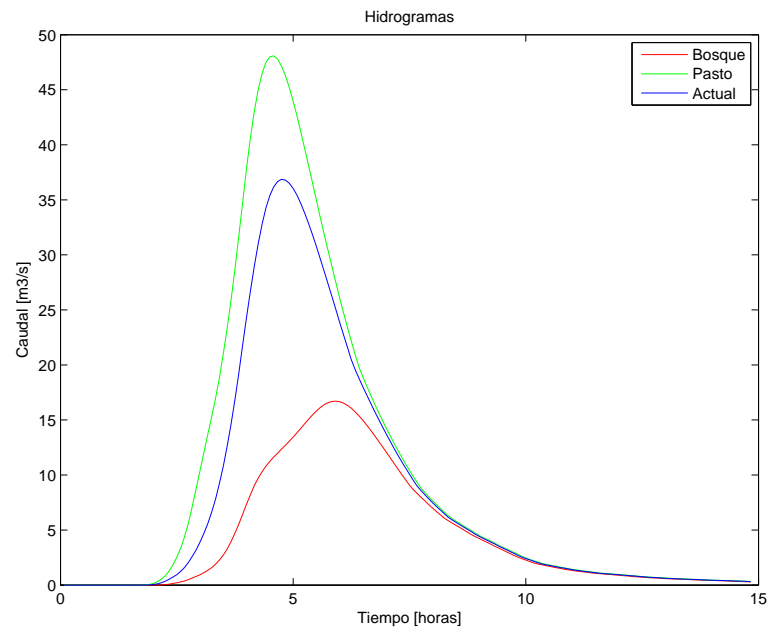

Figura 8.10. Hidrogramas para los tres escenarios

El modelo simula un hidrograma con picos más bajos y con volumen menor en el caso de que la cuenca esté en su totalidad en bosques. La diferencia no es tan 
notable, con respecto a la situación actual, cuando la cuenca está en pastos, en este caso el caudal pico y los volúmenes producidos son muy cercanos a la situación actual.

En la figura 8.11 se observan los sedimentogramas simulados.

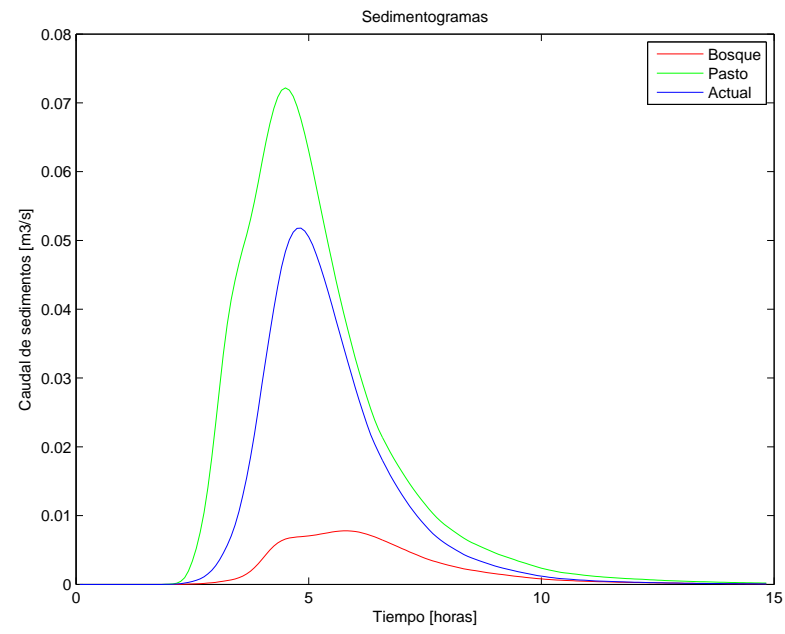

Figura 8.11. Sedimentogramas para los tres escenarios

En este caso se hace evidente las mayores tasas de erosión en el caso más desfavorable (pastos), mientras que se nota una disminución significativa de producción de sedimentos en el caso de que la cuenca se encuentre en bosques. Estas diferencias se aprecian en la tabla resumen 8.3.

\begin{tabular}{|c|c|c|c|}
\hline Escenario & Actual & Pastos & Bosques \\
\hline Caudal máximo $\left[\mathrm{m}^{3} / \mathrm{s}\right]$ & 36,86 & 48,07 & 16,71 \\
\hline Volumen de agua $\left[\mathrm{Hm}^{3}\right]$ & 0,431 & 0,541 & 0,242 \\
\hline Sedimentos erosionados $\left[\mathrm{m}^{3}\right]$ & 1257,14 & 3280,82 & 351,56 \\
\hline Sedimentos depositados $\left[\mathrm{m}^{3}\right]$ & 770,97 & 2501,90 & 242,73 \\
\hline Sedimentos producidos $\left[\mathrm{m}^{3}\right]$ & 485,85 & 777,67 & 108,83 \\
\hline
\end{tabular}

Tabla 8.3. Resumen de resultados para los escenarios analizados 


\section{Capítulo 9}

\section{Conclusiones}

En esta tesis se ha desarrollado un modelo de erosión, transporte y depósito de sedimentos a escala de cuenca. La hipótesis de trabajo, esto es, la formulación del modelo, se basa en la forma en que actualmente se responden las preguntas fundamentales de la dinámica hidrológica y sedimentológica de una cuenca hidrográfica ante un evento de lluvia y en la experiencia adquirida por el autor de la tesis en la aplicación de modelos hidrológicos y sedimentológicos.

Con estas bases teóricas y prácticas se ha desarrollado un código de programación con los postulados de la formulación y se ha aplicado el modelo en una cuenca natural. Al aplicar el modelo se acepta como válida la hipótesis de trabajo. La cuenca de análisis es la cuenca de Goodwin Creek en el estado de Mississippi, en Estados Unidos de América. En la aplicación se reconocen las limitaciones y potencialidades del modelo.

A continuación se resumen las conclusiones generales de la tesis, los aspectos novedosos que constituyen un aporte en el tema en cuestión y los futuros desarrollos y líneas de investigación abiertas.

\subsection{Conclusiones generales}

\subsubsection{Conclusiones del marco teórico}

- De la revisión de la evolución del conocimiento de los modelos de evolución del paisaje y de los modelos de erosión queda clara la complejidad de las dinámicas hidrológicas y sedimentológicas que dan cuenta del comportamiento de una cuenca ante un evento de lluvia. Para acercase a dicha complejidad es necesario tener en consideración la variabilidad espacial y temporal tanto de los procesos relevantes como de los parámetros que describen dichos procesos. Además es necesario tener una adecuada representación de la cuenca, esto se logra definiendo el sistema, sus elementos y la forma de conectar dichos elementos. 
- Una forma adecuada para representar la topografía es a partir de modelos de elevación digital con estructura matricial, en los cuales cada elemento presenta un área cuadrada. Además de permitir la incorporación de técnicas de resolución de ecuaciones en diferencias finitas en todos los elementos de discretización, permiten desarrollar estrategias de interpolación con facilidad. Por otro lado, es fácil y directo derivar información topográfica útil para la parametrización de modelos hidrológicos y sedimentológicos (pendiente, aspecto, dirección de flujo, índices de humedad y erosión, etc.). Por último a partir de un Modelo de Elevación Digital es posible definir las áreas fuentes para procesos erosivos (su iniciación y finalización).

- Son varios los procesos que dan cuenta de la respuesta hidrológica y sedimentológica de una cuenca hidrográfica. La importancia de estos procesos no solo depende de las condiciones particulares de cada cuenca sino del régimen de humedad a la que está sometida (estados de humedad, períodos de recesión o períodos de lluvia). Un modelo debe contar con una estrategia clara para definir los procesos relevantes, tanto hidrológicos y sedimentológicos y debe tener en consideración los estados de humedad inicial, si este es un modelo de evento.

- Los procesos hidrológicos que tienen más relevancia en cuanto a la dinámica sedimentológica son los flujos superficiales y los flujos subsuperficiales de agua en los primeros niveles del suelo, estos procesos se presentan en períodos de lluvia, en los cuales se da la movilización de sedimentos (producción, transporte y sedimentación), por lo cual deben ser bien entendidos y convenientemente simulados.

\subsubsection{Conclusiones de la formulación del modelo}

- Una formulación coherente y que tenga en cuenta todos los aspectos del modelo (conceptualización, procesos relevantes, estimación de parámetros) garantiza su aplicación en diferentes ambientes. El nuevo modelo comprende de forma integral los aspectos necesarios para implementarlo en una cuenca natural, de esta forma es comprensible y fácil de implementar.

- Debido a la gran cantidad de parámetros que es necesario estimar en modelos de erosión con base física para cada elemento de discretización y a la alta incertidumbre de estos parámetros, se justifica utilizar modelos simples con pocos parámetros, más si el modelo es a escala de cuenca.

- En esta tesis se ha demostrado que la utilización de la ecuación de Kilinc y Richardson, modificada por Julien (1998) para la producción de sedimentos en ladera y la ecuación de Engelund y Hansen para la capacidad de transporte de sedimentos en cauce son adecuadas para un modelo de erosión a escala de cuenca. 
- Es de resaltar que el único elemento de calibración necesario para el submodelo sedimentológico sea el factor corrector de Kilinc y Richardson, mientras que la ecuación de Engelund y Hansen, al basarse íntegramente en aspectos hidráulicos de cada sección del cauce no exige de factores correctores. Esta simplicidad hace el modelo robusto y parsimonioso.

- La mejor estrategia para acercarse a la dinámica sedimentológica de una cuenca pasa por simular adecuadamente la dinámica hidrológica. El modelo formulado aplica dicha estrategia con buenos resultados.

\subsubsection{Conclusiones de la aplicación del modelo}

- Un buen conocimiento de las condiciones físicas de la cuenca de análisis, específicamente de aquellas que den cuenta de las dinámicas hidrológicas y sedimentológicas, asegura una adecuada estimación de parámetros. Esta estimación de parámetros necesariamente debe reflejar la variabilidad espacial, más si el modelo es distribuido en el espacio.

- En la aplicación de un nuevo modelo se justifica utilizar una cuenca experimental, en la cual haya disponibilidad de datos para su implementación. Además es fundamental que dicha cuenca tenga suficientes estudios y aplicación de diferentes modelos con el objeto de comparar los datos arrojados por el nuevo modelo con otras aplicaciones ya probadas.

- El desempeño del modelo es adecuado. Al contrastar los resultados del modelo, específicamente el comportamiento sedimentológico, con otras aplicaciones en la cuenca de Goodwin Creek se observa que, en general, el modelo simula con buen desempeño tanto el comportamiento hidrológico como el sedimentológico de la cuenca en eventos de lluvia.

- Tomando en cuenta la complejidad inherente a las dinámicas hidrológicas y sedimentológica, las diferencias entre los resultados del modelo y los datos observados en los hidrogramas y sedimentogramas de salida de los eventos y en las estaciones de aforo analizadas son asumibles.

- Con el modelo es posible determinar zonas de producción de sedimentos y zonas de acumulación o sumideros de sedimentos. Además permite visualizar dichas zonas con mapas distribuidos en el espacio y así efectuar comparaciones con variables ambientales distribuidas espacialmente.

- El modelo es poco sensible ante las condiciones iniciales de sedimentos y las diferencias sólo son perceptibles al iniciar el evento. La utilidad práctica de conservar los sedimentos depositados en un evento e iniciar una simulación con dichos sedimentos es que de esta forma es posible determinar volúmenes depositados para varios eventos. 
- El comportamiento del modelo es altamente sensible a las áreas umbrales para el interflujo y para el flujo base, especialmente en su parte sedimentológica. Puesto que la producción de sedimentos se presenta en ladera, la acumulación del flujo en ladera, teniendo en cuenta un área umbral consecuente con la longitud de las laderas (esto es, el área umbral para el interflujo), asegura una correcta simulación.

- De los resultados del modelo se aprende acerca de la dinámica hidrológica y sedimentológica de la cuenca. Con el programa computacional es posible efectuar análisis cuantitativos de cambios ambientales y antrópicos en una cuenca hidrográfica ante su comportamiento hidrológico y sedimentológico. De esta forma tiene una aplicabilidad no sólo científica, al generar conocimiento y ayudar a la comprensión de procesos naturales, sino también práctica, al ser una herramienta para el diseño ingenieril, el planeamiento del territorio y el análisis de riesgos naturales.

\subsection{Aportes de la tesis}

\subsubsection{Aportes del desarrollo del modelo}

El modelo desarrollado y la herramienta computacional obtenida son ya de por si aportes importantes. El modelo está basado en desarrollos anteriores: en su parte hidrológica en el modelo TETIS desarrollado en el Departamento de Ingeniería Hidráulica y Medio Ambiente de la Universidad Politécnica de Valencia y en su parte sedimentológica en el modelo CASC2D-SED desarrollado en el Engineering Research Center de la Colorado State University. El nuevo modelo toma ventaja de las potencialidades de los dos modelos y genera aportes novedosos, tales como:

- Al determinar de manera precisa en que zonas de la cuenca se presentan las diferentes componentes de la escorrentía y al relacionar dichas zonas con elementos concretos, es posible aplicar las ecuaciones para erosión, transporte y depósito de sedimentos tanto en ladera como en cauces de forma correcta.

- El modelo logra relacionar de forma adecuada el tamaño de la ladera con el tamaño de celda. En esta tesis se aplicó por primera vez el modelo TETIS con un tamaño de celda menor que el tamaño de ladera. Los modelos hidrológicos y sedimentológicos actuales no definen de manera precisa en que zonas de la cuenca se presentan las diferentes componentes de la escorrentía. Además, el modelo relaciona dichas zonas con elementos concretos (ladera para la escorrentía directa, cárcava para el interflujo y cauce para el flujo base) a partir de parámetros fácilmente identificables en una cuenca natural. Así el modelo diseñado mejora la forma de conceptualizar una cuenca y a partir de este aporte se logran mejores desempeños en cuanto a la respuesta de una cuenca hidrográfica ante un evento de lluvia. 
- La mayor parte de modelos efectúan grandes esfuerzos en considerar la distribución y geometría de surcos, estos elementos son en esencia aleatorios, mientras que la red de cárcavas y de cauces presentan estructuras topológicas conectadas y definidas y sus características geométricas responden a condiciones físicas. El modelo aprovecha convenientemente el conocimiento de dichas condiciones físicas y deja de lado aspectos poco entendidos y difíciles de parametrizar.

- La inclusión del factor corrector de Kilinc y Richardson para la erosión en ladera es un aporte novedoso. En las aplicaciones del modelo CASC2D-SED la calibración de la parte sedimentológica se efectuaba a partir de los factores de la USLE.

- En la herramienta computacional desarrollada se mejoraron diversos aspectos del modelo TETIS: se modificaron los ficheros de entrada, especificamente aquellos correspondientes a los aspectos sedimentológicos (mapas de textura del suelo, mapas de factores de la USLE); se efectuaron cambios en las interfaces del programa (inclusión de parámetros sedimentológicos); se incluyó los algoritmos de producción, transporte y depósito de sedimentos; se incluyeron nuevos parámetros geomorfológicos, para diferenciar cárcavas de cauces.

\subsubsection{Aportes de la estimación de parámetros}

- Se desarrolló una herramienta computacional destinada a automatizar el proceso de estimación de parámetros. Anteriormente dicha estimación se efectuaba manualmente. Puesto que el proceso es altamente demandante en aplicaciones de Sistemas de Información Geográfica y para llegar a una adecuada estimación es necesario efectuar muchos pasos, con la automatización se reduce drásticamente el tiempo de trabajo. Con esta herramienta es posible determinar mapas de parámetros distribuidos en el espacio (a nivel de celda) sin la necesidad de tener conocimientos avanzados en SIG.

- Anteriormente el proceso final de estimación de parámetros se efectuaba según análisis de regresiones. Puesto que la incertidumbre en los mapas de entrada es muy alta, al tratarse de mapas con valores estimados para cada unidad cartográfica, con pocos (o nulos) valores medidos en campo, el análisis de regresión parece no ser muy adecuado. En esta tesis de utilizaron regresiones pero con restricciones definidas a priori, específicamente se definió que la variabilidad espacial de los parámetros hidrológicos a escala de celda (capacidad de almacenamiento hídrico y conductividad hidráulica saturada del suelo) está determinada por el Índice Topográfico de Humedad y la Curvatura del terreno. Esta restricción se basa en investigaciones anteriores. 


\subsubsection{Aportes de la aplicación del modelo}

- Un aporte de la tesis deriva en la aplicación en la cuenca de Goodwin Creek. A partir de esta aplicación se logra una mayor comprensión de las dinámicas hidrológicas y sedimentológicas en esta cuenca, como se comprueba con los análisis de sensibilidad ante el tamaño de ladera, el análisis ante diferentes condiciones iniciales de sedimentos y el análisis ante cambios ambientales.

\subsection{Futuras líneas de investigación}

Si se entiende una tesis doctoral como el comienzo de una carrera de investigación, es recomendable que de la lectura de la tesis se planteen cuestiones abiertas. Algunas de estas cuestiones, convenientemente formuladas, pueden llegar a constituir futuras líneas de investigación. A continuación se resumen las preguntas abiertas de la tesis:

- El modelo considera áreas umbrales para la definición de los elementos del sistema. En realidad, el inicio y finalización de estos elementos dependen tanto del área como de la pendiente local. De esta forma, es necesario incluir la pendiente y comprobar con observaciones de campo si se mejora en la representación de los elementos. Cabe esperarse que dicha inclusión no tenga una relevancia significativa en el desempeño del modelo, pero se logra una mejor representación de la realidad.

- El modelo diseñado puede considerarse el corazón de un modelo geomorfológico de evolución del paisaje. Una línea de investigación prominente es la inclusión de procesos de escala temporal amplia (meteorización y formación de suelos, tectónica, cambios climáticos, cambios locales de las geoformas) y efectuar análisis de evolución del paisaje.

- El modelo no efectúa cambios en la topografía, aunque es fácil y rápido de implementar, puesto que para cada celda se calcula tanto la erosión y la depositación. En realidad, los sedimentos erosionados y depositados no se distribuyen uniformemente en toda la celda, por ejemplo, en el caso de los depósitos, estos se concentran en llanuras de inundación y remansos de los cauces. Estos elementos no se detallan en la actual conceptualización del sistema. Una pregunta que puede apuntar a una línea de investigación es la forma de considerar dichas geoformas adecuadamente.

- Una forma de utilizar el modelo con agregación temporal anual es efectuar simulaciones con series temporales anuales, aunque sería más eficiente determinar a priori cuales eventos movilizan sedimentos en determinado año, simularlos con el modelo y agregar los resultados. Esta aplicación puede considerarse una linea de investigación. 
- El modelo en su parte sedimentológica sólo presenta un factor corrector para la erosión en ladera (factor corrector de la ecuación de Kilinc y Richardson). Una posible mejora en el modelo es la inclusión de un factor corrector para el transporte de sedimentos en cauces (ecuación de Engelund y Hansen). De esta forma será posible calibrar no sólo la producción de sedimentos en ladera sino también el transporte de sedimentos en canales y así tener más control en los procesos sedimentológicos. Al tener dos factores correctores es posible aplicar herramientas de calibración automática (por ejemplo el método denominado SCE-UA) y mejorar aspectos tales como la relación caudal líquido - caudal sólido durante un evento (curvas de histéresis). Esta mejora constituye un desarrollo futuro.

- El modelo no considera fuentes puntuales de sedimentos, tales como movimientos en masa. La presencia de deslizamientos y socavamiento en cauces está relacionada con características locales (fallas, taludes inestables, discontinuidades en los primeros niveles del suelo). Una forma de incorporar estas fuentes de sedimentos es con la inclusión de información cartográfica de procesos erosivos. Una línea de investigación abierta surge de la pregunta de cómo incorporar esta información en el modelo.

- Los sedimentos son ya de por si contaminantes de las aguas que los transportan, pero además tiene relevancia en el transporte de otros contaminantes. Analizar la relación entre el caudal sólido y los contaminantes que se mueven en dichos sedimentos constituye otra línea de investigación posible. 


\section{Referencias bibliográficas}

Abbott, M. B., Bathurst, J. C., Cunge, J. A., O'Connell, P. E. y Rasmussen, J., 1986a. An Introduction to the European Hydrological System - Système Hydrologique Européen, "SHE", 1: History and philosophy of a Physically Based, distributed modelling system. Journal of Hydrology, 87, 45-59.

Abbott, M. B., Bathurst, J. C., Cunge, J. A., O’Connell, P. E. y Rasmussen, J., 1986b. An Introduction to the European Hydrological System - Système Hydrologique Européen, "SHE", 2: Structure of a physically - based, distributed modelling system. Journal of Hydrology, 87, 61-77.

Abrahams, A. D., G., L., C., K. y Atkinson, J. F., 2001. A sediment transport equation for interrill overland flow on rough surfaces. Earth Surface Processes and Landforms, 26, 1443-1459.

Aguirre-Pe, J., Machado, D. A., Moncada, A. y Olivero, M. L., 2006. Los mejores modelos de transporte de sedimentos. XXII Congreso Latinoamericano de Hidráulica, Ciudad Guyana, Venezuela.

Allen, J., 1974. Reaction, relaxation and lag in natural sedimentary system: general principles, examples and lessons. Earth Science Review, 10, 263-342.

Arnold, J., Williams, J., Srinivasan, R., King, K. y Griggs, R., 1995. SWAT - Soil and Water Assessment Tool: Draft Users Manual. US Department of Agriculture, Agricultural Research Service, Temple, TX.

Asselman, N., Middelkoop, H. y Van Dijk, P., 2003. The impact of changes in climate and land use on soil erosion, transport and deposition of suspended sediment in the River Rhine. Hydrological Processes, 17, 3225-3244.

Bagnold, R. A., 1966. An approach to the sediment transport problem from general physics. U.S Geological Survey, Professional Paper, 422-I.

Bagnold, R. A., 1977. Bed load transport by natural rivers. Water Resources Research, 13, 303-312. 
Band, L., 1986a. Analysis and representation of drainage basin structure with digital elevation data. Proceedings, Second International Symposium on Spatial Data Handling, págs. 437-450.

Band, L., 1986b. Topographic partition of watersheds with digital elevation models. Water Resources Research, 22, 15-24.

Band, L., 1989. A terrain - based watershed information system. Hydrological Processes, 3, 151-162.

Band, L. E., 1999. Spatial hydrography and landforms. En P. Longley, M. Goodchild, D. Maguire y D. Rhind, eds., Geographical Information Sistem, Volume 1. Principles and Technical Issues, págs. 527-542. Wiley.

Barling, R. D., Moore, I. D. y Grayson, R. B., 1994. A quasi - dynamic wetness index for characterizing the spatial distribution of zones of surface saturation and soil water content. Water Resources Research, 30, 1029-1044.

Beasley, D., Huggins, L. y Monke, E., 1980. ANSWER: a model for watershed planning. Transactions of the American Society of Agricultural Engineers, 23, 939-944.

Betson, R. P., 1964. What is watershed runoff? Journal of Geophysical Research, 69, 1541-1551.

Beven, K., 1989. Changing ideas in hydrology, The case of physically - based models. Journal of Hydrology, 105, 157-172.

Beven, K., 2001a. The Dalton Lecture: How far can we go in distributed hydrological modelling? Hydrology and Earth System Sciences, 5, 1-12.

Beven, K., 2001b. Rainfall - Runoff Modelling, The Primer. Jhon Wiley and Sons, Ltd.

Beven, K. J., 1993. Prophecy, reality and uncertainty in distributed hydrological modelling. Advances in Water Resources, 16, 41-51.

Beven, K. J. y Binley, A. M., 1992. The future of distributed models: model calibration and uncertainty prediction. Hydrological Processes, 6, 279-298.

Beven, K. J. y Kirkby, M. J., 1979. A phyisically - based variable contributing area model of basin hydrology. Bulletin of Hydrological Sciences, 24, 43-69.

Birot, P., 1958. Morphologie Structurale, 2. Presses Universitaires de France, Paris. 
Blackmarr, W. A., 1995. Documentation of Hydrologic, Geomorphic, and Sediment Transport Measurements on the Goodwin Creek Experimental Watershed, Northern Mississippi, for the Period 1982 - 1993. Research Report 3, National Sedimentation Laboratory, Agricultural Research Service of United States Department of Agriculture.

Blösch, G., Grayson, R. B. y Sivapalan, M., 1995. On the representative elementary area (REA) concept and its utility for distributed rainfall - runoff modelling. Hydrological Processes, 9, 313-330.

Blöschl, G. y Sivapalan, M., 1995. Scale issues in hydrological modelling: a review. En J. Kalma y M. Sivapalan, eds., Scale Issues in Hydrological Modelling, págs. 9-48. Wiley.

Boardman, J., 2006. Soil erosion science: Refelctions on the limitations of current approaches. Catena, 68, 73-86.

Bradford, J. y Piest, R., 1980. Erosional development of valley-bottom gullies in the upper midwestern United Status. En D. Coates y J. Vitek, eds., Geomorphic Thresholds, págs. 75-101. Dowden and Culver.

Braun, J. y Sambridge, M., 1997. Modelling landscape evolution on geological time scales: a new method based on irregular spatial discretization. Basin Research, $9,27-52$.

Bronstert, A., 1999. Capabilities and limitations of detailed hillslope hydrological modelling. Hydrological processes, 13, 21-48.

Brunsden, D. y Jones, D., 1984. The geomorphology of high magnitude - low frecuency events in the Karakoram Mountains. International Karakoram Project, $1,383-388$.

Brunsden, D. y Thornes, J., 1979. Landscape sensitivity and change. Transactions of the Institute of British Geographers, 4, 463-484.

Bryan, R., 1987. Processes and significance or rill development. Rill erosion, Catena Supplement, 8, 1-15.

Campbell, I. A., 1981. Spatial and Temporal Variations in Erosion Measurements. Erosion and Sediment Transport Measurement, IAHS-AISH, 133, 448-456.

Casalí, J., López, J. y Giráldez, J., 1999. Ephemeral gully erosion in southern Navarra. Catena, 36, 65-84.

Cerdan, O., Souchère, V., Lecomte, V., Couturier, A. y Le Bissonnais, Y., 2002. Incorporating soil surface crusting processes in an expert-based runoff and erosion model STREAM (Sealing Transfer Runoff Erosion Agricultural Modification). Catena, 46, 189-205. 
Chorley, R., 1972. Spatial Analysis in Geomorphology. Methuen, London.

Chorley, R. y Kennedy, B., 1971. Physical Geography. A Systems Approach. Prentice-Hall, London.

Chorley, R., Schumm, S. y Sugden, D., 1984. Geomorphology. Methuen, London.

Coulthard, T., 2001. Landscape evolution models: a software review. Hydrological Processes, 15, 165-173.

Coulthard, T. J., Kirkby, M. J. y Macklin, M. G., 1999. Modelling the impacts of Holocene environmental change on the fluvial and hillslope morphology of an upland landscape, using a cellular automaton approach. En A. G. Brown y T. M. Quine, eds., Fluvial Processes and Environmental Change, págs. 31-47. Wiley: New York.

Coulthard, T. J., Kirkby, M. J. y Macklin, M. G., 2000. Modelling geomorphic response to environmental change in an upland catchment. Hydrological Processes, 14, 2031-2045.

Crozier, M., 1999. The frequency and magnitude of geomorphic processes and landform behaviour. Zeitschrift f"ur Geomorphologie Suppl, 115, 35-50.

Davis, W., 1899. The Geographical Cycle. The Geographical Journal, 14, 481-504.

De Jong, S., Paracchini, M., Bertolo, F., Folving, S., Megier, J. y De Roo, P., 1999. Regional assessment of soil erosion using the distributed model SEMMED and remotely sensed data. Catena, 37, 291-308.

De Pedraza, J., 1996. GEOMORFOLOGÍA: Principios, Métodos y Aplicaciones. Editorial Rueda, Madrid.

De Ploey, J., 1984. Hydraulics of runoff and loess loam deposition. Earth Surface Processes and Landforms, 9, 533-539.

De Ploey, J. y Poesen, J., 1987. Some reflections on modelling hillslope processes. Geomorphological Models, Theoretical and Empirical Aspect. Catena Supplement, 10, 67-72.

Derruau, M., 1978. Geomorfología. Ariel, Barcelona.

Desmet, P. J. J. y Govers, G., 1997. Two - dimensional modelling of the within - field variation in rill and gully geometry and location related to topography. Catena, 29, 283-306.

Douglas, D., 1986. Experiments to locate ridges and channels and create a new type of digital elevation model. Cartographica, 23, 29-61. 
Duan, Q. S., Sorooshian, S. y Gupta, V., 1992. Effective and efficient global optimisation for conceptual rainfall - runoff models. Water Resources Research, $28,1015-1031$.

Dunne, T., 1998. Wolman Lecture: Hydrologic Science...in Landscapes...on a Planet...in the Future. En Hydrologic Sciences: Taking Stock and Looking Ahead, págs. 10-43. National Academy Press, Washington, D.C.

Dunne, T. y Black, R. D., 1970. An experimental investigation of runoff production in permeable soils. Water Resources Research, 6, 478-490.

Dury, G., 1970. Essay in Geomorphology. Heinemann, London.

Engeln, O., 1948. Geomorphology. Macmillan, New York.

Ewen, J., Parkin, G. y O'Connell, P., 2000. SHETRAN: a couple surface / subsurface modelling system for $3 \mathrm{D}$ water flow and sediment and solvent transport in river basin. ASCE Journal of Hydrologic Engineering, 5, 250-258.

Favis-Mortlock, D., Boardman, J., Parson, A. y Lascelles, B., 2000. Emergence and erosion: a model for rill initiation and development. Hydrological Processes, $14,2173-2205$.

Favis-Mortlock, D., Boardman, J. y MacMillan, V., 2001. The Limits of Erosion Modelling: Why We Should Proceed with Care. En R. Harmon y W. Doe III, eds., Landscape Erosion and Evolution Modelling, págs. 477-516. Kluwer Academic Plenum Publishing, New York.

Favis-Mortlock, D. T., 1998. A self - organising dynamic systems approach to the simulation of rill initiation and development on hillslopes. Computers and Geosciences, 24, 353-372.

Fernández Bono, J. F., Ortiz Andrés, E. y Domínguez Sánchez, C., 1995. Hidráulica Fluvial. Procesos de la mecánica del flujo bifase agua - sedimentos en cauces naturales. Servicio de Publicaciones. Universidad Politécnica de Valencia.

Flanagan, D. y Nearing, M., 1995. USDA - Water Erosion Prediction Project Hillslope Profile and Watershed Model Documentation. NSERL Report No.10. USDA - ARS National Soil Erosion Research Laboratory, West Lafayette, IN.

Fohrer, N., Berkenhagen, J., Hecker, J. y Rudolph, A., 1999. Changing soil and surface conditions during rainfall. Single rainstorm / subsequent rainstorm. $\mathrm{Ca}$ tena, 37, 355-375.

Follett, R. y Stewart, B., 1985. Soil Erosion and Crop Productivity. American Society of Agronomy. Madison, WI. 
Foster, G. R., 1982a. Channel erosion within farm fields. American Society of Civil Engineers, New York.

Foster, G. R., 1982b. Channel erosion within farm fields. American Society of Civil Engineers, 7, 82-107.

Foster, G. R., 1986. Understanding Ephemeral Gully Erosion. En N. R. C. Board on Agriculture, ed., Soil Conservation: An Assessment of the National Resources Inventory, Volume 2, págs. 90-128. National Academy Press, Washington.

Foster, G. R. y Ferreira, V. A., 1981. Deposition in uniform grade terrace channels. American Society of Agricultural Engineers, 7, 185-197.

Foster, G. R. y Meyer, L. D., 1972. Transport of soil particles by shallow flow. Trans. ASAE, 15, 99-102.

Foster, G. R. y Wischmeier, W. H., 1974. Evaluating irregular slopes for soil loss prediction. Transactions of the American Society of Agricultural Engineers, 17, 305-309.

Foster, G. R., Osterkamp, W. R., Lane, L. J. y Hunt, D. W., 1982. Effect of discharge on rill erosion. American Society of Agricultural Engineers, 82.

Francés, F., Vélez, J. I. y Vélez, J. J., 2007. Split-parameter structure for the automatic calibration of distributed hydrological models. Journal of Hydrology, $332,226-240$.

Gafur, A., Jensen, J. R., Borggaard, O. K. y Petersen, L., 2003. Runoff and losses of soil and nutrients from small watersheds under shifting cultivation (Jhum) in the Chittagong Hill Tracts of Bangladesh. Journal of Hydrology, 274, 30-46.

Gallant, J. C. y Wilson, J. P., 2000. Primary Topographic Attributes. En J. P. Wilson y J. C. Gallant, eds., Terrain Analysis, Principles and Applications, págs. 51-85. Wiley.

García-Ruiz, J. M., Arnáez, J., Beguería, S., Seeger, M., Martí-Bono, C., Regüés, D., Lana-Renault, N. y White, S., 2005. Runoff generation in an intensively disturbed, abandoned farmland catchment, Central Spanish Pyrennes. Catena, 59, 79-92.

Garrote, L. y Bras, R., 1995. A distributed model for real-time flood forecasting using digital elevation models. Journal of Hydrology, 167, 279-306.

Gessler, P. E., Moore, I. D., McKenzie, N. H. y Ryan, P. J., 1995. Soil - landscape modelling and spatial predicition of soil attributes. International Journal of Geographical Information Systems, 9, 421-432. 
Gilley, J. E., Kottwitz, E. R. y Simanton, J. R., 1990. Hydraulic characterisitcs of rills. Transactions of the American Society or Agricultural Engineers, 33, 1900-1906.

Govers, G. y Poesen, J., 1988. Assessment of the interrill and rill contributions to total soil loss from an upland field plot. Geomorphology, 1, 343-354.

Graf, W., 1979. Catastrophe theory as a model for change in fluvial systems. Adjustments of the fluvial system. Proceedings, Tenth Annual Geomorphology Symposium Series, págs. 13-32.

Green, W. H. y Ampt, G. A., 1911. Studies on soil physics, I - Flow of air and water through soils. Journal of Agricultural Science, 4, 1-24.

Greysukh, V., 1967. The possibility of studying landforms by means of digital computer. Soviet Geography, Review, and Translations, págs. 137-149.

Gupta, V. K., Rodríguez-Iturbe, I. y Wood, E., 1986. Scale Problems in Hydrology: Runoff generation and basin response. Dordrech: D. Reidel Publishing.

Haan, C. T., Barfield, B. J. y Hayes, J. C., 1994. Design hydrology and sedimentology for small catchments. Academic Press.

Hagen, L. y Foster, G., 1990. Soil erosion prediction technology. Proceedings of Soil Erosion and Productivity Workshop, págs. 117-135.

Hardisty, J., 1987. The transport response function and relaxation time in geomorphic modelling. Geomorphological Models, Theoretical and Empirical Aspect. Catena Supplement, 10, 181-192.

Hauge, C., 1977. Soil erosion definitions. California Geology, 30, 202-203.

Hessel, R., 2002. Modelling soil erosion in a small catchment on the Chinese Loess Plateu. Tesis Doctoral, Faculty of Geographical Sciences, Utrecht University.

Horton, R., 1932. Drainage basin characteristics. Transactions - American Geophysical Union, 13, 350-361.

Horton, R., 1945. Erosional development of streams and their drainage basins: hydrophysical approach to quantitative morphology. Bulletin of the Geological Society of America, 56, 275-370.

Horton, R. E., 1933. The role of infiltration in the hydrologic cycle. Transactions of the American Geophysical Union, 14, 446-460.

Horton, R. E., 1940. An approach to the physical interpretation of infiltration capacity. Soil Science Society of America Proceedings, 5, 399-417. 
Howard, A., 1994. A detachment limited model of drainage basin evolution. Water Resources Research, 30, 2261-2285.

Hutchinson, D. E. y Pritchard, H. W., 1976. Resources conservation glossary. Journal of Soil and Water Conservation, 31, 1-63.

Hutchinson, F. y Gallant, J. C., 2000. Digital Elevation Models and Representation of Terrain Shape. En J. P. Wilson y J. C. Gallant, eds., Terrain Analysis, Principles and Applications, págs. 29-50. Wiley.

Jenson, S. y Domingue, J., 1988. Extracting topographic structure from digital elevation data for geographical information system analysis. Photogrammetric Engineering and Remote Sensing, 54, 1593-1600.

Jetten, V. y De Roo, A., 2001. Spatial analysis of erosion conservation measures with LISEM. En R. Harmon y W. Doe III, eds., Landscape Erosion and Evolution Modelling, págs. 429-445. Kluwer Academic Plenum Publishing, New York.

Jetten, V. y Favis-Mortlock, D., 2006. Erosion modelling in Europe. En J. B. y Jean Poesen, ed., Soil Erosion in Europe, págs. 695-716. Wiley.

Johnson, D. y Beaumont, C., 1995. Preliminary results from a planform kinematic model of orogen evolution, surface processes and the development of clastic foreland basin stratigraphy. En S. Dorobek y G. Ross, eds., Stratigraphic Evolution of Foreland Basin, págs. 3-24. SEPM Special Publication, Vol. 52.

Julien, P., Saghafian, B. y Ogden, F., 1995. Raster-based hydrologic modeling of spatially-varied surface runoff. Water Resources Bolletin, 31, 523-536.

Julien, P. Y., 1998. Erosion and Sedimentation. Cambridge University Press.

Julien, P. Y. y Rojas, R., 2002. Upland erosion modeling with CASC2D-SED. International Journal of Sediment Research, 17, 265-274.

Julien, P. Y. y Simons, D. B., 1985. Sediment Transport Capacity of Overland Flow. Transactions of American Society of Agricultural Engineering, 28, 755762.

Kienzle, S. W., 1996. Using DTMs and GIS to define input variables for hydrological and geomorphological analysis. En K. Kovar y H. P. Nachtnebel, eds., Application of geographic information systems in hydrology and water resources management, págs. 183-190.

Kilinc, M. y Richardson, E., 1973. Mechanics of soil erosion from overland flow generated by simulated rainfall. Hydrological paper number 63, Colorado State University. 
Kirkby, M., 1987. Modelling some influences of soil erosion, landslide and valley gradient on drainage density and hollow development. Geomorphological Models, Theoretical and Empirical Aspect. Catena Supplement, 10, 1-10.

Kirkby, M., 1999. Modelling across scales: the Medalus Family of models. En J. Boardman y D. Favis-Mortlock, eds., Modelling Soil Erosion by Water. NATO ASI Series I: Global Enivronmental Change.

Kirkby, M., Jones, R., Irvine, B., Gobin, A., Govers, G., Cerdan, O., Van Rompaey, A., Le Bissonnais, Y., Daroussin, J., King, D., Montanarella, L., Grimm, M., Vieillefont, V., Puigdefabregas, J., Boer, M., Kosmas, C., Yassoglou, N., Tsara, M., Mantel, S., Van Lynden, G. y Huting, J., 2004. Pan-European Soil Erosion Risk Assessment: The PESERA Map, Version 1 October 2003. Explanation of Special Publication Ispra 2004 No.73 (S.P.I.04.73). European Soil Bureau Research Report, 16.

Kirkby, M. J., 1975. Hydrograph modellin strategies. En R. Peel, M. Chisholm y P. Haggett, eds., Processes in Physical and Human Geography, págs. 69-90. Heinemann, London.

Kirkby, M. J., 1993. Network Hydrology and Geomorphology. En K. Beven y M. J. Kirkby, eds., Channel Network Hydrology, págs. 1-11. Wiley.

Kirkby, M. J. y Chorley, R. J., 1967. Throughflow, overland flow and erosion. Bulletin of the International Association of Scientific Hydrology, 12, 5-21.

Knisel, W., 1980. CREAMS - A field Scale Model for Chemicals, Runoff, and Erosion from Agricultural Management Systems. USDA Conservation Report, 26.

Kuhnle, R., Bingner, R., Foster, G. y Grissinger, E., 1996. Effect of land use changes on sediment transport in Goodwin Creek. Water Resources Research, $32,3189-3196$.

Laflen, J., Elliot, W., Flanagan, D., Meyer, C. y Nearing, M., 1997. WEPPpredicting water erosion using a process-based model. Journal of Soil and Water Conservation, 52, 96-102.

Lane, L. y Nearing, M., 1989. USDA - Water Erosion Prediction Project: Hillslope Profile Model Documentation. NSERL Report No.2. USDA - ARS National Soil Erosion Research Laboratory, West Lafayette, IN.

Lang, A., Hennrich, K. y Dikau, R., 2003. Long term hillslope and fluvial system modelling, concepts and case studies from the Rhine River Catchment. Springer. 
Leonard, R., Knisel, W. y Still, D., 1987. GLEAMS: Groundwater Loading Effects of Agricultural Management Systems. Transactions of the American Society of Agricultural Engineers, 30, 1403-1418.

Leopold, L. y Langbein, W., 1962. The concept of entropy in landscape evolution. U.S. Geol. Surv. Prof. Pap., 500A, 1-20.

Leopold, L., Wolman, M. y Miller, J., 1964. Fluvial Processes in Geomorphology. V.H. Freeman, San Francisco.

Leopold, L. B. y Maddock, T., 1953. The Hydraulic Geometric of stream channel and some physiographic implications. Professional Paper United States Geological Survey, 252, 1-57.

Liu, Q. Q., Xiang, H. y Singh, V. P., 2006. A simulation model for unified interrill erosion and rill erosion on hillslope. Hydrological Processes, 20, 469-486.

Marks, D., Dozier, J. y Frew, J., 1984. Automated basin delineation from digital elevation data. Geoprocessing, 2, 299-311.

Martz, L. W. y Garbrecht, J., 1992. Numerical definition of drainage network and sub-catcment areas from digital elevation models. Computers and Geosciences, $18,747-761$.

Martz, L. W. y Jong, E., 1988. Catch: a FORTRAN program for measuring catchment area from digital elevation models. Computers and Geosciences, 14, 627-640.

Meyer, L. D., 1981. How rain intensity affects interrill erosion. Trans. ASAE, 24, $1472-1475$.

Mitas, L. y Mitasova, H., 1998. Distributed soil erosion simulation for effective erosion prevention. Water Resources Research, 34, 505-516.

Molnár, P. y Ramírez, J. A., 1998. An analysis of energy expenditure in Goodwin Creek. Water Resources Research, 34, 1819-1829.

Montgomery, D. R. y Dietrich, W. E., 1988. Where do channels begin? Nature, $336,232-234$.

Montgomery, D. R. y Dietrich, W. E., 1989. Source Areas, Drainage Density, and Channel Initiation. Water Resources Research, 25, 1907-1918.

Montgomery, D. R. y Dietrich, W. E., 1994. A physically-based model for the topographic control on shallow landslidining. Water Resources Research, 30, $1153-1171$. 
Montgomery, D. R. y Foufoula-Georgiou, E., 1993. Channel network source representation using digital elevation models. Water Resources Research, 29, 39253934 .

Moore, I., Grayson, R. y Ladson, A., 1991. Digital Terrain Modelling: a review of hydrological, geomorphological, and biological applications. Hydrological Processes, 5, 3-30.

Moore, I. D., 1992. Terrain analysis programs for the environmental sciences. Agricultural Systems and Information Technology, 2, 37-39.

Moore, I. D. y Burch, G. J., 1986. Sediment transport capacity of sheet and rill flow: application of unit stream power theory. Water Resources Research, 22, 1294-1298.

Moore, I. D. y Grayson, R. B., 1991. Terrain - based catchment partitioning and runoff prediction using vector elevation data. Water Resources Research, 27, $1177-1191$.

Moore, I. D., Burch, G. J. y MacKenzie, D. H., 1988a. Topographic effects on the distribution of surface soil water and the location of ephemeral gullies. Transactions of the American Society of Agricultural Engineers, 31, 1098-1107.

Moore, I. D., O’Loughlin, E. M. y Burch, G. J., 1988b. A countour - based topographic model por hydrological and ecological applications. Earth Surface Processes and Landforms, 13, 305-320.

Moore, I. D., Gessler, P. E., Nielsen, G. A. y Peterson, G. A., 1993a. Soil attribute prediction using terrain analysis. Soil Science Society of America Journal, 57, $443-452$.

Moore, I. D., Lewis, A. y Gallant, J. C., 1993b. Terrain attributes: estimation methods and scale effects. En A. J. Jakeman, M. B. Beck y M. J. McAleer, eds., Modelling Change in Environmental Systems, págs. 189-214. Wiley.

Morgan, R., 2001. A simple approach to soil loss prediction: a revised MorganMorgan-Finney model. Catena, 44, 305-322.

Morgan, R., Quinton, J., Smith, R., Govers, G., Poesen, J., Auerswald, K., Chisti, G., Torri, D. y Styczen, M., 1998. The European Soil Erosion Model (EUROSEM): a dynamic approach for predicting sediment transport from fields and small catchments. Earth Surface Processes and Landforms, 23, 527-544.

Nachtergaele, J., Poesen, J., Sidorchuk, A. y Torri, D., 2002. Prediction of concentrated flow with in ephemeral gully channels. Hydrological Processes, 16, $1935-1953$. 
O'Callaghan, J. F. y Mark, D. M., 1984. The extraction of drainage networks from digital elevation data. Computer Vision, Graphics, and Image Processing, $28,323-344$.

Ogden, F. y Heilig, A., 2001. Two dimensional watershed scale erosion modeling with CASC2D. En Harmon y Doe, eds., Landscape Erosion and Evolution Modeling, págs. 277-320. Kluwer Academic / Plenum Publishers.

Patton, P. y Schumm, S., 1975. Gully erosion, Nortwestern Colorado: a threshold phenomenon. Geology, 3, 88-90.

Pearce, A. J., Stewart, M. K. y Sklash, M. G., 1986. Storm runoff generation in humid headwater catchments. 1 . Where does the water come from? Water Resources Research, 22, 1263-1272.

Philip, J. R., 1957. The theory of infiltration. 1. The infiltration equation and its solution. Soil Science, 83, 345-357.

Piest, R., Kramer, L. y Heineman, H., 1975a. Sediment movement from loessial watershed. En U. Science y E. Administration, eds., Present and Prospective Technology for Predicting Sediment Yields and Sources, págs. 130-141. ARS-S40, Washington.

Piest, R. F., Bradfor, J. M. y Spomer, R. G., 1975b. Mechanisms of erosion and sedimentat movement from gullies. En U. Science y E. Administration, eds., Present and Prospective Technology for Predicting Sediment Yields and Sources, págs. 162-176. ARS-S-40, Washington.

Poesen, J., 1989. Conditions for gully formation in the Belgian loam belt and some ways to control them. Soil Technology Series, 1, 39-52.

Poesen, J., van Wesemael, B. y Cammeraat, E., 1993. Gully erosion in the loess belt: typology and control measures. En Geomorphological Processes in the Belgian Loess Belt. Memorial Symposium, págs. 16-28.

Poesen, J., Nachtergaele, J., Verstraeten, G. y Valentin, C., 2003. Gully erosion and environmental change: importance and research needs. Catena, 50, 91-133.

Preston, N. y Schmidt, J., 2003. Modelling sediment fluyes at large spatial and temporal scales. En K. H. A. Lang y R. Dikau, eds., Long Term Hillslope and Fluvial System Modelling. Springer, Berlin.

Puricelli, M. M., 2003. Estimación y distribución de parámetros del suelo para la modelación hidrológica. Tesis Doctoral, Departamento de Ingeniería Hidráulica y Medio Ambiente, Universidad Politécnica de Valencia. 
Radoane, M., Ichim, I. y Radoane, N., 1995. Gully distribution and development in Moldavia, Romania. Catena, 24, 127-146.

Raff, D. A., Ramirez, J. A. y Smith, J. L., 2004. Hillslope drainage development with time: a physical experiment. Geomorphology, 62, 169-180.

Raper, J. F., 1999. Spatial representation: the scientist's perspective. En P. Longley, M. Goodchild, D. Maguire y D. Rhind, eds., Geographical Information Sistem, Volume 1. Principles and Technical Issues, págs. 61-70. Wiley.

Regüés, D. y Gallart, F., 2004. Seasonal patterns of runoff and erosion responses to simulated rainfall in a badland area in mediterranean montain conditions (Vallcebre, Southeastern Pyrenees). Earth Surface Process and Landforms, 29, $755-767$.

Renard, K., Foster, G., Weesies, G. y Porter, J., 1989. RUSLE - The Revised Universal Soil Loss Equation. Soil and Water Conservation Society. Ankeny, IA.

Renard, K., Foster, G., Weesies, G., McCool, D. y Yoder, D., 1997. Predicting Soil Erosion by Water: A Guide to Conservation Planning With the Revised Universal Soil Loss Equation (RUSLE). U.S. Department of Agriculture, Agriculture Handbook No. 703.

Rodriguez-Iturbe, I. y Rinaldo, A., 1997. Fractal River Basins, Chance and Self Organization. Cambridge University Press.

Rojas, R., 2002. GIS-Based Upland Erosion Modelling, Geovisualization and Grid Size Effects on Erosion Simulations with CASC2D-SED. Tesis Doctoral, Colorado State University, Department of Civil Engineering, Fort Collins, Colorado.

Scheidegger, A., 1970. Theoretical Geomorphology. Springer, Berlin, Berlin, 2a edición.

Scheidegger, A., 1979. The principle of antagonism in the Earth's evolution. Tectonophys, 55, 7-10.

Scheidegger, A., 1983. Instability principle in geomorphic equilibrium. Z. Geomorphol., 27, 1-19.

Scheidegger, A., 1987. The fundamental principles of landscape evolution. Geomorphological Models, Theoretical and Empirical Aspect. Catena Supplement, 10, 193-197.

Schertz, D. L., 1983. The basis for soil loss tolerances. Journal of Soil and Water Conservation, 38, 10-14. 
Schmidt, J. y Mauersberger, F., 2004. Sensitivity analysis of wind effects on soil erosion by water using the EROSION2D model. En Sino German Workshop on Effect of Landuse and Management System on Soil and Environment.

Schumm, S., 1956. Evolution of drainage systems and slopes in badlands at Perth Amboy, New Jersey. Bulletin of the Geological Society or America, 67, 597-646.

Schumm, S., 1973. Geomorphic thresholds and complex response of drainage systems. En Fluvial Geomorphology. Suny, Binghamton.

Schumm, S., 1979. Geomorphic thresholds: the concept and its applications. Transactions of the Institute of British Geographers, 4, 485-515.

Schumm, S. y Lichty, R., 1965. Time, space, and causality in geomorphology. American Journal of Science, 263, 110-119.

Schumm, S. y Lusby, G., 1963. Seasonal variation of infiltration capacity and runoff on hillslopes in western Colorado. Journal of Geophysical Research, 68, $3655-3666$.

Selby, M., 1985. Earth`s Changing Surface. Oxford University Press, New York.

Shreve, R., 1966. Statistical law of stream numbers. Journal of Geology, 74, 17-37.

Smith, R. E. y Parlange, J. Y., 1978. A parameter efficient infiltration model. Water Resources Research, 14, 533-538.

Smith, T., Zhan, C. y Gao, P., 1990. A knowledge - based, two - step procedure for extracting channel networks from noisy DEM data. Computera and Geosciences, $16,777-786$.

Sorooshian, S., Duan, Q. y Gupta, V. K., 1993. Stochastic parameter estimation procedures for hydrologic rainfall-runoff models: correlated and heteroescedastic error cases. Water Resources Research, 29, 1185-1194.

Stocking, M. y Elwell, H., 1973. Prediction of subtropical storm soil loss from field plot studies. Agricultural Meteorology, 12, 193-201.

Strahler, A., 1957. Quantitative analysis of watershed geomorphology. Trans. Am. Geophys. Un, 38, 913-920.

Summerfield, M., 1991. Global Geomorphology. Longman y John Wiley \& Sons, London y New York.

Takken, I. y Govers, G., 2000. Hydraulics of interrill overland flow on rough, bare soil surfaces. Earth Surface Processes and Landforms, 25, 1387-1402. 
Takken, I., Beuselinck, L., Nachtergaele, J., Govers, G., Poesen, J. y Degraer, G., 1999. Spatial evaluation of a physically-based distributed erosion model (LISEM). Catena, 37, 431-447.

Tarboton, D. G., Bras, R. L. y Rodriguez-Iturbe, I., 1988. The fractal nature of river networks. Water Resources Research, 24, 1317-1322.

Tayfur, G., 2007. Modelling sediment transport from bare rilled hillslopes by areally averaged transport equations. Catena, 70, 25-38.

Terry, J. P., 1998. A rainsplash component analysis to define mechanisms of soil detachment and transportation. Australian Journal of Soil Research, 36, 525542 .

Thornbury, W., 1960. Principios de Geomorfología. Kapelusz, Buenos Aires.

Thorne, C. R., 1984. Prediction of soil loss due to ephemeral gullies in arable fields. Informe técnico, Colorado State University.

Thornes, J., 1983. Evolutionary geomorphology. Geography, 68, 225-235.

Torri, D., Poesen, J., Borselli, L. y Knapen, A., 2006. Channel width - flow discharge relationships for rills and gullies. Geomorphology, 76, 273-279.

Tribe, A., 1991. Automated recognition of valley heads from digital elevation models. Earth Surface Processes and Landforms, 16, 33-49.

Tribe, A., 1992. Problems in automated recognition of valley heads from digital elevation models. Earth Surface Processes and Landforms, 17, 437-454.

Tricart, J. y Cailleux, A., 1965. Traité de Géomorphologie, I, Introduction à la Géomorphologie Climatique. SEDES, Paris.

Tucker, G. y Bras, R., 1998. Hillslope processes, drainage density, and landscape morphology. Water Resources Research, 34, 2751-2764.

Tucker, G. y Slingerland, R., 1994. Erosional dynamics, flexural isostasy, and long-lived escarpments: a numerical modelling study. Journal of Geophysical Research, 99, 12229-12243.

Tucker, G. y Slingerland, R., 1997. Drainage basin response to climate change. Water Resources Research, 33, 2031-2047.

Tucker, G., Lancaster, S., Gasparini, N., Bras, R. y Rybarczyk, S., 2001. An object-oriented framework for distributed hydrologic and geomorphic modeling using triangulated irregular networks. Cumputers and Geosciences, 27, 959-973. 
Van-Asch, T. W. J., Buma, J. y Van-Beek, L. P. H., 1999. A view on some hydrological triggering systems in landslides. Geomorphology, 30, 25-32.

Van Oost, K., Govers, G. y P.J.J., D., 2000. Evaluating the effects of changes in landscape structure on soil erosion by water and tillage. Landscape Ecology, 15, 579-591.

Van Rompaey, A., Verstraeten, G., Van Oost, K., Govers, G. y Poesen, J., 2001. Modelling mean annual sediment yield using a distributed approach. Earth Surface Processess and Landforms, 26, 1221-348.

Vandaele, K., Poesen, J., Govers, G. y Van Wesemael, B., 1996. Geomorphic threshold conditions for ephemeral gully incision. Geomorphology, 16, 161-173.

Vandaele, K., Poesen, J., Marques da Silva, J. R., Govers, G. y Desmet, P., 1997. Assesment of factors controlling ephemeral gully erosion in southern Portugal and central Belgium using aerial photographs. Zeitschrift fur Geomorphologie, 41, 273-287.

Vélez, J. I., 2001. Desarrollo de un modelo hidrológico conceptual y distribuido orientado a la simulación de las crecidas. Tesis Doctoral, Departamento de Ingeniería Hidráulica y Medio Ambiente, Universidad Politécnica de Valencia.

Vélez, J. J., 2003. Desarrollo de un modelo distribuido de predicción en tiempo real para eventos de crecidas. Tesis Doctoral, Departamento de Ingeniería Hidráulica y Medio Ambiente, Universidad Politécnica de Valencia.

Velleux, M., 2005. Spatially Distributed Model to Assess Watershed Contaminant Transport and Fate. Tesis Doctoral, Colorado State University.

Wagensberg, J., 1985. La simulación de la complejidad (ver, mirar, observar, experimentar y simular). En Tusquets, ed., Ideas sobre la complejidad del mundo, págs. 89-104. Wagensberg, Jorge.

Wainwright, J., 1996. Infiltration, runoff and erosion characteristics of agricultural land in extreme storm events, SE France. Catena, 26, 27-47.

Wainwright, J. y Parsons, A. J., 1998. Sensitivity of sediment-transport equations to errors in hydraulic models of overland flow. En J. Boardman y D. T. FavisMortlock, eds., Modelling soil erosion by water, págs. 271-284. Springer-Verlag, Berlin Heidelberg.

Weibel, R. y Heller, M., 1991. Digital terrain modelling. En D. J. Maguier, G. M. F. y D. W. Rhind, eds., Geographical information systems: principles and applications, págs. 269-297. Harlow, Longman / New York, John Wiley and Sons Inc. 
Weyman, D. R., 1970. Throughflow on hillslopes and its relation on the stream hydrograph. Hydrological Science Bolletin, 15, 25-33.

Willgoose, G., 2005. Mathematical modelling of whole landscape evolution. Annual Review of Earth and Planetary Sciences, 33, 443-459.

Willgoose, G., Bras, I. y Rodriguez-Iturbe, I., 1991a. Results from a new model of river basin evolution. Earth Surface Processes and Landforms, 16, 237-254.

Willgoose, G., Bras, R. y Rodriguez-Iturbe, I., 1991b. A physically based coupled network growth and hillslope evolution model, 1, theory. Water Resources Research, 27, 1671-1684.

Willgoose, G., Bras, I. y Rodriguez-Iturbe, I., 1994. Hydrogeomorphology modelling with a physically based river basin evolution model. En M. J. Kirkby, ed., Process Model and Theoretical Geomorphology, págs. 3-22. Wiley, UK.

William, J., 1975. Sediment yield prediction with Universal Equation using runoff energy factor. En: Present and Prospective Technology for Predicting Sediment Yields and Sources. USDA - Agricultural Research Service.

Williams, J., Jones, C. y Dyke, P., 1984. A modelling approach to determining the relationship between erosion and soil productivity. Transactions of the American Society of Agricultural Engineers, 27, 129-144.

Williams, J., Nicks, A. y Arnold, J., 1985. Simulator for water resources in rural basins. Journal of Hydrological Engineering, American Society of Civil Engineers, 111, 970-976.

Wilson, J. P. y Gallant, J. C., 2000a. Digital Terrain Analysis. En J. P. Wilson y J. C. Gallant, eds., Terrain Analysis, Principles and Applications, págs. 1-27. Wiley.

Wilson, J. P. y Gallant, J. C., 2000b. Secondary Topographic Attributes. En J. P. Wilson y J. C. Gallant, eds., Terrain Analysis, Principles and Applications, págs. 87-131. Wiley.

Wischmeier, W. y Smith, D., 1978. Predicting rainfall erosion - a guide to conservation planning. Agriculture Handbook 537. U.S. Department of Agriculture.

Woolhiser, D., Smith, R. y Goodrich, D., 1990. KINEROS: A Kinematic Runoff and Erosion Model. Documentation and User Manual. ARS-77. Department of Agriculture, Agricultural Research Service, Washington, D.C.

Yalin, M. S., 1963. An expression for bed-load transportation. Journal of the Hydraulics Division, 89, 221-248. 
Young, A., 1963. Deductive models of slope evolution. Slope Commun. Rep., 3, 45-65.

Young, R., Onstad, C., Bosch, D. y Anderson, W., 1989. AGNPS: a nonpoint source pollution model for evaluating agricultural watersheds. Journal of Soil and Water Conservation, 44, 168-173. 
Esta tesis aborda el desarrollo de un modelo de producción, transporte y depósito de sedimentos a escala de cuenca.

Partiendo de una revisión del conocimiento de modelos de evolución del paisaje y específicamente de modelos de erosión se plantean las preguntas fundamentales que deben tenerse en cuenta en el modelo. Posteriormente se estudia la forma en que actualmente se resuelven dichas preguntas, basados tanto en el estado del arte del conocimiento como en la experiencia adquirida en la aplicación de modelos hidrológicos y sedimentológicos.

Con estas bases teóricas y prácticas se formula el modelo y se desarrolla un código de programación con los postulados de la formulación, que será la hipótesis de trabajo.

Por último se aplica el modelo en una cuenca natural y se valida la hipótesis de trabajo. La cuenca de análisis es la cuenca de Goodwin Creek en el estado de Mississippi, en Estados Unidos de América. En la aplicación se reconocen las limitaciones y potencialidades del modelo.

De los resultados del modelo se aprende acerca de la dinámica hidrológica y sedimentológica de la cuenca. Con la herramienta computacional obtenida es posible efectuar análisis de cambios ambientales y antrópicos ante dichas dinámicas.

De esta forma tiene una aplicabilidad no sólo científica, al generar conocimiento y ayudar a la comprensión de procesos naturales, sino también práctica, al ser una herramienta para el diseño ingenieril, el planeamiento del territorio y el análisis de riesgos naturales. 